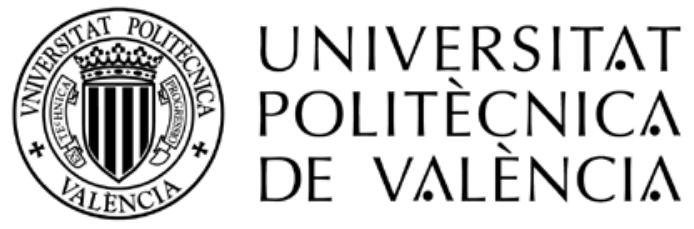

TESIS DOCTORAL

\title{
DESARROLLO Y CARACTERIZACIÓN DE ALEACIONES Ti-Nb-Sn OBTENIDAS POR VÍA PULVIMETALÚRGICA.
}

\author{
Instituto de Tecnología de Materiales \\ Departamento de Ingeniería Mecánica y de Materiales
}

Autor:

Francisco Devesa Albeza

Director:

Dr. Vicente Amigó Borrás

Valencia, Enero 2013 

A mi familia, amigos y todas las personas que son especiales para mí, por su apoyo incondicional. 



\section{Agradecimientos.}

Me gustaría agradecer en primer lugar a la Universitat Politècnica de València Por la financiación recibida a través del programa de Formación de Personal Investigador para la realización de esta tesis doctoral.

Por otro lado me gustaría agradecer al Instituto de Tecnología de Materiales la oportunidad que me ha brindado y el apoyo de todo su personal. 



\section{Resumen.}

Las aleaciones de titanio con microestructura $\beta$ destacan sobre todo por sus buenas propiedades específicas, su resistencia a la corrosión y por su bajo módulo elástico que las hacen muy apropiadas para su utilización como biomaterial en implantología ya que reducen de forma drástica fenómenos indeseados como el apantallamiento de tensiones.

Existen grandes dificultades para procesar este tipo de aleaciones pero la pulvimetalurgia convencional se muestra como una de las mejores opciones. Unido a la mezcla elemental de polvos se aprovecha la gran reactividad del titanio para obtener aleaciones homogéneas a pesar del carácter refractario de los principales aleantes betágenos del titanio. Pero esta gran reactividad entorpece el procesado ya que se debe tener especial cuidado para no contaminar u oxidar el material.

En este trabajo se ha desarrollado una serie de aleaciones de titanio tipo $\beta$ procesadas por pulvimetalurgia y mezcla elemental de polvos. Se ha utilizado el niobio como principal elemento de aleación betágeno, $\mathrm{y}$ se ha incluido pequeños contenidos de estaño estudiándose la influencia de éste como tercer elemento en la aleación.

En primer lugar se ha optimizado el procesado logrando un nivel de repetitividad y homogeneidad muy alto. Se ha estudiado las microestructuras obtenidas para comprender el comportamiento mecánico de las mismas así como su comportamiento frente a la corrosión simulando las solicitaciones requeridas como biomaterial. Se ha puesto especial hincapié en la determinación del módulo elástico por diferentes métodos de modo que permita un mayor acercamiento a la modificación del mismo mediante aleación, y todo ello comparado con los resultados alcanzados por otros investigadores. Los resultados obtenidos muestran que las aleaciones desarrolladas mediante la adición de 2 y $4 \%$ de estaño a aleaciones base Ti 30Nb, así como la técnica de procesado seleccionada son una gran alternativa, desde el punto de vista de propiedades, y económicamente viable. 

Resum.

Els aliatges de titani amb microestructura $\beta$ destaquen sobretot per les seues bones propietats específiques, la seua resistència a la corrosió i pel seu baix mòdul elàstic que els fan molt apropiats per a la seua utilització com a biomaterial en implantología ja que reduïxen de forma dràstica fenòmens no desitjats com l'apantallament de tensions.

Hi ha grans dificultats per a processar este tipus d'aliatges però la pulverimetal•lúrgia convencional es mostra com una de les millors opcions. Unit a la mescla elemental de pols s'aprofita la gran reactivitat del titani per a obtindre aliatges homogenis a pesar del caràcter refractari dels principals elements d'aliatge betàgens del titani. Però esta gran reactivitat entorpix el processat ja que s'ha de tindre especial atenció per a no contaminar o oxidar el material.

En este treball s'ha desenvolupat una sèrie d'aliatges de titani tipus $\beta$ processades per pulverimetal•lúrgia i mescla elemental de pols. S'ha utilitzat el niobi com principal element d'aliatge betàgen, i s'ha inclòs xicotets continguts d'estany estudiant-se la influència d'este com a tercer element d'aliatge.

En primer lloc s'ha optimitzat el processat aconseguint un nivell de repetitivitat i homogeneïtat molt alt. S'ha estudiat les microestructures obtingudes per a comprendre el comportament mecànic així com el seu comportament front la corrosió simulant les sol licitacions requerides com a biomaterial. S'ha posat especial insistència en la determinació del mòdul elàstic per diferents mètodes de manera que permeta un major acostament a la modificació del mateix per mitjà d'aliatge, i tot això comparat amb els resultats aconseguits per altres investigadors. Els resultats obtinguts mostren que els aliatges desenvolupats per mitjà de l'addició de 2 i $4 \%$ d'estany a aliatges base Ti $30 \mathrm{Nb}$, així com la tècnica de processat seleccionada són una gran alternativa, des del punt de vista de propietats, i econòmicament viable. 



\begin{abstract}
.
Titanium alloys with $\beta$ microstructure stand out for their good specific properties, corrosion resistance and its low elastic modulus, making them very suitable as biomaterial implants because they reduce unwanted phenomena known as stress shielding.

There are great difficulties to process this type of alloys but conventional powder metallurgy is listed as one of the best options. Attached to the elemental mixture of powders it takes advantage of the high reactivity titanium has to obtain homogeneous alloys despite the refractory nature of the main betagenous alloying of titanium. But this high reactivity drags out the processing that must take special care not to contaminate or oxidize the material.

This paper has developed a series of $\beta$-type titanium alloys processed by powder metallurgy and elemental powder blending. Niobium has been used as main $\beta$ - stabilizing element alloying and small tin contents have been included to study the influence of this alloy as a third element.

Firstly the processing has been optimized achieving a level of homogeneity and high repeatability. The obtained microstructures have been studied to understand the mechanical behavior of them and their corrosion behavior simulating the stresses required as a biomaterial. It has been placed special emphasis on the determination of the elastic modulus by different methods so as to allow a better approach to the modification thereof by alloying, and all compared with the results obtained by other researchers. The results show that the alloys developed by adding 2 to $4 \%$ tin to $\mathrm{Ti} 30 \mathrm{Nb}$ based alloys, and the selected processing technique are an alternative, from the viewpoint of properties, and economically viable.
\end{abstract}



ÍNDICE.

1. INTRODUCCIÓN. ............................................................... 1

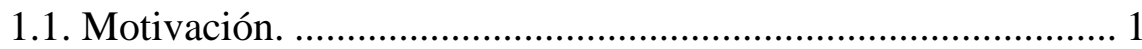

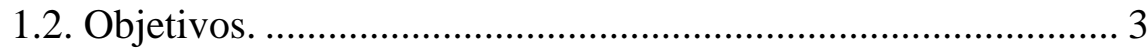

1.3. Aportaciones de la tesis........................................................... 5

1.4. Ámbito de la investigación....................................................... 5

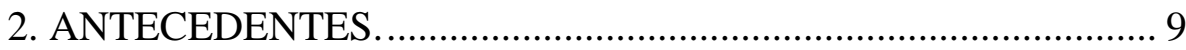

2.1. El titanio como biomaterial. ................................................... 10

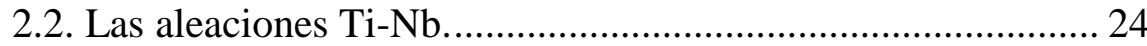

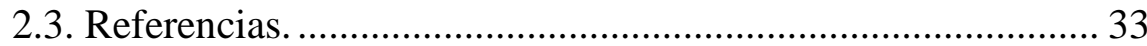

3. PLANIFICACIÓN DE LA INVESTIGACIÓN. ............................ 41

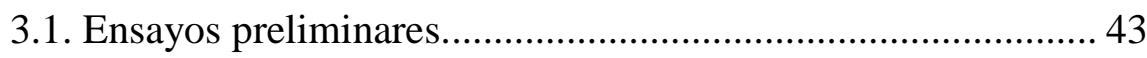

3.2. Selección del proceso más adecuado. ................................... 44

3.3. Procesado de las aleaciones.................................................... 46

3.4. Caracterización de los materiales.......................................... 47

3.4.1. Caracterización microestructural.................................... 47

3.4.2. Caracterización mecánica............................................... 49

3.4.3. Caracterización tecnológica. ........................................ 51

4. DESARROLLO EXPERIMENTAL............................................ 53

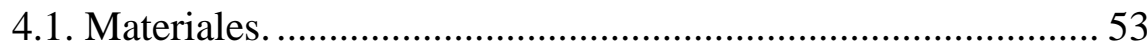


4.2. Procesado de las aleaciones.................................................... 59

4.2.1. Obtención del polvo por mezcla elemental..................... 59

4.2.2. Obtención de las piezas de trabajo................................ 61

4.3. Caracterización microestructural............................................. 66

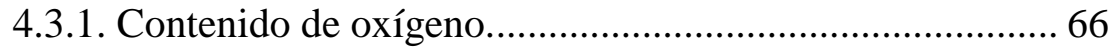

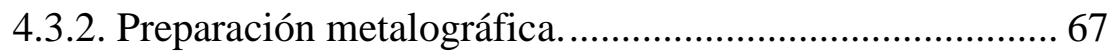

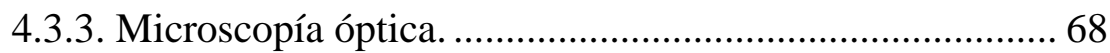

4.3.4. Microscopía electrónica de barrido (SEM)...................... 68

4.3.5. Microscopía electrónica de transmisión (TEM)............... 71

4.3.6. Difracción de rayos $\mathrm{X}(\mathrm{DRX})$......................................... 74

4.4. Caracterización mecánica....................................................... 77

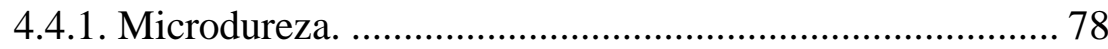

4.4.2. Ensayo de flexión a tres puntos........................................ 79

4.4.3. Determinación del módulo elástico por ultrasonidos....... 80

4.4.4. Ensayo de nanoindentación........................................... 81

4.4.5. Ensayo de compresión.................................................... 91

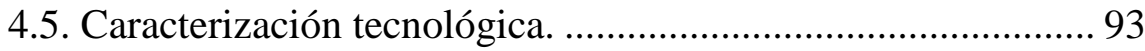

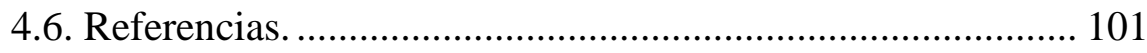

5. RESULTADOS Y DISCUSIÓN................................................. 103

5.1. Ensayos preliminares......................................................... 103

5.1.1. Optimización del tamaño de partícula del polvo............. 103 
5.1.2. Contenido de niobio........................................................ 107

5.1.3. Parámetros de sinterizado................................................ 112

5.1.4. Análisis ensayos preliminares......................................... 120

5.2. Caracterización microestructural de las aleaciones Ti-30Nb-XSn......................................................................... 122

5.2.1. Imágenes de microscopía óptica. ..................................... 123

5.2.2. Microscopía electrónica de barrido................................... 132

5.2.3. Microscopía electrónica de transmisión.......................... 145

5.2.4. Difracción de rayos X. ..................................................... 155

5.2.5. Discusión de resultados de características microestructurales. …………………………………………...... 156

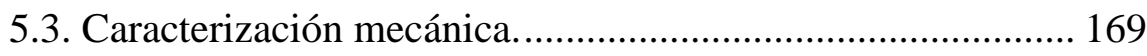

5.3.1. Microdureza. ....................................................................... 170

5.3.2. Flexión a tres puntos. ...................................................... 170

5.3.3. Obtención del módulo elástico por medio de ultrasonidos. 171

5.3.4. Ensayo de nanoindentación.............................................. 172

5.3.4.1. Cálculo por Oliver y Pharr. ........................................ 176

5.3.4.2. Cálculo mediante medida de rigidez continua (CSM). 176

5.3.5. Ensayo de compresión..................................................... 180

5.3.6. Discusión propiedades mecánicas.................................... 181 
5.4. Caracterización tecnológica.

193

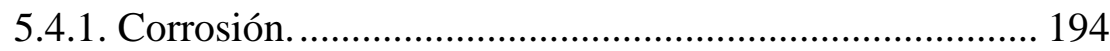

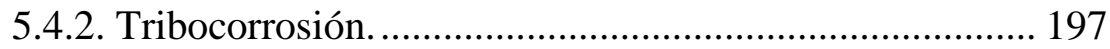

5.4.3. Discusión caracterización tecnológica............................ 202

5.5. Referencias......................................................................... 206

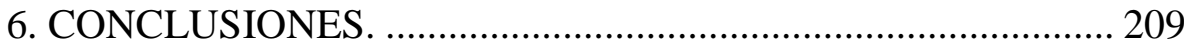

7. FUTURAS LÍNEAS DE INVESTIGACIÓN ............................... 215 


\section{INTRODUCCIÓN.}

\subsection{Motivación.}

El titanio es uno de los materiales que está experimentando un mayor aumento en su demanda. Al tratarse de un metal ligero posee buenas propiedades específicas, también presenta un buen comportamiento frente a la corrosión. Por esto y por su carácter biocompatible su utilización como biomaterial en implantología está aumentando y desplazando a otros materiales más tradicionales como las aleaciones CrCo o el acero inoxidable 316L. Por otro lado, presenta una serie de inconvenientes para su procesado, principalmente su alta reactividad y su facilidad de oxidación.

Pero a pesar de que el titanio presenta buenas propiedades para implantología también presenta un módulo elástico alto en comparación al del hueso cortical, aunque esta diferencia es menor que la de otros materiales tradicionales. Debido a esta diferencia aparecen problemas de apantallamiento de tensiones. Para minimizar este tipo de problemas se busca materiales con módulo elástico mucho más bajos. Una buena opción es la utilización de aleaciones de titanio con microestructura tipo $\beta$. Este tipo de microestructura presenta un módulo elástico menor y minimiza los problemas de apantallamiento de tensiones y su consecuente reabsorción del hueso. 
Para conseguir la microestructura tipo $\beta$ se utilizan elementos aleantes que estabilizan la fase $\beta$ a temperatura ambiente. El Nb, Mo o Ta son los elementos betágenos más comunes. Pero estos elementos presentan mayor peso que el titanio y tienen carácter refractario con lo que, unido a que se utilizan en altos porcentajes, dificultan mucho el procesado de las aleaciones.

De estos elementos el que mayor aceptación y con el que mejores resultados se obtiene es el niobio. Se consigue aleaciones con una microestructura homogénea, presenta buenas características mecánicas y, sobre todo el módulo elástico es bajo comparado con el Ti puro comercial (Ti c.p.) o el Ti 6Al 4V. Para mejorar aún más las propiedades las aleaciones Ti-Nb con altos porcentajes de niobio se utiliza pequeñas cantidades de otros elementos aleantes que mejoran algunas características específicas. El estaño, por su bajo punto de fusión ayuda a la homogeneidad microestructural y limita la aparición de fases microestructurales no deseadas.

Tradicionalmente este tipo de aleaciones se ha procesado mediante técnicas de fusión pero, como se ha comentado anteriormente, la alta reactividad del titanio unido al carácter refractario de los elementos aleantes y su incorporación en altos porcentajes dificulta mucho el procesado. Se realiza varias refusiones para homogeneizar la distribución de los elementos aleantes, con todo el procesado en atmósferas controladas o alto vacío, además, la dificultad del mecanizado posterior limita mucho el procesado de las aleaciones. 
Como alternativa se plantea la utilización del procesado mediante pulvimetalurgia. La pulvimetalurgia convencional mediante la mezcla elemental de polvos, se muestra como una alternativa al procesado por técnicas de fusión. Se consigue piezas casi acabadas eliminando etapas de mecanizado posteriores. Se puede controlar de forma precisa las propiedades finales del material y el procesado es mucho más sencillo y aplicable con el entramado industrial actual.

Estas buenas expectativas del procesado pulvimetalúrgico no limitan la aparición de nuevas dificultades. Al utilizar mezcla elemental de polvos todos los procesos de difusión se realizan en estado sólido por lo que la homogeneidad microestructural es un punto complejo de abordar así como la microestructura final obtenida. Por otro lado las características intrínsecas de la pulvimetalurgia convencional, como la porosidad, han de ser tenidas en cuenta para analizar su influencia en las características finales de las aleaciones obtenidas.

\subsection{Objetivos.}

El objetivo principal de este proyecto es caracterizar la influencia del contenido de estaño en aleaciones Ti 30Nb XSn procesadas mediante pulvimetalurgia convencional con mezcla elemental de polvos. Para conseguir este objetivo global se han fijado hitos parciales para 
estructurar y facilitar el trabajo. Algunos se han englobado dentro de fases previas o trabajos preliminares.

- Optimizar el procesado de las aleaciones de Ti-Nb binarias y obtener el porcentaje en el cual se obtiene una microestructura mayoritariamente tipo $\beta$.

- Mejorar los parámetros utilizados en el procesado mediante pulvimetalurgia. De este modo, obtener aleaciones con mayor homogeneidad microestructural.

- Analizar la influencia del contenido en estaño de las aleaciones en la microestructura final obtenida.

- Estudiar el comportamiento en función del porcentaje de estaño en las características mecánicas de las aleaciones Ti 30Nb XSn. La propiedad a caracterizar con mayor intensidad y rigor es el módulo elástico ya que es la propiedad mecánica más importante en la vida en servicio de este tipo de biomateriales.

- Analizar las características tecnológicas según el contenido de estaño presente. Realizar ensayos de corrosión y tribocorrosión para observar el comportamiento de las aleaciones, caracterizar y examinar su respuesta. 


\subsection{Aportaciones de la tesis.}

Con la realización de este proyecto se pretende obtener una relación clara entre el proceso y las aleaciones obtenidas. Se procura fijar los parámetros del procesado por pulvimetalurgia y mezcla elemental de polvos para obtener alta tasa de repetitividad y aleaciones válidas. Es decir, se quiere controlar los parámetros de procesado para obtener la relación directa con las características finales de las aleaciones y para poder ajustarlas a las requeridas en servicio.

Por otro lado se persigue procesar aleaciones con microestructura $\beta$ y con la mayor homogeneidad posible para que las características mecánicas finales sean apropiadas y sobre todo poder pronosticar la influencia en la reducción del módulo elástico.

Por último, mediante la caracterización tecnológica se busca una primera aproximación al comportamiento de las aleaciones en condiciones de trabajo como biomaterial para implantología. De este modo afrontar con garantías posteriores etapas de ensayos de cultivo celular e incluso ensayos in vivo.

\section{4. Ámbito de la investigación.}

Esta investigación y la realización de la tesis que conlleva se incluye dentro de la línea de investigación que se está realizando dentro del 
Instituto de Tecnología de Materiales (ITM) y ha sido posible gracias fundamentalmente a la financiación por parte de la Universitat Politècnica de València (UPV). Pero en este proyecto también se han visto implicados distintos centros y varias universidades. Estas colaboraciones están enmarcadas en proyectos de colaboración y acuerdos interdisciplinares del grupo de investigación del ITM que ha potenciado y complementado este proyecto.

En primer lugar cabe destacar la colaboración que ha prestado la Faculdade de Engenharia Mecánica de la Universidade Estadual de Campinas, y más concretamente el Departamente de Engenharia de Fabricaçâo. Ha colaborado aportando su experiencia y todas sus posibilidades para complementar la investigación en el área de la caracterización microestructural. También ha colaborado en la caracterización microestructural el Departamento de Engenharia de Materiais de la Universidade Federal de São Carlos, y en especial al profesor C.R.M. Afonso. Por su inestimable ayuda en los ensayos de microscopía electrónica de transmisión realizados en sus instalaciones. Estas dos colaboraciones están enmarcadas en el proyecto de colaboración, suscrito entre estas dos universidades y el grupo del ITM de la UPV, del Ministerio de Ciencia e Innovación dentro del Proyecto de Investigación Bilateral España - Brasil PIB 2010BZ 00448.

Por otro lado, dentro de la Universitat Politècnica de València y enmarcado en un proyecto de colaboración interdisciplinar con el 
Instituto de Seguridad Industrial, Radiofísica y Medioambiental se ha podido llevar a cabo la caracterización tecnológica gracias a la colaboración de Anna Neus Igual Muñoz y su equipo de colaboradoras. 


\section{ANTECEDENTES.}

El titanio tiene unas características muy especiales y valoradas. Por una parte su baja densidad, junto a elevadas propiedades específicas y su gran resistencia a la corrosión [1, 2]. Esto hace que su utilización esté creciendo en diferentes sectores industriales como el aeronáutico, espacial o el automovilístico. Además en aplicaciones más concretas, como biomaterial, en implantes óseos o dentales $[3,4,5]$. Dentro de las aplicaciones biomédicas es uno de los mejores materiales y el que mayor crecimiento está experimentando, por sus características frente a la corrosión y su menor módulo elástico.

Por otro lado, el titanio es uno de los materiales metálicos que más fácilmente reacciona con los elementos de su alrededor. Esto es un arma de doble filo porque; es muy positivo para obtener aleaciones homogéneas con facilidad, pero es un grave inconveniente a la hora de procesarlo. Reacciona fácilmente con el entorno. Es decir, forma óxidos con mucha facilidad cuando se calienta en atmósferas no controladas u oxidantes. También forma compuestos con elementos como el aluminio, el carbono o el nitrógeno fácilmente. Esto obliga a controlar meticulosamente los parámetros en el procesado.

Dentro de las aleaciones de titanio hay varios tipos de aleaciones según su microestructura. En esta investigación se estudia la microestructura tipo $\beta$. Este tipo de microestructura se caracteriza, 
sobre todo, por su bajo módulo elástico [6]. La microestructura $\beta$ se consigue mediante la adición, en grandes cantidades, de elementos estabilizantes de la fase $\beta$. Estos elementos son muy pesados, en comparación con el titanio, y presentan un carácter refractario que dificulta la formación de aleaciones. Los principales elementos betágenos son el Nb y el Mo.

La pulvimetalurgia se muestra como una de las mejores formas de procesar estos materiales frente a procesados por técnicas de fusión ya que se obtienen piezas prácticamente acabadas, sin necesidad de grandes mecanizados posteriores y no es necesario, en la mayoría de casos, hacer tratamientos térmicos posteriores ya que la microestructura resultante es apropiada. La mezcla elemental de polvos se presenta como un proceso relativamente sencillo y de fácil aplicación industrial. Pero presenta grandes dificultades, como la homogeneidad microestructural debido al carácter refractario y el alto porcentaje presente de los elementos aleantes, que anteriormente se ha comentado, ya que todos los mecanismos de difusión se llevan a cabo en estado sólido.

\subsection{El titanio como biomaterial.}

El titanio se encuentra entre las mejores opciones para su utilización como biomaterial. Entre los materiales que tradicionalmente se han utilizado en estas aplicaciones se encuentran el acero inoxidable 316L 
(aceros inoxidable austenítico con bajo contenido en carbono) o las aleaciones CrCo. Las propiedades de estas familias de materiales son inferiores, comparadas con el titanio, en muchos casos: tiene mayor densidad, mayor módulo elástico, peor comportamiento a corrosión, etc.

El gran problema de los materiales para implantología de piezas que requieren una función estructural y permanente es, en primer lugar, la biocompatibilidad y posteriormente la adecuación de las características del material a las características del tejido que se sustituye. En este punto aparecen grandes problemas cuando por ejemplo se procede a implantar una prótesis de cadera. Las propiedades del material implantado deben ser lo más cercanas posibles al hueso cortical que sustituye. En este campo el módulo elástico ha de ser muy próximo al del hueso (10-30 GPa) para que no aparezcan problemas de apantallamiento de tensiones, o stress shielding, debido a la gran diferencia entre el módulo del material implantado y el del hueso al que se fija la prótesis $[7,8]$.

El fenómeno de apantallamiento de tensiones conlleva una reabsorción del hueso debido a la falta de carga o solicitaciones. Cuando se implanta un pieza estructural en el cuerpo humano con un módulo elástico excesivamente alto, al realizar las carga sobre el conjunto implante-hueso toda la carga es soportada por el implante. Consecuentemente el cuerpo advierte que el hueso ya no realiza ninguna función por lo que es reabsorbido. Este fenómeno tiene una 
gran repercusión ya que deja a la prótesis, a largo plazo, desprovista de sujeción y puede llegar a producirse fallos de funcionamiento que requieran de una segunda o tercera intervención con la retirada del implante. Para minimizar esta pérdida de masa ósea por falta de solicitaciones se pretende que trabajen en conjunto hueso e implante para ello el módulo elástico de ambos materiales ha de ser lo más parecido posible. En la Figura 2.1 se muestra el valor de módulo elástico de los materiales para implantología.

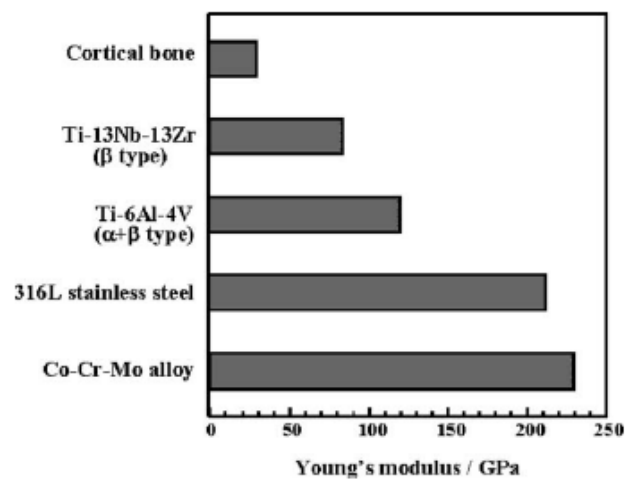

Figura 2.1. Módulo elástico de varios materiales utilizados en implantología [7].

Se observa como las aleaciones de Ti poseen un módulo mucho menor y más próximo al del hueso que el AISI 316L o el CrCo. La utilización de las aleaciones de CrCo está cada vez más en desuso y se buscan nuevos materiales con mejores prestaciones. En la siguiente figura se puede observar una comparativa de la reacción del cuerpo humano ante la presencia de un implante de cadera con la misma geometría pero con distinto material, observándose una importante 
pérdida de masa ósea debida a la reabsorción por parte del propio cuerpo humano en el caso del implante de acero inoxidable 316L.
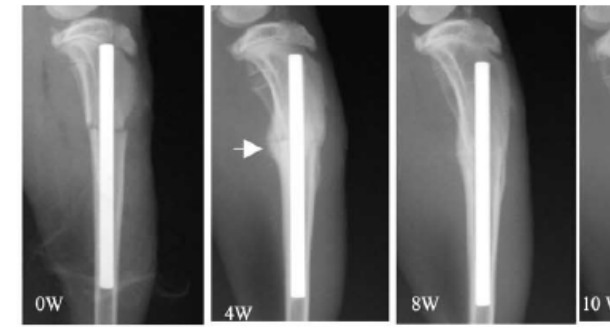

(a) $\mathrm{Ti}-29 \mathrm{Nb}-13 \mathrm{Ta}-4.6 \mathrm{Zr}$
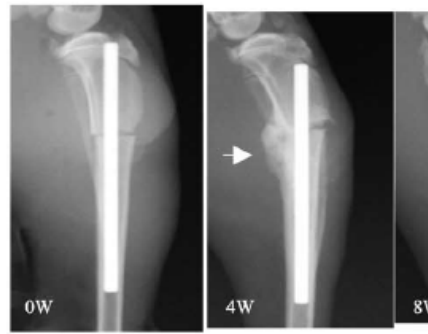

8W
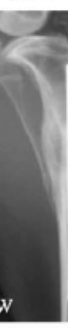

(b) Ti-6AI-4V ELI
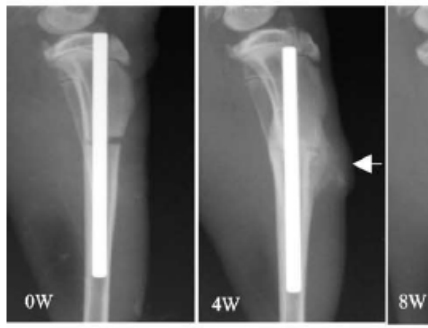

$8 \mathrm{~W}$
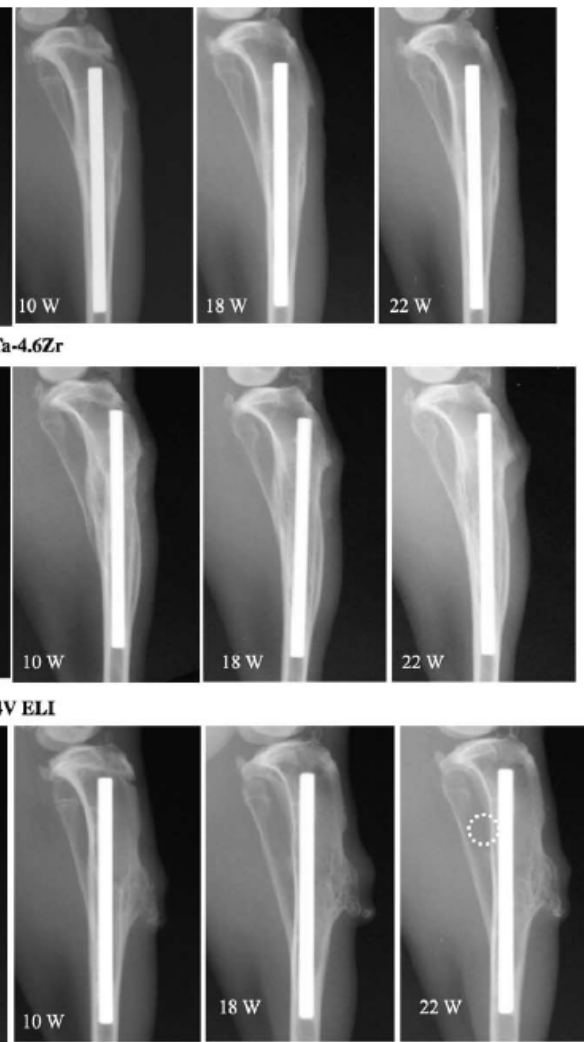

(c) SUS 316L

Figura 2.2. Comportamiento del cuerpo humano ante un implante de distinto material [7].

En la figura 2.3 se observa con mayor detalle el fenómeno de reabsorción del hueso y de la buena osteointegración de las aleaciones de titanio. 


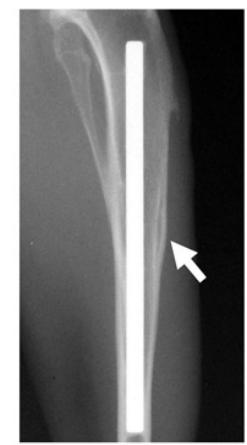

Ti-29Nb-13Ta-4.6Zr

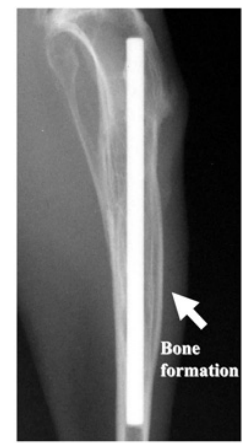

Ti-6Al-4V ELI

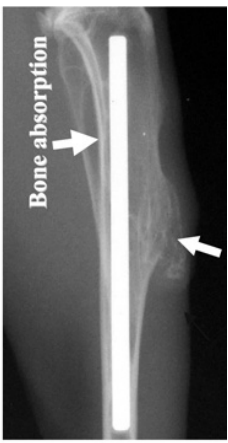

SUS316L

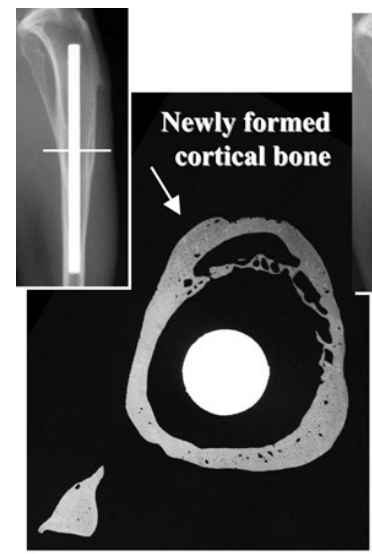

TNTZ

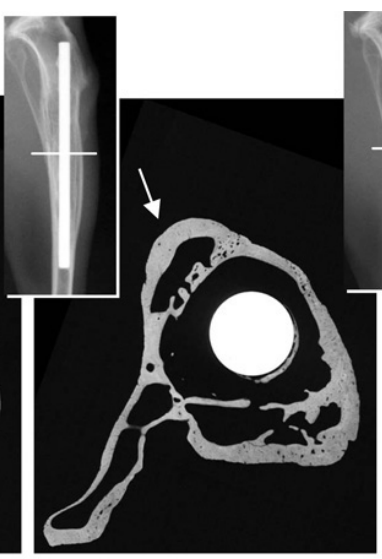

Ti-6Al-4V ELI

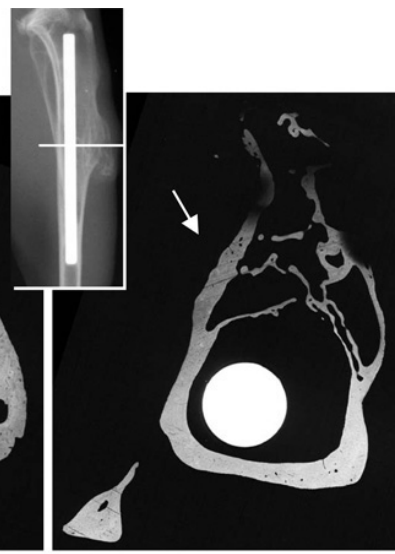

SUS316L

Figura 2.3. Detalle de la respuesta del cuerpo humano ante implantes de distintos materiales [8].

Uno de los caminos que buscan algunos investigadores [9, 10], una vez ya han seleccionado el titanio como material de partida para implantología, es la obtención de materiales porosos para reducir aún más el módulo elástico. Mediante procesos pulvimetalúrgicos se genera una porosidad controlada que repercute en la reducción drástica del módulo elástico pero, como contrapartida, aparecen nuevas variables en el proceso de fabricación que dificultan sobremanera y obligan a un control muy exhaustivo que obstaculiza su 
procesado [10]. En la siguiente gráfica se puede observar la evolución del módulo en función de la porosidad y de la presión de compactación en un estudio llevado a cabo sobre titanio comercialmente puro (Ti c.p.) en el que se utiliza sal común $(\mathrm{NaCl})$ como espaciador [10]. Se muestra los valores del módulo para distintos porcentajes de espaciador (70, 60, 50, y 40 \%) y para muestras procesadas por pulvimetalurgia convencional (sin espaciador) con distintas presiones de compactación 211.5, 147.4, 89.7 y $38.5 \mathrm{MPa}$.

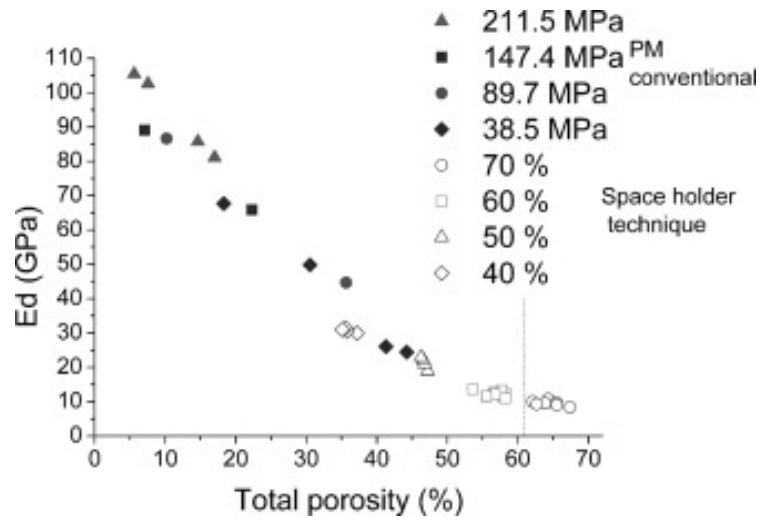

Figura 2.4. Evolución del módulo elástico en función de la porosidad en muestras de Ti c.p. y la presión de compactación [10].

Pero para mejorar el comportamiento de las aleaciones de titanio sin complicar en exceso el procesado por pulvimetalurgia se puede recurrir a una mejor elección en el material. Es decir, por su microestructura, en las aleaciones de titanio fase $\beta$, el módulo elástico ya es mucho menor que el Ti c.p. o la aleación Ti 6Al 4V como se ha 
podido observar en la figura 2.1 con la aleación Ti $13 \mathrm{Nb} 13 \mathrm{Zr}$ (microestructura tipo $\beta$ ).

Las aleaciones tipo $\beta$ presentan microestructura metaestable $\beta$ a temperatura ambiente. Se utilizan elementos betágenos para conseguir este efecto. Obtener una microestructura cúbica centrada en el cuerpo (BCC) a temperatura ambiente es muy propicio para la deformación en frio y presentan mejores valores de endurecimiento y mayor límite elástico que las aleaciones $\alpha+\beta$. En la tabla 2.1 se muestra las principales aleaciones de Ti- $\beta$ y su denominación comercial.

Tabla 2.1. Aleaciones comerciales con microestructura tipo $\beta$ [11].

\begin{tabular}{|c|c|}
\hline Aleación & Nom bre com ercial \\
\hline Ti $-11,5 \mathrm{~V}-2 \mathrm{~A} 1-2 \mathrm{Sn}-11 \mathrm{Zr}$ & Transage 129 \\
\hline Ti- 12V - 2,5A1-2Sn- $6 \mathrm{Zr}$ & Transage 134 \\
\hline$T i-13 V-2,7 A 1-7 \mathrm{Sn}-2 \mathrm{Zr}$ & Transage 175 \\
\hline Ti $-5 \mathrm{AI}-5 \mathrm{Mo}-1 \mathrm{~V}-1 \mathrm{Cr}-1 \mathrm{Fe}-1,5 \mathrm{Sn}-2 \mathrm{Zr}$ & VT22M \\
\hline Ti $-4 \mathrm{Mo}-2 \mathrm{Cr}-1,2 \mathrm{Fe}-5 \mathrm{Al}-2 \mathrm{Sn}-4 \mathrm{Zr}$ & BetaCEZ \\
\hline Ti - 5A1 - 2Sn - 2Zr - 4Mo-4Cr & IMI 617 \\
\hline $\mathrm{Ti}-10 \mathrm{~V}-2 \mathrm{Fe}-3 \mathrm{Al}$ & Ti-10-2-3 \\
\hline \multicolumn{2}{|l|}{ Ti- $16 \mathrm{~V}-2,5 \mathrm{Al}$} \\
\hline $\mathrm{Ti}_{\mathrm{i}}-11,5 \mathrm{Mo}-6 \mathrm{Zr}-4,5 \mathrm{Sn}$ & Beta III \\
\hline Ti $-5 \mathrm{Al}-4,75 \mathrm{Mo}-4,75 \mathrm{~V}-1 \mathrm{Cr}-1 \mathrm{Fe}$ & VT22 \\
\hline $\mathrm{Ti}-3 \mathrm{~A} 1-5 \mathrm{~V}-5 \mathrm{Mo}-1,2 \mathrm{Cr}-1,2 \mathrm{Fe}$ & VT22c \\
\hline \multicolumn{2}{|l|}{ Ti - 20V - 4A1 - 1Sn } \\
\hline \multicolumn{2}{|l|}{ Ti- $15 \mathrm{Mo}$} \\
\hline Ti- $15 \mathrm{Mo}-5 \mathrm{Zr}$ & Ti-15-5 \\
\hline Ti- $15 \mathrm{Mo}-5 \mathrm{Zr}-3 \mathrm{Al}$ & Ti-15-5-3 \\
\hline \multicolumn{2}{|l|}{$T_{i}-8 \mathrm{~V}-5 \mathrm{Fe}-1 \mathrm{Al}$} \\
\hline Ti- 15V - 3Cr - 3A1 - 3Sn & Ti-15-3 \\
\hline $\mathrm{Ti}-15 \mathrm{Mo}-3 \mathrm{Al}-2,7 \mathrm{Nb}-0,25 \mathrm{Si}$ & Beta 2 IS \\
\hline Ti - $15 \mathrm{~V}-3 \mathrm{Cr}-3 \mathrm{Al}-3 \mathrm{Sn}-1 \mathrm{Zr}-1 \mathrm{Mo}$ & VT35 \\
\hline $\mathrm{Ti}-5,5 \mathrm{Mo}-3,5 \mathrm{~V}-5,5 \mathrm{Cr}-3 \mathrm{Al}-1 \mathrm{Zr}$ & VT19 \\
\hline Ti- $10 \mathrm{Mo}-8 \mathrm{~V}-1 \mathrm{Fe}-3,5 \mathrm{Al}$ & TV3 \\
\hline $\mathrm{Ti}-8 \mathrm{Mo}-8 \mathrm{~V}-2 \mathrm{Fe}-3 \mathrm{Al}$ & $\mathrm{Ti}-8823$ \\
\hline Ti- $10 \mathrm{~V}-7 \mathrm{Mo}-2 \mathrm{Fe}-1 \mathrm{Zr}-4 \mathrm{Al}$ & Ti-4721 \\
\hline $\mathrm{Ti}_{\mathrm{i}}-8 \mathrm{~V}-8 \mathrm{Mo}-1,5 \mathrm{Cr}-1,5 \mathrm{Fe}-3 \mathrm{Al}$ & VT32 \\
\hline Ti $-8 \mathrm{~V}-6 \mathrm{Cr}-4 \mathrm{Mo}-4 \mathrm{Zr}-3 \mathrm{Al}$ & Beta C \\
\hline Ti- $8 \mathrm{Cr}-5 \mathrm{Mo}-5 \mathrm{~V}-3 \mathrm{Al}$ & TV 2 \\
\hline Ti $-6 \mathrm{~V}-6,2 \mathrm{Mo}-5,7 \mathrm{Fe}-3 \mathrm{Al}$ & Ti-125 \\
\hline $\mathrm{Ti}-13 \mathrm{~V}-11 \mathrm{Cr}-3 \mathrm{Al}$ & $\mathrm{Ti}-13-11-3$ \\
\hline
\end{tabular}


Añadiendo elementos estabilizadores de la fase $\beta$ se reduce el módulo elástico de la aleación de titanio y se mejora el comportamiento del material reduciendo el apantallamiento de tensiones en mayor medida.

En la siguiente figura se puede observar el comportamiento de los principales elementos presentes en aleaciones de titanio.

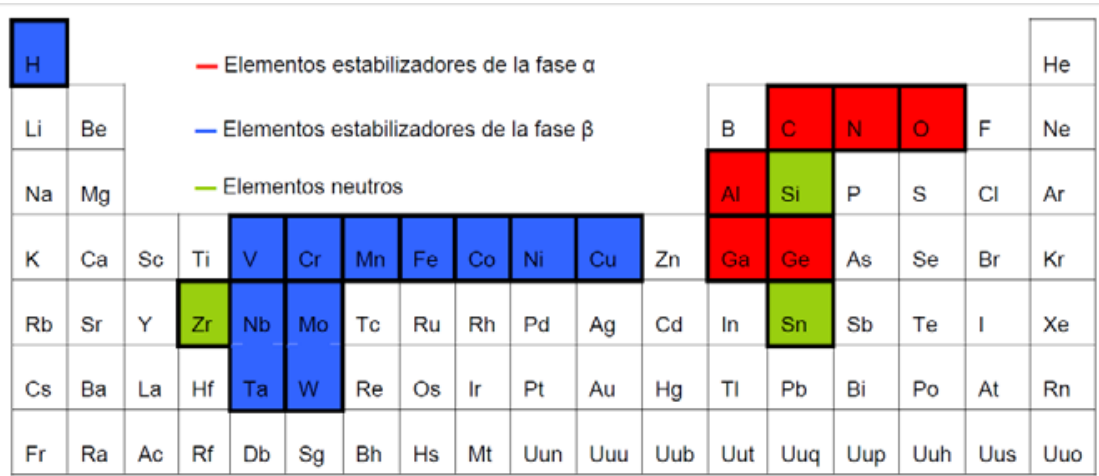

Figura 2.5. Tabla periódica con las especificaciones de cada elemento según la fase que estabiliza [12].

Según la influencia en la microestructura del titanio, del elemento aleante, se producen distintos efectos que se ven reflejados en los diagramas de equilibrio del titanio. Los elementos alfágenos aumentan la región de microestructura tipo $\alpha$ y elevan la temperatura del cambio alotrópico. Los elementos estabilizadores de la fase $\beta$ bajan la temperatura del cambio alotrópico y aumentan la región de la fase $\beta$. Pueden dividirse en $\beta$ isomorfos como el $\mathrm{Mo}, \mathrm{Nb}$ o el $\mathrm{V}$, elementos que no forman compuestos intermetálicos con el titanio en fase $\beta, o \beta$ eutectoides como el Fe, $\mathrm{Cr}$ o $\mathrm{Cu}$ y que forman sistemas eutectoides. 


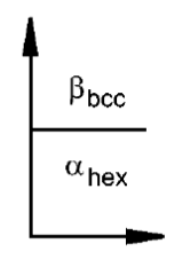

$\mathrm{Ti}$

neutral

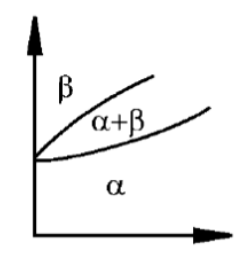

Ti

$\alpha$-stabilizing

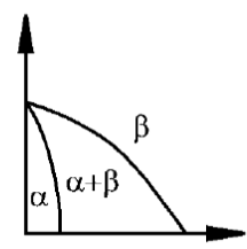

$\mathrm{Ti}$

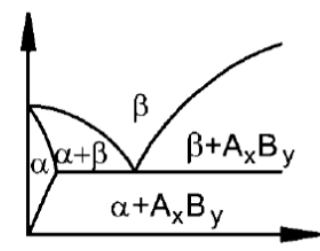

Ti

$\beta$-stabilizing

$\beta$-isomorphous

$\beta$-eutectoid

Figura 2.6. Efecto en el diagrama de equilibrio del titanio de los elementos aleantes [13].

Existe gran cantidad de elementos estabilizadores de la fase $\beta$ pero los más utilizados son el niobio y el molibdeno por su mejor comportamiento. Existen estudios que avalan que los elementos aleantes estabilizadores de la fase $\beta$ no presentan ningún peligro para el cuerpo humano y son totalmente biocompatibles [14, 15].

Como se muestra en la figura 2.7 las aleaciones con microestructura $\beta$ presentan mejores comportamientos para su utilización como biomaterial, destacando entre sus características su menor módulo elástico. 

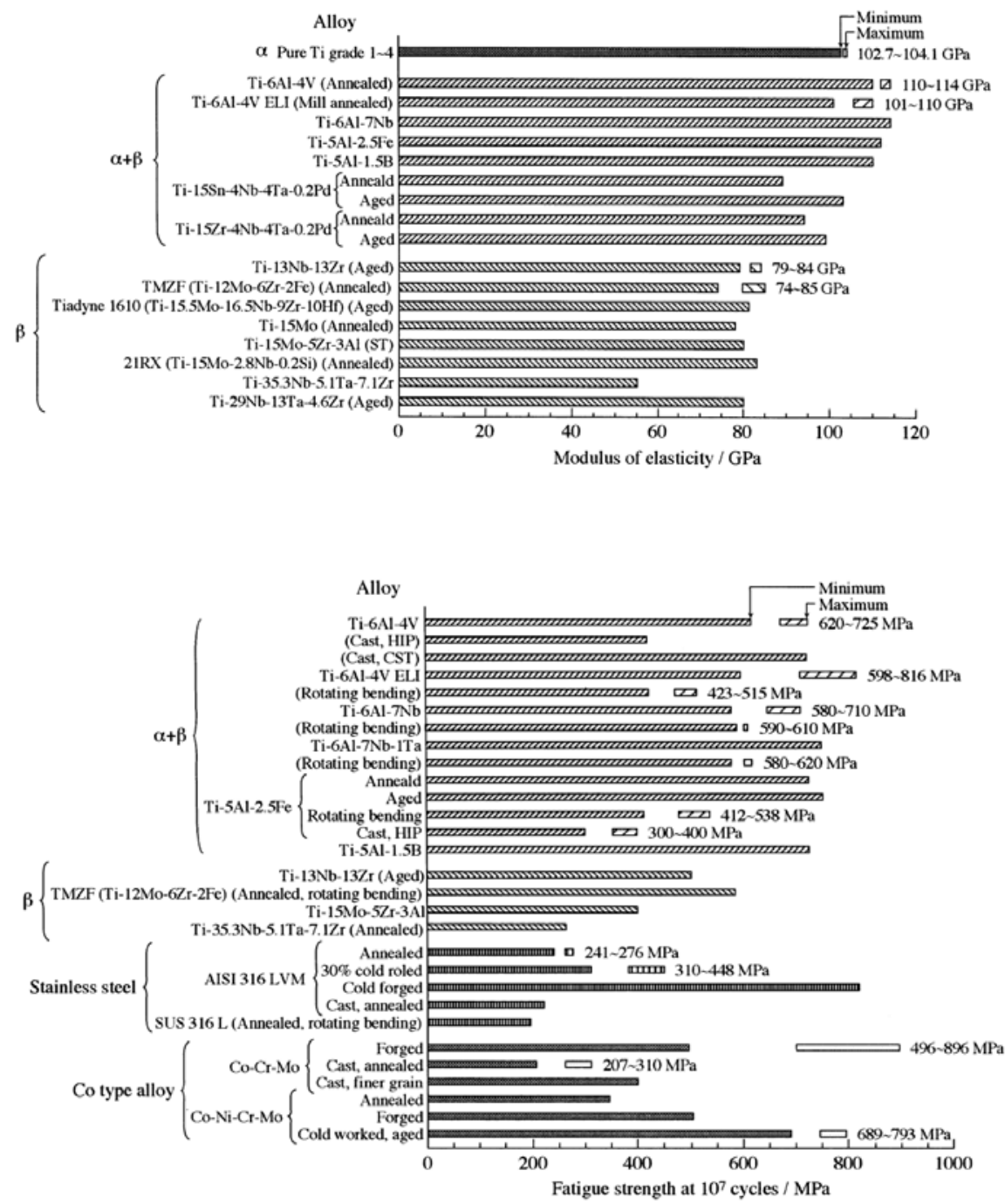


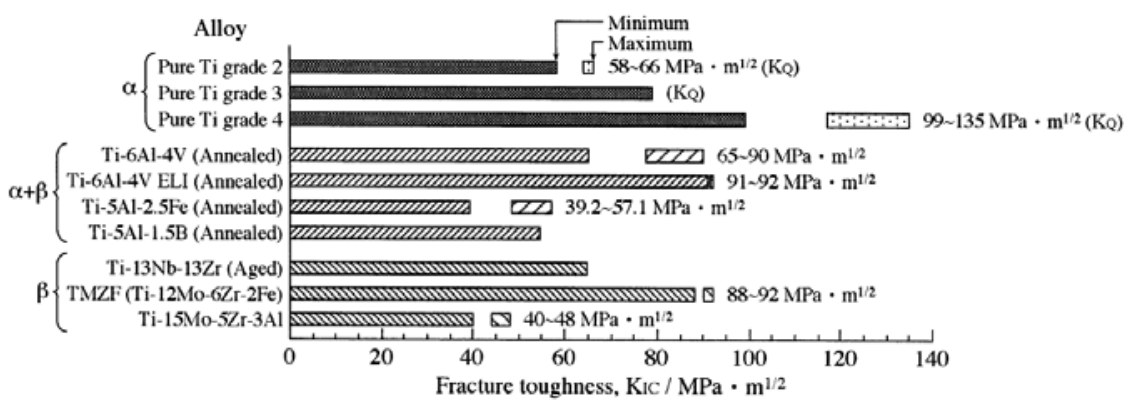

Figura 2.7. Comparación de las propiedades mecánicas de las aleaciones Ti con microestructura tipo $\beta$ con otros materiales para implantología [8].

Se observa como las aleaciones $\beta$ poseen valores más bajos de módulo elástico, siempre menores de 85 GPa por lo que se reduce el problema de apantallamiento de tensiones. Se observa como la resistencia a la fatiga y la resistencia a la fractura es ligeramente menor que las aleaciones con microestructura $\alpha+\beta$ pero no menores que el acero inoxidable o aleaciones de Co. Estas características justifican el interés en la utilización de las aleaciones de titanio con microestructura $\beta$ frente a otros materiales para implantología.

Entre los elementos más perjudiciales, para las aleaciones con microestructura $\beta$, está el oxígeno. El oxígeno es uno de los mayores estabilizadores de la fase $\alpha$ y en pequeño porcentaje influye de forma notable en el comportamiento del material. En la figura 2.8 se muestra la influencia del oxígeno en pequeñas cantidades en el comportamiento de la curva tensión deformación y en el valor del módulo elástico de la aleación Ti 22.5Nb 0.7Zr 2Ta con pequeñas adiciones de oxígeno [16]. 

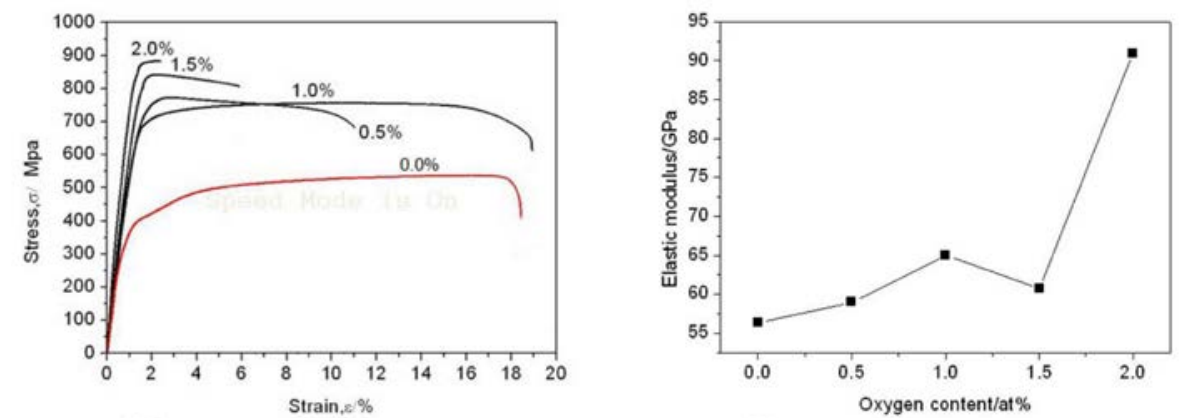

Figura 2.8. Evolución del comportamiento mecánico de la aleación Ti 22.5Nb 0.7Zr 2Ta en función del contenido de oxígeno [16].

El aumento del límite elástico y sobre todo del módulo elástico muestran una rigidización del material por el aumento del contenido en oxígeno, a pesar de ser en pequeñas cantidades, debido a la aparición, según el autor, de solución sólida intersticial y compuestos intermetálicos especialmente en la microestructura $\beta$. Esta influencia motiva el control exhaustivo durante todo el procesado para minimizar el aporte de oxígeno a las aleaciones $\beta$.

Como se ha dicho anteriormente los elementos estabilizadores de la fase $\beta$ más utilizados son el molibdeno y el niobio. Viendo el número de publicaciones existentes que utilizan $\mathrm{Nb}$ o Mo se observa que la utilización de $\mathrm{Nb}$ es mucho mayor.

En trabajos desarrollados por el propio autor se demuestra como la difusión del niobio en el titanio es mucho mejor que la del molibdeno en el titanio [17]. A pesar de esto, se ha realizado un estudio del 
procesado por pulvimetalurgia convencional y mezcla elemental de polvo utilizando la aleación Ti 15Mo para optimizar el procesado [18]. En este trabajo se plantea la utilización de Mo como elemento de aleación para obtener microestructura tipo $\beta$. Se utilizan porcentajes más bajos que con el niobio, $15 \%$, y los resultados muestran que siguiendo las directrices planteadas se consiguen aleaciones con suficiente homogeneidad microestructural, incluso para el molibdeno, a pesar de su peor difusividad. Por este motivo se ha seguido el mismo procedimiento de obtención del polvo planteado para el Mo en este estudio. En el apartado de ensayos previos se muestra con más detalle los resultados obtenidos.

En la mayoría de las investigaciones con $\mathrm{Nb}$ se utiliza un segundo o tercer elemento de aleación, en pequeñas cantidades para observar la influencia y mejorar algunas propiedades finales. En trabajos anteriores del propio grupo de investigación se propuso la utilización de Fe como elemento de aleación [19] pero la utilización de hierro como elemento aleante no es una de las mejores alternativas ya que presenta mayor toxicidad que otros elementos [15]. Otros autores proponen la utilización de Pd [20], Ta [21] o Zr [22] entre otros muchos. La utilización de la familia de aleaciones conocida como TNZT (Ti-Nb-Zr-Ta) también ha experimentado un gran aumento de las investigaciones por sus buenas características [16, 23, 24].

El paladio reduce la aparición de la fase $\omega$ y mejora la homogeneidad de la microestructura $\beta$. También mejora la elongación del material en 
comparación a las aleaciones sin Pd y es un elemento no tóxico [15]. Pero su alto punto de fusión $\left(1555^{\circ} \mathrm{C}\right)$ dificulta su utilización en pulvimetalurgia convencional con mezcla elemental de polvos. Por el mismo motivo tampoco se ha utilizado el tantalio como elemento de aleación, su carácter refractario y su alto punto de fusión $\left(3017{ }^{\circ} \mathrm{C}\right)$ dificultan mucho la homogeneidad estructural cuando se utilizan técnicas pulvimetalúrgicas. Otra razón para no utilizar tantalio es porque la microestructura obtenida no es adecuada para su utilización en implantología y el módulo elástico no se reduce significativamente [21]. Por último se ha descartado la utilización de circonio, a pesar de su buena difusión durante la etapa de sinterizado [17], porque el polvo de circonio se suministra en suspensión acuosa y durante el procesado se pueden contaminar con oxígeno, procedente de la suspensión, la aleación final procesada. Aunque puede utilizarse para producir aleaciones madre de las que, posteriormente, derivan otras con la composición requerida.

En este proyecto se ha optado por la utilización de estaño porque disminuye la presencia de fases indeseadas, sobre todo fase $\omega \mathrm{y}$ porque se reduce el módulo elástico con el incremento del porcentaje de estaño en el contenido de la aleación [4]. También se utiliza el Sn porque su punto de fusión es relativamente bajo $\left(232{ }^{\circ} \mathrm{C}\right)$ y se ha comprobado que difunde bien durante el sinterizado [17]. El estaño también ayuda a la difusión del niobio en la etapa de sinterizado [25]. 


\subsection{Las aleaciones $\mathrm{Ti}-\mathrm{Nb}$.}

Dentro del gran abanico de aleaciones con microestructura $\beta$ se encuentran las aleaciones con niobio. El $\mathrm{Nb}$ es uno de los grandes elementos betágenos en las aleaciones de titanio y da lugar a numerosas aleaciones. Las aleaciones de Ti-Nb han destacado por su utilización como material superconductor y por sustituir al Ti-Ni como aleación libre de níquel en aplicaciones en la que es necesario utilizar materiales con memoria de forma [26]. En la figura 2.9 se muestra el diagrama de equilibrio del Ti-Nb.

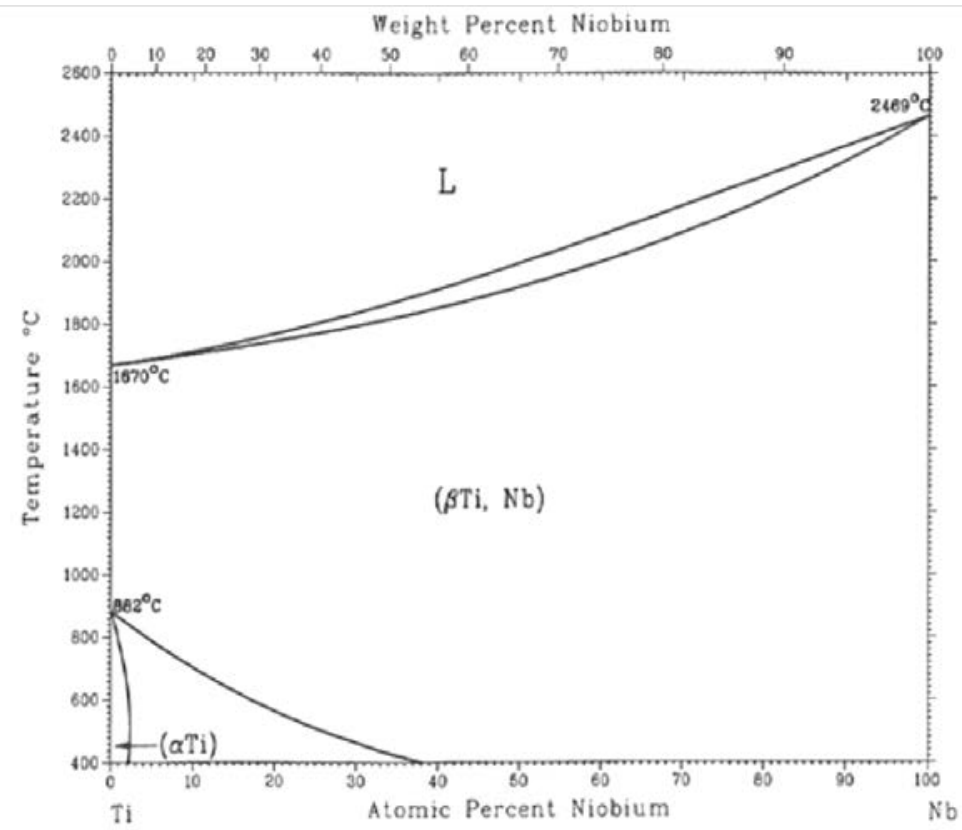

Figura 2.9. Diagrama de equilibrio del Ti-Nb [27].

Existe un gran interés por este tipo de aleaciones de Ti-Nb. El estado del arte se ha focalizado principalmente en las aleaciones binarias Ti- 
$\mathrm{Nb}$ con un porcentaje superior al $20 \%$ en peso de titanio y se ha descartado las aleaciones que utilizan otro tipo de elemento aleante como segundo elemento de aleación que no sea el estaño. De este modo se obtiene claramente el estado del arte en el ámbito de acción y se focaliza mucho mejor el objetivo que justifica la utilización de las aleaciones Ti-Nb-Sn.

El primer punto que se pretende mejorar en todos los estudios es la caracterización microestructural y la obtención de aleaciones con microestructura totalmente $\beta$ o, si no es posible, con sólo pequeñas trazas de microestructura $\alpha$. Sobre todo se intenta evitar la aparición de la fase $\alpha$ '. Esta fase es una formación martensítica que aparece cuando el enfriamiento se realiza demasiado rápido [28]. Por otro lado también se evita la formación de fase $\omega$, Esta fase también es totalmente indeseada ya que fragiliza mucho el material. Otro de los grandes inconvenientes de esta fase $\omega$ es su dificultad a la hora de detectar su formación ya que es una fase con un tamaño que en ningún caso supera los $50 \mathrm{~nm}$ [29].

Por todo esto, se trabaja en mejorar y controlar de forma precisa la microestructura de estas aleaciones. Cabe destacar que la gran mayoría de publicaciones que aparecen son con aleaciones obtenidas por métodos de fusión, sobre todo en hornos de arco eléctrico y realizando varias refusiones para homogeneizar la composición final. Posteriormente se efectúan tratamientos térmicos de envejecimiento y en muchas ocasiones, se laminan las muestras tanto en frio como en 
caliente [2, 7, 20]. Pero los parámetros y los pasos de estos tratamientos térmicos no están estandarizados y no se conoce muy bien la influencia de parámetros tan importantes como son el tiempo o la temperatura.

Todos estos procesos de fusión, refusión, tratamientos térmicos, laminados, etc. con gran número de etapas desembocan en un proceso de obtención de aleaciones muy costoso tanto por recursos tecnológicos como económicamente hablando. La pulvimetalurgia reduce de forma drástica estas etapas dadas sus características y facilita el procesado y la implantación a nivel industrial.

En el procesado por pulvimetalurgia y utilizando la mezcla elemental de polvos, se aprovecha la gran reactividad del titanio para formar aleaciones, obteniéndose aleaciones con la concentración de elementos aleantes deseada y una buena homogeneidad química $\mathrm{y}$, consecuentemente, microestructural en la aleación.

En la mezcla elemental de polvos se propone mezclar el porcentaje de cada elemento para obtener la composición deseada del material, después de la etapa de sinterizado, cuando ya se ha producido todos los procesos de difusión. Esta técnica ofrece gran versatilidad ya que se puede variar la composición de la aleación sin grandes dificultades y su implantación a nivel industrial es relativamente sencilla. En contrapartida existe una limitación en la obtención de materiales 
homogéneos ya que los procesos de difusión se realizan en estado sólido.

Controlar dichos procesos para obtener aleaciones con la microestructura deseada, una buena homogeneidad química $\mathrm{y}$, en consecuencia, homogeneidad microestructural es uno de los puntos importantes en el trabajo. El titanio por sus características, reacciona con gran facilidad con la mayoría de elementos de la tabla periódica lo que facilita los procesos de difusión pero, debido al carácter refractario de los elementos estabilizadores de la fase $\beta$ (Nb, Mo, Ta), este punto presenta grandes inconvenientes. Es necesario utilizar ciclos de sinterizado con gran aporte energético, alargando el tiempo o la temperatura de los ciclos. También hay que destacar que se utilizan altos porcentajes de elementos aleantes que dificultan aún más el procesado.

Por otro lado esta gran reactividad obliga a tomar una serie de consideraciones para minimizar la presencia de elementos no deseados dentro de la aleación, que empeoren las propiedades finales del material, como se ha visto anteriormente con el oxígeno.

Por este motivo también es necesario llevar a cabo los ciclos de sinterizado en atmosferas controladas o incluso alto vacío. La presencia de elementos externos dentro de la atmosfera del horno repercute en contaminación en el material sinterizado. La mejor 
opción, pero a la vez la más costosa, es utilizar alto vacío para minimizar la repercusión de cualquier elemento sobre el material final.

Ya que la pulvimetalurgia ofrece la posibilidad de obtener piezas prácticamente acabadas hay que optimizar la geometría de éstas y los acabados logrados antes del sinterizado para minimizar las etapas posteriores, eliminar mecanizados innecesarios y la consecuente pérdida de material. Esta virtud se ve muy acentuada si se compara con la obtención de aleaciones de titanio por procesos de fusión. La pulvimetalurgia es un proceso costoso por las peculiaridades del titanio y de la obtención de aleaciones con microestructura tipo $\beta$ pero en comparación con los procesos de fusión es más sencillo y fácil de implantar a nivel industrial.

La mayoría de grupos actúan primero sobre la aleación binaria Ti-Nb, obteniendo las propiedades del material y observando la influencia del porcentaje de niobio [29]. Posteriormente trabajan sobre las aleaciones que mejores resultados han obtenido [30,31] por último y después de haber reducido el número de variables en los parámetros de procesado, añaden un tercer elemento en la aleación, el Sn, y observan su influencia [32]. Un grupo importante en la investigación de estas aleaciones es el liderado por R. Caram [2, 21, 28-32] y aparecen otros grupos como el de I.S. Golovin [33] u otros autores como Y. Mantani [34]. Todos los estudios se centran en la caracterización microestructural y en evitar la aparición de fases indeseadas (fase $\alpha$ ", y fase $\omega)$ mediante la combinación de tratamientos térmicos o 
tratamientos termomecánicos. Por este motivo en este estudio se va a caracterizar de forma exhaustiva la microestructura obtenida y la influencia del estaño en la microestructura.

Otra de las propiedades, anteriormente mencionada, es la memoria de forma de estas aleaciones Ti-Nb [26], que también es estudiada por algunos autores como S. Miyazaki [35, 36]. Se consigue excelente superplasticidad mediante el recocido a $853 \mathrm{~K}$ durante $600 \mathrm{~s}$ debido al endurecimiento conseguido en el procesado. Pero estas características son muy difíciles de conseguir mediante el procesado por pulvimetalurgia debido a la porosidad intrínseca de la técnica.

Dada la creciente utilización de estas aleaciones como biomateriales surgen muchos trabajos que profundizan en el estudio de la corrosión y la cinética de corrosión del Ti xNb [37], e incluso con porcentajes de niobio muy altos como $\mathrm{Ti} 35 \mathrm{Nb}$ [2] o $\mathrm{Ti} 45 \mathrm{Nb}$ [38]. Estos estudios se realizan en ambientes que simulan las condiciones de trabajo dentro del cuerpo humano como material de implante. Los resultados justifican la utilización de niobio para mejorar las propiedades [37]. Cuando se utilizan altos porcentajes de $\mathrm{Nb}$ la resistencia es mejor que la del Ti y del Ti 6Al 4V [38] por lo que se argumenta su sustitución en aplicaciones biomédicas remplazando a estos materiales. Algunos investigadores han llegado a trabajar con cultivos celulares [39] o incluso se ha realizado investigaciones de aleaciones Ti-Nb-Sn implantadas en fémur de conejos [40]. Este último trabajo destaca porque completa todo el ciclo de investigación de un nuevo material. 
El grupo de trabajo abarca desde el procesado y caracterización microestructural hasta su aplicación real en implantología. Estos trabajos muestran buenos resultados para las aleaciones Ti-Nb-Sn obteniendo buenos resultados en el cultivo celular y obteniendo valores equiparables al $\mathrm{Ti} 6 \mathrm{Al} 4 \mathrm{~V}$ por lo que, al tener menor módulo elástico que éste, se muestra como una mejor opción para implantología.

Por otro lado, y como se viene repitiendo dado su gran interés por su repercusión en su aplicación en servicio, uno de los grandes inconvenientes en la utilización como biomateriales, es la reducción del módulo elástico, haciéndolo lo más próximo al módulo elástico del hueso humano, 10-30 GPa [41]. Las aleaciones Ti-Nb y Ti-Nb-Sn poseen un bajo módulo elástico que minimiza la aparición del apantallamiento de tensiones o stress-shielding [32]. Debido a esto hay un gran número de autores que centra su investigación en la caracterización mecánica y más concretamente en la obtención del módulo elástico como M. Niinomi [41, 42] o H. Matsumoto [43] obteniendo módulos elásticos bajos.

En el procesado por técnicas pulvimetalúrgicas de aleaciones Ti-Nb y Ti-Nb-Sn hay pocas publicaciones [25, 44-46], a pesar de que es una de las técnicas de procesado más ventajosas para estos materiales. Pero por ello no deja de tener una gran complejidad. En primer lugar aparecen estudios que, como en el procesado por fusión, estudian la relación entre el procesado y la microestructura obtenida [44]. 

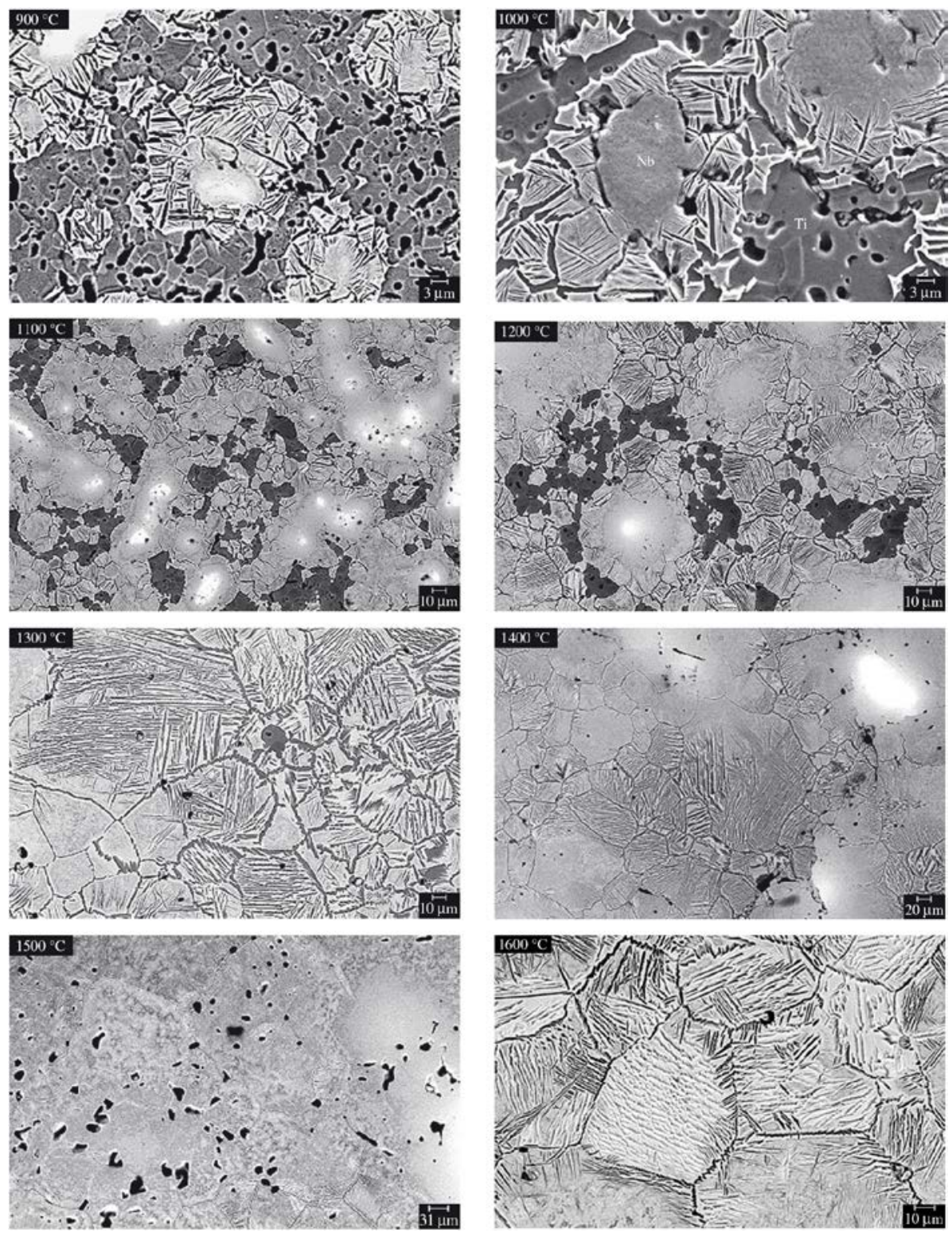

Figura 2.10. Microestructuras obtenidas por mezcla elemental de polvos y sinterización a distintas temperaturas por Rodriguez V.A.H. [44]. 
Pero los resultados que ofrecen en cuanto a homogeneidad química y microestructural no son los óptimos, como se puede observar en la figura 2.10. de un trabajo de Rodriguez V.A.H. (como segundo autor) que estudia la aleación Ti 35Nb procesada mediante mezcla elemental de polvos, una primera compactación uniaxial y una posterior mediante prensado isostático en frio (CIP) a 300MPa y en la que se varia la temperatura de sinterizado desde $900{ }^{\circ} \mathrm{C}$ hasta $1600{ }^{\circ} \mathrm{C}$ [44].

A pesar de trabajar con temperaturas muy altas, con contenidos de niobio mayores que el planteado en nuestro proyecto y tamizar el polvo de partida por debajo de 20 micras se consiguen niveles de homogeneidad muy bajos debido al poco tiempo empleado en la etapa de sinterización (1 h). Pero sí que representa un buen punto de partida debido a que sólo presenta microestructura $\alpha$ y $\beta$.

Trabajos más recientes [45] muestran la influencia de un segundo elemento de aleación en el $\mathrm{Ti} 22 \mathrm{Nb}$, pero ya se trabaja con tratamientos térmicos posteriores de solubilización para homogeneizar el material. Este trabajo procesa el polvo por métodos no convencionales como es el sinterizado por inducción (SPS) [45]. Se consiguen buenos resultados en las propiedades de memoria de forma debido a que la microestructura es la adecuada.

Por último, W. Xiaopeng [25, 46] utiliza el procesado pulvimetalúrgico para introducir otros elementos en la aleación que favorecen las propiedades en servicio y su utilización como 
biomaterial. Incluyendo hidroxiapatita $(\mathrm{HA}), \mathrm{Ca}_{5}\left(\mathrm{PO}_{4}\right)_{3}(\mathrm{OH})$, que favorece la osteointegración. Aunque existen diferencias con nuestra investigación ya que $\mathrm{W}$. Xiaopeng utiliza el procesado mediante aleado mecánico y SPS. Ha trabajado con la aleación Ti 35Nb 2.5Sn 15HA optimizando los tiempos de molienda para conseguir una buena microestructura y propiedades mecánicas adecuadas [25], llegando incluso a realizar ensayos de tribocorrosión en un fluido que simula los fluidos del interior cuerpo humano, Hank's solution, sobre las aleaciones del trabajo anterior [46]. Debido a la diferencia en el fluido utilizado para los ensayos de tribocorrosión los datos aportados por este autor no son comparables con los alcanzados en nuestro estudio pero sí que ofrecen una buena indicación del comportamiento de las aleaciones Ti-Nb-Sn.

Por todos los datos expuestos durante todo este punto se justifica la necesidad de obtener la influencia del estaño en las aleaciones Ti-Nb procesadas mediante pulvimetalurgia convencional y mezcla elemental de polvos. Ya que es una de las mejores alternativas y los datos de este tipo de aleaciones procesadas por técnicas de fusión exponen muy buenos resultados.

\subsection{Referencias.}

[1] Ivasishin O.M., Savvakin D.G., Moxson V.S., Bondareval K.A., Froes F.H.: "Titanium powder metallurgy for automotive components”. Materials technology, 17 (1), 2002. 
[2] Cremasco A., Osório W.R., Freire C.M.A., Gracia A. Caram R., "Electrochemical corrosion behavior of a Ti-35Nb alloy for medical prostheses”. Electrochimica Acta 53 (2008) 4867-4874.

[3] Kawahara H., "Cellular responses to implant materials: biological, physical and chemicals factors”. Int Dent 1983; 33:350-75.

[4] Hanada S., Matsumoto H., Watanabe S., "Mechanical compatibility of titanium implants in hard tissues". International Congress Series 1284 (2005) 239- 247.

[5] XU Li-juan, XIAO Shu-long, TIAN Jing, CHEN Yu-yong, HUANG Yu-dong, "Microstructure and dry wear properties of Ti-Nb alloys for dental prostheses”. Trans. Nonferreus Met. Soc. China 19(2006) s639-s644.

[6] Laheurte P., Prima F., Eberhardt A., Gloriant T., Wary M., Patoor E., "Mechanical properties of low modulus $\beta$ titanium alloys designed from the electronic approach". Journal of the mechanical behavior of biomedical materials 3 (2010) 565-573.

[7] Niinomi M. "Recent research and development in titanium alloys for biomedical applications and healthcare goods". Science and Technology of Advanced Materials 4 (2003) 445454.

[8] Niinomi M. "Mechanical properties of biomedical titanium alloys”. Materials Science and Engineering A243 (1998) 231236.

[9] Tojal, C., Candel, J.J., Amigó, V., Devesa, F., "Processing of Ti Scaffolds by Sintering with Different Spacers”. Materials Science Forum Vols. 727-728 (2012) pp 398-403.

[10] Torres Y., Pavón J.J., Rodríguez J.A., "Processing and characterization of porous titanium for implants by using $\mathrm{NaCl}$ 
as space holder". Journal of Materials Processing Technology 212 (2012) 1061-1069.

[11] http://www.titaniumfiko.com.ua/pages/GOSTS/e_Ti_aloys_ru.htm

[12] http://upcommons.upc.edu/pfc/bitstream/2099.1/3214/1/450621.pdf

[13] Leyens C., Peters M. "Titanium and Titanium alloys”. wileyvch.

[14] Eisenbarth E., Velten D., Müller M., Thull R., Breme J. "Biocompatibility of $\beta$-stabilizing elements of titanium alloys". Biomaterials 25 (2004) 5705-5713.

[15] Kuroda D., Niinomi M., Morinaga M., Kato Y., Yashiro T., "Design and mechanical properties of new $\beta$ type titanium alloys for implant materials”. Materials Science and Engineering A243 (1998) 244-249.

[16] Wei Q., Wang L., Fu Y., Qin J., Lu W., Zhang D., “Influence of oxygen content on microstructure and mechanical properties of Ti-Nb-Ta-Zr alloy”. Materials and Design 32 (2011) 29342939.

[17] Devesa F., Candel J.J., Franconetti P., Amigo V., "Estudio de la difusión, en la etapa de sinterizado, de elementos estabilizadores de la fase $\beta$ del titanio”. IV Congreso Nacional de Pulvimetalurgia Sevilla 2012.

[18] Devesa F., "Estudio de las propiedades microestructurales y mecánicas de aleaciones de Ti-Mo obtenidas por pulvimetalurgia”. Tesis de Máster UPV.

[19] Devesa F., Amigó V., Benavente E., Torres Y., "Influencia del porcentaje de Fe en las propiedades mecánicas en aleaciones Ti25Nb-xFe obtenidas por pulvimetalurgia”. III Congreso nacional de Pulvimetalurgia. Valencia, 14 y 15 de junio de 2010. 
[20] Cui C.Y., Ping D.H., "Microstructural evolution and ductility improvement of a Ti-30Nb alloy with Pd addition”. Journal of Alloys and Compounds 471 (2009) 248-252.

[21] Souzaa S.A., Manicardi R.B., Ferrandini P.L., Afonso C.R.M., Ramirez A.J., Caram R., "Effect of the addition of Ta on microstructure and properties of $\mathrm{Ti}-\mathrm{Nb}$ alloys". Journal of Alloys and Compounds 504 (2010) 330-340.

[22] Martins D.Q., Osório W. R., Souza M. E.P., Caram R., Garcia A., "Effects of $\mathrm{Zr}$ content on microstructure and corrosion resistance of $\mathrm{Ti}-30 \mathrm{Nb}-\mathrm{Zr}$ casting alloys for biomedical applications” Electrochimica Acta 53 (2008) 2809-2817.

[23] Taddeia E.B., Henriques V.A.R., Silva C.R.M., Cairo C.A.A., "Production of new titanium alloy for orthopedic implants". Materials Science and Engineering C 24 (2004) 683-687.

[24] Banerjee R., Nag S., Fraser H.L., "A novel combinatorial approach to the development of beta titanium alloys for orthopaedic implants”. Materials Science and Engineering C 25 (2005) $282-289$.

[25] Xiaopeng W., Yoyong C., LiJuan X., Sholung X., Fantao K., Do Woo, K., "Ti-Nb-Sn-hydroxyapatite composites synthesized by mechanical alloying and high frequency induction heated sintering”. Journal of the Mechanical Behavior of Biomedical Materials 4 (2011) 2074-2080.

[26] Tobe H., Kim H.Y., Inamura T., Hosoda H., Nam T.H., Miyazaki S., "Effect of Nb content on deformation behavior and shape memory properties of $\mathrm{Ti}-\mathrm{Nb}$ alloys”. Journal of Alloys and Compounds xxx (2012) xxx- xxx.

[27] J.L. Murray, 1987. ASM Metalls Handbook Volume 3: Alloy Phase Diagrams 1992. 
[28] Martins D.Q., Souza M.E.P., Souza S.A., Andrade D.C., Freire C.M.A., Caram R., "Solute segregation and its influence on the microstructure and electrochemical behavior of $\mathrm{Ti}-\mathrm{Nb}-\mathrm{Zr}$ alloys”. Journal of Alloys and Compounds 478 (2009) 111-116.

[29] Cremasco A., Andrade P.N., Contieri R.J., Lopes E.S.N., Afonso C.R.M., Caram R., "Correlations between aging heat treatment, $\omega$ phase precipitation and mechanical properties of a cast Ti-Nb alloy”. Materials and Design 32 (2011) 2387-2390.

[30] Lopes E.S.N., Cremasco A., Afonso C.R.M., Caram R., "Effects of double aging heat treatment on the microstructure, Vickers hardness and elastic modulus of $\mathrm{Ti}-\mathrm{Nb}$ alloys". Materials characterization 62 (2011) 673-680.

[31] Afonso C.R.M., Aleixo G.T., Ramirez A.J., Caram R., "Influence of cooling rate on microstructure of $\mathrm{Ti}-\mathrm{Nb}$ alloy for orthopedic implants” Materials Science and Engineering C 27 (2007) 908-913.

[32] Lopes E.S.N., Cremasco A., Contieri R., Caram R., "Effects of Aging Heat Treatment on the Microstructure of $\mathrm{Ti}-\mathrm{Nb}$ and $\mathrm{Ti}-$ Nb-Sn Alloys Employed as Biomaterials”. Advanced Materials Research Vol. 324 (2011) pp 61-64.

[33] Ilyin A.A., Kollerov M. Yu., Golovin I.S., "Hydrogen influence on plastic deformation mechanism of $\beta$-titanium alloys of Ti-Nb system”. Journal of Alloys and Compounds 253-254 (1997) 144-147.

[34] Mantani Y., Tajima M., "Phase transformation of quenched $\alpha$ ", martensite by aging in Ti-Nb alloys". Materials Science and Engineering A 438-440 (2006) 315-319.

[35] Kim H.Y., Ikehara Y., Kim J.I., Hosoda H., Miyazaki S., "Martensitic transformation, shape memory effect and superelasticity of Ti-Nb binary alloys". Acta Materialia 54 (2006) 2419-2429. 
[36] Kim H.Y., Sarotu H., Kim J.I., Hosoda H., Miyazaki S., "Mechanical Properties and Shape Memory Behavior of Ti-Nb Alloys”. Materials Transactions, Vol. 45, No. 7 (2004) pp. 2443 to 2448 .

[37] Lee C.M., Ju C.P., Chern L.J.H., "Structure-property relationship of cast Ti-Nb alloys". Journal of Oral Rehabilitation 29 (2002) 314-322.

[38] Godley R., Strarosvetsky D., Gotman I., "Corrosion behavior of a low modulus $\beta-\mathrm{Ti}-45 \% \mathrm{Nb}$ alloy for use in medical implants". Journal of Materials Science: Materials in Medicine 17 (2006) 63-67.

[39] Cremasco A., Messias A.D., Esposito A.R., Rezende Duek E.A., Caram R., "Effects of alloying elements on the cytotoxic response of titanium alloys”. Materials Science and Engineering C 31 (2011) 833-839.

[40] Miura K., Yamada N., Hanada S. Jung T., Itoi E., "The bone tissue compatibility of a new Ti-Nb-Sn alloy with a low Young’s modulus”. Acta Biomaterialia 7 (2011) 2320-2326.

[41] Niinomi M., Nakai M., Hieda J., "Development of new metallic alloys for biomedical applications” Acta Biomaterialia Volume 8, Issue 11, November 2012, Pages 3888-3903.

[42] Niinomi M., "Mechanical biocompatibilities of titanium alloys for biomedical applications". Journal of the Mechanical Behavior of Biomedical Materials I (2008) 30-42.

[43] Ozaki T., Matsumoto H., Watanabe S., Hanada S., "Beta Ti Alloys with Low Young's Modulus”. Materials Transactions, Vol. 45, No. 8 (2004) pp. 2776 to 2779.

[44] Santos D.R., Rodriguez V.A.H., Alves C.A., Santos C.A., "Production of a Low Young Modulus Titanium Alloys by Powder Metallurgy”. Materials Research, Vol. 8, No. 4, 439442, 2005. 
[45] Terayama A., Fuyama N., Yamashita Y., Ishizaki I., Kyogoku H., "Fabrication of Ti-Nb alloys by powder metallurgy process and their shape memory characteristics". Journal of Alloys and Compounds xxx (2012) xxx- xxx. Article in press.

[46] Yoyong C., Xiaopeng W., LiJuan X., Zhinguang L., Do Woo, K., "Tribological behavior study on Ti-Nb-Sn/hydroxyapatite composites in simulated body fluid solution”. Journal of the Mechanical Behavior of Biomedical Materials 10 (2012) 97107. 


\section{PLANIFICACIÓN DE LA INVESTIGACIÓN.}

Por todo lo anterior y atendiendo a los objetivos fundamentales de la investigación se planifica ésta en 4 bloques temáticos. En un primer bloque se intentará recoger todo el trabajo preliminar en el que se abarca la adecuación de un método de trabajo y se fijará una serie de variables del proceso. Ello requiere de una importante documentación, la cual se renueva y continua vigente durante todo el proyecto. Posteriormente se seleccionará el proceso más adecuado para poder cubrir los objetivos planteados y se obtendrán las muestras necesarias para la caracterización.

Se ha planificado todas las tareas para la obtención de la caracterización en los campos que se ha considerado más relevantes e influyentes para tener una idea clara del comportamiento en servicio del material y la influencia del estaño en dicho comportamiento. Se tiene previsto partir de la caracterización microestructural ya que es la base en la que se sustenta el comportamiento final de las aleaciones. Se va a utilizar gran variedad de técnicas, poniendo especial atención en la homogeneidad microestructural y en la distribución de los elementos de aleación. Posteriormente se caracterizará el material mecánicamente, se pondrá gran interés en la obtención del módulo elástico por toda la problemática que conlleva la utilización de materiales con módulo excesivamente alto cuando se utiliza en implantología, por el fenómeno de apantallamiento de tensiones que 
se ha expuesto en el punto anterior. Finalmente, en la caracterización tecnológica se va a analizar la influencia del estaño en el comportamiento a corrosión y tribocorrosión. En la figura 3.1 se muestra el esquema general del proyecto.

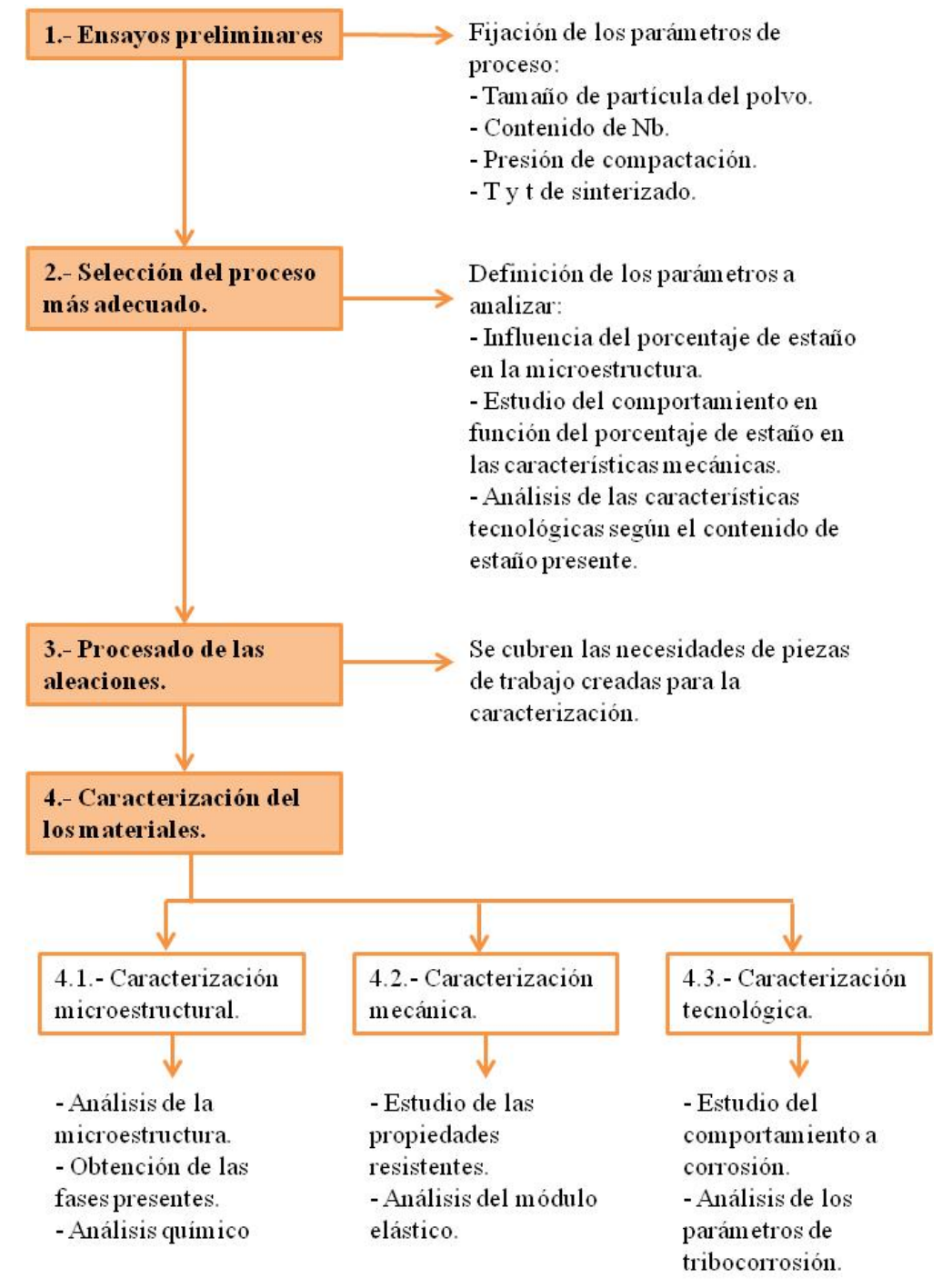

Figura 3.1. Planificación del proyecto. 


\subsection{Ensayos preliminares.}

Este punto engloba todos los ensayos previos necesarios para fijar los parámetros del procesado. En primer lugar es necesario conocer el tamaño de polvo adecuado para mejorar los procesos de difusión. Para conseguirlo se va a realizar un estudio de la difusión en función del tamaño de partícula del elemento aleante. Para ello se pretende utilizar distintos tamaños de partícula de polvo de molibdeno y estudiar la microestructura obtenida. No se ha creído necesario realizar este mismo estudio para el titanio debido a su alta reactividad.

Debido a la necesidad de obtener microestructura $\beta$ se obtendrá el contenido mínimo de $\mathrm{Nb}$ para el cual la microestructura es la deseada. Se obtendrán aleaciones $\mathrm{Ti}-\mathrm{Nb}$ con distintos porcentajes de niobio, desde el 20 hasta el 40 \%, y se observará la evolución de la microestructura. Existen parámetros del procesado ya fijados de antemano como es la presión de compactación que se establece en 700 MPa por experiencias previas del propio autor ya que es el máximo valor en el cual se trabaja de forma segura sin comprometer la integridad de las matrices utilizadas.

Por último, en la etapa de sinterización, se estudiará la influencia del tiempo de sinterizado para obtener una buena homogeneidad microestructural sin aumentar en exceso el tamaño de grano. Se pretende sinterizar aleaciones con la composición requerida y estudiar la homogeneidad microestructural y el aumento del tamaño de grano. 
Se pretende abarcar desde 2 horas de sinterización hasta 4 horas, utilizar tiempos mayores se muestran como excesivos. Este estudio también se utilizará para obtener las características básicas finales de las aleaciones procesadas (porosidad, tamaño de poro, tamaño de grano, etc.) Por otro lado, se ha fijado la temperatura de sinterización en $1250^{\circ} \mathrm{C}$ (aproximadamente $0.75 \%$ de la temperatura de fusión del Ti). Este parámetro viene limitado por el material del interior del horno de alto vacío utilizado y definido por proyectos previos del grupo de investigación en los que se sabe que es una temperatura óptima de sinterizado para aleaciones de Ti.

\subsection{Selección del proceso más adecuado.}

Por lo expuesto en los antecedentes se justifica la utilización del procesado por pulvimetalurgia y mezcla elemental de polvos de las aleaciones a estudiar ya que es una alternativa viable a los procesos de fusión. Pero se crea la necesidad de definir los parámetros a analizar y observar la influencia del contenido de estaño en éstos. Básicamente se pretende trabajar sobre tres parámetros: microestructura, propiedades mecánicas y caracterización tecnológica.

Ya que todas las características dependen irrefutablemente de la microestructura es el primer parámetro que se necesita analizar. Se pretende observar la influencia del estaño en la microestructura, se analizará la influencia en la homogeneidad de la microestructura $\beta$ y 
en el contenido de microestructura $\alpha$ residual observado en los ensayos previos. También es necesario obtener la composición química de las aleaciones para observar la difusión de los elementos de aleación dentro del material.

Posteriormente, se plantea los parámetros mecánicos que se pretende analizar de las aleaciones obtenidas. Será necesario obtener propiedades resistentes para analizar la influencia del porcentaje de Sn en las características resistentes de los materiales. Por otro lado, y debido la gran influencia del módulo elástico en el comportamiento de las aleaciones durante la vida en servicio en su utilización en implantología, será necesario analizar con minuciosidad y gran profundidad el módulo elástico.

Para comprobar el comportamiento de las aleaciones en ambientes corrosivos y la evolución durante el desgate en condiciones de trabajo dentro del cuerpo humano será necesaria una caracterización tecnológica. Se pretende analizar el comportamiento frente a corrosión pura y estudiar la influencia del contenido de estaño. Consecutivamente será necesario analizar, en una mejor aproximación al comportamiento en servicio, la evolución introduciendo el fenómeno de desgaste combinado con los efectos de corrosión. 


\subsection{Procesado de las aleaciones.}

En este bloque será obligatorio cubrir las necesidades generadas para la caracterización del material. Es decir, se pretende tener resueltas las necesidades de piezas de trabajo para la realización de los distintos ensayos que engloban el siguiente bloque de caracterización del material. Para ello, se seguirán las directrices obtenidas en los ensayos preliminares y se utilizarán los parámetros de proceso fijados en dicha fase. El contenido de elementos aleantes, tamaño del polvo utilizado, presión de compactación y parámetros de sinterizado serán características del procesado por pulvimetalurgia convencional y mezcla elemental de polvos que ya se conocerán y se habrán fijado.

La utilización de la pulvimetalurgia convencional y la mezcla elemental de polvos para el procesado de las aleaciones también está justificada por sus ventajas frente al procesado por técnicas de fusión. Se obtendrán piezas de trabajo con la geometría necesaria para los ensayos posteriores y en cantidad suficiente ya que será necesario obtener valores representativos y con un nivel de error suficientemente pequeño para que los resultados sean válidos. Posterior al procesado de las piezas de trabajo será necesaria la preparación de muestras para las distintas etapas de caracterización. 


\subsection{Caracterización de los materiales.}

En este bloque se van a exponer las distintas necesidades de caracterización y la metodología que se pretende seguir para dar respuesta a estas necesidades.

\subsubsection{Caracterización microestructural.}

Para la caracterización microestructural será necesario analizar la microestructura general de las aleaciones estudiadas. Para estudiarla será necesaria la utilización de un microscopio óptico que ofrece esta posibilidad, de este modo se analizará la microestructura en una visión general para determinar el grado de homogeneidad alcanzado. Será necesaria una preparación metalográfica y un ataque químico de la superficie. También se pretende analizar y comprobar las características finales de las aleaciones obtenidas en los ensayos preliminares: porosidad, tamaño de poro y tamaño de grano.

Debido a la necesidad de una resolución mejor para resolver zonas más concretas será obligatoria la utilización de la microscopía electrónica de barrido (SEM). Se analizarán las formaciones de microestructura $\alpha$ cercanas al borde de grano y la propia frontera de grano. Por otro lado, para observar las diferencias de composición dentro del material se pretende trabajar en dos áreas: la primera es mediante la captura de imágenes utilizando la técnica de electrones retrodispersados (BS) por la cual los elementos más pesados aparecen 
más claros que los elementos más ligeros. Y en segundo lugar, se pretende estudiar la distribución de los elementos aleantes dentro del material mediante el análisis por espectrómetro de rayos $\mathrm{X}$ de energía dispersiva (EDS).

Para obtener el análisis y el estudio de las composiciones dentro de la formación lamelar es imprescindible realizar sesiones de trabajo con el equipo de microscopía electrónica de transmisión con modo barrido (STEM). Se analizará la composición dentro de las lamelas para observar la homogeneidad en la distribución de los elementos aleantes y la influencia del porcentaje de estaño. También se pretende identificar la estructura cristalina que corresponde a cada fase dentro de las lamelas para este análisis será necesario la utilización de un equipo de microscopía electrónica de transmisión.

Otra necesidad que se pretende cubrir es la identificación de la estructura cristalina de las fases presentes en las aleaciones, por lo que se analizará mediante difracción de rayos $\mathrm{X}$ la presencia de las fases más estables del titanio, fase $\alpha$ y fase $\beta$.

Para acabar con la caracterización microestructural, se debe estudiar el contenido en oxígeno después del procesado, ya que es un parámetro muy importante. Se debe analizar para conocer el comportamiento de los materiales ya que es muy influyente como se ha visto anteriormente. Se analizará el contenido de oxígeno y nitrógeno de las aleaciones obtenidas. 
Por lo tanto se ha planificado la observación de la microestructura con microscopio óptica, mediante microscopía electrónica de barrido y mediante microscopía electrónica de transmisión. Para el análisis de las fases presentes se pretende utilizar la difracción de rayos $\mathrm{X}$ y el equipo de TEM. El análisis químico de las aleaciones se pretende analizar con SEM y con STEM para el interior de las lamelas. Por último, se analizará el contenido de oxígeno final.

\subsubsection{Caracterización mecánica.}

Debido a la gran plasticidad que muestran los materiales en los ensayos preliminares será necesario realizar varios ensayos para obtener las propiedades resistentes. Se obtendrá el límite elástico gracias al ensayo de compresión pero no se podrá analizar la tensión máxima o la tensión de rotura ya que las aleaciones presentan un comportamiento plástico y no llegan a fractura.

Para analizar la tensión máxima será necesario la utilización del ensayo a flexión en una máquina universal de ensayos con los útiles pertinentes. También se pretende conocer la microdureza de las aleaciones ya que es un valor fácilmente comparable con el de otros autores y ofrece una información muy válida de las propiedades finales del material. Para conocer la microdureza se va a realizar el ensayo de microdureza Vickers. 
Como se ha expuesto en los antecedentes, se busca que módulo elástico sea lo más parecido al módulo elástico del hueso cortical. Para analizar con garantías el módulo elástico se va a obtener mediante distintos ensayos. Utilizando el ensayo de compresión se va a medir el módulo elástico, se pretende utilizar el ensayo de ultrasonidos para obtener también el módulo elástico. Estos dos parámetros obtenidos por el ensayo de compresión y por ultrasonidos serán analizados exhaustivamente ya que son muy representativos porque se ven afectados por características macroscópicas del material como la porosidad.

Para obtener el módulo elástico con mucha precisión a nivel nanoscópico será necesario el estudio de este mediante nanoindentación. Debido a la complejidad de la técnica se va a realizar el cálculo del módulo elástico por dos metodologías: la primera en la zona de descarga de la curva de carga-profundidad del ensayo y en segundo lugar durante todo el ensayo, cuando se esta indentando el material, para obtener un perfil de módulo elástico en toda la profundidad del ensayo.

Resumiendo, se planifica la obtención de la caracterización mecánica mediante el ensayo de flexión para la obtención de la resistencia máxima, la microdureza de las aleaciones estudiadas y se analizará el módulo elástico por medio del ensayo de nanoindentación utilizando dos métodos distintos de cálculo, por el ensayo de ultrasonidos y por 
el ensayo de compresión, a partir del cual también se analizará el límite elástico.

\subsubsection{Caracterización tecnológica.}

Como se pretende obtener los parámetros básicos de corrosión de las aleaciones estudiadas y observar su comportamiento frente al contenido de estaño será necesario la realización de varios ensayos de corrosión. Se pretende relacionar la intensidad de corriente con el potencial aplicado para observar las distintas regiones del material (región anódica, catódica, etc.). Para esto será necesario el ensayo potenciodinámico para tener una idea clara del comportamiento de las aleaciones y de la influencia del porcentaje de estaño. Posteriormente se pretende observar la pasivación del material a circuito abierto, por lo que se realizará ensayos de potencial de circuito abierto (OCP).

Para finalizar se pretende conocer el comportamiento cuando se combina la acción de la corrosión y del desgaste por lo que se realizarán ensayos de tribocorrosión. Se realizarán ensayos de OCP en tribocorrosión para observar la influencia de la tribología y comparar con los valores sin realizar tribología. Por último, para observar la relación de la pérdida debida a la corrosión y a la pérdida debida a la tribología (pérdida mecánica) se pretende realizar ensayos a potencial constante. 
En resumen para la caracterización tecnológica se realizarán ensayos de corrosión y tribocorrosión. Los ensayos de corrosión que se realizarán son potenciodinámicos y de OCP. Los ensayos de tribocorrosión que se pretenden realizar son de OCP y de potencial constante.

Con esta planificación se pretende abarcar el objetivo principal del proyecto de obtener el comportamiento de las aleaciones procesadas según el contenido en estaño de cada aleación. Para ello se intentará abarcar cada objetivo secundario para conjuntamente obtener el objetivo principal del proyecto. 


\section{DESARROLLO EXPERIMENTAL.}

En este punto se va a exponer de forma detalla las técnicas experimentales y los procedimientos seguidos en la investigación para acometer el objetivo principal del estudio: analizar y comprender la influencia del contenido de estaño en las aleaciones.

Con todo esto a continuación se expone, en un primer punto los materiales utilizados, para posteriormente profundizar en la metodología experimental seguida.

Se ha utilizado el equipamiento necesario para el procesado de las piezas de trabajo mediante pulvimetalurgia convencional y mezcla elemental de polvos. Posteriormente se ha utilizado equipos específicos de caracterización de los distintos parámetros a analizar.

\subsection{Materiales.}

El titanio utilizado ha sido suministrado por la empresa Se - Jong materials CO., LTD. y ha sido suministrado como un Ti grado 2. Tiene la composición química, según análisis certificado por la propia empresa, que se muestra en la siguiente tabla. 
Tabla 4.1. Composición del titanio utilizado.

\begin{tabular}{|c|r|}
\hline Elem ento & Peso wt. (\%) \\
\hline $\mathrm{Ti}$ & 99.700 \\
\hline $\mathrm{Fe}$ & 0.029 \\
\hline $\mathrm{Mg}$ & 0.009 \\
\hline $\mathrm{Si}$ & 0.900 \\
\hline $\mathrm{Mn}$ & 0.00 \\
\hline $\mathrm{N}$ & 0.010 \\
\hline $\mathrm{O}$ & 0.362 \\
\hline $\mathrm{H}$ & 0.013 \\
\hline
\end{tabular}

Se puede observar como el contenido en elementos aleantes es mínimo pero el contenido en oxígeno es excesivamente alto por lo que el Ti de partida no corresponde a un Ti grado 2. Que el contenido en oxígeno sea alto repercute de forma negativa, ya que fragiliza el comportamiento del material y puede formar durante el procesado posterior una capa de titanio con microestructura tipo $\alpha$ muy frágil o Alpha Case que afecta negativamente a las propiedades que se están buscando [1]. Sin embargo, el mayor problema es que este contenido no puede reducirse con el procesado pulvimetalúrgico y se aumentará durante el procesado.

La distribución granulométrica del titanio en estado de recepción se observa en la figura 4.1. En la gráfica se observa que aparecen partículas con un tamaño mayor de $45 \mu \mathrm{m}$. El Ti fue suministrado como -325 mesh pero se observa cómo no es del todo cierto ya que, 325 mesh equivalen aproximadamente a menos de $45 \mu \mathrm{m}$. Se trata de una distribución normal en la que la campana de Gauss no es 
totalmente simétrica. Aparecen más partículas con tamaños pequeños mientras que a partir de $100 \mu \mathrm{m}$ ya no hay partículas. El tamaño medio del polvo es de $24.13 \mu \mathrm{m}$ y como se comentaba anteriormente hay un $10 \%$ de partículas mayores de $48.18 \mu \mathrm{m}$.

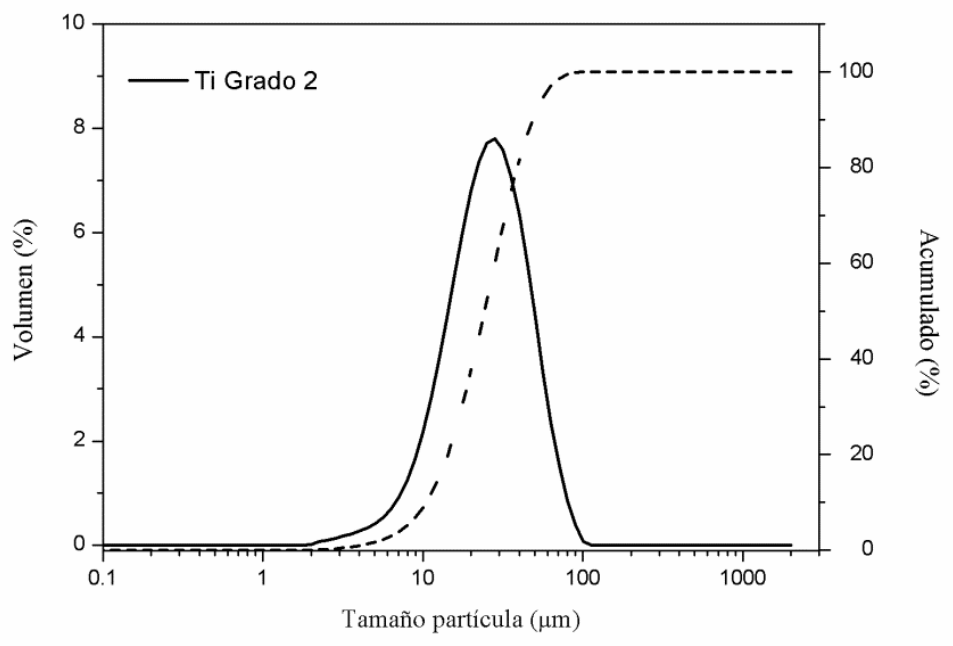

Figura 4.1. Tamaño de partícula del Ti en estado de recepción. También se muestra el acumulado de la distribución de partículas.

Se ha utilizado todo el Titanio suministrado del mismo lote, SPTi100120, para evitar problemas de diferencias entre lotes en cuestión de composición o de distribución granulométrica.

El polvo de niobio utilizado ha sido suministrado por la empresa Alfa Aesar. La composición química de las impurezas y contaminación del polvo es la que se muestra en la siguiente tabla. 
Tabla 4.2. Análisis químico del polvo de Nb.

\begin{tabular}{|c|r|}
\hline Elem ento & Contenido (ppm) \\
\hline $\mathrm{O}$ & 3000 \\
\hline $\mathrm{C}$ & 360 \\
\hline $\mathrm{Si}$ & 20 \\
\hline $\mathrm{Mo}$ & 10 \\
\hline $\mathrm{Ni}$ & 30 \\
\hline $\mathrm{Cr}$ & 20 \\
\hline $\mathrm{Cu}$ & 10 \\
\hline $\mathrm{Ta}$ & 500 \\
\hline $\mathrm{H}$ & 17 \\
\hline $\mathrm{Ni}$ & 49 \\
\hline $\mathrm{Ti}$ & 50 \\
\hline $\mathrm{W}$ & 50 \\
\hline $\mathrm{Fe}$ & 58 \\
\hline $\mathrm{Mn}$ & 30 \\
\hline $\mathrm{Al}$ & 30 \\
\hline
\end{tabular}

El polvo de $\mathrm{Nb}$ es -325 mesh y tiene una pureza teórica del $99.8 \%$. También es destacable el contenido en oxígeno del polvo de niobio ya que repercute de forma negativa en las propiedades finales buscadas. Dado que todos los procesos de difusión en el procesado por pulvimetalurgia se dan en estado sólido se ha optimizado dichos procesos para mejorar la homogeneidad química de las aleaciones obtenidas como se mostrará en los ensayos previos. Los elementos de aleación se han tamizado con un tamiz con luz de malla menor de 25 $\mu \mathrm{m}$. La distribución granulométrica del polvo de $\mathrm{Nb}$ se muestra en la gráfica de la figura 4.2. El tamaño medio de partícula es de $14.82 \mu \mathrm{m}$. 
La pequeña medición que se observa en $400 \mu \mathrm{m}$ es un error de lectura derivado de un apelmazamiento de las partículas del polvo de niobio.

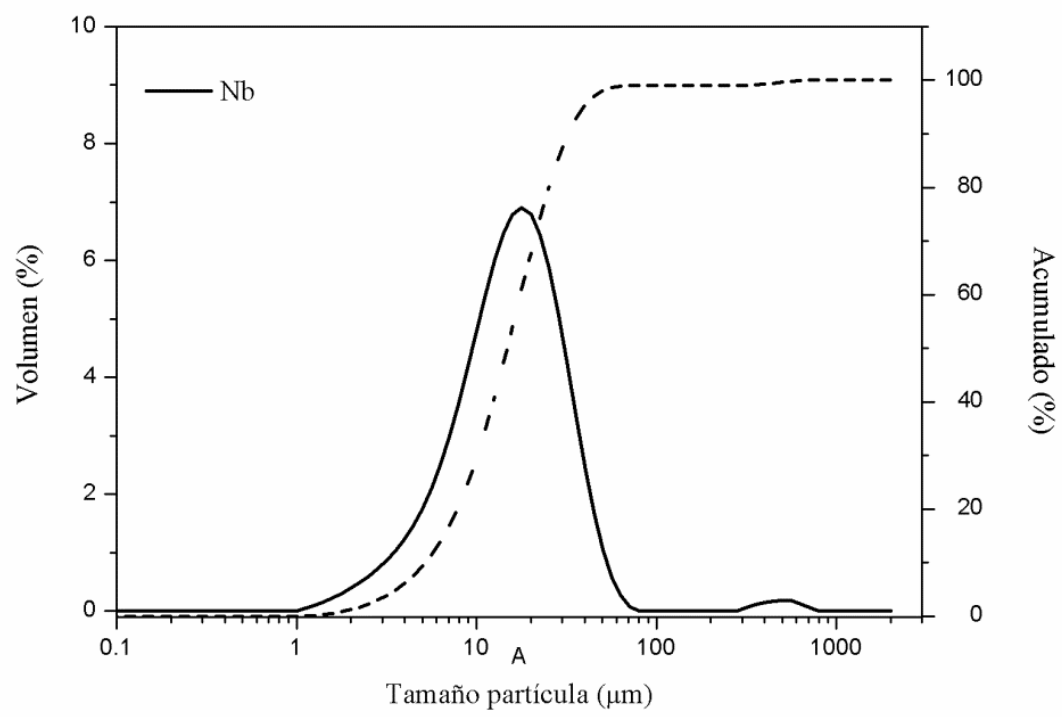

Figura 4.2. Distribución granulométrica del polvo de Nb utilizado después de tamizado por debajo de $25 \mu \mathrm{m}$.

El polvo metálico de estaño ha sido suministrado por Pometon España y las características básicas ofrecidas por el fabricante son las que se muestran en la siguiente tabla: 
Tabla 4.3. Características del polvo de estaño en estado de recepción.

\begin{tabular}{|c|r|}
\hline Propiedades físicas & \multicolumn{1}{c|}{ Sn 75F } \\
\hline Pureza (\%) & $<99.700$ \\
\hline Densidad aparente $\left(\mathrm{g} / \mathrm{cm}^{3}\right)$ & $3.70 \pm 0.30$ \\
\hline Granulometria $(\% \mathrm{ocum})$ & 0.009 \\
\hline $106 \mu \mathrm{m}$ & 0 \\
\hline $75 \mu \mathrm{m}$ & $0.5 \mathrm{max}$ \\
\hline $45 \mu \mathrm{m}$ & $3-15$ \\
\hline
\end{tabular}

La distribución granulométrica después del tamizado se muestra en la figura 4.3. El tamaño medio de partícula es de $18.47 \mu \mathrm{m}$.

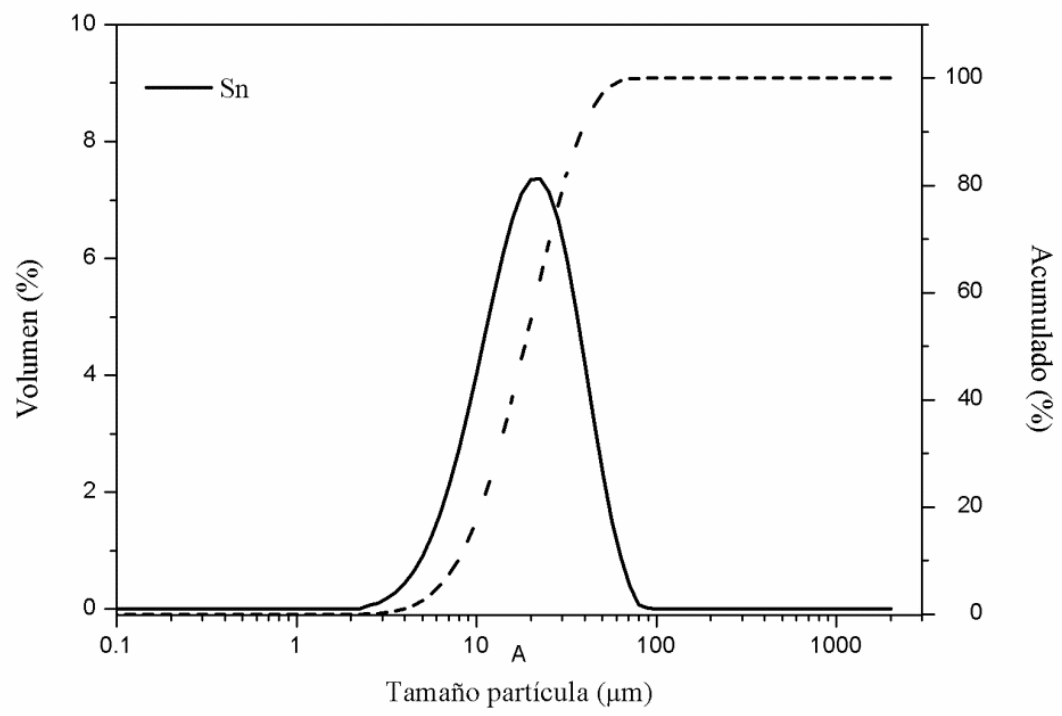

Figura 4.3. Distribución granulométrica del polvo de Sn utilizado después de tamizado por debajo de $25 \mu \mathrm{m}$. 


\subsection{Procesado de las aleaciones.}

Este punto se divide en dos tareas diferenciadas:

1. Obtención del polvo por mezcla elemental.

2. Obtención de las piezas de trabajo.

\subsubsection{Obtención del polvo por mezcla elemental.}

Se ha procesado el polvo metálico de titanio, niobio y estaño, en el caso de las aleaciones con estaño, mediante mezcla elemental de polvos según proporción estequiométrica para las aleaciones estudiadas: Ti 30Nb, Ti 30Nb 2Sn y Ti 30Nb 4Sn. La proporción ha sido en peso. Cabe recordar que los polvos de $\mathrm{Nb}$ y $\mathrm{Sn}$ se han tamizado con un tamaño de partícula $<25 \mu \mathrm{m}$.

Posteriormente se ha mezclado los polvos en una túrbula, modelo inversina taumelmischer $2 l$, como la que se muestra en la imagen. En la mezcla elemental no se modifica de ninguna forma el polvo sólo se homogeniza la distribución de partículas dentro de la mezcla. 


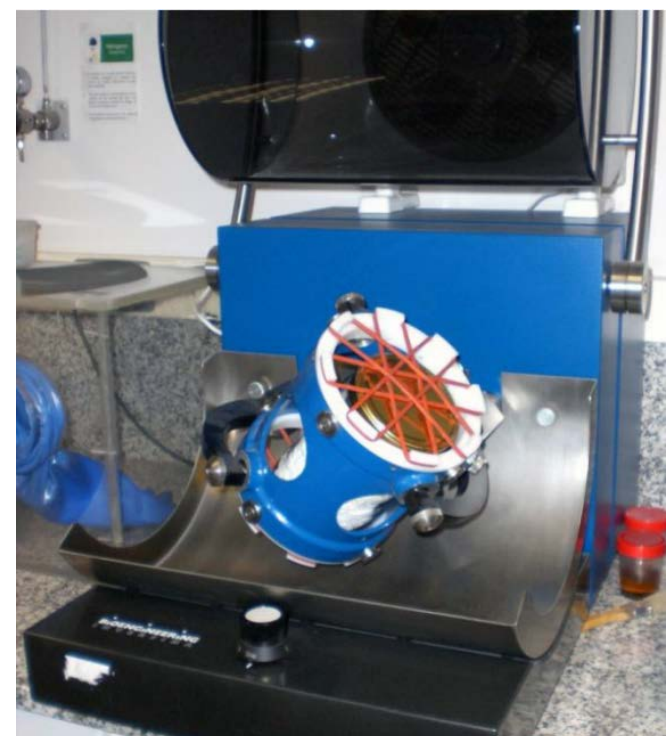

Figura 4.4. Túrbula utilizada para la mezcla elemental de polvos.

Cada aleación se ha mezclado durante $20 \mathrm{~min}$ a una velocidad de 7 sobre 10 . Se ha introducido 3 bolas de circona de $10 \mathrm{~mm}$ de diámetro en el recipiente donde se ha mezclado los polvos. Se ha mezclado justo antes de la compactación para evitar la decantación de las partículas más pesadas entre el mezclado y la compactación.

La caracterización del polvo se ha realizado mediante la distribución granulométrica y se ha obtenido justo antes de la compactación para cada polvo de cada aleación, figura 4.5 . 


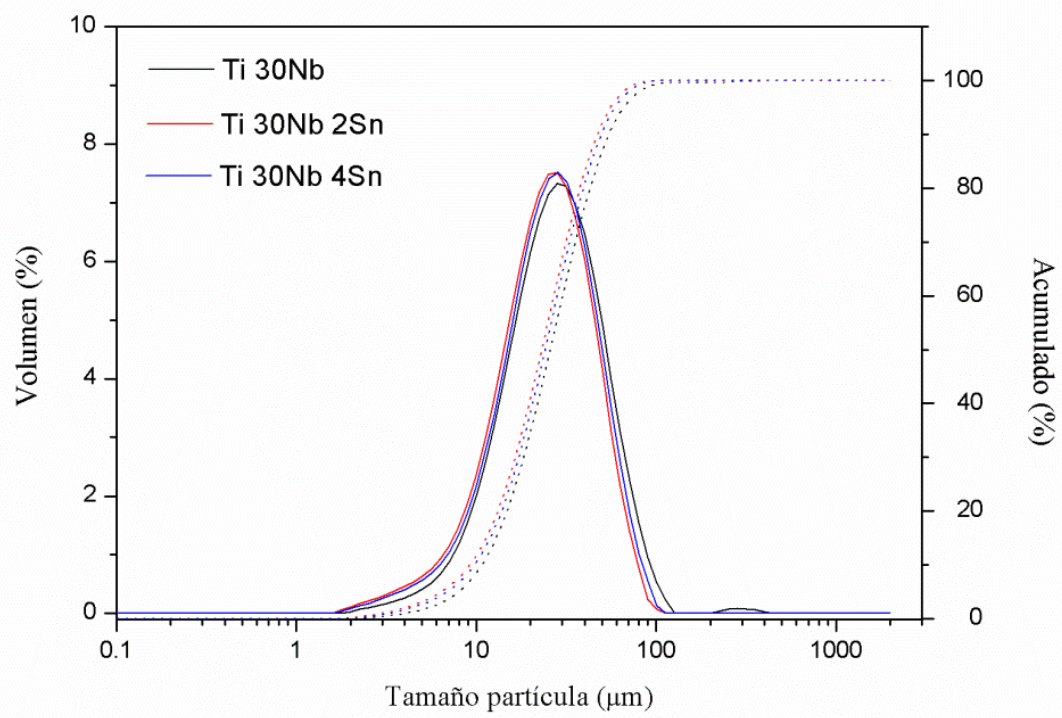

Figura 4.5. Distribución granulométrica y el acumulado de las aleaciones procesadas después de la mezcla elemental de polvos.

Se observa como la influencia de los elementos aleantes en la distribución granulométrica de la aleación es poca ya que las partículas están tamizadas $<25 \mu \mathrm{m}$. Se observa cómo hay un pequeño incremento en la sección referente a las partículas más finas si se comparan las aleaciones con estaño frente a la Ti 30Nb.

\subsubsection{Obtención de las piezas de trabajo.}

La compactación se ha llevado a cabo utilizando una máquina de ensayos universal para poder monitorizar todo el proceso, el equipo utilizado es de la marca Instron modelo 432 con una célula de carga de 500 kN. La presión de compactación utilizada ha sido de 700 MPa, 
la velocidad de aplicación $5 \mathrm{~mm} / \mathrm{min}$ y se ha mantenido la fuerza de compresión durante $10 \mathrm{~s}$. Posteriormente se han extraído las piezas mediante control manual de la máquina utilizando un anillo concéntrico con la matriz y mediante el movimiento relativo entre el punzón y el cuerpo de la matriz flotante. La siguiente imagen muestra el montaje utilizado para la compactación.

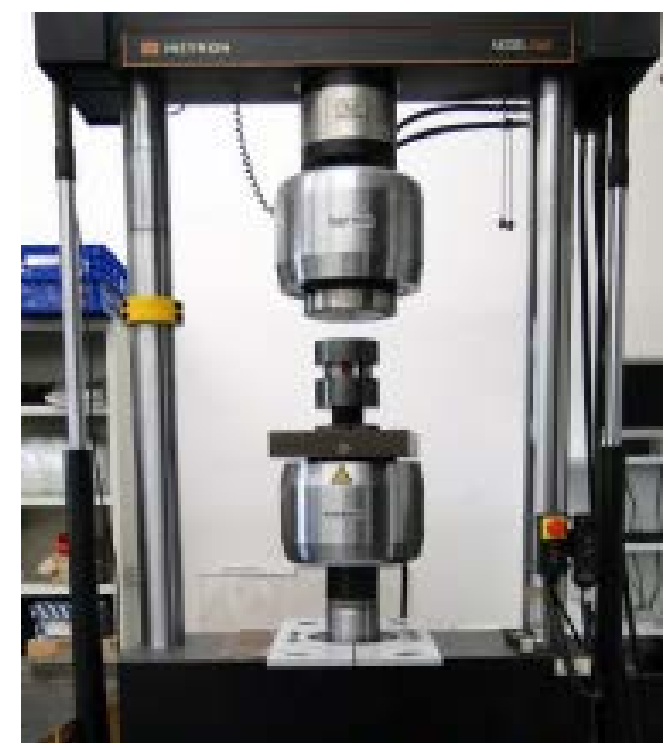

Figura 4.6. Montaje para la compactación de las piezas de ensayo.

Se ha compactado piezas para realizar el ensayo de flexión. Para ello se ha utilizado una matriz flotante con una geometría rectangular de $30 \times 12 \mathrm{~mm}$. El espesor que se consigue es de $5 \mathrm{~mm}$ aproximadamente utilizando $7 \mathrm{~g}$ de polvo. Se ha compactado 12 piezas de cada aleación para tener un remanente suficiente para todos los ensayos. Se ha utilizado una matriz flotante para mejorar la distribución de presiones en toda la altura del material. 
Para las probetas de compresión se ha utilizado una matriz cilíndrica de acción simple y $10 \mathrm{~mm}$ de diámetro, en este caso se tiene pensado obtener piezas de $10 \mathrm{~mm}$ de altura utilizando $4 \mathrm{~g}$ de polvo. Se va a compactar 10 probetas de cada aleación.

Por último se ha compactado 20 probetas de cada aleación con una matriz de $25 \mathrm{~mm}$ de diámetro, se ha utilizado $7 \mathrm{~g}$ de polvo con lo que el espesor ha sido de 5mm aproximadamente. Este tipo de probetas es para la caracterización tecnológica. La utilización de matrices circulares de acción simple viene dada porque no se tiene acceso a matrices cilíndricas flotantes las cuales darían mejores resultados de distribución de presiones.

Para lubricar la matriz en todos los casos se ha utilizado estearato de cinc en forma de película repartida homogéneamente en el punzón y la matriz. En ningún momento se ha utilizado ningún tipo de lubrificante incluido en el propio material.

La sinterización posterior se ha llevado a cabo en un horno de alto vacío para evitar la oxidación de las piezas. El horno utilizado es un Cabolite tubular de alto vacío modelo HVT 15/75/450. Se ha conseguido el alto vacío, 5 × $10^{-4}$ bares, después de hacer el bajo vacío y romperlo en tres ocasiones consecutivas con argón. Este procedimiento se lleva a cabo porque, a pesar de conseguir el alto vacío posterior siempre queda residuos de los gases anteriores. Para 
evitar que estos gases contengan oxígeno se lleva a cabo estos barridos. De este modo el gas que queda es argón que es un gas inerte y no oxida las muestras El argón utilizado es de calidad 5.0 con menos de $3 \mathrm{ppm} / \mathrm{v}$ de impurezas de agua. El ciclo térmico seguido es el que se muestra en la figura 4.7 .

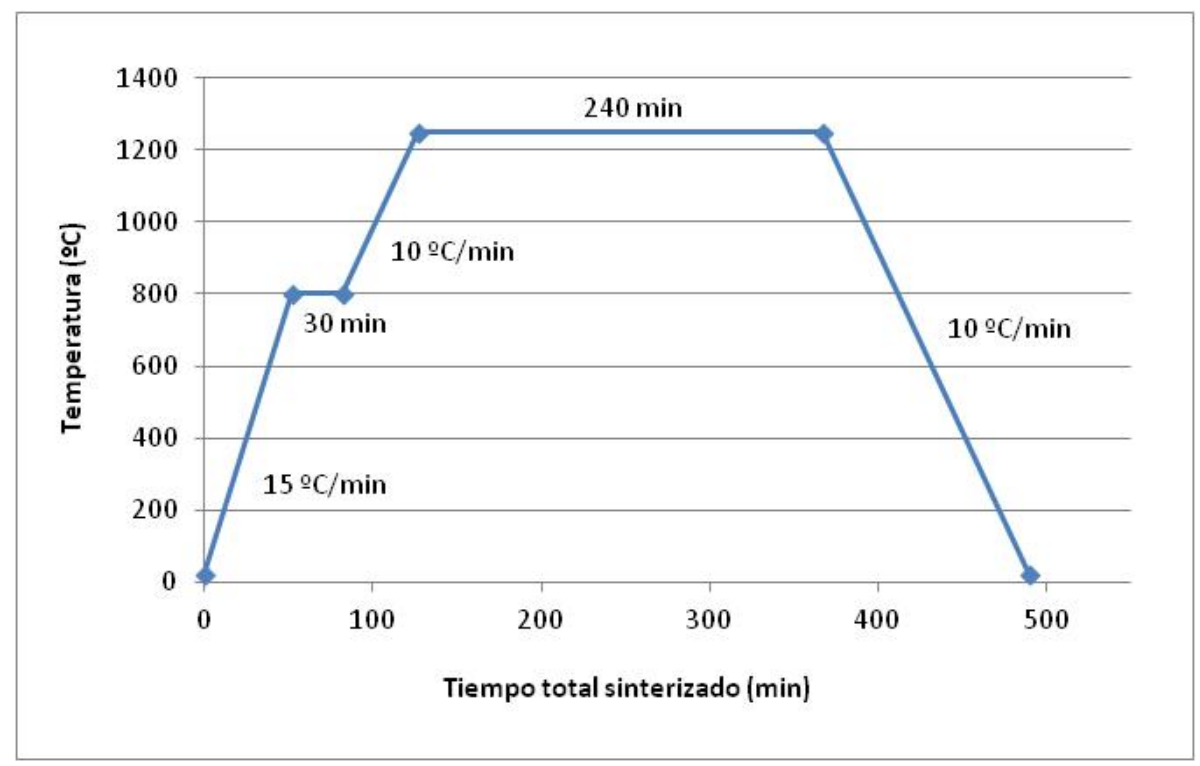

Figura 4.7. Ciclo de sinterizado.

Como se puede observar el ciclo de sinterizado básicamente abarca dos mesetas o estancias en las que se mantiene la temperatura. El primer calentamiento es un calentamiento rápido, a $15^{\circ} \mathrm{C} / \mathrm{min}$ para alcanzar $800{ }^{\circ} \mathrm{C}$. A esta temperatura se mantiene durante 30 min para homogeneizar la temperatura en todo el horno y en la propia pieza, evitar agrietamientos por gradientes de temperatura y preparar el cambio alotrópico del titanio a $882{ }^{\circ} \mathrm{C}$. Cabe recordar que en este punto se tiene partículas de polvo de los materiales de la aleación en la 
pieza en verde, no ha habido ningún tipo de aleado entre los elementos. Las partículas de $\mathrm{Ti}$ se comportan de forma totalmente distinta a las partículas de $\mathrm{Nb}$ y Sn. Por este motivo es importante realizar esta meseta antes del cambio alotrópico.

Posteriormente el calentamiento hasta la temperatura de sinterizado se realiza algo más lento, a $10{ }^{\circ} \mathrm{C} / \mathrm{min}$, hasta $1250{ }^{\circ} \mathrm{C}$ que es la temperatura de sinterización. El tiempo de sinterización se extiende hasta las 4 horas y posteriormente se realiza un enfriamiento controlado a $10{ }^{\circ} \mathrm{C} / \mathrm{min}$ hasta temperatura ambiente.

Las piezas que se obtienen después del sinterizado son las que se muestran en la figura 4.8.

a) Probetas rectangulas

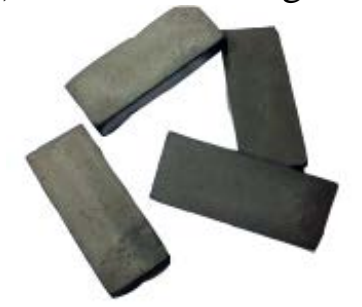

b) Probeta cilindrica $10 \mathrm{~mm}$.

c) Probeta cilindrica $25 \mathrm{~mm}$.
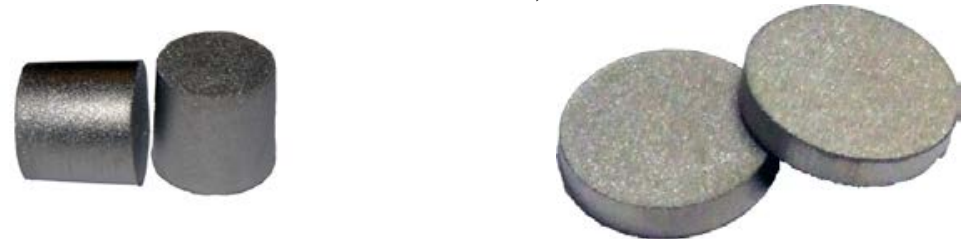

Figura 4.8. Probetas obtenidas durante el procesado: a) probeta rectangular de flexión, b) probeta para ensayo de compresión de diámetro $10 \mathrm{~mm}$ y $10 \mathrm{~mm}$ de altura y c) probeta para la caracterización tecnológica de 25 mm de diámetro y 5 mm de espesor. 


\subsection{Caracterización microestructural.}

\subsubsection{Contenido de oxígeno.}

Como se ha dicho con anterioridad el oxígeno es un elemento alfágeno y provoca la fragilización del material [1, 2]. El equipo utilizado para la determinación del contenido de oxígeno es un Leco TC400 que utiliza gas inerte para evitar la oxidación de los materiales durante el ensayo, se obtiene una precisión máxima de 1 ppm. En la figura 4.9 se puede observar el equipo.

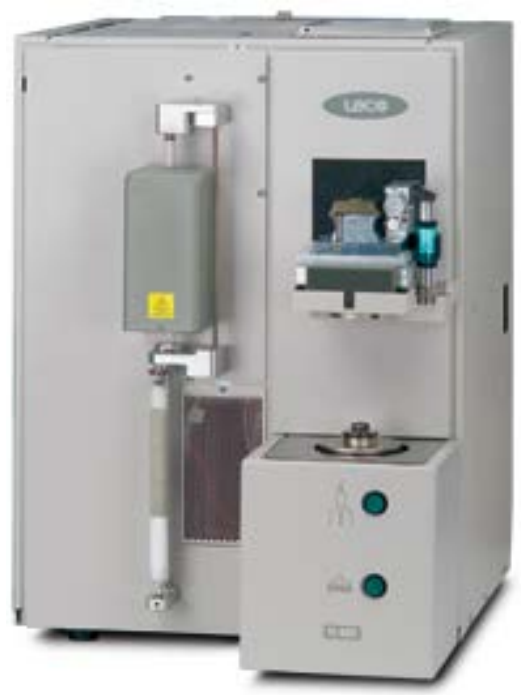

Figura 4.9. Equipo para la obtención del contenido en oxígeno y nitrógeno Leco TC400.

La utilización de este equipo ha sido posible gracias a la colaboración enmarcada dentro proyecto del Ministerio de Ciencia e Innovación de investigación Bilateral España - Brasil PIB 2010BZ - 00448. En este 
proyecto se ha colaborado con el Departamente de Engenharia de Fabricaçâo de la Faculdade de Engenharia Mecánica en la Universidade Estadual de Campinas.

\subsubsection{Preparación metalográfica.}

Para el análisis de la microestructura mediante microscopía óptica se ha utilizado cortes transversales de la zona central de la probeta de flexión para observar el material sin ningún tipo de efecto de superficie. Para la preparación se ha seguido los pasos básicos de la metalografía convencional. Después de cortar y embutir las muestras en polimetilmetacrilato (PMMA), para el desbaste, se ha utilizado papel de lija de carburo de silicio ( $\mathrm{SiC}$ ) de una granulometría de 500, 1000 y 4000. Para el pulido, se ha utilizado pasta de diamante de $3 \mu \mathrm{m}$ lubricando con aceite y posteriormente una suspensión de sílice coloidal base agua con granulometría $0.06 \mu \mathrm{m}$. El último paso ha sido la limpieza de la muestra con ultrasonidos para eliminar los restos de material de pulido, y de partículas de la propia muestra, de los poros.

El ataque químico para revelar la microestructura se ha realizado con reactivo de Kroll. La composición de este reactivo es la siguiente: 100

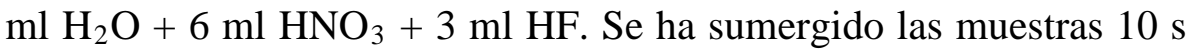
aproximadamente en el reactivo. 


\subsubsection{Microscopía óptica.}

El microscopio metalográfico utilizado es un Nikon LV100. Puede utilizarse en campo claro, campo oscuro y luz polarizada incluyendo filtro Nomanski. La magnificación abarca desde 50 aumentos hasta 1000 y los objetivos son apocromáticos.

El equipo se ha utilizado en campo claro hasta el valor máximo de aumento de $1000 \mathrm{X}$. Se ha utilizado campo claro porque se obtienen imágenes con mayor detalle de las zonas de interés que con las otras posibilidades que ofrece el microscopio. Las imágenes se han capturado con un programa de tratamiento y medición del propio equipo Nikon elements software 4.0.

\subsubsection{Microscopía electrónica de barrido (SEM).}

La microscopía electrónica ofrece una mejor resolución y mayor detalle en la observación de la microestructura, en concreto la Microscopía Electrónica de Barrido (SEM). También ofrece la capacidad de realizar análisis químico. El equipo utilizado ha sido un JEOL JSM 6300 equipado con los siguientes detectores entre otros:

- Detector de electrones secundarios (SE) de Jeol.

- Detector de electrones retrodispersados (BS) de Jeol.

- Detector de rayos X (EDS) de Oxford Instruments 
En la siguiente imagen se puede observar el equipo utilizado.

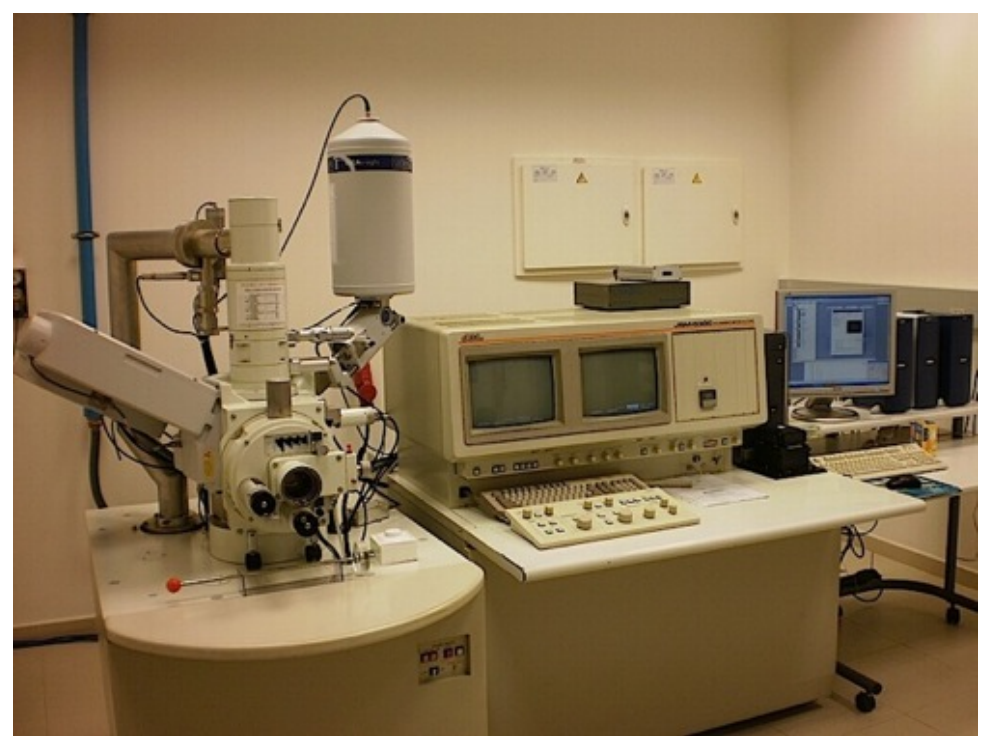

Figura 4.10. Microscopio JEOL JSM6300.

Se ha tomado imágenes utilizando la técnica de electrones retrodispersados (BS). Los electrones retrodispersados son electrones del haz incidente que han interaccionado (colisionado) con los átomos de la muestra y posteriormente son analizados por el detector. La intensidad de emisión de los electrones retrodispersados depende de la probabilidad de colisión y por tanto del número atómico medio de los átomos de la muestra, así los átomos más pesados originan mayor cantidad de electrones retrodispersados. Una imagen obtenida por BS revela diferencias en la composición química por diferencias de contraste. Su ventaja consiste en que es sensible a las variaciones en el número atómico de los elementos presentes en la superficie. Si se 
observa una superficie totalmente lisa se obtendrá distintos tonos de gris en función de que existan varias fases con distintos elementos.

Para observar bien estas diferencias se ha tomado una imagen de la misma zona y con la misma magnificación utilizando la técnica común, electrones secundarios, y utilizando electrones retrodispersados. No obstante, debe tenerse en cuenta que trabajando a $20 \mathrm{kV}$, la imagen de SE ya incorpora parte de la información de la imagen de BS.
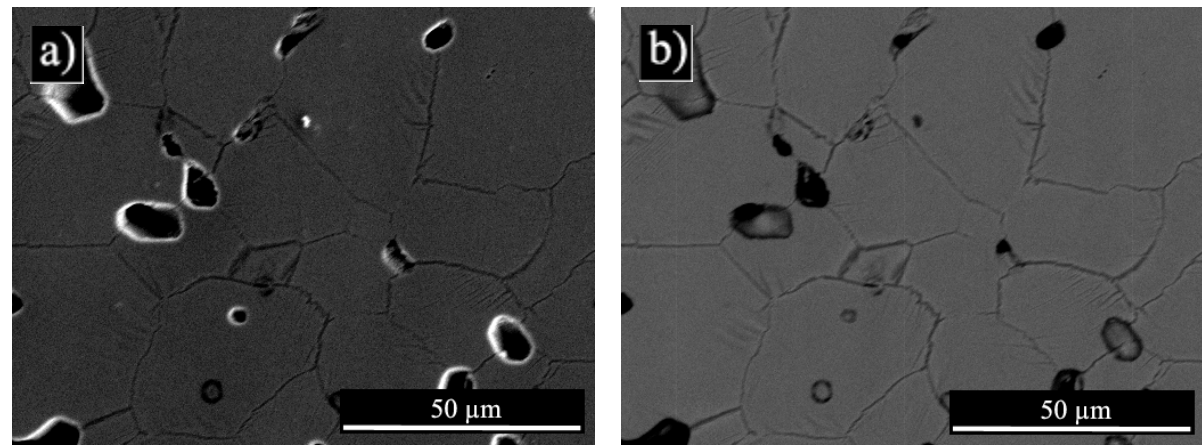

Figura 4.11. Comparación de imágenes tomadas con electrones secundarios (a) y electrones retrodispersados (b) con el microscopio electrónico de barrido de la aleación Ti 30Nb.

Se puede observar de forma más clara y con mayor definición las lamelas de microestructura $\alpha+\beta$ en la imagen con BS. Cuanto mayor son los aumentos, mayor es la ganancia de una técnica respecto a la otra. Por todo esto todas las imágenes se han tomado mediante electrones retrodispersados. 
Además se ha obtenido las composiciones de las zonas de interés con EDS. No se ha metalizado las muestras para evitar interferencias por la metalización en los análisis de EDS. Las muestras utilizadas han sido las mismas que para microscopía óptica pero sin ataque químico para no desvirtuar los resultados del análisis químico ya que cuando se ataca químicamente la muestra se modifica su composición en la superficie. Para hacer conductora la muestra, entendiendo como muestra la aleación estudiada más el soporte de PMMA, se ha utilizado un puente de plata desde la aleación hasta la base del portamuestra para que actúe como toma de tierra.

\subsubsection{Microscopía electrónica de transmisión (TEM).}

El equipo utilizado es el que se muestra en la figura 4.12. Es un Jeol JEM modelo 2100 con tensión nominal de trabajo de $200 \mathrm{kV}$, equipado con un cañón de electrones LaB6 y sistemas de microscopía electrónica de transmisión con modo barrido (STEM). Se dispone de un equipo integrado de análisis por espectrómetro de rayos $\mathrm{X}$ de energía dispersiva (EDS). 


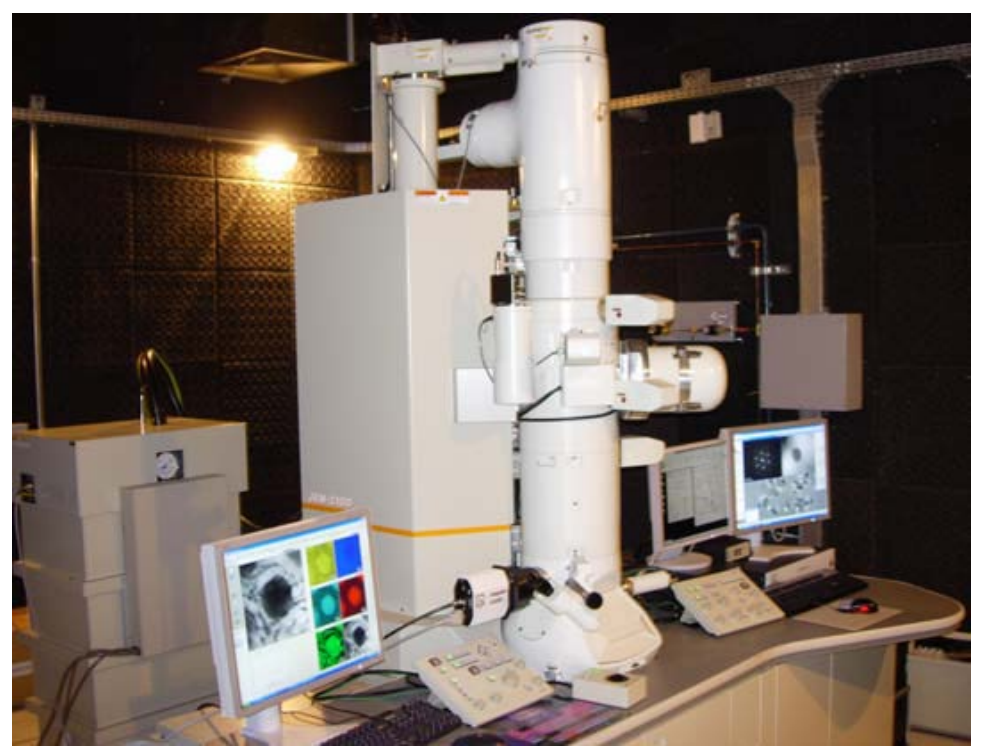

Figura 4.12. Microscopio electrónico de transmisión (TEM) Jeol JEM 2100 de $200 \mathrm{kV}$ de LaB6 con STEM y EDS integrados.

Para la preparación se ha partido de una lamina lo más delgada posible de la pieza de flexión, se ha desbastado hasta un espesor menor de 100 $\mu \mathrm{m}$. A continuación, se ha cortado un disco de $3 \mathrm{~mm}$ de diámetro con el equipo Ultrasonic Disk Cutte pues este es el tamaño de la muestra que se puede introducir en el equipo. El siguiente paso ha sido ahondar el disco por ambas caras hasta obtener una zona central de unas $20 \mu \mathrm{m}$ con el equipo Dimpling Grinder. Una vez conseguido, se ha introducido este disco en el equipo de Ion Milling para que sea atacado por ambos lados con sendos haces de iones de argón hasta que estos realizan un pequeño orificio central, alrededor del cual queda una zona suficientemente delgada para poder ser observada. 
La mayoría de las imágenes de microscopía electrónica de transmisión (TEM) que se van a mostrar se han obtenido en campo claro o brightfield (BF), ya que ofrecen mayor información y son de mayor calidad que las imágenes obtenidas con la técnica de campo oscuro o darkfield (DF). En la figura 4.13 se muestra la diferencia entre las dos técnicas de obtención de imágenes sobre la misma zona, también se ha incluido una imagen obtenida mediante high angular annular dark field (HAADF) o campo oscuro de alto ángulo anular con lo que se obtiene mayor definición e imágenes más nítidas y con menor ruido de fondo pero la zona de observación es menor.
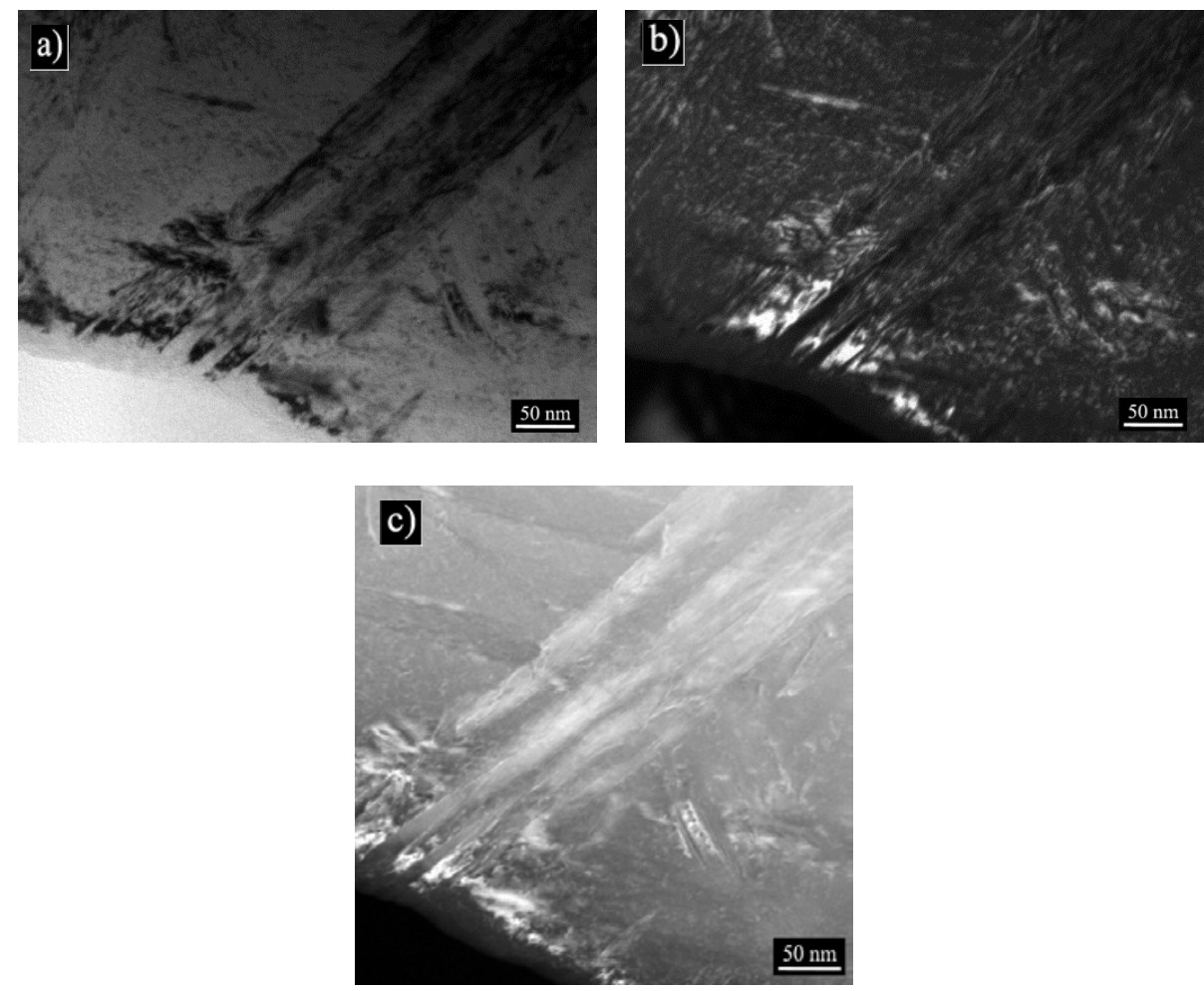

Figura 4.13. Comparación entre imágenes tomadas en BF (a), DF (b) y HAADF (c) de la misma zona de la aleación Ti 30Nb 2Sn. 
La utilización del equipo de STEM ha sido posible gracias a la colaboración con la Universidade Federal de São Carlos, más concretamente con el Departamento de Engenharia de Materiais y en especial al profesor C.R.M. Afonso. Esta colaboración también está incluida dentro del proyecto de colaboración anteriormente nombrado del Ministerio de Ciencia e Innovación del Proyecto de Investigación Bilateral España - Brasil PIB 2010BZ - 00448.

\subsubsection{Difracción de rayos $X(D R X)$.}

Los ensayos de difracción de rayos $\mathrm{X}$ se han llevado a cabo en un difractómetro Panalitycal X-Pert Pro PW3040/60 con detector PIXcel, con fuente de $\mathrm{Cu}(\mathrm{K}$ alfa) y filtro de $\mathrm{Ni}$, operado en tensión eléctrica de $40 \mathrm{kV}$ y corriente de $30 \mathrm{~mA}$. El intervalo de barrido es de $30<2 \theta<$ 90 con pasos de 0.02. El equipo es el que se muestra en la figura 4.14
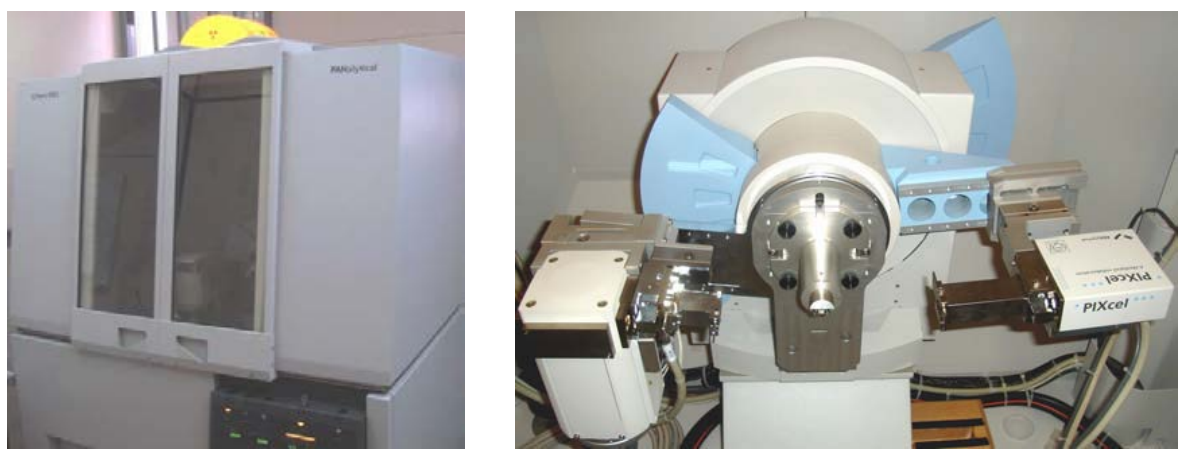

Figura 4.14. Equipo de DRX utilizado. 
Para la preparación de las muestras ha sido necesario preparar la superficie de las aleaciones desbastando una de las caras, para ello se ha utilizado papel de esmeril (SiC) de granulometría 2000.

A continuación se muestra las tablas y las gráficas con los picos característicos de todas las microestructuras que se pueden encontrar en las aleaciones de titanio. Estas microestructuras son las ya nombradas $\alpha$ y $\beta$, pero además las poco deseadas $\alpha$ ” y fase $\omega$.

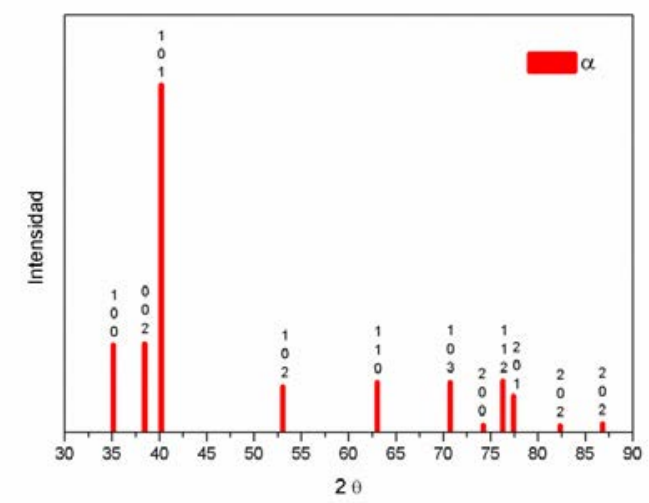

\begin{tabular}{|c|c|c|}
\hline \multicolumn{3}{|c|}{$\boldsymbol{\alpha}$} \\
\hline$(\mathbf{h}, \mathbf{k}, \mathbf{l})$ & $2 \theta$ & Intensidad \\
\hline$(1,0,0)$ & 35.12 & 252 \\
\hline$(0,0,2)$ & 38.44 & 255 \\
\hline$(1,0,1)$ & 40.20 & 1000 \\
\hline$(1,0,2)$ & 53.04 & 132 \\
\hline$(1,1,0)$ & 63.00 & 143 \\
\hline$(1,0,3)$ & 70.70 & 143 \\
\hline$(2,0,0)$ & 74.21 & 20 \\
\hline$(1,1,2)$ & 76.27 & 147 \\
\hline$(2,0,1)$ & 77.42 & 105 \\
\hline$(0,0,4)$ & 82.34 & 19 \\
\hline$(2,0,2)$ & 86.83 & 25 \\
\hline
\end{tabular}

Figura 4.15. Gráfico con los picos característicos y tabla con su intensidad de la microestructura $\alpha$ del titanio. 


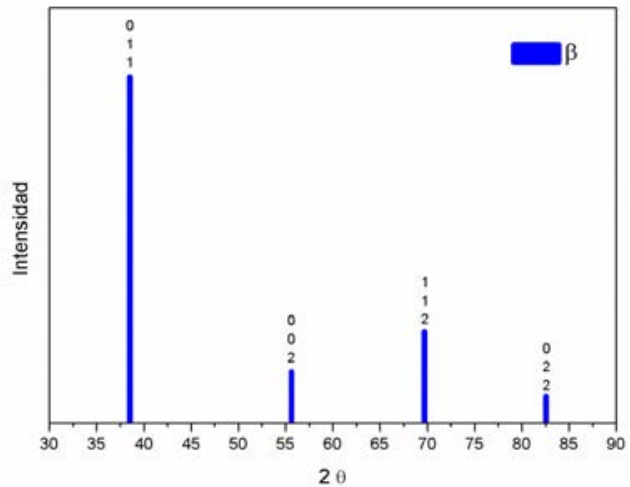

\begin{tabular}{|c|c|r|}
\hline \multicolumn{3}{|c|}{$\boldsymbol{\beta}$} \\
\hline$(\mathbf{h}, \mathbf{k}, \mathbf{l})$ & $\mathbf{2} \boldsymbol{\theta}$ & Intensidad \\
\hline$(0,1,1)$ & 38.51 & 1000 \\
\hline$(0,0,2)$ & 55.60 & 147 \\
\hline$(1,1,2)$ & 69.67 & 263 \\
\hline$(0,2,2)$ & 82.53 & 75 \\
\hline
\end{tabular}

Figura 4.16. Gráfico y tabla con los picos característicos de la microestructura $\beta$ del titanio.

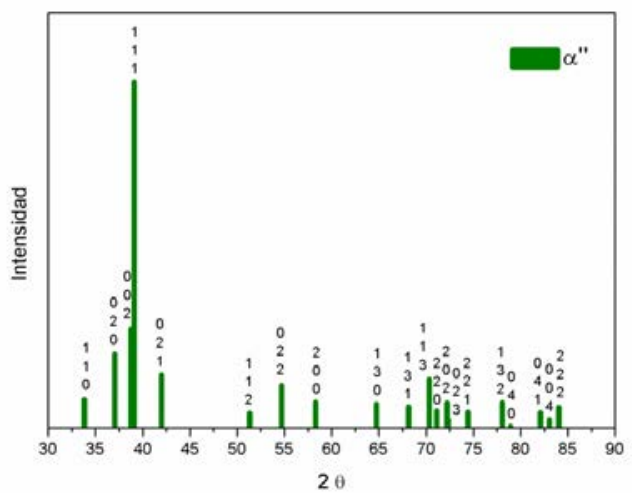

\begin{tabular}{|c|r|r|}
\hline \multicolumn{3}{|c|}{$\boldsymbol{u}^{\prime \prime}$} \\
\hline$(\mathbf{h}, \mathbf{k}, \mathbf{l})$ & $\mathbf{2} \boldsymbol{\theta}$ & Intensidad \\
\hline$(1,1,0)$ & 33.81 & 81 \\
\hline$(0,2,0)$ & 37.04 & 213 \\
\hline$(0,0,2)$ & 38.72 & 285 \\
\hline$(1,1,1)$ & 39.10 & 1000 \\
\hline$(0,2,1)$ & 41.99 & 153 \\
\hline$(1,1,2)$ & 52.32 & 41 \\
\hline$(0,2,2)$ & 54.66 & 122 \\
\hline$(2,0,0)$ & 58.29 & 74 \\
\hline$(1,3,0)$ & 64.70 & 68 \\
\hline$(1,3,1)$ & 68.14 & 60 \\
\hline$(1,1,3)$ & 70.33 & 140 \\
\hline$(2,2,0)$ & 71.11 & 49 \\
\hline$(2,0,2)$ & 72.19 & 71 \\
\hline$(0,2,3)$ & 72.31 & 24 \\
\hline$(2,2,1)$ & 74.40 & 44 \\
\hline$(1,3,2)$ & 78.02 & 72 \\
\hline$(0,4,0)$ & 78.89 & 3 \\
\hline$(0,4,1)$ & 82.08 & 43 \\
\hline$(0,0,4)$ & 83.04 & 23 \\
\hline$(2,2,2)$ & 84.02 & 58 \\
\hline & & \\
\hline
\end{tabular}

Figura 4.17. Gráfico con los picos característicos de la microestructura $\alpha$ ” del titanio. 


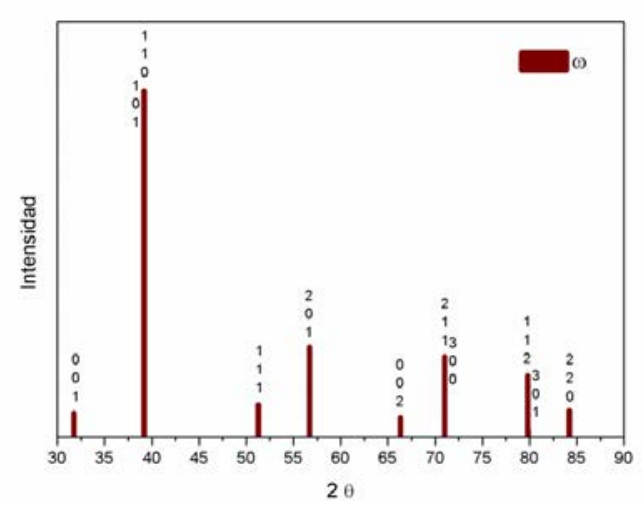

\begin{tabular}{|c|c|r|}
\hline \multicolumn{3}{|c|}{$\boldsymbol{\omega}$} \\
\hline$(\mathbf{h}, \mathbf{k}, \mathbf{l})$ & $\mathbf{2} \boldsymbol{\theta}$ & Intensidad \\
\hline$(0,0,1)$ & 31.71 & 69 \\
\hline$(1,0,1)$ & 39.14 & 891 \\
\hline$(1,1,0)$ & 39.17 & 1000 \\
\hline$(1,1,1)$ & 51.26 & 92 \\
\hline$(2,0,1)$ & 56.57 & 259 \\
\hline$(0,0,2)$ & 66.29 & 55 \\
\hline$(2,1,1)$ & 70.96 & 231 \\
\hline$(3,0,0)$ & 70.98 & 130 \\
\hline$(1,1,2)$ & 79.78 & 176 \\
\hline$(3,0,1)$ & 79.84 & 19 \\
\hline$(2,2,0)$ & 84.19 & 75 \\
\hline
\end{tabular}

Figura 4.18. Gráfico y tabla con los picos característicos de la microestructura $\omega$ del titanio.

La realización de estos ensayos en este equipo también ha sido posible por la colaboración bilateral España - Brasil PIB 2010BZ - 00448. Los ensayos se han realizado en las instalaciones de la Universidade Estadual de Campinas, la Faculdade de Engenharia Mecánica y más concretamente el Departamente de Engenharia de Fabricaçâo.

\subsection{Caracterización mecánica.}

A continuación se va a detallar los ensayos llevados a cabo, el procedimiento seguido y los parámetros de ensayo. 


\subsubsection{Microdureza.}

La microdureza ha sido obtenida con el equipo Matsuzawa MHT2, figura 4.19. Con un indentador Vickers (punta piramidal de base cuadrada). La dureza de las aleaciones estudiadas se ha determinado con la siguiente expresión (4.1):

$$
H V=\frac{1,85 * 1000 * P}{d^{2}}
$$

Siendo P la fuerza aplicada y d la longitud de las dos diagonales medidas sobre la huella.

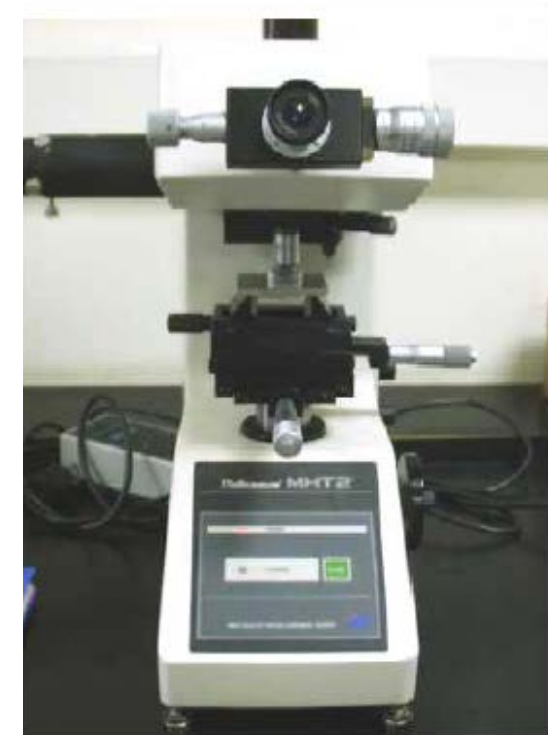

Figura 4.19. Microdurómetro Matsuzawa MHT2.

Los ensayos se han realizado siguiendo la norma ISO 4498 y sobre las probetas preparadas para microscopía sin ataque químico. Se ha 
aplicado una carga de 200 g durante 15 s para todas las probetas con el fin de obtener una huella fácilmente medible. Para cada una de las muestras se ha tomado 10 medidas. Midiéndose las dos diagonales principales de la huella y calculándose la dureza Vickers según la expresión anterior.

\subsubsection{Ensayo de flexión a tres puntos.}

Para la obtención de la relación entre las características resistentes y el contenido de estaño se ha obtenido el valor de la resistencia máxima a flexión. Este ensayo se ha realizado en una máquina de ensayos universal Instron 4204 y el montaje en el extremo de las mordazas es el que se puede observar en la figura 4.20.

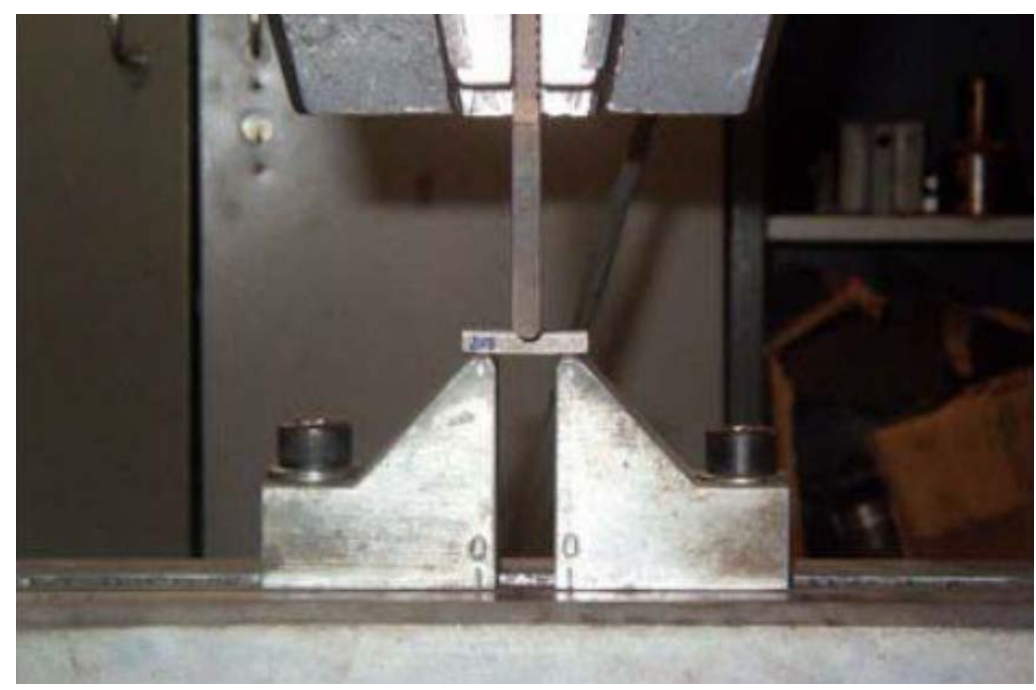

Figura 4.20. Montaje para el ensayo de flexión. 
Para el cálculo de la resistencia máxima a flexión se ha utilizado la siguiente expresión (4.2):

$$
R_{t r}=\frac{3 * \mathrm{~F} * L}{2 * b * h^{2}}
$$

Donde $R_{\text {tr }}$ es la resistencia a flexión; $F$ la carga requerida para la rotura; $L$ la distancia entre apoyos; $b$ la anchura de la probeta y $h$ la altura. Los ensayos se han realizado siguiendo las directrices de la norma ISO 3325 de flexión para materiales sinterizados y se ha utilizado las probetas rectangulares procesadas con anterioridad.

\subsubsection{Determinación del módulo elástico por ultrasonidos.}

En el ensayo de ultrasonidos para la obtención del módulo elástico se ha utilizado las muestras de $10 \mathrm{~mm}$ de diámetro y $10 \mathrm{~mm}$ de altura. Al ser un ensayo no destructivo se ha podido utilizar posteriormente las mismas muestras para el ensayo de compresión. El equipo utilizado ha sido un KARL DEUTSCH ECHOGRAPH 1090. Se trata de un equipo portátil muy versátil, en el que se ha utilizado dos tipos de palpadores rectos para obtener cada velocidad de propagación del sonido en el material: un palpador modelo DS 6 PB 4- 14 para calcular la velocidad longitudinal y un palpador YS 12 HB 1 para el cálculo de la velocidad transversal. Estos dos palpadores se han utilizado en modo emisor receptor. 
La ecuación (4.3) permite obtener el valor de módulo elástico, donde $E_{d}$ es el módulo elástico del material a calcular, $\rho$ la densidad de la aleación, $V_{T}$ la velocidad transversal y $V_{L}$ la velocidad longitudinal de propagación de la onda sonora.

$$
E_{d}=\frac{\mathrm{V}_{\mathrm{T}}^{2}\left(3 \mathrm{~V}_{\mathrm{L}}^{2}-4 \mathrm{~V}_{\mathrm{T}}^{2}\right)}{\mathrm{V}_{\mathrm{L}}^{2}-\mathrm{V}_{\mathrm{T}}^{2}}
$$

También puede obtenerse el coeficiente de Poisson mediante la relación entre la velocidad de propagación de onda transversal y longitudinal, expresión (4.4):

$$
v=\frac{E_{d}}{2 G}-1=\frac{\frac{V_{L}^{2}}{2}-V_{T}^{2}}{V_{L}^{2}-V_{T}^{2}}
$$

\subsubsection{Ensayo de nanoindentación.}

El ensayo de nanoindentación es básicamente, un ensayo de dureza de pequeños volúmenes de material y con un procedimiento de cálculo distinto en comparación con, por ejemplo la dureza Vickers. La diferencia entre un ensayo de nanoindentación y un ensayo de microdureza se encuentra principalmente en el cálculo del área de la huella. En el ensayo de microdureza convencional se obtiene el área de la huella mediante la observación de ésta después de retirar la carga, es decir se miden las diagonales para obtener el área. En el ensayo de nanoindentación no se mide la diagonal de la huella sino que se monitoriza y se controla la profundidad de penetración del 
indentador. De este modo, se puede obtener el área de la zona ensayada de forma directa sin la necesidad de retirar la carga para obtener el área. Por este motivo a la nanoindentación también se la conoce como Técnicas de Indentación Instrumentadas o Instrumented Indentation Techniques (IIT) porque se puede controlar y monitorizar en todo momento la curva carga - profundidad (P-h) en el ensayo.

De este modo se consigue trabajar con volúmenes de material muy pequeños ya que no existe la limitación de tener que observar la huella y se pueden aplicar cargas muy pequeñas que penetren en el material unos pocos nanómetros. Además de esta diferencia, también aparecen diferencias referentes a la carga de ensayo. Al ser las cargas de ensayo mucho mayores en un microdurómetro que en un nanoindentador se activan nuevos mecanismos de deformación (movimientos de dislocaciones, creación de grietas, etc.). Esto hace que el valor de dureza del material disminuya al aumentar la carga en la indentación, este fenómeno se conoce como efecto de tamaño de indentación o indentation size effect (ISE).

En nuestro caso se ha utilizado un equipo Nanoindenter G-200 de Agilent. El equipo se puede observar en la figura 4.21 junto con un esquema básico de las partes clave del mecanismo de indentación instrumentada. 


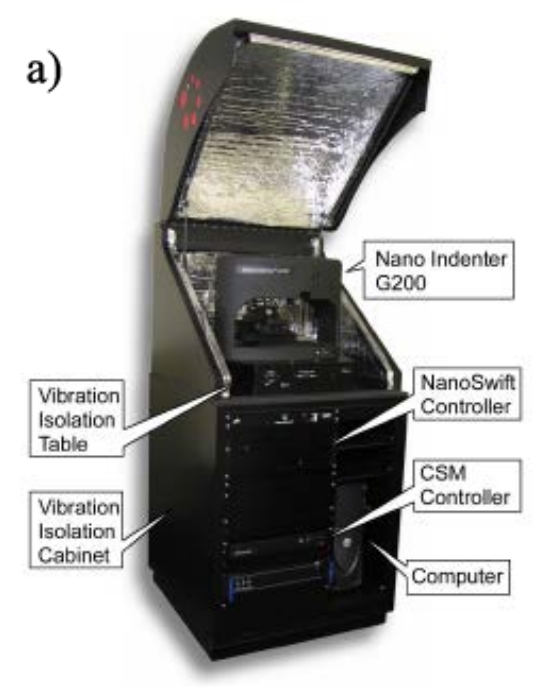

b)

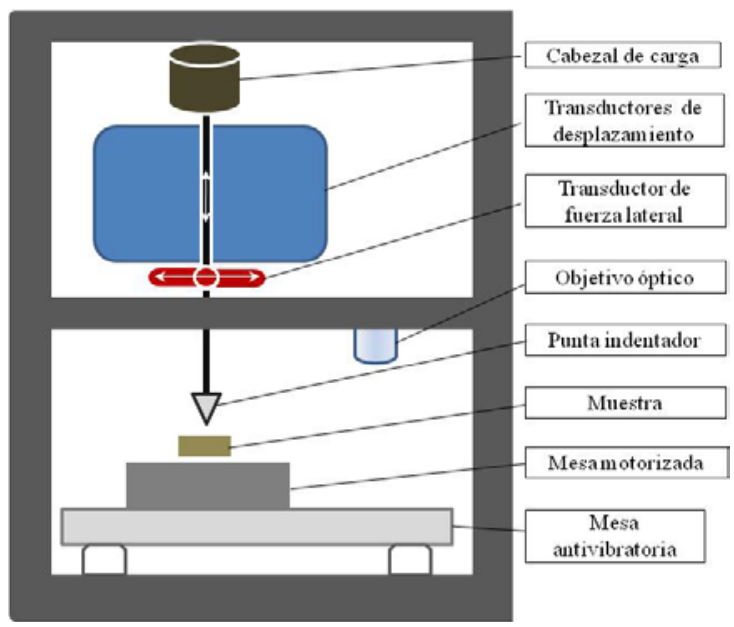

Figura 4.21. Nanoindentador Nanoindenter G-200 de Agilent (a) con el esquema de sus partes básicas (b).

Se ha utilizado una punta Berkovich como la que se muestra en la figura 4.22. Este tipo de puntas están fabricadas con diamante y su geometría aguda genera deformación plástica desde el inicio de la indentación. Los indentadores tipo Berkovich tienen un ángulo entre sus tres caras de $\theta=65.27^{\circ}$, gracias a esta característica se consigue 
que el coeficiente de área respecto a profundidad no varíe con lo que se consigue que la deformación del material sea constante durante toda la indentación, y por tanto, se pueda calcular la dureza a cualquier profundidad de ensayo.

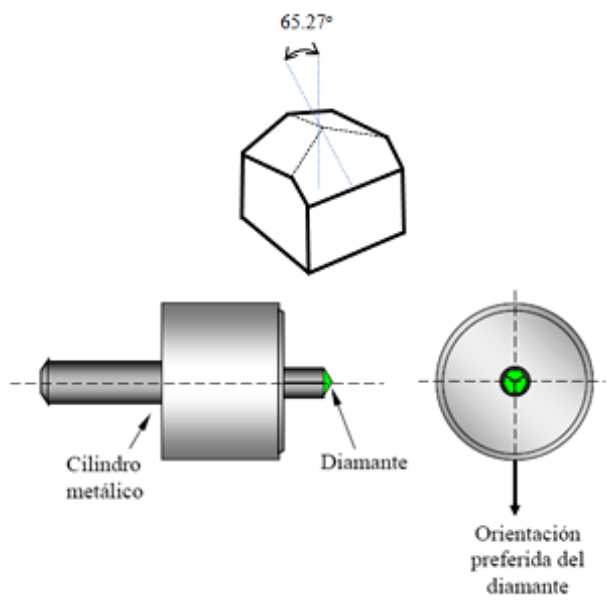

Figura 4.22. Geometría del indentador Berkovich y esquema básico del soporte.

La representación de la curva de P-h de un ensayo de nanoindentación se puede observar en la figura 4.23 a). También aparece el comportamiento del indentador sobre el material con todos los parámetros destacables para el cálculo posterior, figura 4.23 b). Se trata de un ensayo con un indentador Berkovich sobre un material con comportamiento elástico-plástico que recrea el comportamiento de las aleaciones estudiadas. 


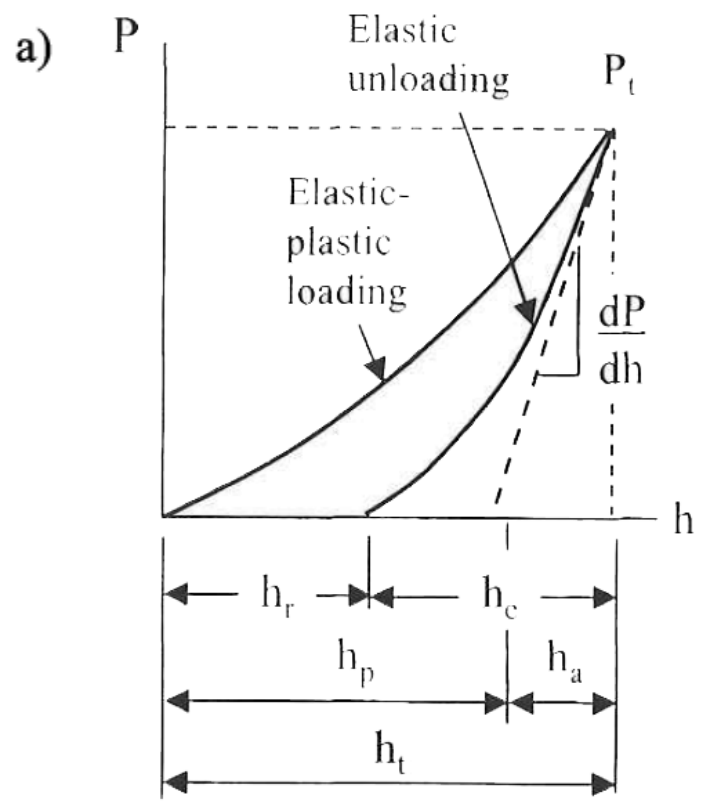

b)

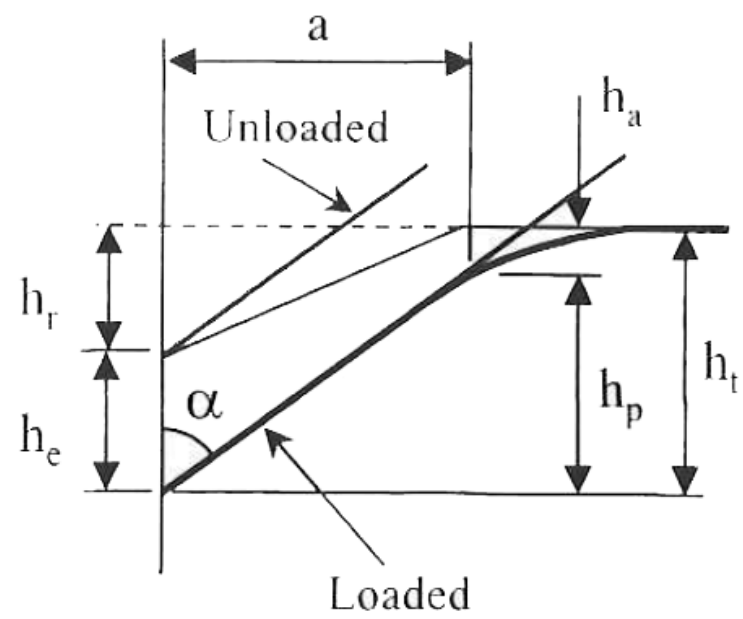

Figura 4.23. a) Curva de P-h de un material elástico plástico con punta Berkovich y b) representación esquemática de la indentación y la superficie del material [3]. 
Se ha obtenido el módulo elástico (E) y la dureza (H) del material por dos procedimientos para mayor seguridad en los resultados. El primer método utilizado ha sido el propuesto por Oliver y Pharr mediante el cual se obtiene los datos de $\mathrm{E}$ y $\mathrm{H}$ en los primeros instantes de la descarga.

En la representación de la carga y descarga (figura 4.23 a)) se puede observar el valor de carga máxima alcanzada $\left(\mathrm{P}_{\mathrm{t}}\right)$, la profundidad máxima alcanzada $\left(\mathrm{h}_{\mathrm{t}}\right)$, la profundidad después de la descarga $\left(\mathrm{h}_{\mathrm{r}}\right)$ y la profundidad de contacto $\left(\mathrm{h}_{\mathrm{p}}\right)$.

La rigidez de contacto $(\mathrm{S})=\mathrm{dP} / \mathrm{dh}$, representa la pendiente en la descarga en el primer tramo, es decir entre la profundidad máxima alcanzada y la profundidad de contacto. El gran éxito de método de Oliver y Pharr es ajustar la curva de descarga a la ley de la potencia (4.5) [3]:

$$
P=\alpha\left(\mathrm{h}-\mathrm{h}_{\mathrm{a}}\right)^{\mathrm{m}}
$$

Donde $\alpha$ y m son factores de ajuste obtenidos empíricamente, $\mathrm{h}_{\mathrm{a}}$ es la profundidad referente al inicio de la deformación plástica y que se puede expresar como $h_{a}=h_{t}-h_{p}$. En el momento de máxima carga se obtiene, a partir de la expresión de la rigidez de contacto, la siguiente expresión (4.6):

$$
S=\left.\frac{\mathrm{dP}}{\mathrm{dh}}\right|_{\mathrm{h}_{\mathrm{t}}} ; \mathrm{S}=\mathrm{m} \alpha\left(\mathrm{h}_{\mathrm{t}}-\mathrm{h}_{\mathrm{p}}\right)^{\mathrm{m}-1}
$$


Debido a que es un material elastoplástico, y hay una respuesta plástica del material, el contacto no es perfecto entre la superficie del material y el nanoindentador, por lo que existe una diferencia y $h_{p}<$ $h_{t}$.

Con todo esto y sustituyendo en la ecuación:

$$
\mathrm{h}_{\mathrm{a}}=\mathrm{h}_{\mathrm{t}}-\mathrm{h}_{\mathrm{p}}
$$

de la curva P-h en el momento de máxima carga y máxima profundidad de indentación el valor de $\mathrm{h}_{\mathrm{p}}$ por su relación con la rigidez de contacto se obtiene:

$$
\begin{gathered}
\mathrm{h}_{\mathrm{p}}=\varepsilon \frac{\mathrm{P}_{\mathrm{t}}}{\mathrm{S}} \\
\mathrm{h}_{\mathrm{a}}=\mathrm{h}_{\mathrm{t}}-\varepsilon \frac{\mathrm{P}_{\mathrm{t}}}{\mathrm{S}}
\end{gathered}
$$

Donde $\varepsilon$ es un factor referente a la geometría del indentador; $\varepsilon=0.75$ para indentadores Berkovich. Por lo que ya se puede calcular el valor del área de contacto para un indentador Berkovich en función de $\mathrm{h}_{\mathrm{p}}$; se obtiene que $A\left(h_{p}\right)=24.56 h_{p}$.

En el ensayo, tanto el material como el indentador sufren deformación al aplicar la carga por lo que con la expresión (4.10) se puede calcular el módulo efectivo o módulo compuesto $\mathrm{E}_{\mathrm{f}}$. Se determina utilizando la 
rigidez de contacto (S), el área de contacto (A), y un factor de corrección que sirve para ajustar la geometría del indentador a las ecuaciones de contacto de Sneddon. Para el caso de una punta Berkovich $\beta=1.034$

$$
E_{f}=\frac{1}{\beta} S \frac{\sqrt{\pi}}{2} \frac{1}{\sqrt{\mathrm{A}}}
$$

Oliver y Pharr [4] comprobaron que las ecuaciones extraídas de la teoría de contacto elástico funcionaban bien para cualquier geometría de indentador en el tramo de recuperación elástica en la zona de descarga del ensayo. Por tanto puede relacionarse el $\mathrm{E}_{\mathrm{f}}$ con el módulo elástico y el coeficiente de Poisson del material estudiado y del indentador mediante la expresión:

$$
\frac{1}{E_{f}}=\frac{1-v^{2}}{E} \frac{1-v_{\text {ind }}^{2}}{E_{\text {ind }}}
$$

De este modo se puede calcular el módulo del material ensayado, sabiendo que el material del indentador Berkovich es diamante que tiene unos valores de $\mathrm{E}_{\text {ind }}=1141 \mathrm{GPa} \mathrm{y} v_{\text {ind }}=0.07$.

Del mismo modo para calcular la dureza del material (4.12) se ha utilizado el área efectiva en el momento de iniciar la descarga.

$$
H=\frac{\mathrm{P}_{\mathrm{t}}}{\mathrm{A}\left(\mathrm{h}_{\mathrm{p}}\right)}
$$


Pero este modelo de cálculo puede tener algunas incoherencias para materiales blandos o metales como el aluminio y el titanio, ya que se puede generar un cálculo poco preciso del área de contacto por efecto de apilamiento o pile-up [3]. Este fenómeno aparece por la acumulación de material alrededor de la zona de indentación, el material fluye por las caras del indentador y se acumula en la superficie. El efecto se observa mucho mejor en la figura 4.24.
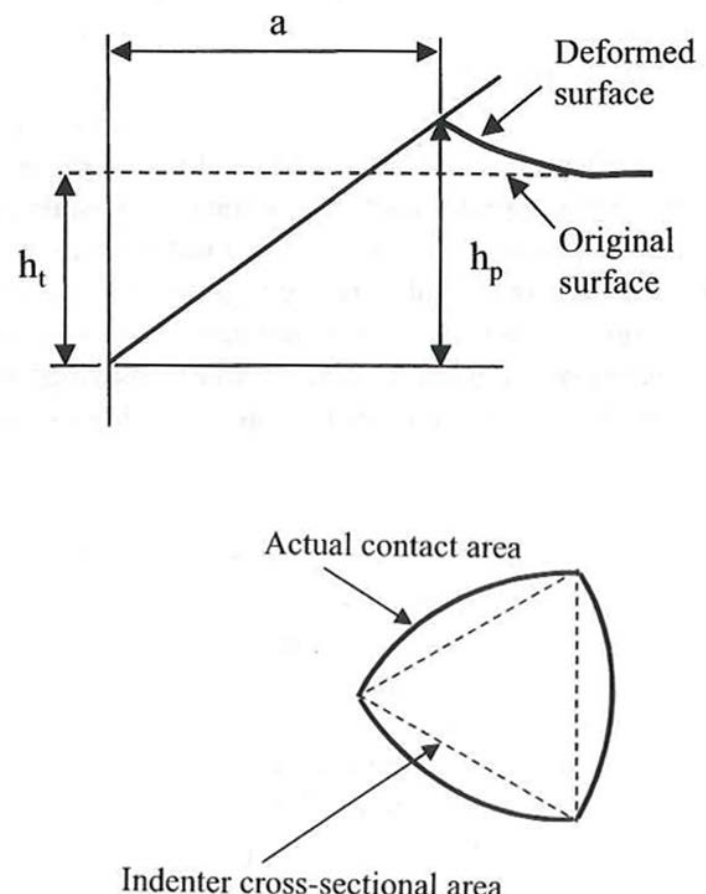

Figura 4.24. Efecto de apilamiento o piling-up en el ensayo de nanoindentación [3]. 
Por este apilamiento el valor de $h_{p}$ puede ser erróneo ya que $h_{p}$ nunca puede ser mayor que $h_{t}$. Para evitar este tipo de error se ha implementado otro método de cálculo para el ensayo de nanoindentación, conocido como medida de rigidez continua o Continuous Stiffness Measurement (CSM). Este método de obtención de $\mathrm{S}$ se fundamenta en que durante el tramo de carga, se aplica la carga con una oscilación sinusoidal, con una frecuencia y amplitud conocidas. De este modo sí el material tiene un comportamiento elástico-plástico ofrecerá una respuesta retardada en el tiempo en función de sus propiedades elásticas.

Cuando el indentador está en contacto con la muestra, se crea un desfase en la respuesta del material que responde a las características de la rigidez de contacto (S) según la ecuación (4.13):

$$
S=\left[\frac{1}{\frac{F_{O S}}{h_{0}} \cos \Phi-\left(K_{S}-m \omega^{2}\right)}-\mathrm{K}_{f}^{-1}\right]^{-1}
$$

Donde $K_{f}$ y $K_{s}$ son factores de amortiguamiento, $F_{o s}$ la fuerza de oscilación, $\cos \Phi$ el desfase entre el indentador y la respuesta del material, $m$ una constante para el ajuste del modelo y $\omega$ la frecuencia aplicada. Este cálculo para obtener S es mucho más interesante que el planteado por Oliver y Pharr: pues no se ve afectado por efectos como el pile-up y permite obtener perfiles de dureza y módulo elástico en todo el rango de profundidades. La posibilidad de obtener las 
propiedades mecánicas de un material en perfil de profundidad es una cualidad exclusiva de esta técnica y permite conocer las propiedades mecánicas a escala nanométrica.

Resumiendo, se ha obtenido los valores de E y H utilizando la técnica planteada por Oliver y Pharr en la descarga y por el método de medida de rigidez continua o CSM. Las muestras que se han utilizado son las preparadas para la observación con el microscopio en estado de pulido, sin ataque químico.

Las condiciones en las que se han llevado a cabo los ensayos son con control de profundidad hasta una profundidad máxima de 1500 nm, utilizando el método de CSM. El cálculo de E y H por Oliver y Pharr se ha obtenido utilizando el 50 \% de la curva en la descarga para obtener la rigidez de contacto $(\mathrm{S})$.

\subsubsection{Ensayo de compresión.}

Para los ensayos de compresión se ha utilizado una máquina universal de ensayos, Shimadzu modelo AG-X Plus equipada con una célula de carga de $100 \mathrm{kN}$ y el software para el control del equipo Trapeziumx. El equipo con el montaje de los platos para compresión se muestra en la figura 4.25 . 

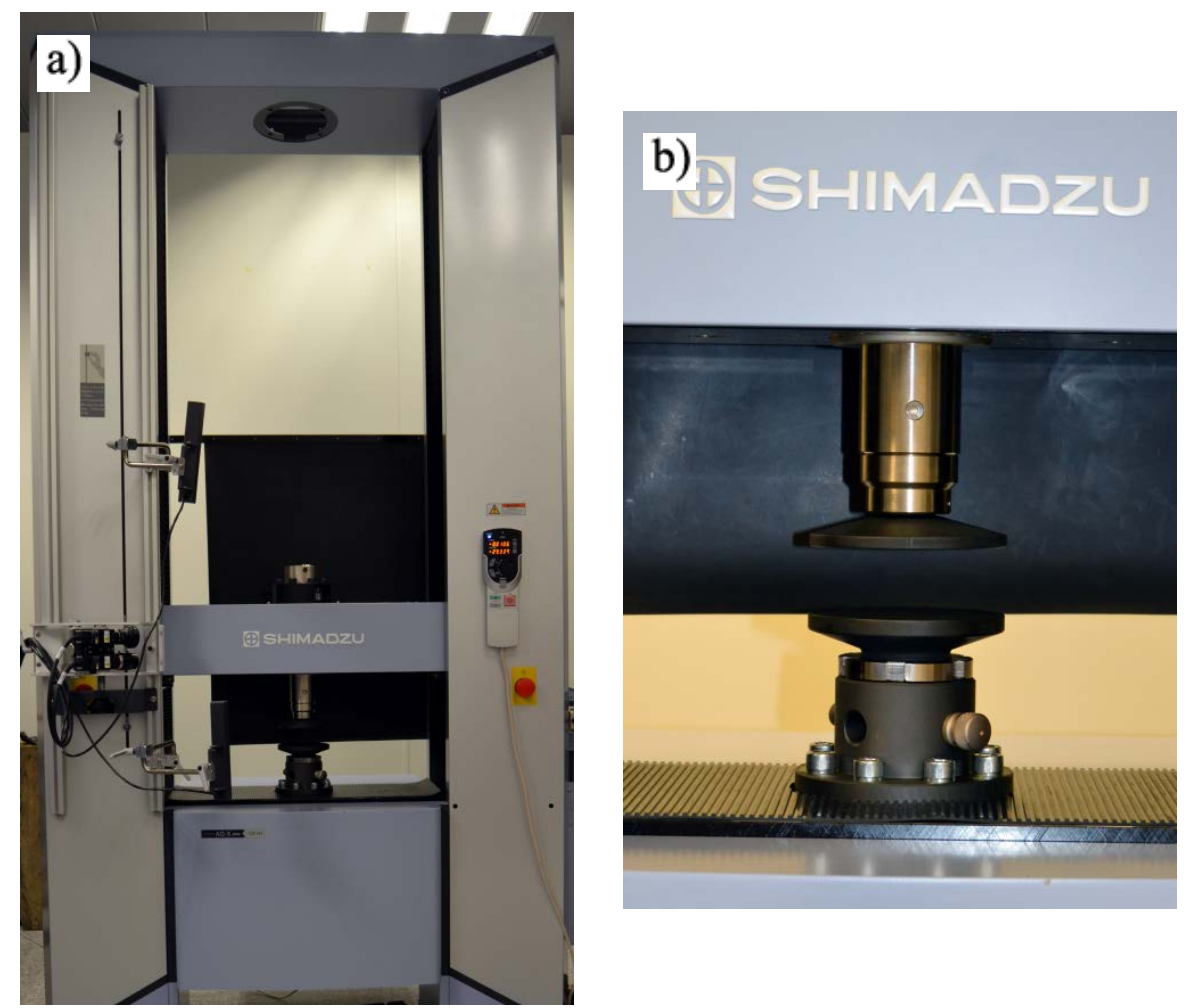

Figura 4.25. a) Máquina universal de ensayo y b) montaje de los platos para compresión.

El ensayo se ha realizado sobre las 10 muestras cilíndricas de $10 \mathrm{~mm}$ de diámetro y $10 \mathrm{~mm}$ de altura. A una velocidad de desplazamiento de cruceta de $0.1 \mathrm{~mm} / \mathrm{min}$. Se ha compensado la deformación del montaje de compresión aplicando una corrección sobre el ensayo. Se ha calculado el módulo elástico y el límite elástico de las aleaciones estudiadas para apreciar la influencia del Sn en el comportamiento a compresión de los materiales. El límite elástico se ha calculado como la tensión cuando se incrementa $0.2 \%$ el valor de deformación con respecto a la representación del módulo elástico, es decir, la 
intersección entre la curva del ensayo y una paralela al módulo elástico a + $0.2 \%$ de deformación.

\subsection{Caracterización tecnológica.}

El objetivo de esta fase es la obtención de las características a corrosión y tribocorrosión del material y su relación con el contenido de estaño. Se ha utilizado en ambos ensayos una disolución que simula el fluido humano en el entorno de trabajo. El suero humano se compone de sales, fosfatos y proteínas principalmente. El $\mathrm{NaCl}$ y el $\mathrm{KCl}$ son las sales que en mayor proporción se encuentran, pero también aparecen sales como el $\mathrm{CaCl}_{2}$ y el $\mathrm{MgCl}_{2}$ cuya concentración no supera el $0.15 \mathrm{~g} / \mathrm{l}$. En cuanto a fosfatos la concentración siempre es inferior a 2 g/l y aparecen asociados a distintos iones, en forma de $\mathrm{Na}_{2} \mathrm{HPO}_{4}$ y $\mathrm{KH}_{2} \mathrm{PO}_{4}$. Por último aparece una gran variedad de proteínas destacando: albúmina (54 - $62 \%)$, a-globulinas (9 - $15 \%$ ), $\beta$-globulinas ( 8 - $13 \%$ ), y $\gamma$-globulinas (14 - $19 \%$ ). Los porcentajes expresados para la concentración de proteínas se refieren al total de proteínas en peso. Destacar que estos valores de concentración en los tres casos pueden variar dependiendo del individuo, las circunstancias e incluso la zona del cuerpo donde se realiza el estudio.

El fluido utilizado simula esta composición, pero para simplificar la propia composición y complejidad del fluido se ha utilizado una disolución de fosfatos conocida como Phosfate Buffered Solution 
(PBS). La composición del fluido utilizado se muestra en la tabla siguiente:

Tabla 4.4. Composición de la disolución PBS utilizada para los ensayos de corrosión y tribocorrosión.

\begin{tabular}{|c|r|}
\hline Compuesto & Concentración (g/) \\
\hline $\mathrm{NaCl}$ & 8 \\
\hline $\mathrm{KCl}$ & 0.2 \\
\hline $\mathrm{Na}_{2} \mathrm{HPO}_{4}$ & 1.44 \\
\hline $\mathrm{KH}_{2} \mathrm{PO}_{4}$ & 0.25 \\
\hline
\end{tabular}

Todos estos ensayos se han realizado a una temperatura de $37^{\circ} \mathrm{C}$ para simular las condiciones de temperatura cuando las aleaciones están implantadas dentro del cuerpo humano.

Para el montaje experimental en el ensayo de corrosión se ha utilizado una celda electroquímica con una configuración de tres electrodos y un potenciostato. El potenciostato utilizado es un AUTOLAB 302N. En la figura 4.26 se puede observar el potenciostato utilizado y el montaje de la celda electroquímica con la configuración de tres electrodos. 


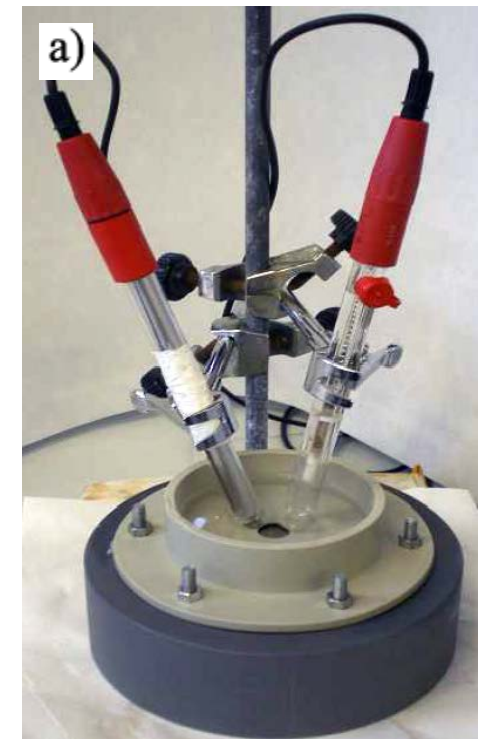

b)

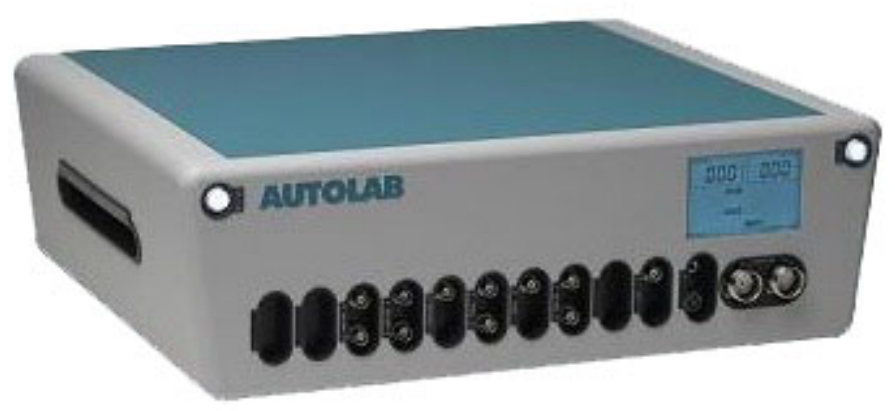

Figura 4.26. a) Celda electroquímica con una configuración de tres electrodos y b) potenciostato AUTOLAB 302N. 


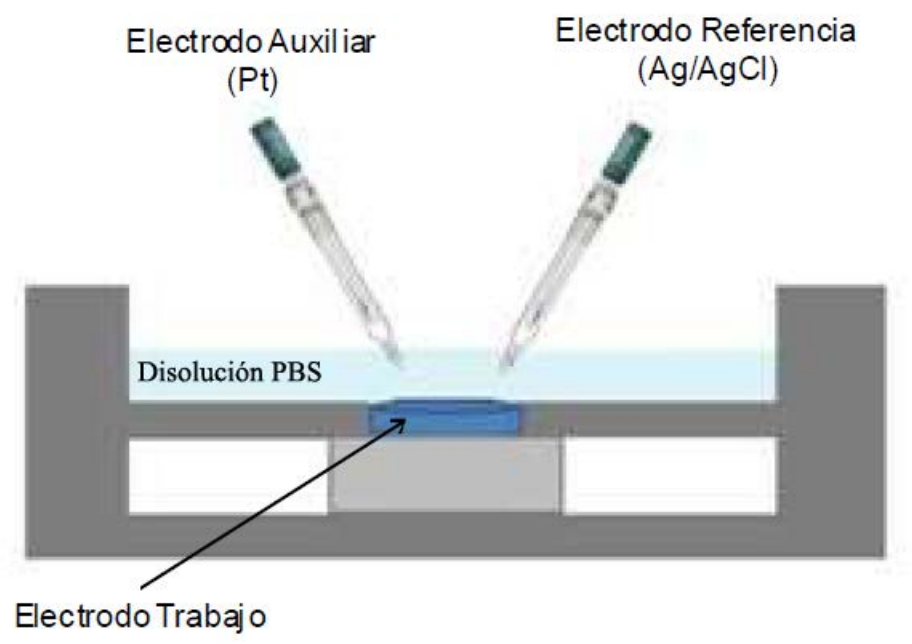

Figura 4.27. Esquema de la celda electroquímica con configuración de tres electrodos: referencia, auxiliar y ensayo.

Se ha llevado a cabo una serie de ensayos para caracterizar de forma precisa el comportamiento de las aleaciones estudiadas frente a la corrosión en el medio de fosfatos. El primer ensayo ha sido la obtención de la curva de polarización potenciodinámica. En este ensayo se registra la variación de intensidad o de potencial cuando se aplica una variación de intensidad creciente al sistema.

El potencial inicial es inferior al de corrosión y el avance es en sentido anódico hasta un potencial suficientemente alto para barrer toda la zona de interés, desde -1.2 hasta $3 \mathrm{~V}_{\mathrm{Ag} / \mathrm{AgCl}}$. La velocidad de barrido ha sido lo suficientemente lenta $(1 \mathrm{mV} / \mathrm{s})$ como para permitir de forma normal el intercambio de carga en la intercara disolución-superficie de trabajo. 
Los parámetros químicos que se pretende caracterizar en este ensayo son: $E_{\text {corr }}$ que es el potencial de equilibrio entre el metal, la aleación de estudio, y el electrolito (PBS) respecto a un electrodo de referencia y la $I_{\text {corr }}$ que es la densidad de corriente que circula a través de la pila electroquímica formada justo en el instante en el que se obtiene el potencial de corrosión. Por último se ha calculado la densidad de pasivación $\left(\mathrm{I}_{\mathrm{p}}\right.$ ) al potencial de $1 \mathrm{~V}_{\mathrm{Ag} / \mathrm{AgCl}}$ ya que la zona de pasivación es muy estable en todas las aleaciones. Cabe destacar que los valores de $\mathrm{E}_{\text {corr }}$ e $\mathrm{I}_{\text {corr }}$ se han obtenido aplicando el método de intersección o método de las pendientes de Tafel.

En la siguiente figura se puede observar las zonas más significativas de los dominios en la curva potenciodinámica y la representación de los valores obtenidos en dicho ensayo: $\mathrm{E}_{\text {corr }}, \mathrm{I}_{\text {corr }}$ e $\mathrm{I}_{\mathrm{p}}$.

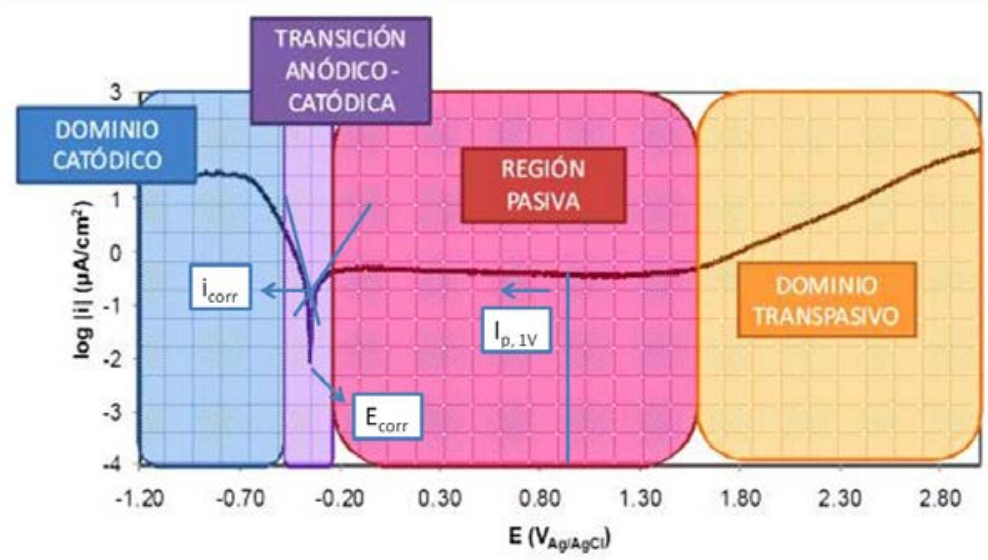

Figura 4.28. Esquema de los dominios en la curva potenciodinámica y principales parámetros obtenidos a partir del ensayo [5]. 
Para el cálculo de la densidad de pasivación $\left(\mathrm{I}_{\mathrm{p}}\right)$ se ha utilizado los valores de área activa corregidos. Es decir, como hay una porosidad considerable se ha calculado el área activa ya que es una medida mucho más precisa que el área nominal o expuesta (área de trabajo suponiendo una superficie ideal). De este modo se corrigen y se ajustan mucho mejor los datos a la realidad del proceso.

En segundo lugar se realiza los ensayos de potencial de circuito abierto (OCP). La medida del OCP es uno de los principales parámetros de corrosión y permite conocer el potencial de la muestra bajo circuito abierto. A través del valor del potencial se conoce la capacidad protectora del recubrimiento sobre el sustrato, en este caso de la capa pasiva que forman las aleaciones estudiadas.

Cabe destacar que antes de iniciar la serie de ensayos, se realiza un barrido potenciodinámico múltiple de $-1.2 \mathrm{~V}$ Ag/AgCl al potencial de corrosión a una velocidad de $10 \mathrm{mV} / \mathrm{s}$ para activar la superficie de la aleación estudiada. Posteriormente y antes de cada ensayo se realiza una limpieza catódica aplicando un potencial de $-1.2 \mathrm{~V}_{\mathrm{Ag} / \mathrm{AgC}}$ durante 5 min.

Para los ensayos de tribocorrosión se ha utilizado un tribómetro convencional, del fabricante Microtest S.A. modelo MT 60/Ni/CORR. Se ha utilizado en modo ball on disk, es decir se ha hecho deslizar una bola sobre un disco del material de ensayo en un movimiento circular 
de 6 mm diámetro, la rotación del equipo es de 60 r.p.m. por lo que la velocidad de deslizamiento es de $20 \mathrm{~mm} / \mathrm{s}$. El material de la bola es alúmina $\left(\mathrm{Al}_{2} \mathrm{O}_{3}\right)$ y tiene un diámetro de $6 \mathrm{~mm}$. La carga aplicada en los ensayos es de $5 \mathrm{~N}$. El potenciostato utilizado es el mismo que para los ensayos de corrosión potenciodinámicos y de OCP, y la celda electroquímica también tiene las mismas características que en caso anterior pero adecuado al tribómetro. En la figura 4.29 se muestran los equipos utilizados y el montaje de los mismos.
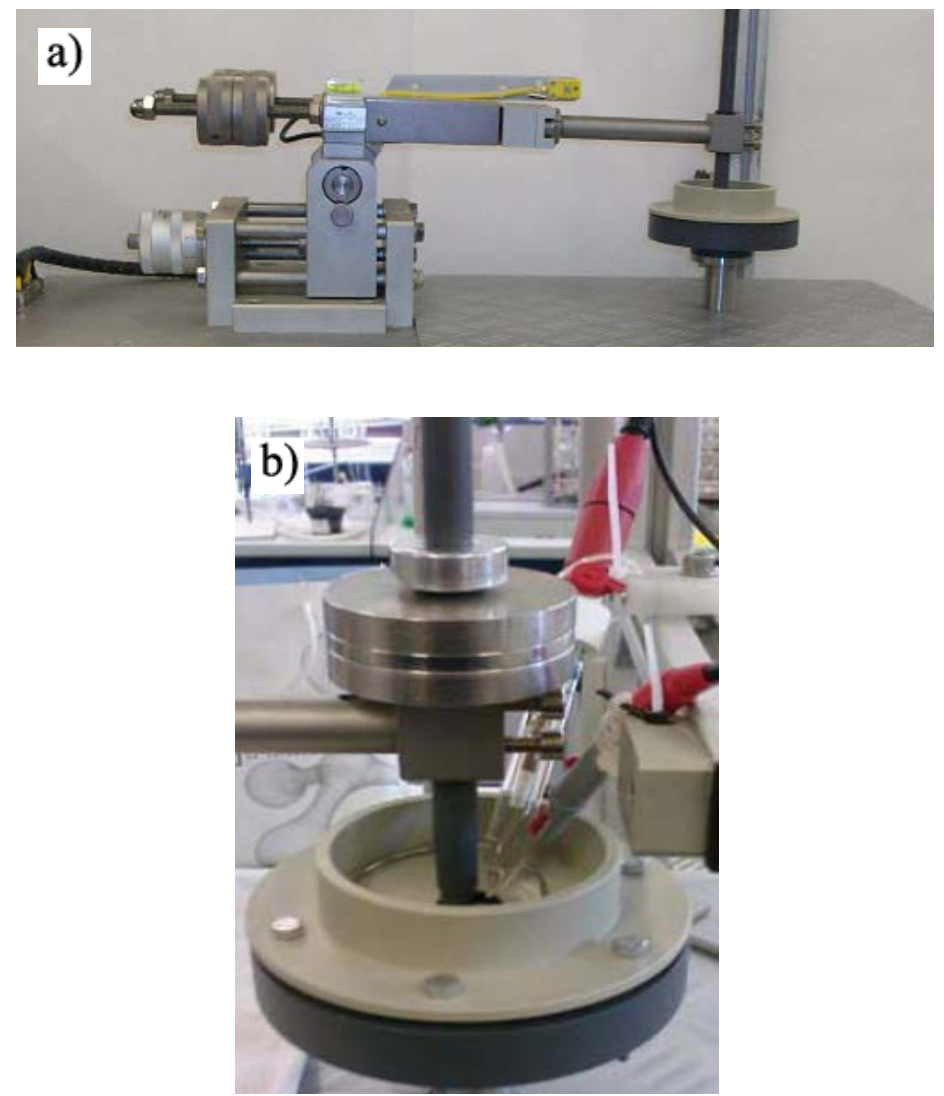

Figura 4.29. Equipo de tribología utilizado (a) y montaje de la celda electroquímica en el tribómetro (b). 
Se ha obtenido los valores de potencial de circuito abierto (OCP) antes, durante y después de la realización del ensayo de tribocorrosión para observar la evolución de dicho valor antes, durante y después del ensayo. También se ha comprobado el valor de $\mathrm{E}_{\mathrm{OCP}}$ obtenido en el ensayo anterior ya que la celda electroquímica tiene el mismo montaje pero no es exactamente la misma celda.

Posteriormente se ha realizado el ensayo a potencial constante de 1 $\mathrm{V}_{\mathrm{Ag} / \mathrm{AgCl}}$. De la misma manera se ha registrado el ensayo antes, durante y después de la tribología para obtener la evolución. Se ha calculado el valor de $\mathrm{I}_{0}$, densidad de pasivación antes de tribología e $\mathrm{I}_{\text {sliding, }}$, densidad de pasivación durante la tribología. De los datos obtenidos de la $\mathrm{I}_{\text {sliding }} \mathrm{y}$ mediante la ecuación 4.14 se obtiene el volumen de pérdida química $\left(\mathrm{V}_{\text {quim }}\right)$, debida a la corrosión.

$$
V_{\text {quim }}=\left(I_{\text {sliding }} \mathrm{tM}\right) /(\mathrm{n} \mathrm{F} \rho)
$$

Donde $I_{\text {sliding }}$ es la densidad de pasivación durante la tribología obtenida en el ensayo, $\mathrm{M}$ es la masa molecular, $\mathrm{t}$ la duración del ensayo de desgaste (en este caso 3600 s), n el numero de carga para la reacción de oxidación (4), F la constante de Faraday y $\rho$ la densidad de cada aleación.

Posteriormente, y con la ayuda de un microscopio confocal (Olympus LEXT OLS3000) se observa la pista de desgaste y se obtiene el 
volumen total de pérdida de material $\left(\mathrm{V}_{\text {total }}\right)$. Este $\mathrm{V}_{\text {total }}$ se ha calculado a partir del cálculo del área del perfil suavizado de la pista de tribocorrosión.

Mediante la relación 4.15 se obtiene finalmente el valor de pérdida de volumen mecánico $\mathrm{V}_{\mathrm{mec}}$, es decir, el material perdido por el desgaste mecánico.

$$
V_{\text {total }}=\mathrm{V}_{\text {quim }}+\mathrm{V}_{\text {mec }}
$$

\subsection{Referencias.}

[1] Guilin Y., Nan L., Yousheng L., Yining W., "The effects of different types of investments on the alpha-case layer of titanium castings”. Volume 97, Issue 3, March 2007, Pages 157164.

[2] Wei Q., Wang L., Fu Y., Qin J., Lu W., Zhang D., “Influence of oxygen content on microstructure and mechanical properties of Ti-Nb-Ta-Zr alloy”. Materials and Design 32 (2011) 29342939.

[3] Anthony C. Fischer-Cripps, 2004. Mechanical engineering series Nanoindentation. Springer, $2^{\mathrm{a}}$ edición.

[4] Oliver W.C., Pharr G.M., “An improved technique for determining hardness and elastic modulus using load and displacement sensing indentation experiments”. J. Meter. Res. Vol. 7, No. 6, June 1992. 
[5] Dalmau A., "Caracterización y estudio del comportamiento electroquímico de aleaciones de titanio para uso biomédico". Tesis de Máster UPV. 


\section{RESULTADOS Y DISCUSIÓN.}

En este apartado se va a exponer y analizar los datos obtenidos en cada punto para posteriormente discutirlos y compararlos con los obtenidos por otros investigadores. La diferencia entre la serie de aleaciones estudiada y la influencia del contenido de estaño se observa mucho mejor si se estructura este apartado por características o ensayos. De este modo, se ha expuesto las características de las tres aleaciones en conjunto.

\subsection{Ensayos preliminares.}

Dada la gran complejidad que presenta el procesado por pulvimetalurgia y mezcla elemental de polvos y la dificultad de obtener aleaciones con las características requeridas de homogeneidad microestructural se ha llevado a cabo los ensayos necesarios en los que se optimiza el procesado.

\subsubsection{Optimización del tamaño de partícula del polvo.}

En este punto se ha estudiado la técnica de procesado de polvos por mezcla elemental. A pesar de no trabajar con aleaciones de Ti-Nb, se ha trabajado con la aleación Ti 15Mo, los resultados son totalmente extrapolables ya que el niobio y el molibdeno son dos de los 
elementos más betágenos en las aleaciones de titanio. Tampoco influye que se utilice menor porcentaje de molibdeno en comparación al porcentaje de niobio ya que el niobio difunde mucho mejor en el titanio [1].

El mayor inconveniente que se ha encontrado a la hora de obtener materiales válidos ha sido la promoción de la difusión para obtener microestructuras homogéneas derivadas de una composición química homogénea. Para ello el mejor método que se ha encontrado ha sido el de minimizar el tamaño de partícula para maximizar la superficie útil y promover al máximo los procesos de difusión.

Se ha tamizado los polvos metálicos de molibdeno y se ha observado la influencia en la microestructura obtenida. Se ha empezado utilizando los polvos metálicos en estado de recepción. Posteriormente se ha tamizado utilizando distintas luces de malla hasta la luz de malla menor en la que el tamizado se puede realizar en seco y es fácilmente aplicable a la industria.

Tabla 5.1. Aleaciones de Ti 15Mo utilizadas para optimizar el procesado por mezcla elemental de polvos.

\begin{tabular}{|r|l|l|}
\hline \multicolumn{1}{|c|}{ Id. } & Aleación & \multicolumn{1}{c|}{ Procesado del polvo } \\
\hline 15 & \multirow{3}{*}{ Ti 15Mo } & Sin modificar \\
\cline { 1 - 1 } 23 & & Tamizado por debajo de $100 \mu \mathrm{m}$ \\
\cline { 1 - 1 } & & Tamizado por debajo de $25 \mu \mathrm{m}$ \\
\hline
\end{tabular}


Estas aleaciones se han procesado con los mismos parámetros en la etapa de compactación y sinterización. De este modo se obtiene resultados que se pueden comparar fácilmente. Las micrografías obtenidas en cada caso son las siguientes.
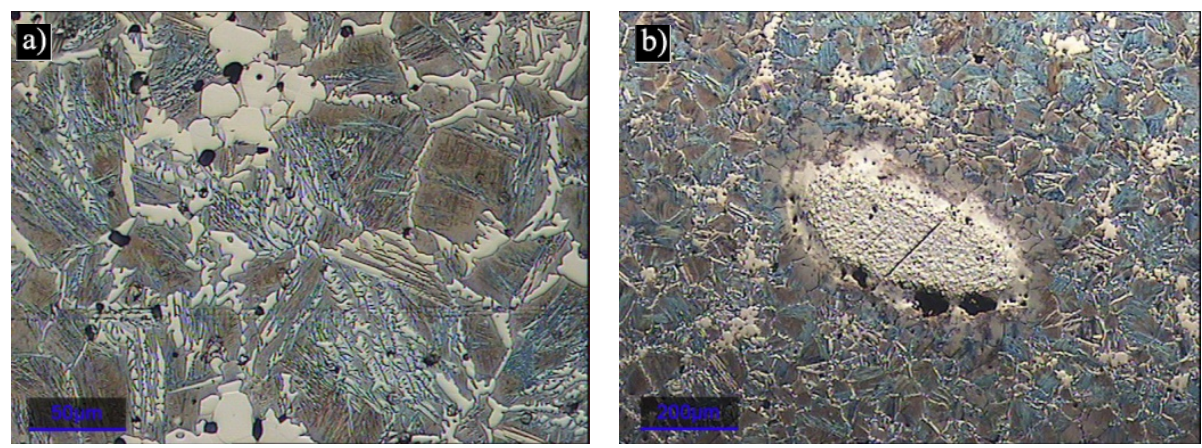

Figura 5.1. a) Microestructura obtenida y b) partícula primitiva de molibdeno sin difundir de la aleación Ti 15Mo sin modificar el polvo de recepción.

La microestructura es en muchas zonas totalmente $\alpha$ y se observa partículas de molibdeno que no han difundido por su gran tamaño. Cuando se tamiza el polvo con un tamiz de luz de malla inferior a 100 $\mu \mathrm{m}$ se observa como la mejoría es notable. 

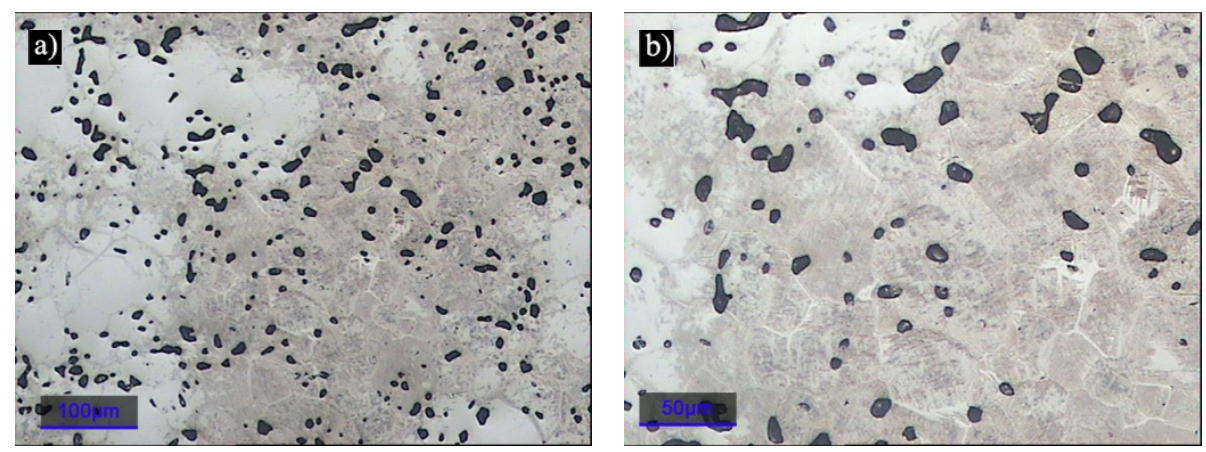

Figura 5.2. Microestructura de la aleación Ti 15Mo con el polvo de molibdeno tamizado $<100 \mu \mathrm{m}$ a pocos aumentos (a) y con mayor nivel de detalle (b).

Para favorecer aun más los procesos de difusión en estado sólido se ha tamizado el polvo de molibdeno por debajo de $25 \mu \mathrm{m}$ y se ha utilizado justo después de tamizarlo para evitar que se apelmace por atracción electrostática entre las partículas.
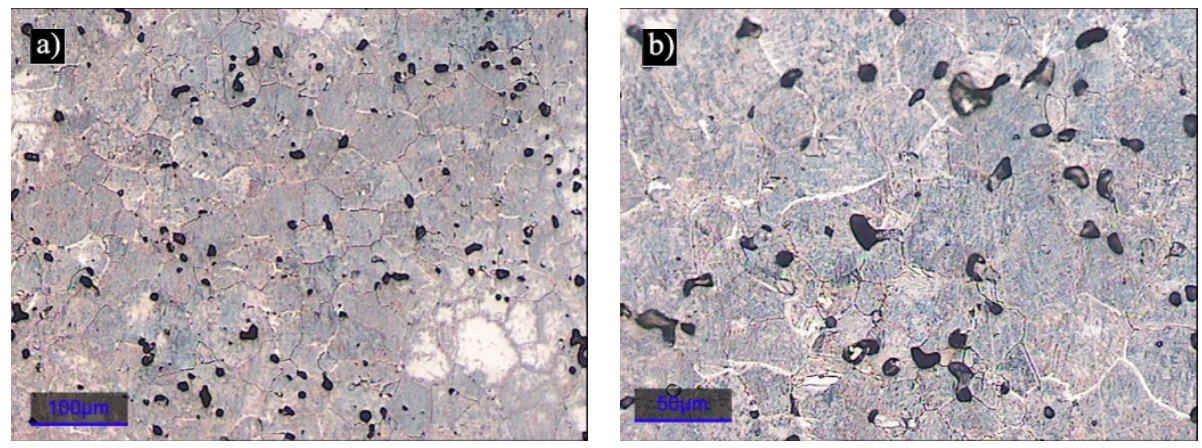

Figura 5.3. a) Microestructura general y b) detalle de los granos de la aleación de Ti 15Mo con el proceso de mezcla elemental de polvos totalmente optimizado.

Se observa que la microestructura es mucho más homogénea y no aparecen partículas primitivas de Mo embebidas dentro del material y que no han difundido. 
Mediante el tamizado por debajo de $25 \mu \mathrm{m}$ se ha podido optimizar el procesado de polvos por mezcla elemental. Se consigue una metodología que garantiza la homogeneidad microestructural de los materiales obtenidos, que como se ha mencionado anteriormente, es uno de los grandes problemas cuando se procesa aleaciones de titanio con elementos estabilizadores de la fase $\beta$ por su carácter refractario y su alto porcentaje dentro de las aleaciones procesadas por pulvimetalurgia y mezcla elemental de polvos.

\subsubsection{Contenido de niobio.}

Posterior a la optimización del procesado por mezcla elemental se ha trabajado sobre el porcentaje mínimo con el que se obtiene microestructura totalmente $\beta$ en la aleación binaria Ti-Nb. Obviamente se ha seguido el protocolo establecido y se ha variado el porcentaje en peso del niobio en fracciones de $5 \%$, desde un 20 hasta un $40 \%$ es decir: Ti 20Nb, Ti 25Nb, Ti 30Nb, Ti 35Nb y Ti 40Nb.

Las imágenes de microscopía óptica obtenidas se muestran en la figura 5.4. 

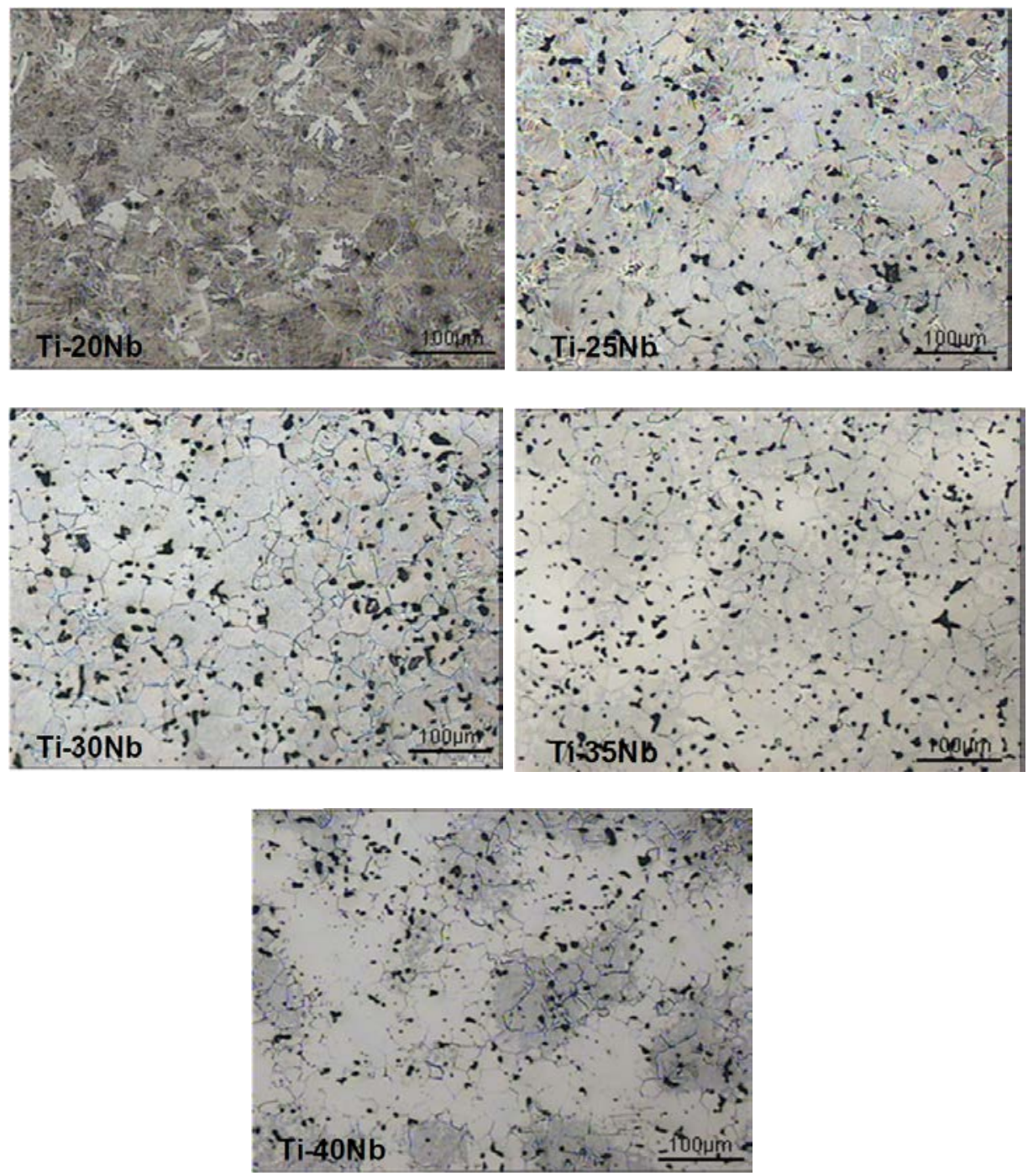

Figura 5.4. Microestructura en función del porcentaje de niobio de aleaciones Ti-Nb.

Se observa como la aleación $\mathrm{Ti} 20 \mathrm{Nb}$ es totalmente $\alpha+\beta$ con estructura lamelar y algunos granos con microestructura tipo $\alpha$. En cambio la aleación Ti 25Nb muestra sólo regiones con microestructura tipo $\alpha+\beta$ lamelar y la mayoría de zonas pertenecen a microestructura 
tipo $\beta$. Con un $30 \%$ de contenido de niobio sólo existen pequeñas zonas en las que aparecen pequeñas lamelas de microestructura $\alpha$ que crecen de forma perpendicular al borde de grano. Las aleaciones $\mathrm{Ti}$ $35 \mathrm{Nb}$ y $\mathrm{Ti} 40 \mathrm{Nb}$ presentan una estructura totalmente $\beta$ pero también aparecen estas zonas con microestructura tipo $\alpha$ al igual que en la aleación Ti 30Nb. Para observar mejor las lamelas y la microestructura en cada caso se muestran imágenes tomados por SEM.
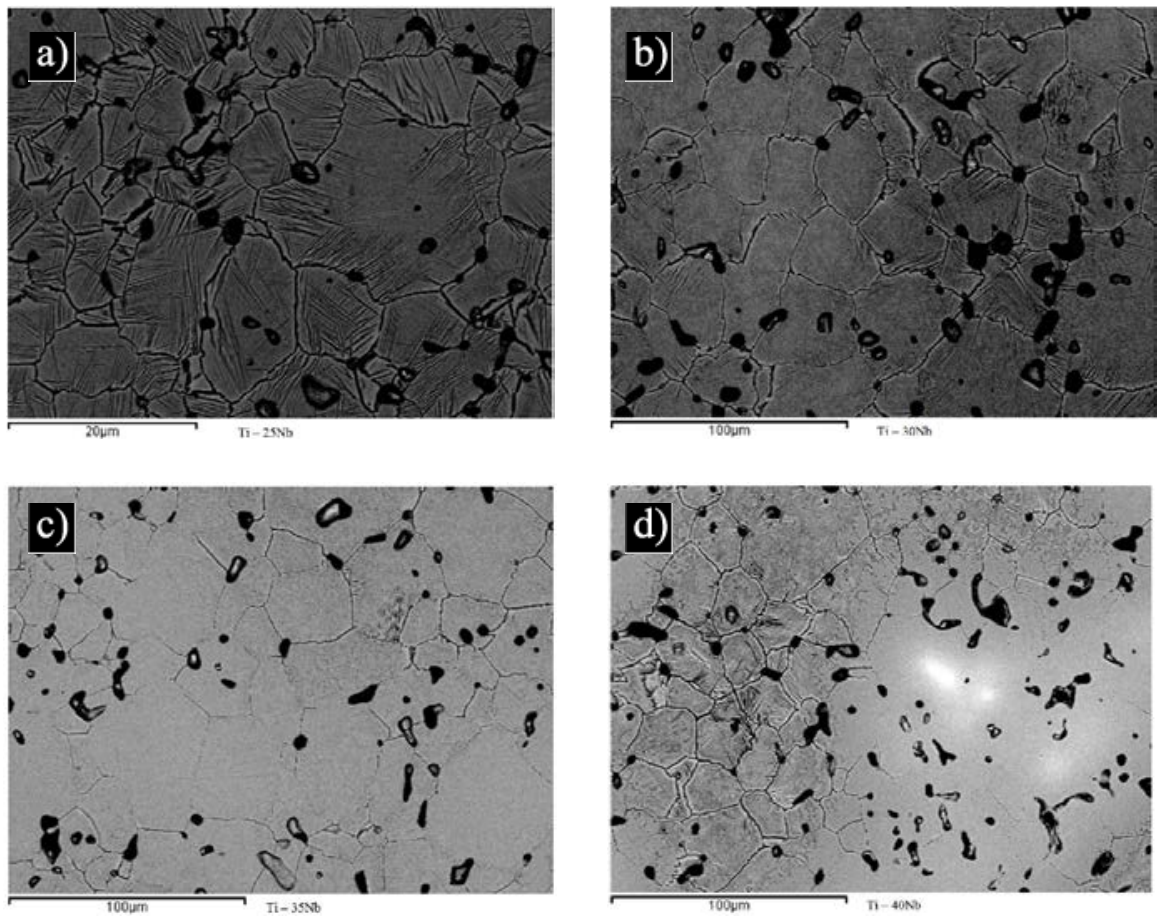

Figura 5.5. Microestructuras de las aleaciones Ti-Nb en función del contenido en niobio: a) Ti 25Nb, b) Ti 30Nb, c) Ti 35Nb y d) $\mathrm{Ti}$ $40 \mathrm{Nb}$. 
Las imágenes de electrones retrodispersados (BS) obtenidas, mediante SEM, muestran muy bien las diferencias composicionales y se observa de forma clara como las lamelas de $\alpha$ sólo aparecen en zonas muy concretas en la aleación Ti 30Nb. En la aleación Ti 40Nb aparecen partículas primitivas de niobio que no han difundido en el titanio debido simplemente a la saturación en el contenido de $\mathrm{Nb}$ en los alrededores de la partícula y al corto tiempo de sinterización, 2 horas.

Se observa un descenso en todas las propiedades mecánicas (resistencia a flexión y módulo elástico) con el aumento del porcentaje de niobio debido a que la microestructura evoluciona desde aleaciones $\alpha+\beta$ hasta aleaciones con microestructura prácticamente $\beta$.

Tabla 5.2. Propiedades de las aleaciones Ti-Nb.

\begin{tabular}{|c|c|c|c|}
\hline Aleación & $\begin{array}{c}\text { Resistencia máxima en } \\
\text { el ensayo de flexión } \\
\text { biaxial (MPa) }\end{array}$ & $\begin{array}{c}\text { Microdureza } \\
\text { (GPa) }\end{array}$ & $\begin{array}{c}\text { Módulo elástico } \\
\text { (GPa) }\end{array}$ \\
\hline Ti $20 \mathrm{Nb}$ & $2238 \pm 172$ & $2.87 \pm 0.21$ & - \\
\hline $\operatorname{Ti} 25 \mathrm{Nb}$ & $1353 \pm 31$ & $2.76 \pm 0.21$ & - \\
\hline $\operatorname{Ti} 30 \mathrm{Nb}$ & $1369 \pm 267$ & $2.82 \pm 0.32$ & $93.46 \pm 3.03$ \\
\hline $\operatorname{Ti} 35 \mathrm{Nb}$ & $1318 \pm 69$ & $2.81 \pm 0.21$ & $89.73 \pm 6.67$ \\
\hline $\operatorname{Ti} 40 \mathrm{Nb}$ & $1046 \pm 82$ & $2.59 \pm 0.29$ & $79.99 \pm 3.67$ \\
\hline
\end{tabular}

Como se observa en la tabla anterior la tensión máxima de las aleaciones Ti-Nb se ha obtenido mediante el ensayo de flexión biaxial. Este ensayo está orientado a materiales que no presentan deformación y con mucha fragilidad, como los materiales cerámicos. Al intentar aplicarlo a las aleaciones estudiadas se ha observado que no es un ensayo valido ya que la deformación en la zona de contacto en los 110 
apoyos aparece una deformación excesiva debida a la plasticidad del material.

También se observa en la tabla anterior como las propiedades resistentes de las aleaciones con mayores contenidos de niobio son menores que las aleaciones con porcentajes menores de $\mathrm{Nb}$ debido a la evolución en la microestructura. Esta misma evolución también se observa con el módulo elástico en las aleaciones con microestructura $\beta$.

En resumen, se consigue obtener aleaciones Ti-Nb con microestructura prácticamente $\beta$, sólo con pequeñas lamelas de microestructura $\alpha$ que crecen perpendiculares al borde de grano a partir de la adición de un 30 \% de niobio. De este modo se mejoran las propiedades en servicio del material cuando trabaja como biomaterial ya que, sobre todo, el módulo elástico de las aleaciones Ti $\beta$ es menor y se minimiza el efecto del apantallamiento de tensiones. Por otro lado el ensayo de flexión biaxial no es representativo debido a la deformación excesiva sufrida por el material en el contacto con los apoyos.

Estos ensayos previos han desembocado en una publicación en la Revista de Metalurgia, vol. 46; No extraordinario, 19-25, 2010. ISSN: 0034-8570; eISSN: 1988-4222, titulado “Caracterización mecánica de aleaciones Ti-Nb mediante ensayos de flexión biaxial”. 


\subsubsection{Parámetros de sinterizado.}

Se ha realizado distintas pruebas y estudios en la fase de sinterizado para obtener aún mayor homogeneidad y evitar, en todo lo posible, consecuencias contraproducentes como, por ejemplo, un crecimiento de grano excesivo.

Para mejorar dicho punto se ha trabajado con una temperatura de sinterización fijada con anterioridad y se ha variado el tiempo de sinterización. Todos las investigaciones anteriores se habían realizado con 2 horas como tiempo fijo de sinterizado. Dicho tiempo se propone como el tiempo mínimo para obtener una sinterización completa y con buenos valores de homogeneidad.

Trabajando ya con la tripla de aleaciones que centran este estudio: $\mathrm{Ti}$ $30 \mathrm{Nb}$, Ti $30 \mathrm{Nb} 2 \mathrm{Sn}$ y Ti $30 \mathrm{Nb} 4 \mathrm{Sn}$ se ha realizado sinterizaciones a 2 horas y 4 horas de tiempo de permanencia a la temperatura de sinterizado, $1250{ }^{\circ} \mathrm{C}$. La utilización de tiempos mayores de 4 horas de sinterización no se contempla porque el crecimiento del tamaño de grano sería excesivo.

Se ha observado la homogeneidad composicional y las posibles consecuencias en otros parámetros como el tamaño de grano o el tamaño y distribución de la porosidad. En la figura 5.6 se observa la microestructura de las aleaciones obtenidas, en la primera columna 
sinterizadas durante 2 horas y en la segunda columna sinterizadas durante 4 horas.
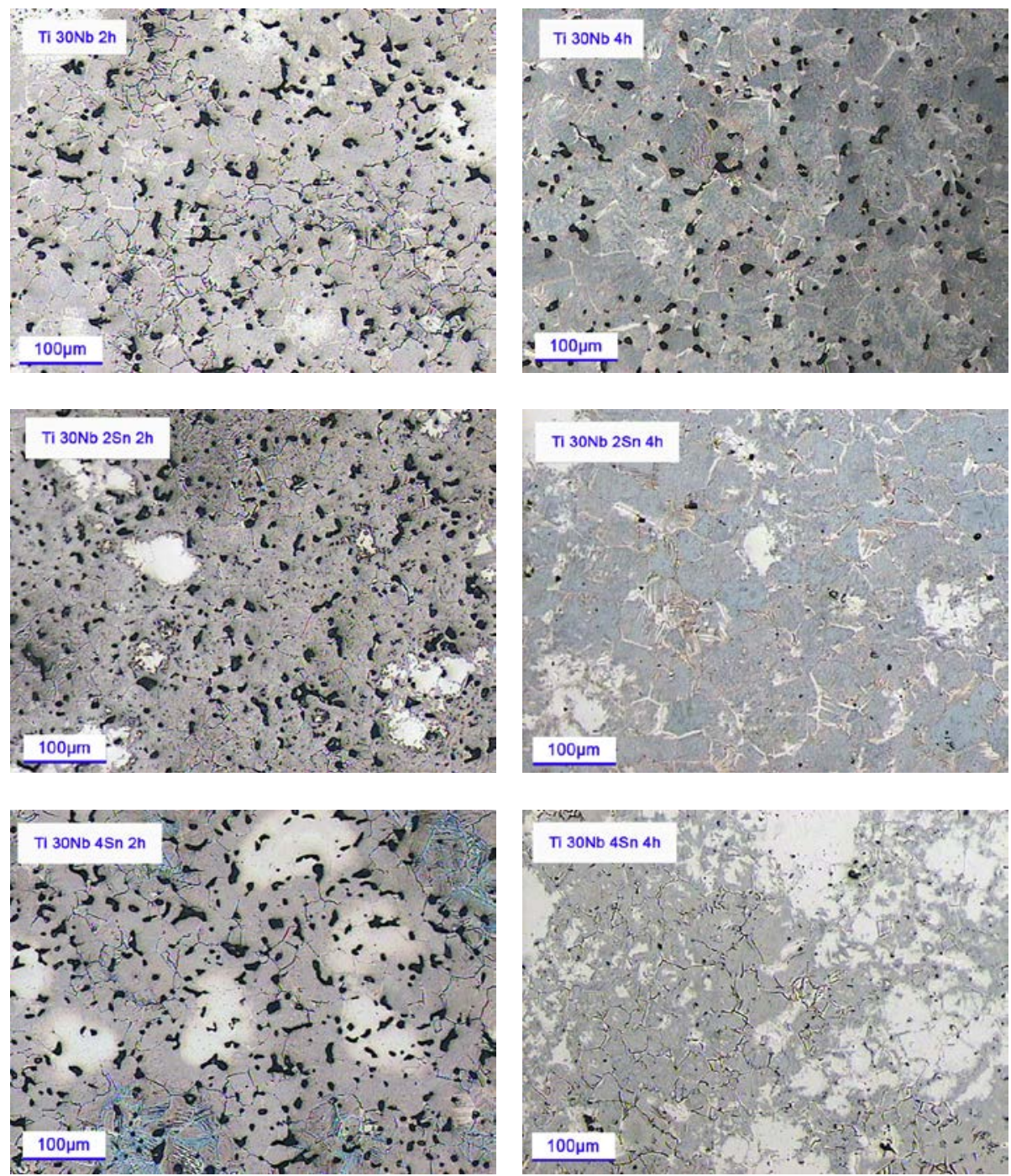

Figura 5.6. Ti 30Nb, Ti 30Nb $2 \mathrm{Sn}$ y Ti $30 \mathrm{Nb} 4 \mathrm{Sn}$ sinterizado durante 2 y 4 horas. 
La homogeneidad es mucho mayor y, a priori, el tamaño de grano no ha crecido de forma exagerada. La homogeneidad de las muestras se observa mucho mejor en las imágenes de SEM tomadas mediante BS de la siguiente figura.
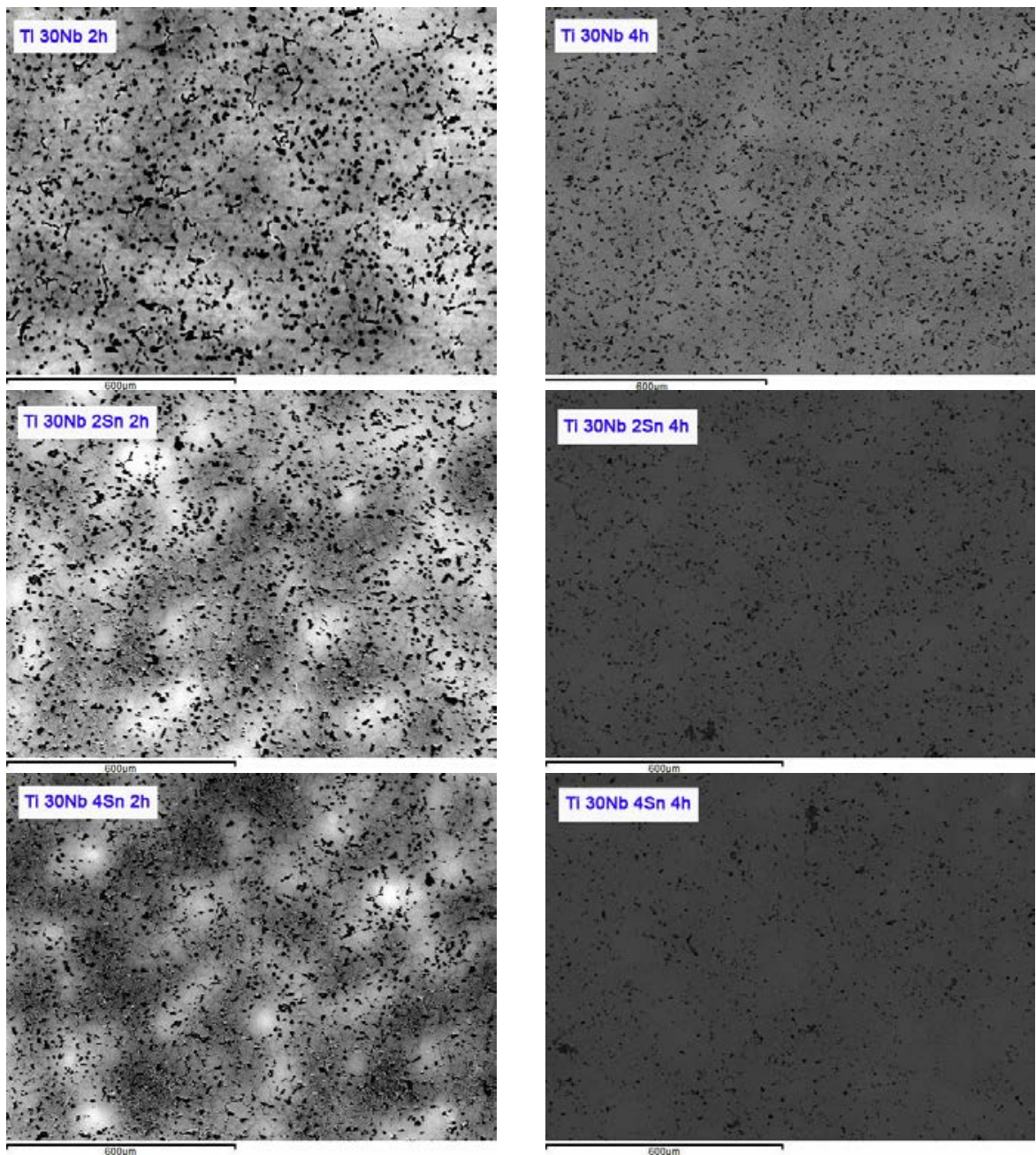

Figura 5.7. Imágenes de la homogeneidad composicional tomado mediante SEM con la técnica de BS de las aleaciones estudiadas. 
Observada la notable mejoría en cuanto a homogeneidad composicional y en consecuencia microestructural se procede a caracterizar las aleaciones con los distintos tiempos de sinterizado para cuantificar la influencia en cada parámetro. Una primera aproximación es la variación en cuanto a parámetros antes y después del sinterizado como son la densidad en verde $\mathrm{y}$ después de sinterizado, con su correspondiente contracción volumétrica asociada a la sinterización.

Tabla 5.3. Parámetros de densidad antes y después de sinterizado y contracción asociada.

\begin{tabular}{|c|c|c|c|c|c|c|}
\hline \multirow[b]{2}{*}{ Aleación } & \multirow[b]{2}{*}{$\begin{array}{c}\text { Tiempo de } \\
\text { sinterizado (h.) }\end{array}$} & \multirow[b]{2}{*}{$\begin{array}{c}\text { Contracción } \\
\text { volum étrica }(\%)\end{array}$} & \multicolumn{4}{|c|}{ Densidad } \\
\hline & & & $\begin{array}{l}\text { Verde } \\
\left(\mathrm{g} / \mathrm{cm}^{3}\right)\end{array}$ & $\begin{array}{c}\text { Relativa } \\
\text { en verde } \\
(\%)\end{array}$ & $\begin{array}{c}\text { Final } \\
\left(\mathrm{g} / \mathrm{cm}^{3}\right)\end{array}$ & $\begin{array}{l}\text { Relativa } \\
\text { final }(\%)\end{array}$ \\
\hline \multirow{2}{*}{$\mathrm{Ti} 30 \mathrm{Nb}$} & 2 & 13.78 & \multirow{2}{*}{$4.32 \pm 0.01$} & \multirow{2}{*}{82} & $4.82 \pm 0.04$ & 91 \\
\hline & 4 & 13.45 & & & $4.97 \pm 0.02$ & 95 \\
\hline \multirow{2}{*}{$\mathrm{Ti} 30 \mathrm{Nb} 2 \mathrm{Sn}$} & 2 & 12.29 & \multirow{2}{*}{$4.21 \pm 0.03$} & \multirow{2}{*}{79} & $4.78 \pm 0.03$ & 90 \\
\hline & 4 & 13.01 & & & $4.84 \pm 0.02$ & 91 \\
\hline \multirow{2}{*}{$\mathrm{Ti} 30 \mathrm{Nb} 4 \mathrm{Sn}$} & 2 & 13.19 & \multirow{2}{*}{$4.45 \pm 0.01$} & \multirow{2}{*}{83} & $4.71 \pm 0.02$ & 88 \\
\hline & 4 & 12.04 & & & $5.01 \pm 0.05$ & 94 \\
\hline
\end{tabular}

La densidad relativa está referida a la teórica según la fórmula siguiente (5.1).

$$
\rho_{\text {Teórica }}=\frac{m_{\text {Total }}}{\left(\frac{m_{T i}}{\rho_{T i}}\right)+\left(\frac{m_{N b}}{\rho_{N b}}\right)+\left(\frac{m_{S n}}{\rho_{S n}}\right)}
$$


Donde $\mathrm{m}_{\text {total }}$ es la masa total de la aleación, $\mathrm{m}_{\mathrm{Ti}}, \mathrm{m}_{\mathrm{Nb}} \mathrm{y} \mathrm{m}_{\mathrm{Sn}}$ la masa de titanio, niobio y estaño respectivamente y $\rho_{\mathrm{Ti}}, \rho_{\mathrm{Nb}}$ y $\rho_{\mathrm{Sn}}$ la densidad del titanio, niobio y estaño respectivamente.

Los valores de contracción son muy parecidos, rondando el $13 \%$, pero no existe diferencia asociada al tiempo de sinterización. La densidad antes de sinterizado, en verde, evidentemente es la misma y se observa un ligero aumento en la densidad final conseguida con tiempos de sinterizado mayores.

En cuanto a la porosidad la tabla siguiente muestra como las variaciones son leves entre composiciones pero entre los distintos tiempos son algo mayores lo que justifica la mayor densidad final alcanzada. Cuanto mayor es el tiempo de sinterizado menor es la porosidad y el tamaño del poro.

Tabla 5.4. Porosidad de las aleaciones Ti 30Nb XSn con distintos tiempos de sinterizado.

\begin{tabular}{|l|c|c|c|}
\hline \multirow{2}{*}{ Aleación } & $\begin{array}{c}\text { Tiempo de } \\
\text { sinterizado (h.) }\end{array}$ & Porosidad (\%) & $\begin{array}{c}\text { Diám etro equivalente } \\
\text { de poro }(\boldsymbol{\mu m})\end{array}$ \\
\hline \multirow{2}{*}{$\mathrm{Ti} 30 \mathrm{Nb}$} & 2 & $7.13 \pm 1.10$ & $9.07 \pm 0.48$ \\
\cline { 2 - 4 } & 4 & $6.81 \pm 0.86$ & $8.86 \pm 0.36$ \\
\hline \multirow{2}{*}{$\mathrm{Ti} 30 \mathrm{Nb} 2 \mathrm{Sn}$} & 2 & $7.22 \pm 0.65$ & $9.28 \pm 0.42$ \\
\cline { 2 - 4 } & 4 & $6.98 \pm 0.32$ & $6.65 \pm 0.23$ \\
\hline \multirow{2}{*}{$\mathrm{Ti} 30 \mathrm{Nb} 4 \mathrm{Sn}$} & 2 & $10.15 \pm 0.98$ & $9.55 \pm 0.41$ \\
\cline { 2 - 4 } & 4 & $5.90 \pm 1.03$ & $5.84 \pm 0.41$ \\
\hline
\end{tabular}

La porosidad de las muestras se ha medido con las muestras en estado de pulido, sin ataque químico y se ha utilizado un programa de 
tratamiento de imagen. Este programa binariza las imágenes para hacer un recuento de material-poro. De este modo, se comete menor error en la medida si la muestra está sin atacar ya que la imagen es más homogénea y está mejor definido el borde del poro.

Las imágenes con las que se ha trabajado son como la que se muestra en la siguiente figura.

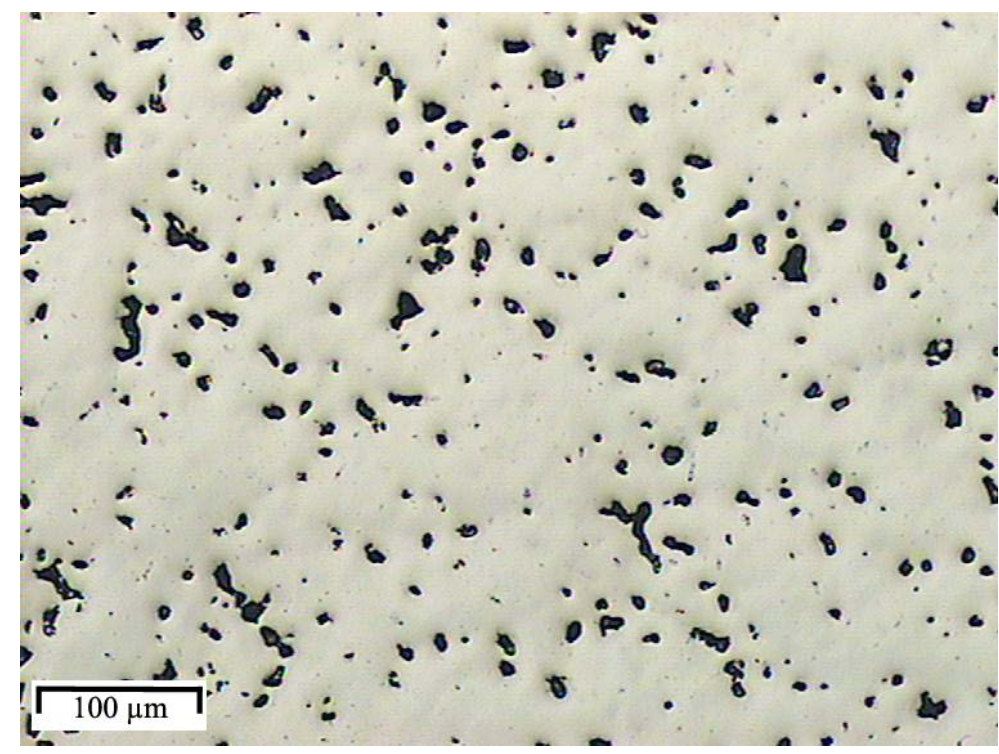

Figura 5.8. Imagen de la aleación Ti 30Nb para obtener la porosidad.

Posteriormente se muestra la misma imagen pero con la binarización ya realizada. En color rojo aparecen los pixeles que se cuentan como poro. Posteriormente se realiza un recuento automático de los pixeles coloreados y los que no, obteniendo el porcentaje de porosidad. 


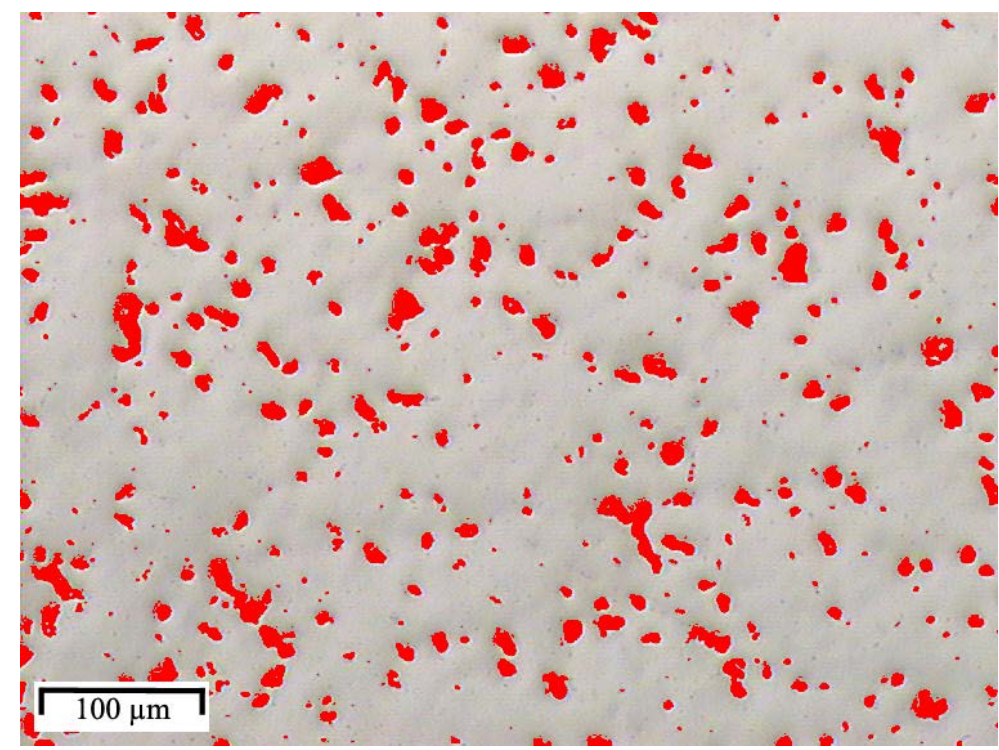

Figura 5.9. Imagen de la aleación Ti 30Nb con la binarización y el recuento de pixeles de poros para obtener la porosidad.

Se ha utilizado esta metodología para medir la porosidad ya que es la más sencilla y el error que se comente con respecto a otras técnicas es pequeño, como se comprobó en investigaciones anteriores y como han expuesto otros autores [2]. Además esta técnica se complementa con la obtención del diámetro equivalente del poro. Este dato de diámetro equivalente del poro ofrece una idea clara del tamaño de poro y referencia dicho tamaño al de un círculo perfecto. Es una aproximación muy buena a pesar de estar midiendo la porosidad en un plano, dos dimensiones, y no en volumen, o 3 dimensiones, ya que los poros tienen forma esférica en su mayoría o muy redondeada. En la tabla anterior también se muestra los resultados obtenidos de porosidad. 
Por último se ha medido el tamaño de grano, observando un aumento importante pero queda compensado su efecto por la mejor homogeneidad química y microestructural mostrada en las imágenes de SEM, figura 5.7.

Tabla 5.5. Tamaño de grano de las aleaciones sinterizadas 2 y 4 horas.

\begin{tabular}{|c|c|c|}
\hline Aleación & $\begin{array}{c}\text { Tiempo de } \\
\text { sinterizado (h.) }\end{array}$ & 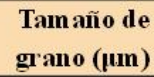 \\
\hline \multirow{2}{*}{$\mathrm{Ti} 30 \mathrm{Nb}$} & 2 & $35.07 \pm 0.79$ \\
\hline & 4 & $53.35 \pm 1.10$ \\
\hline \multirow{2}{*}{$\mathrm{Ti} 30 \mathrm{Nb} 2 \mathrm{Sn}$} & 2 & $37.02 \pm 0.90$ \\
\hline & 4 & $50.08 \pm 0.85$ \\
\hline \multirow{2}{*}{$\mathrm{Ti} 30 \mathrm{Nb} 4 \mathrm{Sn}$} & 2 & $40.15 \pm 0.77$ \\
\hline & 4 & $49.99 \pm 1.17$ \\
\hline
\end{tabular}

Se ha podido aumentar de manera significativa la homogeneidad química de las aleaciones y en consecuencia la homogeneidad microestructural optimizando la etapa de sinterizado dentro del procesado por pulvimetalurgia. De esta forma se ha conseguido una hoja de ruta en la que se procesan las aleaciones $\mathrm{Ti} 30 \mathrm{Nb}$, Ti 30Nb 2Sn y Ti 30Nb 4Sn obteniendo materiales totalmente homogéneos en los que se puede estudiar de forma clara la influencia del estaño en las propiedades microestructurales, propiedades mecánicas y su comportamiento a corrosión y tribocorrosión.

Estos resultados del estudio de la influencia de los parámetros de la sinterización en las características de las aleaciones Ti 30Nb XSn se han publicado en la revista indexada Materials Science Forum Vols. 727-728 (2012) pp 61-66, cuyo título es "Processing and 
characterization of $\beta$-Ti alloys by means of powder metallurgy processing and blender elemental".

\subsubsection{Análisis ensayos preliminares.}

En la optimización del tamaño del polvo se ha conseguido optimizar el procesado mediante mezcla elemental de polvos para maximizar la homogeneidad de las aleaciones. Para aumentar dicha homogeneidad se ha promovido la mejor difusión de las partículas de elemento aleante minimizando el tamaño de partícula. De esta forma la superficie activa es mucho mayor.

En consecuencia se ha podido obtener un protocolo de acción para maximizar la homogeneidad microestructural. Los pasos de esta hoja de ruta son los siguientes:

- Tamizar el polvo por debajo de $25 \mu \mathrm{m}$ del elemento aleante.

- Mezclar el polvo inmediatamente después de tamizarlo para evitar que se apelmace.

- Utilizar tiempos muy largos en la túrbula para homogeneizar la distribución, justo antes de la compactación para evitar la estratificación por diferencia de densidades.

En segundo lugar se ha obtenido que para el procesado seguido de pulvimetalurgia convencional y mezcla elemental de polvos el contenido mínimo de niobio para que la microestructura sea 
mayoritariamente $\beta$ es del $30 \%$. La aleación Ti $30 \mathrm{Nb}$ muestra una microestructura totalmente $\beta$ a excepción de pequeñas lamelas de microestructura $\alpha$ formadas perpendicularmente al borde de grano.

Las propiedades mecánicas de las aleaciones Ti-Nb descienden de forma notable con el aumento del porcentaje de niobio debido al cambio microestructural que se aprecia. Las aleaciones varían de microestructura $\alpha+\beta$ hasta microestructura $\beta$.

Tabla 5.6. Propiedades físicas de las aleaciones Ti 30Nb XSn sinterizadas durante 4 horas.

\begin{tabular}{|l|c|c|c|c|c|}
\hline \multirow{2}{*}{ Aleación } & \multirow{2}{*}{$\begin{array}{c}\text { Contracción } \\
\text { volum étrica (\%) }\end{array}$} & $\begin{array}{c}\text { Verde } \\
\left(\mathbf{g} / \mathbf{c m}^{\mathbf{3}}\right)\end{array}$ & $\begin{array}{c}\text { Relativa } \\
\text { en verde } \\
(\mathbf{\%})\end{array}$ & $\begin{array}{c}\text { Final } \\
\left(\mathbf{g} / \mathbf{c m}^{\mathbf{3}}\right)\end{array}$ & $\begin{array}{c}\text { Relativa } \\
\text { final (\%) }\end{array}$ \\
\cline { 3 - 6 } & 13.45 & $4.32 \pm 0.01$ & 82 & $4.97 \pm 0.02$ & 95 \\
\hline Ti $30 \mathrm{Nb}$ & 13.01 & $4.21 \pm 0.03$ & 79 & $4.84 \pm 0.02$ & 91 \\
\hline Ti $30 \mathrm{Nb} 2 \mathrm{Sn}$ & 12.04 & $4.45 \pm 0.01$ & 83 & $5.01 \pm 0.05$ & 94 \\
\hline Ti $30 \mathrm{Nb} 4 \mathrm{Sn}$ & &
\end{tabular}

\begin{tabular}{|c|c|c|c|}
\hline Aleación & $\begin{array}{l}\text { Tam año de } \\
\text { grano (ןum) }\end{array}$ & $\begin{array}{c}\text { Porosidad } \\
(\%)\end{array}$ & $\begin{array}{c}\text { Diám etro } \\
\text { equivalente de } \\
\text { poro ( } 1 \text { um) }\end{array}$ \\
\hline $\mathrm{Ti} 30 \mathrm{Nb}$ & $53.35 \pm 1.10$ & $6.81 \pm 0.86$ & $8.86 \pm 0.36$ \\
\hline $\mathrm{Ti} 30 \mathrm{Nb} 2 \mathrm{Sn}$ & $50.08 \pm 0.85$ & $6.98 \pm 0.32$ & $6.65 \pm 0.23$ \\
\hline $\mathrm{Ti} 30 \mathrm{Nb} 4 \mathrm{Sn}$ & $49.99 \pm 1.17$ & $5.90 \pm 1.03$ & $5.84 \pm 0.41$ \\
\hline
\end{tabular}

Por último, los mayores niveles de homogeneidad microestructural se consiguen con tiempos de sinterizado largos, 4 horas. También se consigue que el tamaño de grano no crezca en exceso ya que se dificulta su crecimiento porque los bordes de grano se anclan a los poros, por este motivo se observa la mayoría de poros en los bordes de grano. En la tabla 5.6 se muestran las propiedades intrínsecas del 
procesado por pulvimetalurgia convencional y mezcla elemental de polvos de las aleaciones obtenidas sinterizadas durante 4 horas.

La densidad final alcanzada por la aleación Ti 30Nb 2Sn es menor que las demás debido a su mayor porosidad, a pesar que el tamaño de dichos poros es menor que la aleación sin estaño. La contracción es muy alta en todos los casos por los procesos de difusión que se llevan a cabo en el sinterizado. Esto conlleva una gran diferencia entre la densidad en verde y la densidad final. Pese a esto, en todos los casos se consiguen densidades finales muy altas.

\subsection{Caracterización microestructural de las aleaciones Ti-30Nb-XSn.}

El contenido de nitrógeno y, sobre todo, de oxígeno es uno de los factores influyentes en las aleaciones de titanio que se han caracterizado en este proyecto ya que fragiliza su comportamiento. En la tabla 5.7 se puede ver la evolución del contenido de oxígeno y nitrógeno después de procesar las piezas de trabajo. 
Tabla 5.7. Contenido de oxígeno y nitrógeno de las aleaciones después del procesado.

\begin{tabular}{|c|c|c|}
\hline Aleación & $\mathbf{O}(\%)$ & $\mathbf{N}(\%)$ \\
\hline Ti 30Nb & $0.516 \pm 0.014$ & $0.029 \pm 0.002$ \\
\hline Ti 30Nb 2Sn & $0.516 \pm 0.004$ & $0.030 \pm 0.002$ \\
\hline Ti 30Nb 4Sn & $0.550 \pm 0.011$ & $0.026 \pm 0.002$ \\
\hline
\end{tabular}

En primer lugar cabe destacar que el valor de oxígeno presente en todas las aleaciones al finalizar el procesado es exageradamente alto. Debido sobre todo al oxígeno presente en el polvo de partida. El polvo de titanio de partida, suministrado por se-jong materials, contiene un 0.362 (wt. \%). Al finalizar el procesado se ha conseguido que el contenido en oxígeno este en torno al $0.5 \%$ por lo que sólo se ha incrementado en un $0.2 \%$ durante todo el procesado, pero esto significa un aumento del $50 \%$.

\subsubsection{Imágenes de microscopía óptica.}

A continuación se muestran las imágenes de las tres aleaciones estudiadas atacadas con reactivo de Kroll, se observa cómo debido a la heterogeneidad en la composición ha habido una heterogeneidad del ataque. Las imágenes de la aleación Ti 30Nb son las que se muestran a continuación. La figura 5.10 muestra la microestructura de toda el área central de la probeta de compresión. En la figura 5.11 se puede observar dos capturas generales a bajos aumentos. 


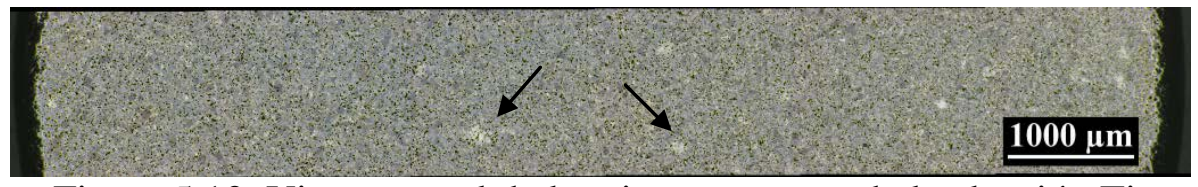

Figura 5.10. Vista general de la microestructura de la aleación Ti 30Nb de la sección transversal de la probeta de compresión.
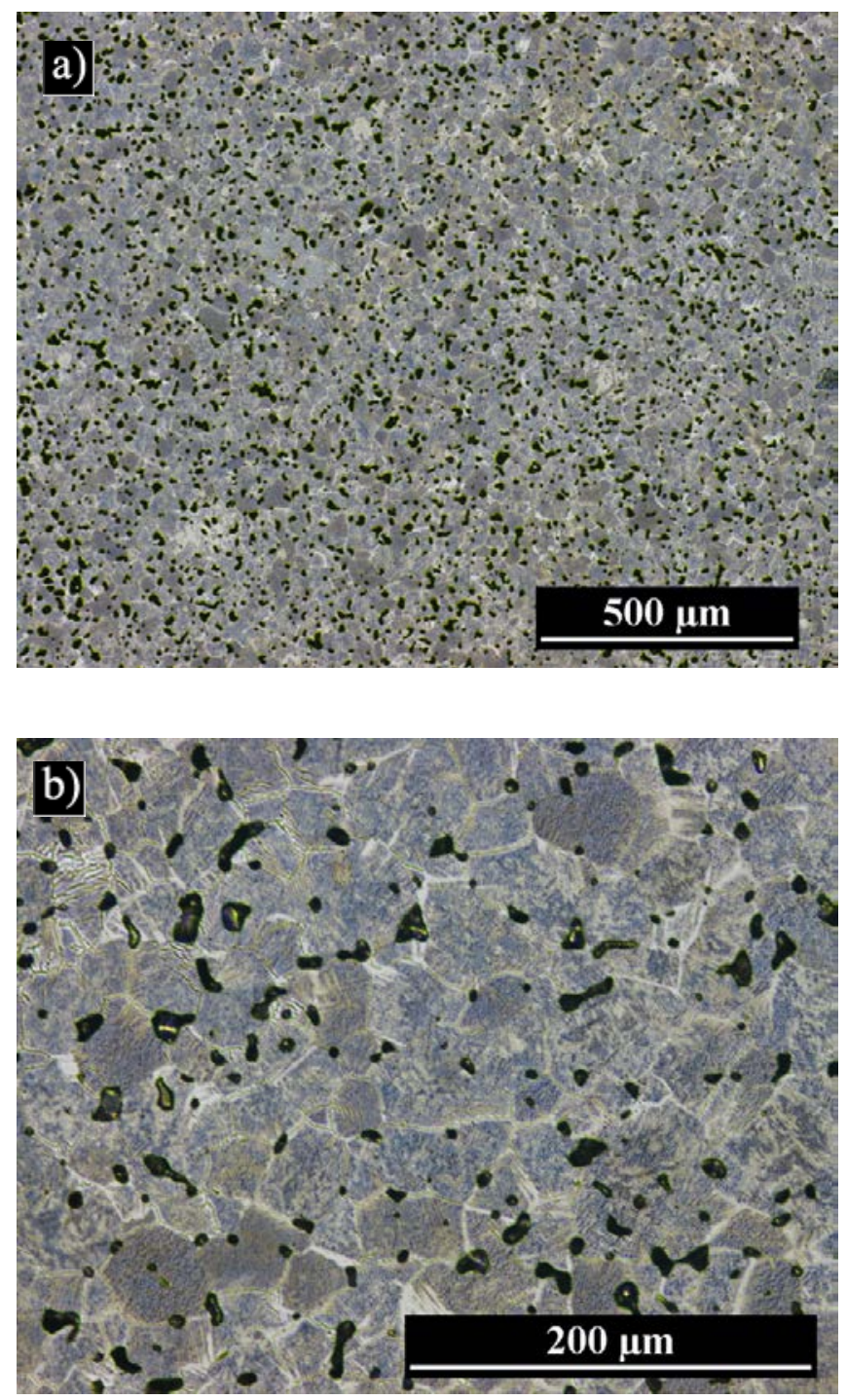

Figura 5.11. Vista general (a) y detalle (b) de la microestructura de la aleación $\mathrm{Ti} 30 \mathrm{Nb}$. 
Se puede observar estas zonas más claras donde hay una falta de ataque químico debido a la heterogeneidad composicional. Se ha comprobado que si se incrementa el tiempo del ataque químico con el reactivo estas zonas muestran las mismas características que se observa en las otras regiones de la aleación, pero se produce un efecto de sobreataque en las regiones que antes se revela la microestructura.

En la figura 5.12 se observa dos capturas de la zona lamelar: en la primera imagen a) los detalles de las distintas zonas de microestructura $\alpha+\beta$ y en la segunda imagen b) la zona con microestructura $\alpha+\beta$ a mayores aumentos donde se aprecian las lamelas de $\alpha+\beta$ perpendiculares al borde de grano. Se puede ver en el centro del grano que la microestructura es totalmente $\beta$.
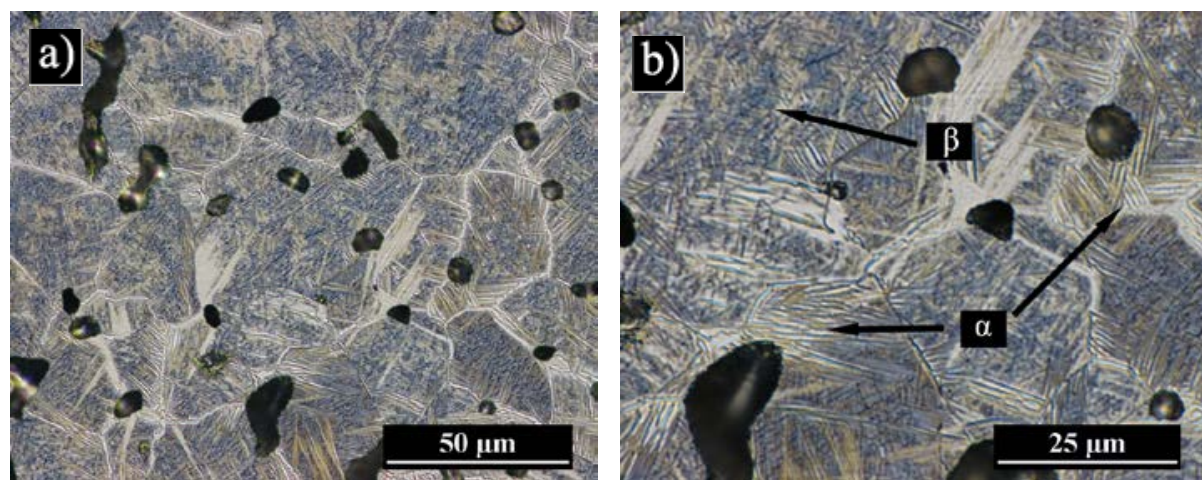

Figura 5.12. Detalles de la microestructura (a) y de las lamelas de $\alpha$ y $\beta$ (b) de la aleación Ti 30Nb. 
Se puede observar como la fase $\alpha$ se acumula en el borde de grano y crece desde la frontera hasta el interior del grano en forma de láminas formando lamelas de $\alpha+\beta$.

La microestructura de la aleación Ti 30Nb 2Sn retiene mucho más la fase $\beta$. No aparece tanto crecimiento de láminas de $\alpha$ hacia el centro del grano desde las fronteras. En la figura 5.13 se observa toda la sección transversal de la probeta de compresión en la que se aprecia las pequeñas diferencias en el ataque químico que ya aparecían en la aleación sin estaño. Aparecen zonas donde el ataque químico ha sido menos severo. En la figura 5.14 se puede observar con más detalle la visión general de la microestructura mediante dos capturas.

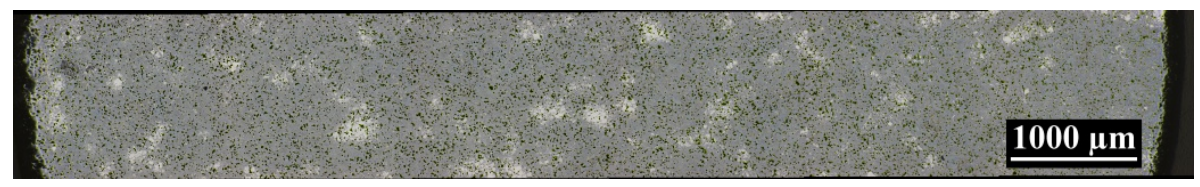

Figura 5.13. Microestructura de la aleación Ti 30Nb 2Sn de la sección transversal de la probeta de compresión. 

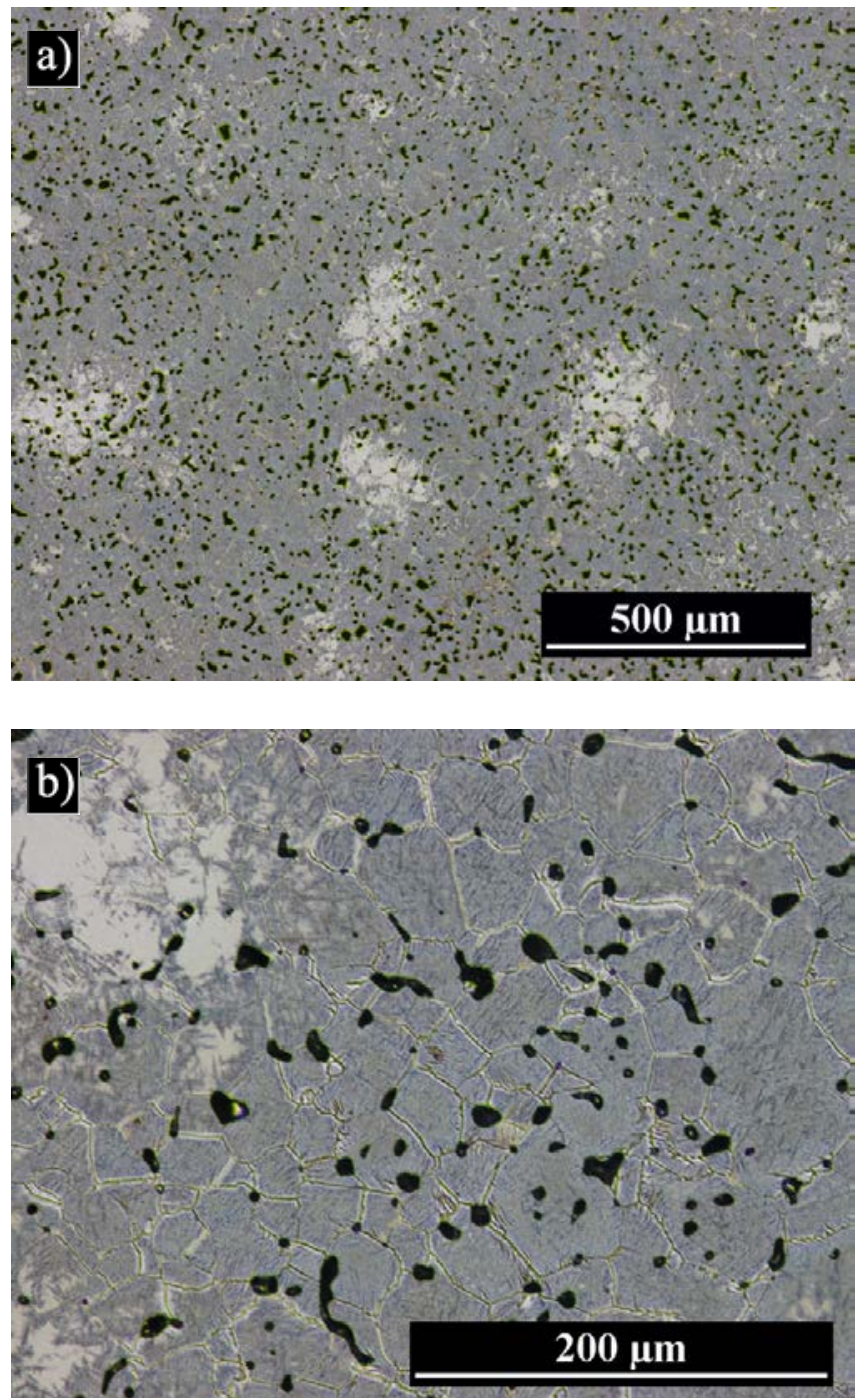

Figura 5.14. Plano general (a) y detalle con mayor magnificación (b) de la microestructura de la aleación Ti 30Nb 2Sn.

Se observa como las zonas claras son mayores. En análisis posteriores se muestra que no existen diferencias en cuanto a composición entre las zonas claras y las zonas más atacadas. En cambio sí que existen 
diferencias composicionales entre las zonas con microestructura lamelar y microestructura totalmente $\beta$.

En las imágenes de detalle de la figura 5.15 se muestran estas zonas donde el ataque químico ha sido menos severo.
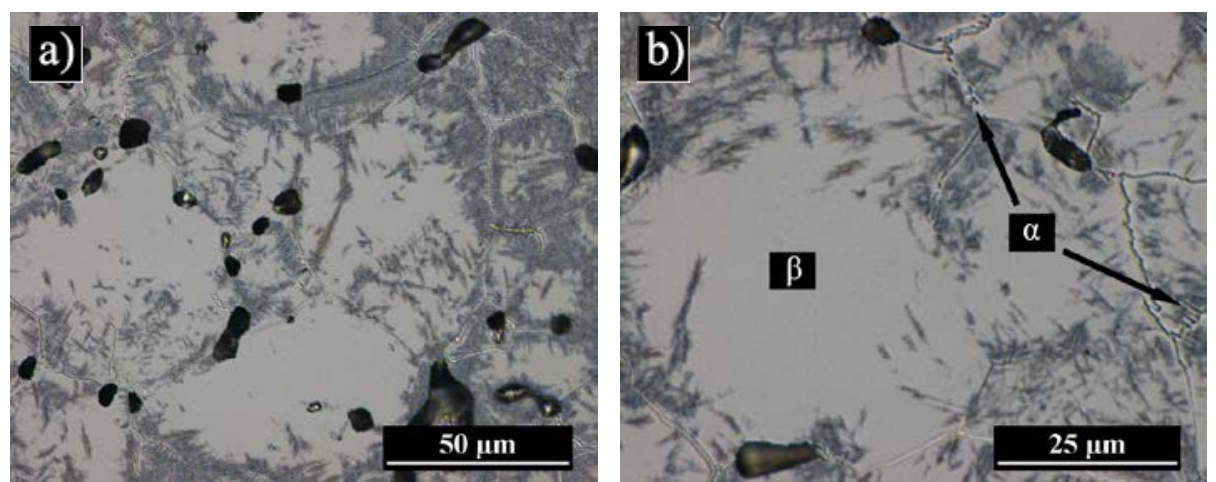

Figura 5.15 Detalle de la microestructura (a) y zonas de detalle con microestructura $\alpha$ y microestructura $\beta$ (b) de la aleación Ti 30Nb 2Sn en la zona menos atacada.

En la figura 5.16 las zonas más atacadas. A pesar de estas diferencias la microestructura es la misma aunque en las zonas más oscuras la presencia de la fase $\alpha$ es ligeramente mayor. 

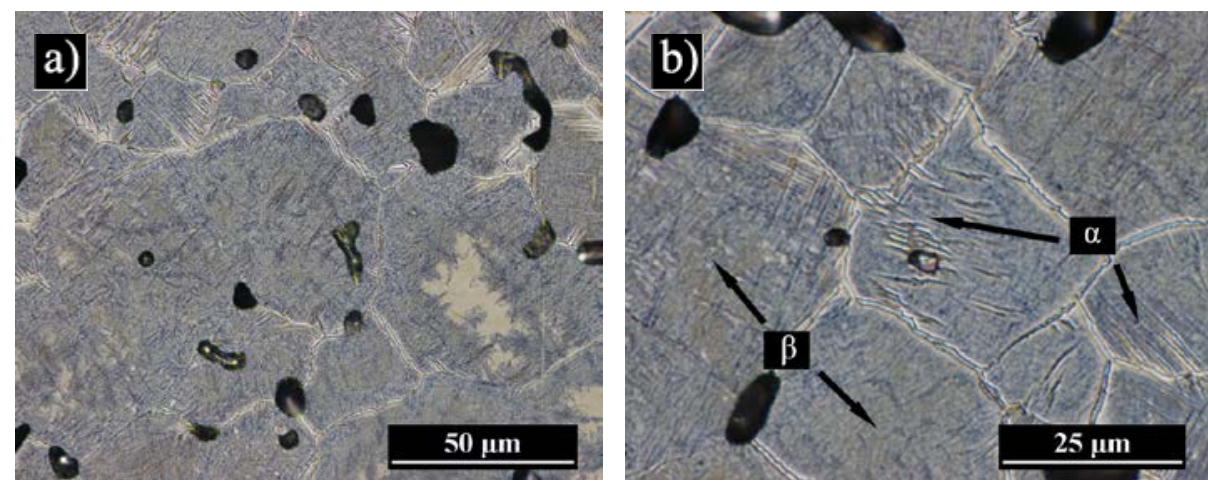

Figura 5.16. Detalles de la microestructura (a) y diferenciación de la microestructura $\alpha$ y microestructura $\beta$ (b) de la zona más atacada en la aleación Ti 30Nb 2Sn.

Por último, en la aleación con mayor cantidad de estaño, Ti 30Nb 4Sn se acentúan las diferencias en el ataque químico. La formación de laminas de microestructura tipo $\alpha$ es mucho menor. La diferencia en el ataque se observa muy bien en la sección transversal de la probeta de compresión, figura 5.17.

\section{$1000 \mu \mathrm{m}$}

Figura 5.17. Sección transversal de la probeta de tracción de la aleación Ti 30Nb 4Sn. 

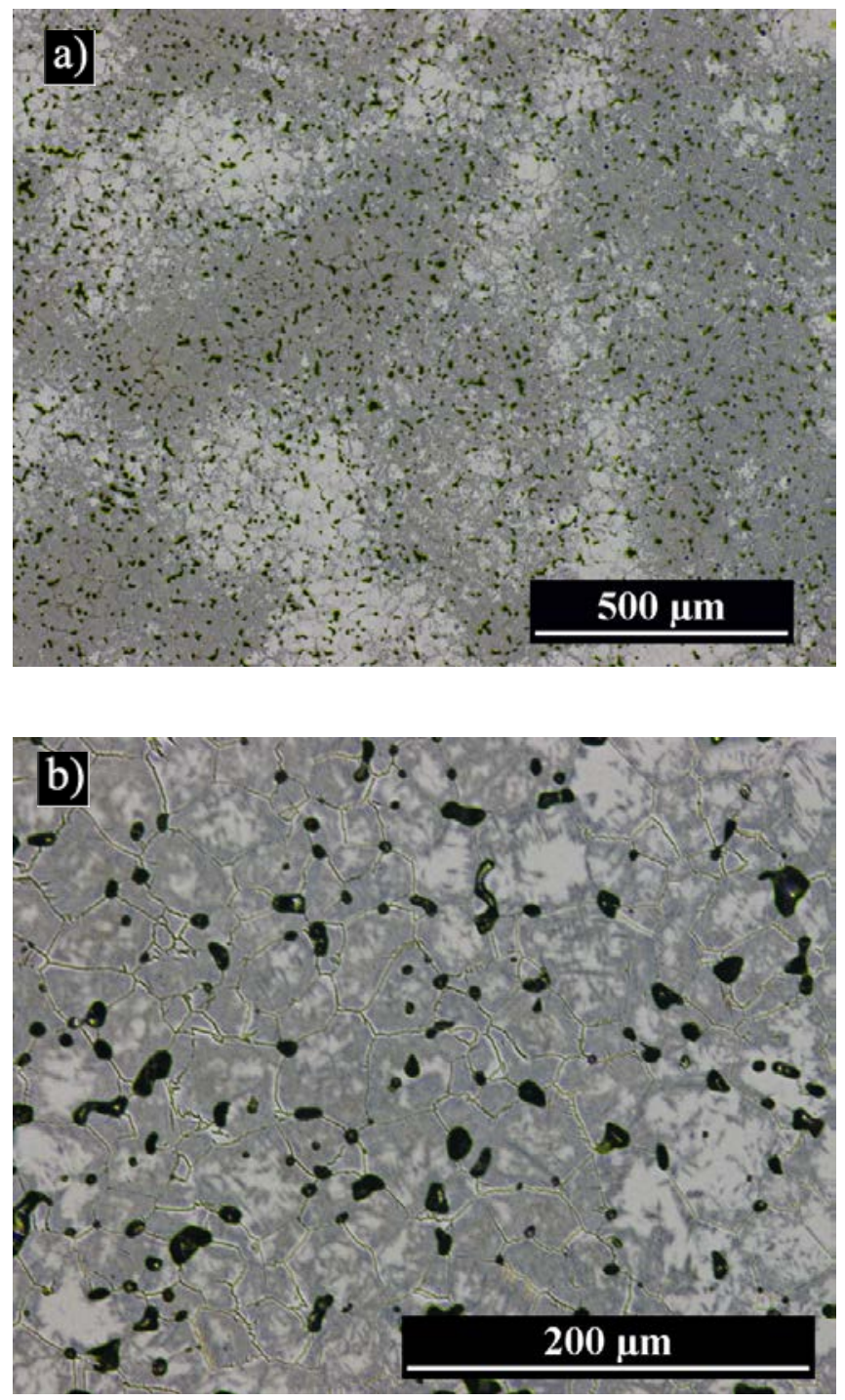

Figura 5.18. Microestructura de la aleación Ti 30Nb 4Sn. (a) Captura general y (b) imagen con mayores aumentos.

En las imágenes de la figura 5.18 hay zonas donde se revela antes la microestructura que otras y se ha optado por un tiempo de ataque mínimo para no observar zonas con exceso de ataque. 
La figura 5.19 expone las zonas con menor ataque, más claras y la figura 5.20 las zonas donde el ataque ha sido más severo.
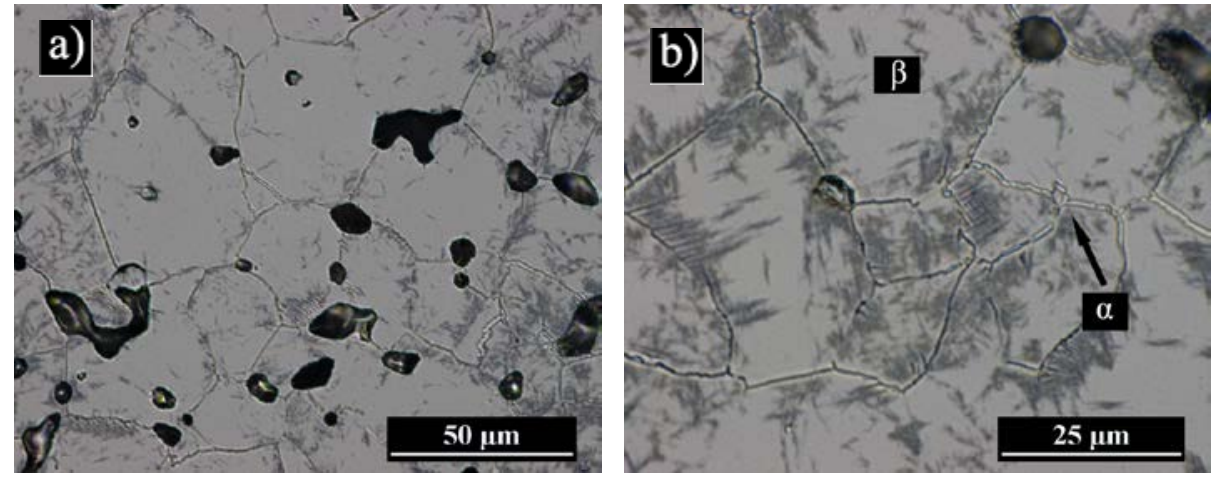

Figura 5.19. Ejemplo de las zonas claras con menor ataque químico (a) y formación de las distintas fases (b) en la aleación Ti 30Nb 4Sn.
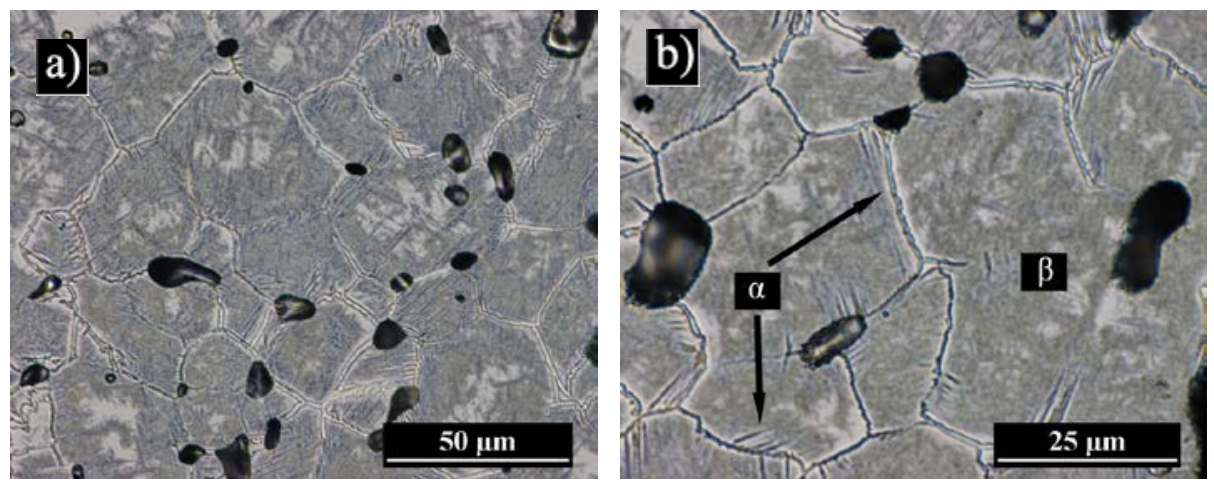

Figura 5.20. Detalle de la microestructura (a) y localización de las láminas de microestructura $\alpha$ y microestructura $\beta$ (b) de la aleación Ti $30 \mathrm{Nb} 4 \mathrm{Sn}$ en la zona con mayor ataque químico.

En general se observa como en los tres materiales la fase $\alpha$ se acumula en el borde de grano y crece en forma de láminas perpendiculares al borde de grano en dirección al centro. Este tipo de crecimiento provoca una estructura laminar en la región cercana al borde de grano. 
La falta de homogeneidad en el ataque químico se piensa que viene derivada por pequeñas diferencias en la composición, las zonas en las que el ataque ha sido más severo se observa mayor formación de lamela que las zonas con menor incidencia del ataque químico.

Por otro lado, se observa como la porosidad se acumula, en gran medida, en la frontera de grano. Como se ha comentado anteriormente tiene formas redondeadas y se ve influido por el contenido en estaño.

\subsubsection{Microscopía electrónica de barrido.}

Las imágenes tomadas con el microscopio electrónico de barrido (SEM) confirman las conclusiones que se han obtenido de las figuras expuestas en el apartado anterior. Cabe destacar que se ha trabajado con el SEM en modo electrones retrodispersados (BS). De este modo se consigue mayor contraste entre las zonas con distinta composición química aunque esta sea mínima.

En primer lugar se muestran las imágenes de la aleación Ti 30Nb con pocos aumentos, se observa que la microestructura es homogénea y que la formación de lamelas se centra en algunas regiones aleatoriamente distribuidas en toda la muestra. 


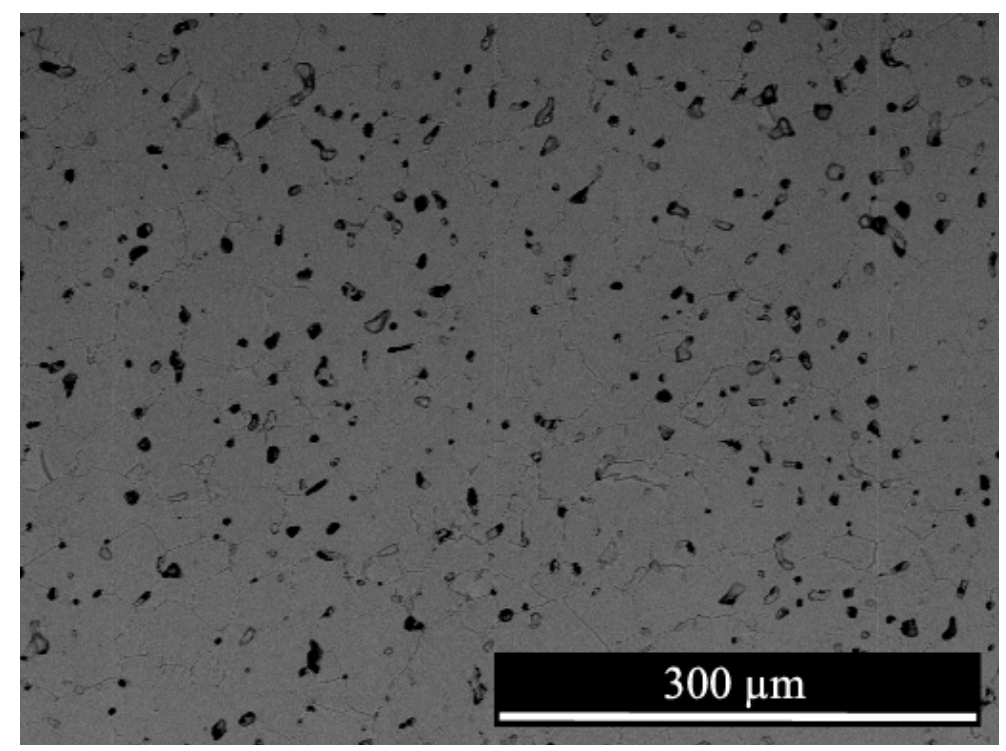

Figura 5.21. Imagen general de la aleación Ti 30Nb.

Se observan regiones que despiertan mayor interés, pues hay zonas en las que la formación de lamelas de $\alpha+\beta$ es mayor. En la Figura 5.22 se muestra en detalle las lamelas formadas en la aleación Ti 30Nb en las zonas ricas en microestructura $\alpha+\beta$. 

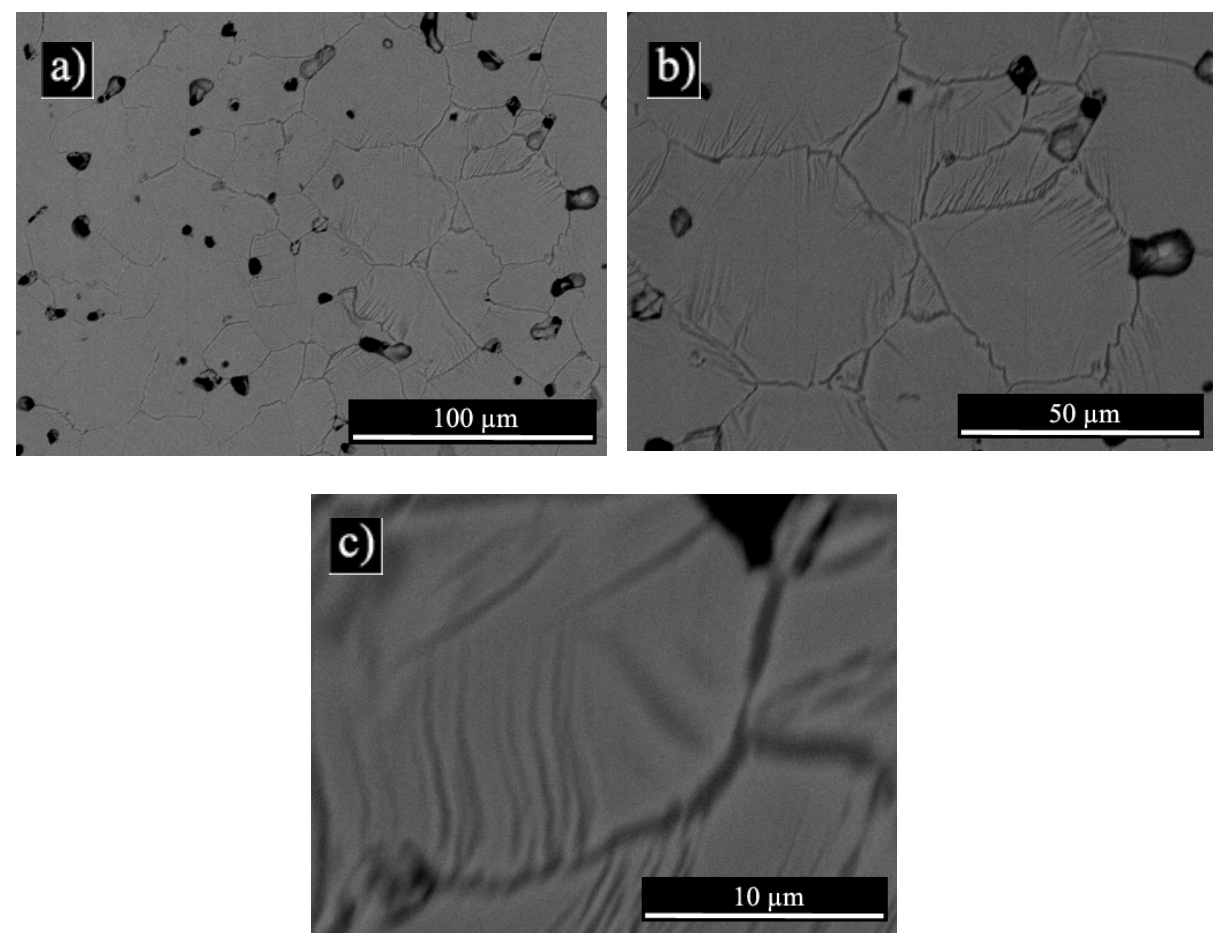

Figura 5.22. Imagen general de la zona con mayor formación de lamelas (a); detalle de las zonas (b) y detalle de las lamelas de microestructura $\alpha+\beta$ (c) de la aleación Ti 30Nb.

Se observa claramente en las imágenes b) y c) de la figura anterior como la orientación de las lamelas es del borde del grano hacia el centro perpendicularmente.

Las zonas con microestructura tipo $\beta$ no muestran ninguna variación en el interior del grano y la microestructura es totalmente $\beta$ pese a que continúan habiendo pequeñas regiones con microestructura $\alpha+\beta$. 

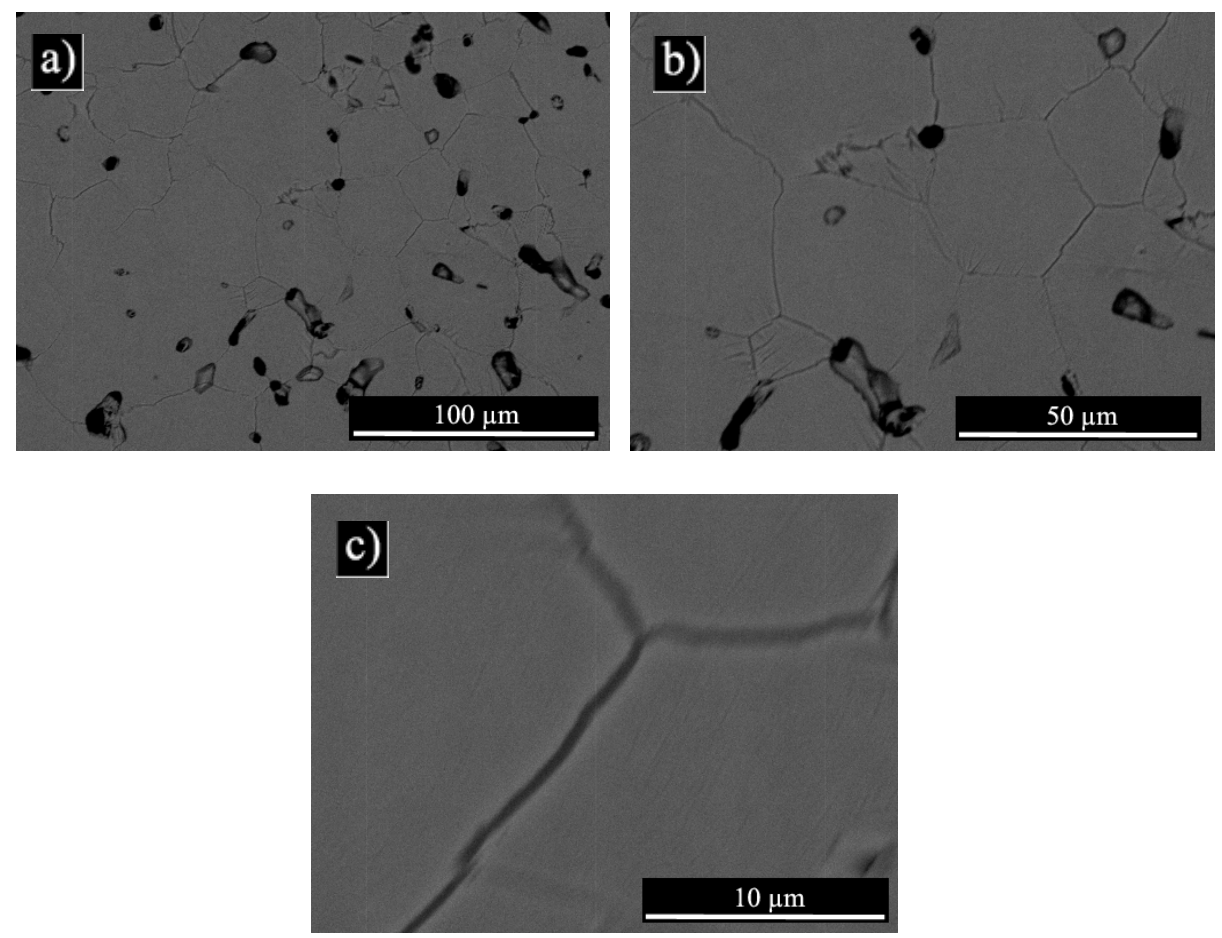

Figura 5.23. Imágenes de la aleación Ti 30Nb en las zonas ricas en microestructura tipo $\beta$. imagen general (a), imagen de detalle de la microestructura (b) e imagen de detalle del borde de grano (c).

Con la adición de estaño se observa como las regiones de microestructura tipo $\alpha+\beta$ se van reduciendo y la homogeneidad en toda la muestras es mayor. En la figura 5.24 se observa una imagen general de la aleación Ti 30Nb 2Sn. 


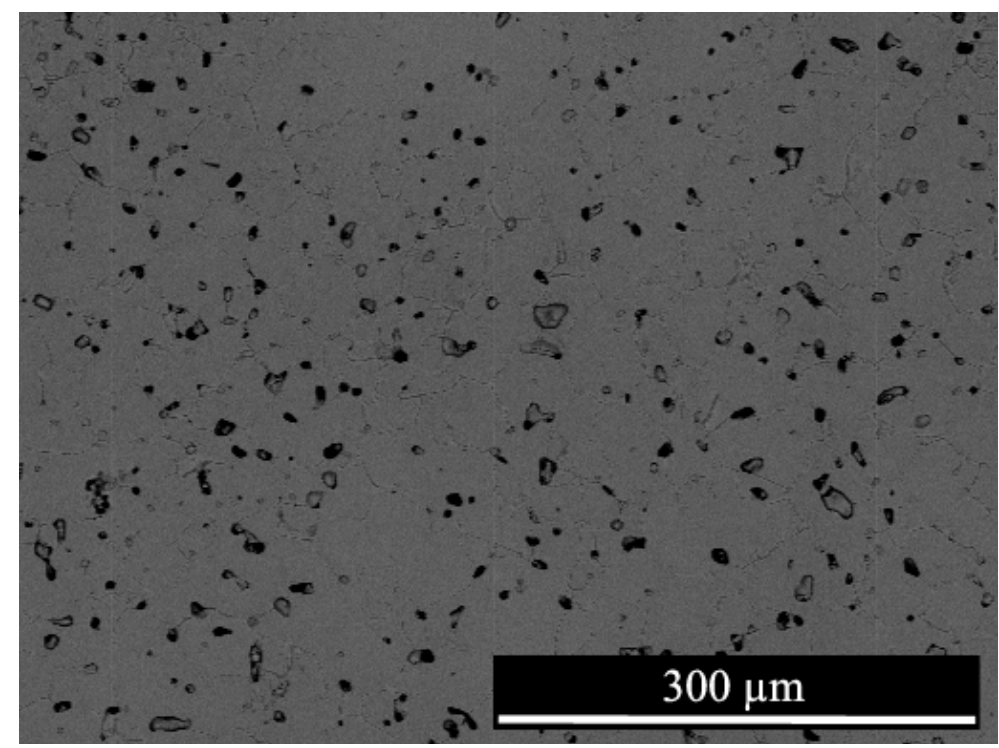

Figura 5.24. Imagen general de la aleación Ti 30Nb 2Sn.

La presencia de lamelas de microestructura $\alpha+\beta$ se ve reducida con la presencia del estaño. En la siguiente figura se observa en detalle una zona con abundancia de lamelas de $\alpha+\beta$. 

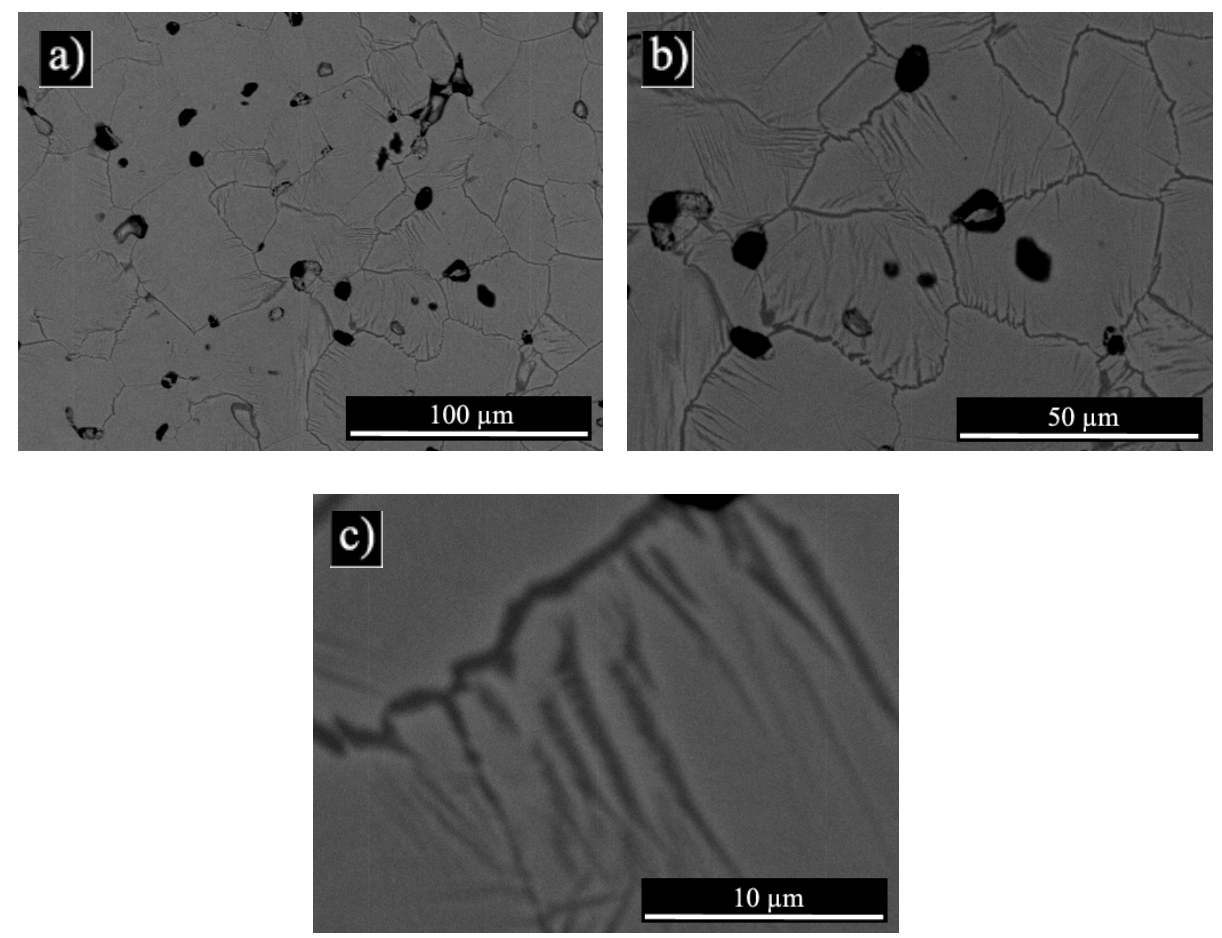

Figura 5.25. Imagen general de la zona con mayor fonación de lamelas (a), detalle de la zona lamelar (b) y detalle de la formación de las lamelas (c) en la aleación Ti 30Nb 2Sn.

En las regiones con microestructura totalmente $\beta$ las lamelas de $\alpha+\beta$ son prácticamente inexistentes y el tamaño es mucho menor. La microestructura es muy homogénea y no aparecen discontinuidades. 

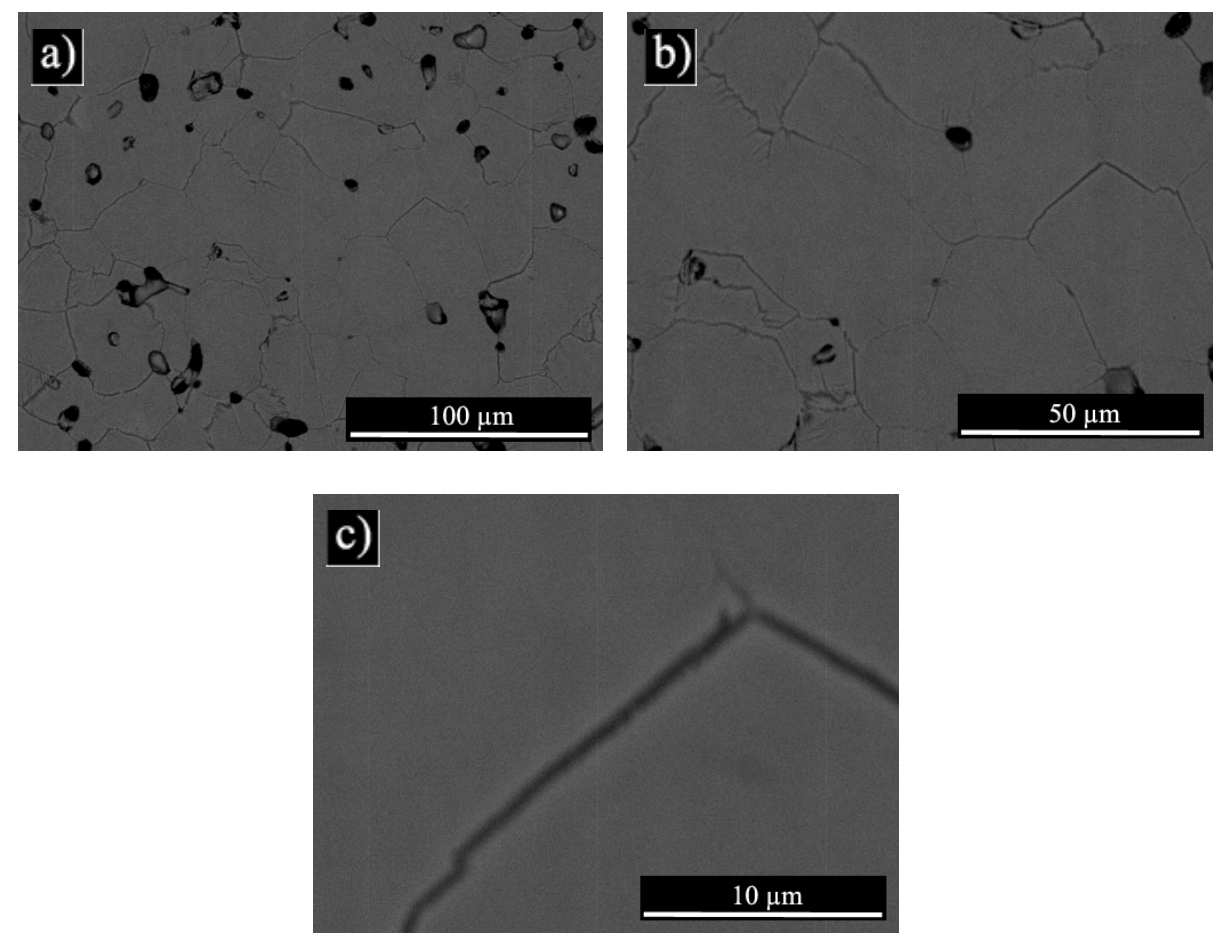

Figura 5.26. Imágenes general de la región $\beta$ (a), detalle de los granos equiaxiales de fase $\beta$ (b) y detalle de la frontera de grano (c) de la aleación Ti 30Nb 2Sn.

Por último, en la aleación $\mathrm{Ti} 30 \mathrm{Nb} 4 \mathrm{Sn}$ se muestra el mismo comportamiento que en la aleación anterior, hay menos presencia de lamelas de $\alpha+\beta$ y las zonas de microestructura totalmente $\beta$ son mayores. Pero este refinamiento de la microestructura no es tan marcado como en el caso anterior. 


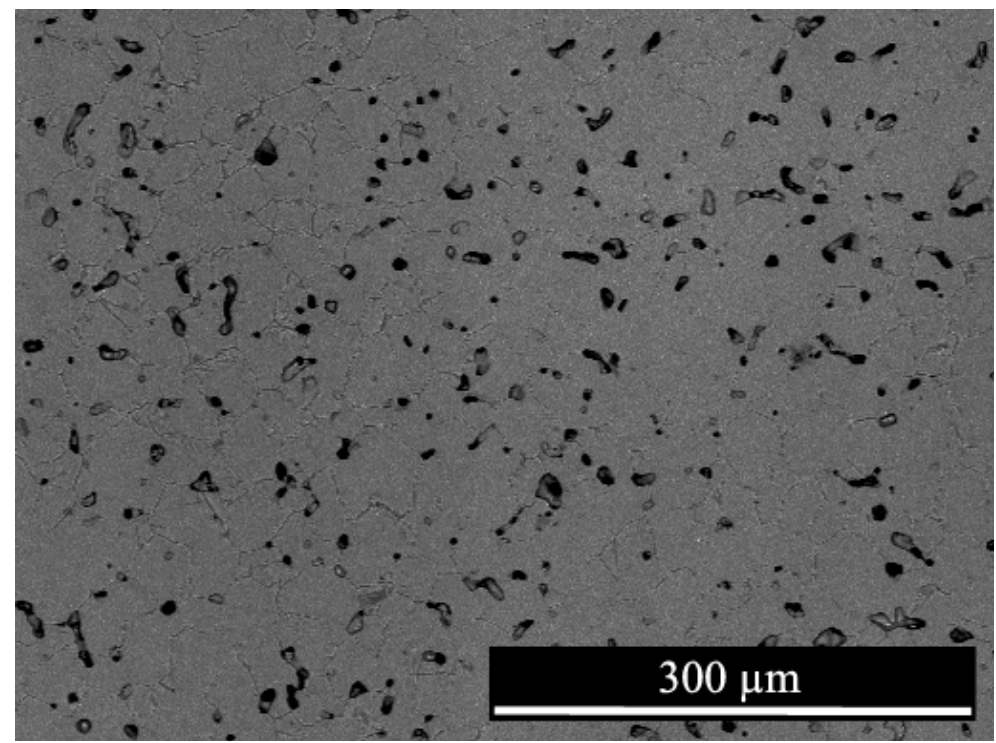

Figura 5.27. Imagen general de la aleación Ti 30Nb 4Sn.

Las zonas con lamelas de $\alpha+\beta$ son más escasas y reducidas en el conjunto de toda la superficie de estudio. La figura 5.28 muestra en detalle una de estas zonas de la aleación Ti 30Nb 4Sn. 

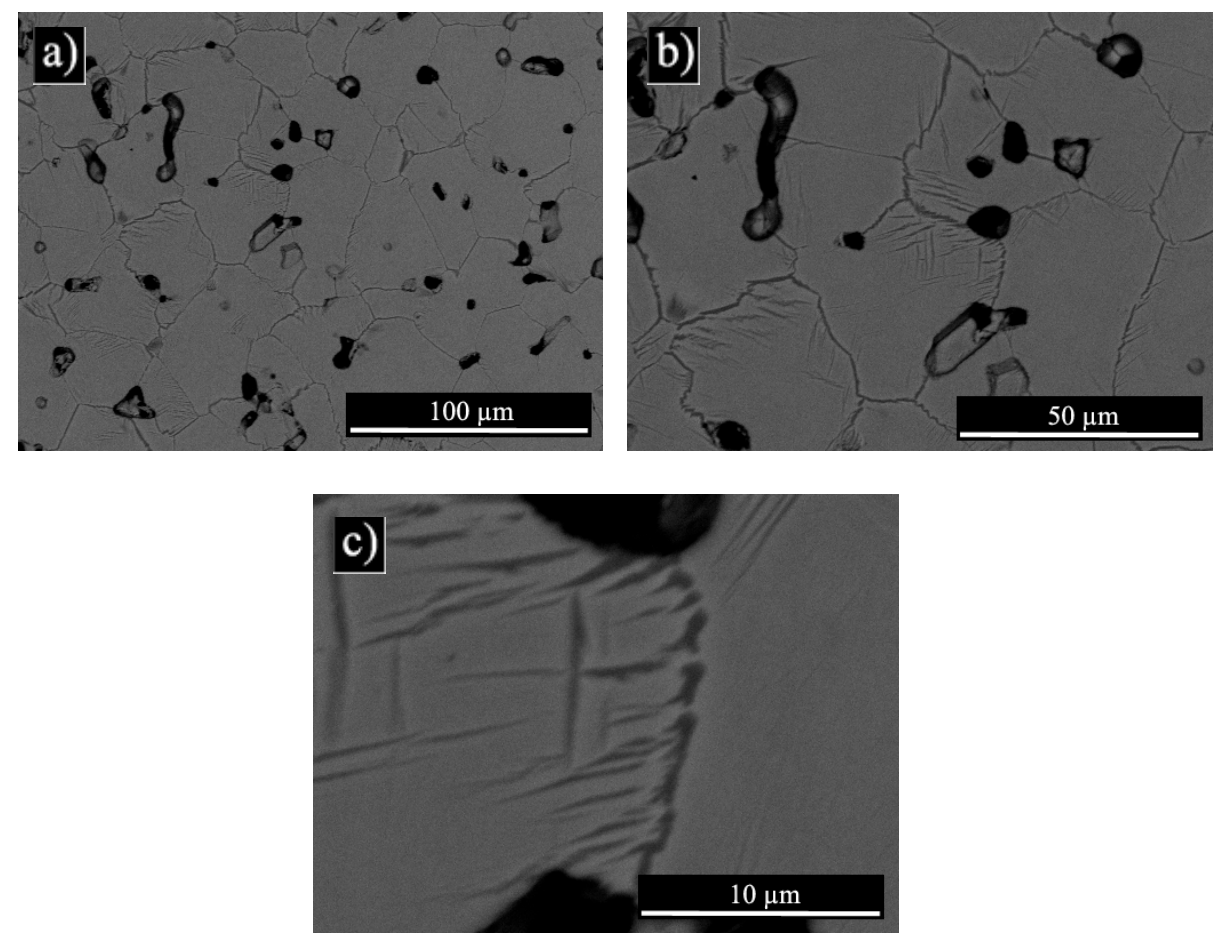

Figura 5.28. Detalle de la aleación Ti 30Nb 4Sn en las zonas ricas en lamelas de $\alpha+\beta$. Imagen general de la zona lamelar (a), imagen de detalle de zona lamelar (b) e imagen de detalle de las lamelas en el borde de grano (c).

En general la aleación Ti 30Nb 4Sn presenta una microestructura $\beta$ sin lamelas de $\alpha+\beta$ como la que se muestra en detalle en la figura 5.29. El borde de grano se observa bien definido y no aparece ninguna formación de lamelas perpendiculares al borde de grano. 

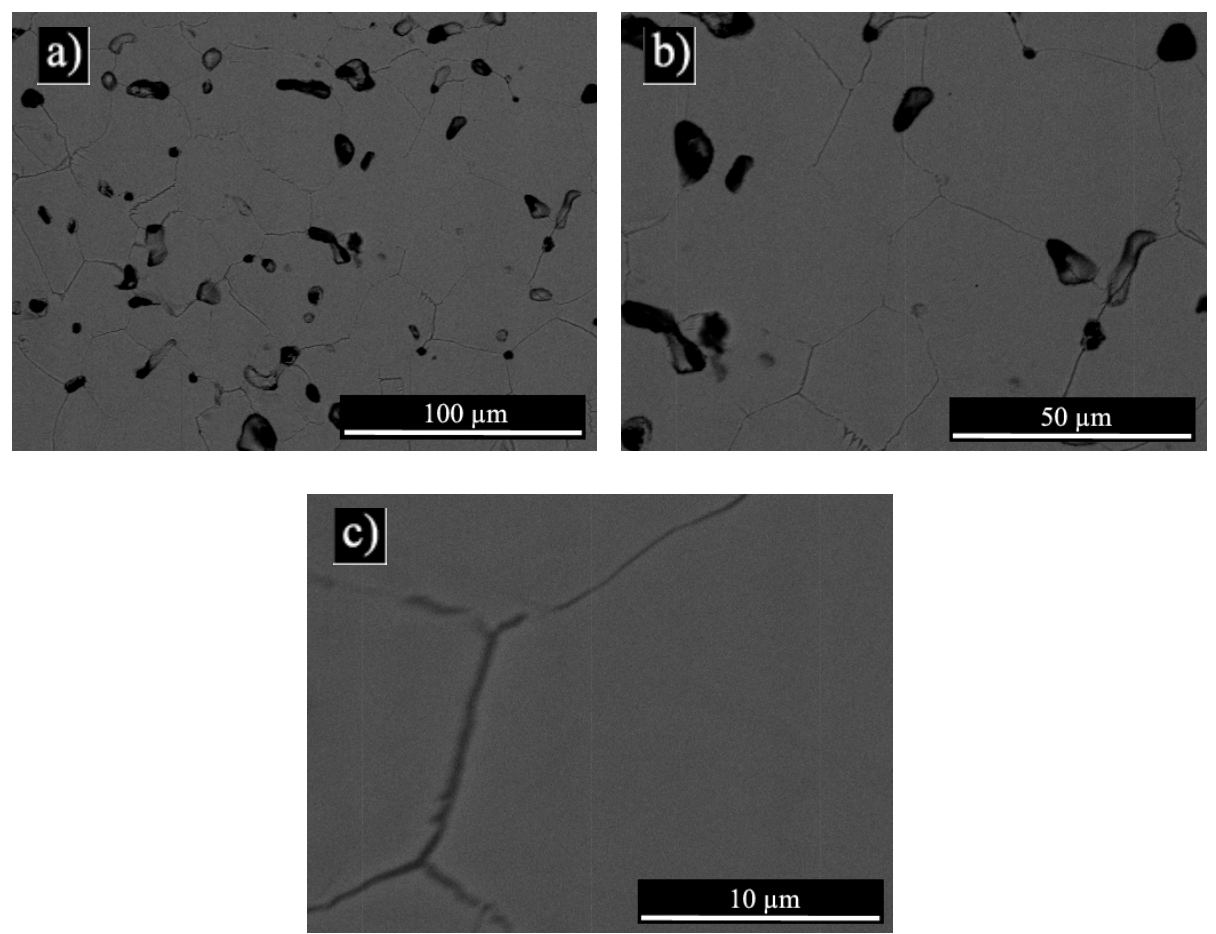

Figura 5.29. Imagen general de la zona con microestructura $\beta$ (a), detalles de la microestructura (b) y detalle del borde de grano (c) de la aleación Ti 30Nb 4Sn.

En los análisis mediante energía dispersiva de rayos X (EDS) existe una limitación a la hora de identificar elementos poco pesados y sobre todo para limitar el área de análisis ya que el tamaño mínimo de análisis es, prácticamente, el área del haz de electrones que incide en la muestra. A pesar de esto se ha podido observar diferencias entre las zonas con formaciones lamelares de $\alpha+\beta$ y zonas totalmente $\beta$ aunque no son muy significativas. Se ha realizado también análisis generales barriendo una gran superficie para comprobar la composición de la aleación y corroborar la relación estequiométrica entre los elementos presentes. 
En primer lugar, en la figura 5.30 se muestra el difractograma obtenido en el análisis general de las tres aleaciones. Se observa como tienen los tres en común el pico correspondiente a los electrones de titanio de la capa K y los del niobio de la capa L. En las aleaciones con estaño el pico de este elemento aparece pero poco destacado ya que el contenido es bajo aunque se distingue bien.

Ti 30Nb

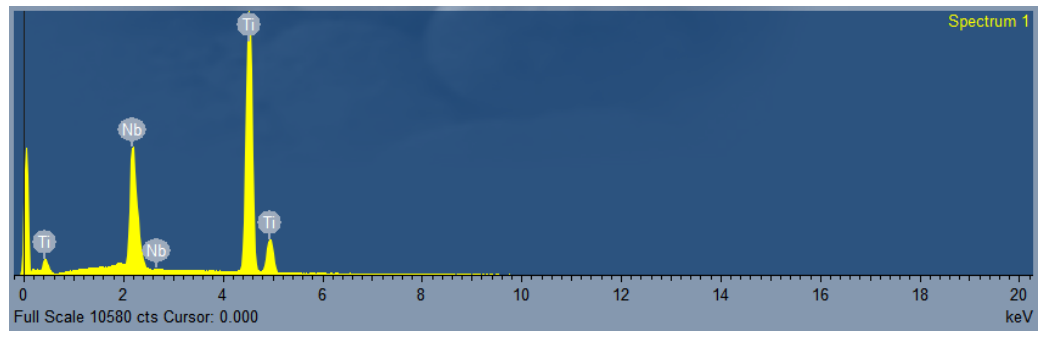

Ti 30Nb 2 Sn

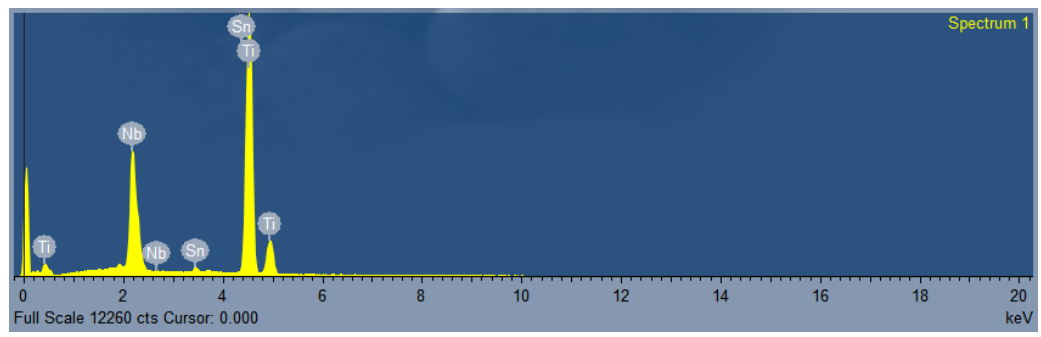

$\mathrm{Ti} 30 \mathrm{Nb} 4 \mathrm{Sn}$

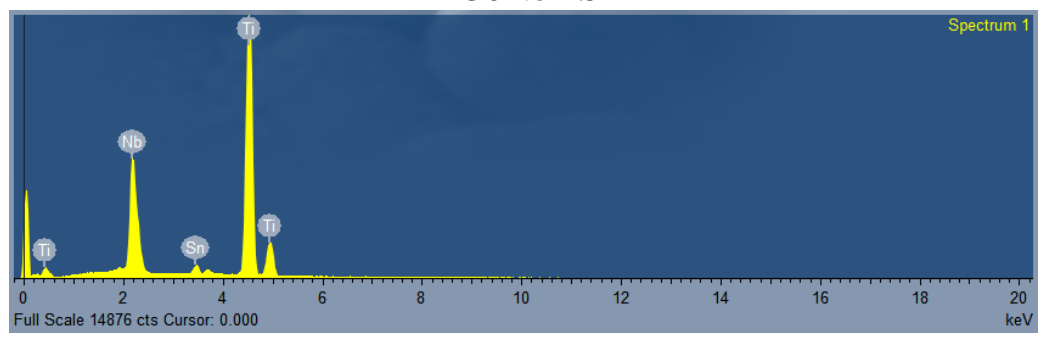

Figura 5.30. Difractogramas del análisis general de las tres aleaciones estudiadas. 
Los resultados de los análisis correspondientes a la figura anterior se muestran en la tabla 5.8 para cada aleación. Los resultados muestran pequeñas variaciones y los valores se encuentran muy próximos a los valores estequiométricos.

Tabla 5.8. Composición de cada aleación estudiada.

\begin{tabular}{|l|c|r|}
\hline \multicolumn{3}{|c|}{ Ti 30Nb General } \\
\hline Elem ento & Peso (\%) & Atómico (\%) \\
\hline Ti & $67.07 \pm 0.85$ & 78.55 \\
\hline Nb & $32.93 \pm 0.85$ & 21.45 \\
\hline
\end{tabular}

\begin{tabular}{|l|c|r|}
\hline \multicolumn{3}{|c|}{ Ti 30Nb 2Sn General } \\
\hline Elem ento & Peso (\%) & Atómico (\%) \\
\hline Ti & $64.83 \pm 0.26$ & 78.35 \\
\hline Nb & $33.24 \pm 0.25$ & 20.71 \\
\hline Sn & $1.94 \pm 0.13$ & 0.95 \\
\hline
\end{tabular}

\begin{tabular}{|l|c|r|}
\hline \multicolumn{3}{|c|}{ Ti 30Nb 4Sn General } \\
\hline Elemento & Peso (\%) & Atómico (\%) \\
\hline Ti & $65.04 \pm 1.81$ & 78.74 \\
\hline Nb & $30.84 \pm 1.77$ & 19.25 \\
\hline Sn & $4.12 \pm 1.01$ & 2.01 \\
\hline
\end{tabular}

Los análisis de zonas más concretas muestran cambios más marcados entre las zonas de lamelas $\alpha+\beta$ y zonas totalmente $\beta$. En la siguiente figura se muestra los análisis de la aleación Ti 30Nb en la que se ha realizado diversos análisis para comprobar las diferencias en la composición. 


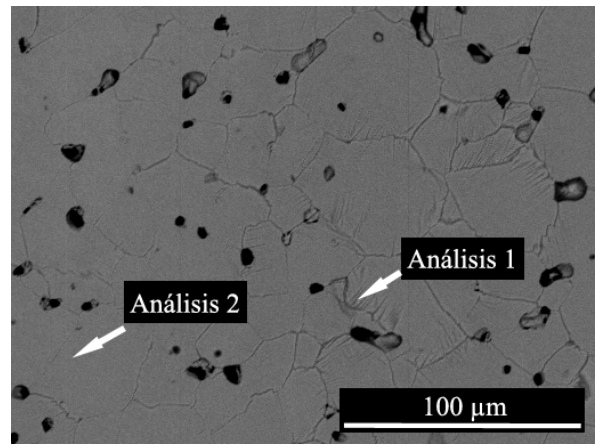

\begin{tabular}{|l|c|r|}
\hline \multicolumn{3}{|c|}{ Análisis 1 } \\
\hline Elem ento & Peso (\%) & Atómico (\%) \\
\hline Ti & $66.24 \pm 0.26$ & 79.19 \\
\hline Nb & $33.76 \pm 0.26$ & 20.81 \\
\hline
\end{tabular}

Figura 5.31. Análisis de las zonas ricas en lamelas de $\alpha+\beta$ (análisis 1 ) y las zonas totalmente $\beta$ (análisis 2 ) de la aleación Ti 30Nb.

No existen grandes diferencias entre ambas zonas debido a la resolución del análisis que viene dado por el diámetro del haz de electrones. En las aleación Ti 30Nb 2Sn las diferencias son algo mayores.

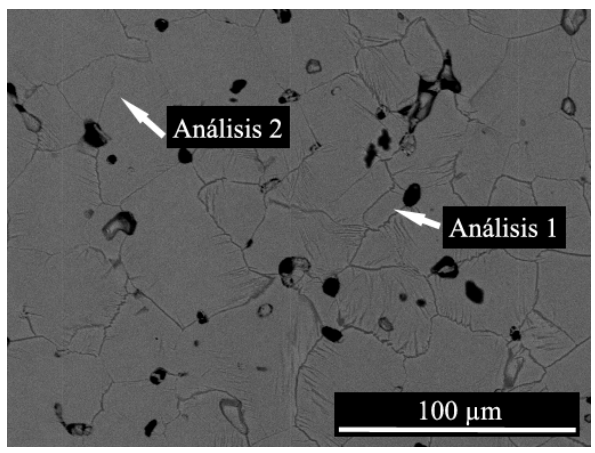

\begin{tabular}{|l|r|r|}
\hline \multicolumn{3}{|c|}{ Análisis 1 } \\
\hline Elem ento & Peso (\%) & Atómico (\%) \\
\hline Ti & $66.13 \pm 0.26$ & 79.32 \\
\hline Nb & $31.93 \pm 0.25$ & 19.74 \\
\hline Sn & $1.94 \pm 0.13$ & 0.94 \\
\hline
\end{tabular}

\begin{tabular}{|l|r|r|}
\hline \multicolumn{3}{|c|}{ Análisis 2 } \\
\hline Elem ento & Peso (\%) & \multicolumn{1}{|c|}{ Atómico (\%) } \\
\hline Ti & $65.27 \pm 0.32$ & 78.73 \\
\hline Nb & $32.25 \pm 0.31$ & 20.06 \\
\hline Sn & $2.48 \pm 0.16$ & 1.21 \\
\hline
\end{tabular}

Figura 5.32. Análisis composicional de la aleación Ti 30Nb 2Sn para las zonas $\alpha+\beta$ (análisis 1 ) y la zona totalmente $\beta$ (análisis 2 ).

Por último, el análisis de la aleación Ti 30Nb 4Sn ofrece mayores diferencias entre la zona con estructura lamelar $\alpha+\beta$ y la zona $\beta$. En 
la figura 5.33 se observa la zona de análisis y las tablas con los valores obtenidos.

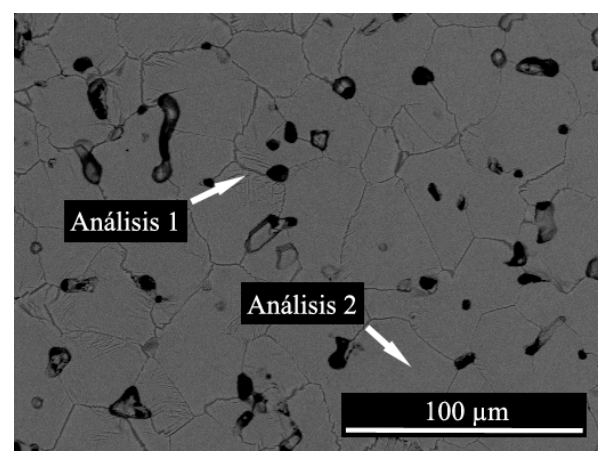

\begin{tabular}{|l|c|r|}
\hline \multicolumn{3}{|c|}{ Análisis 1 } \\
\hline Elem ento & Peso (\%) & Atómico (\%) \\
\hline Ti & $65.89 \pm 0.23$ & 79.37 \\
\hline Nb & $30.02 \pm 0.22$ & 18.64 \\
\hline Sn & $4.09 \pm 0.12$ & 1.99 \\
\hline
\end{tabular}

\begin{tabular}{|l|c|r|}
\hline \multicolumn{3}{|c|}{ Análisis 2 } \\
\hline Elem ento & Peso (\%) & Atómico (\%) \\
\hline Ti & $64.14 \pm 0.23$ & 78.03 \\
\hline Nb & $32.02 \pm 0.22$ & 20.08 \\
\hline Sn & $3.84 \pm 0.13$ & 1.88 \\
\hline
\end{tabular}

Figura 5.33. Composición de las zonas con microestructura $\alpha+\beta$ (análisis 1) y zonas con microestructura tipo $\beta$ (análisis 2) de la aleación Ti 30Nb 4Sn.

Evidentemente, aparece mayor contenido de niobio en la zona $\beta$ en todas las aleaciones, dado el carácter betágeno del niobio. Es lógico que se encuentre en mayor concentración en las zonas con microestructura totalmente $\beta$.

\subsubsection{Microscopía electrónica de transmisión.}

Se ha observado con especial atención las zonas en la que la microestructura es lamelar $\alpha+\beta$ para confirmar la formación de este tipo de microestructura. Se ha obtenido imágenes en BF y se han realizado análisis de difracción de área o Selected area diffraction (SAD) en cada lamela para obtener la estructura cristalina y analizar el 
tipo de microestructura presente. El estudio se ha centrado sobre todo en la aleación de Ti 30Nb ya que es a priori la que mayor zona lamelar presenta. Las zonas con estructura totalmente $\beta$ son mucho más fáciles de resolver y no entrañan tanta dificultad como las zonas con estructura $\alpha+\beta$. En la figura 5.34 se muestra la estructura de red de dos zonas marcadas 1 y 2 en la imagen BF: el primer análisis es de las lamelas más claras, lamelas de $\beta$ y el segundo análisis es de las lamelas más oscuras, lamelas $\alpha$.

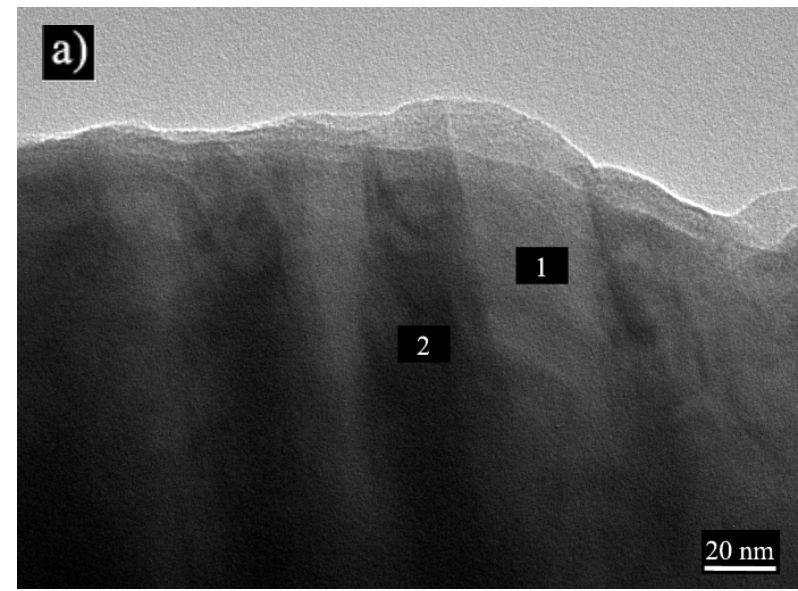

Análisis 1

Análisis 2

b) $(315)_{\beta}$

Figura 5.34. a) Imagen BF de la aleación Ti 30Nb de la zona lamelar con análisis SAD en los dos tipos de lamela (b). 
En el primer análisis se ha identificado de forma clara el plano (3 1 5) que corresponde a la estructura cristalina de $\beta$. en el análisis 2 se ha identificado dos planos el (1 1100$)$ y el (llll $\left.\begin{array}{lll}1 & 0\end{array}\right)$ que corresponden a la estructura cristalina de $\alpha$.

Para observar la diferencia entre la estructura de los granos de $\alpha+\beta$ y los granos totalmente $\beta$ se ha realizado varias capturas en las que se observa esta diferencia. Se ha capturado parte de un grano $\beta$, el borde de grano y parte de un grano de $\alpha+\beta$.

La imagen a) de la figura 5.35 muestra de forma clara la formación de laminas de fase $\alpha$ y fase $\beta$ lo que repercute en una microestructura laminar $\alpha+\beta$ en la que la mayoría de lamelas está orientada perpendicularmente al borde de grano. En la imagen b) de la misma figura se observa el borde de grano que delimita los granos de distinta microestructura y como el grano de microestructura $\beta$ no presenta ningún tipo de discontinuidad en su interior a pesar de la suciedad que se observa en la zona inferior izquierda. 

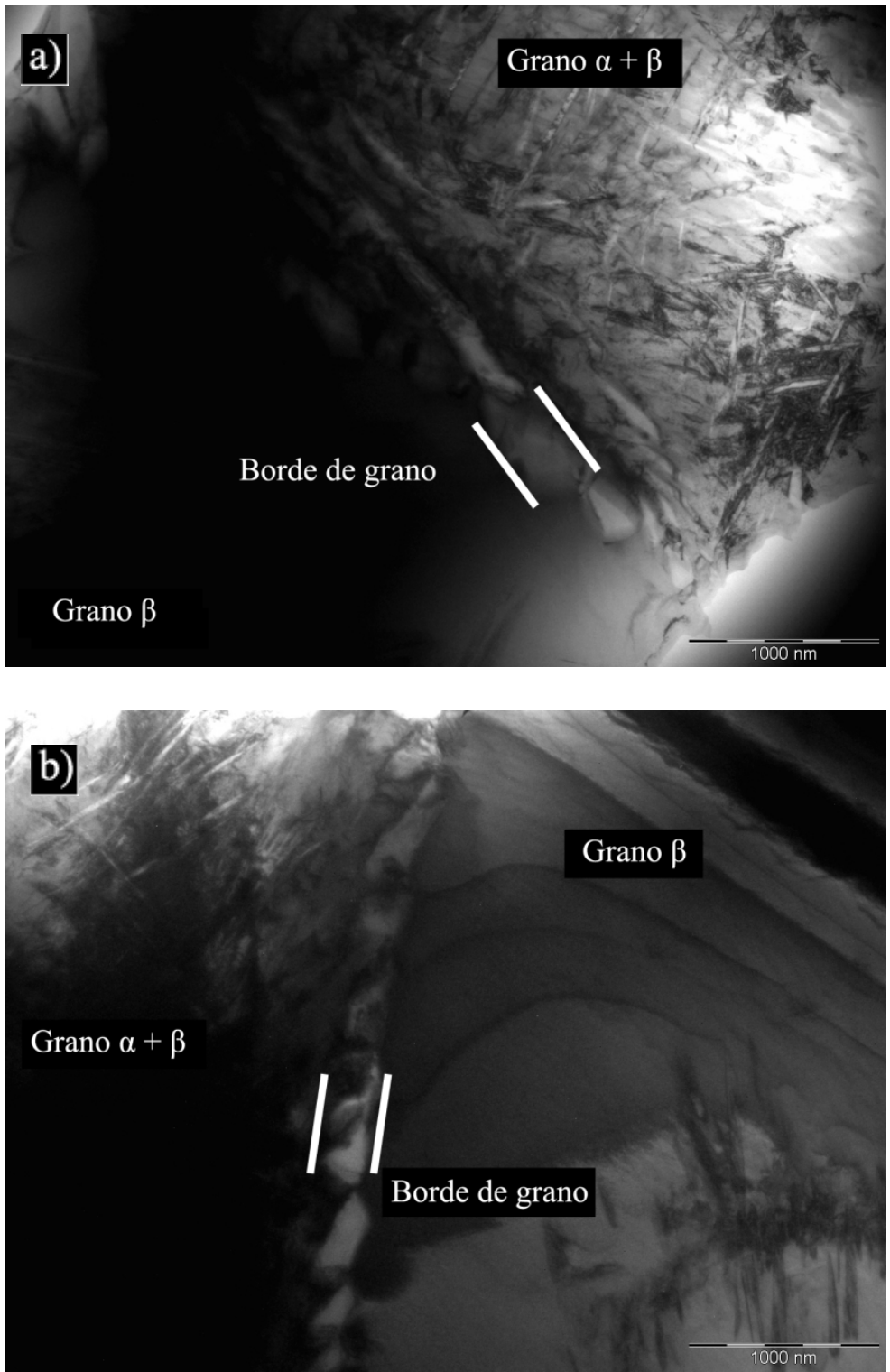

Figura 5.35. Imágenes de distintos granos con estructura $\alpha+\beta$, estructura totalmente $\beta$ y el borde de grano de la aleación Ti 30Nb.

En cuanto a la aleación Ti 30Nb 2Sn no se ha realizado análisis SAD de las lamelas porque la estructura es muy similar a la anteriormente 
comentada y no aparecen zonas con microestructura lamelar con tanta asiduidad. En la figura 5.36 se observa la estructura lamelar de $\alpha+\beta$ a relativamente pocos aumentos.

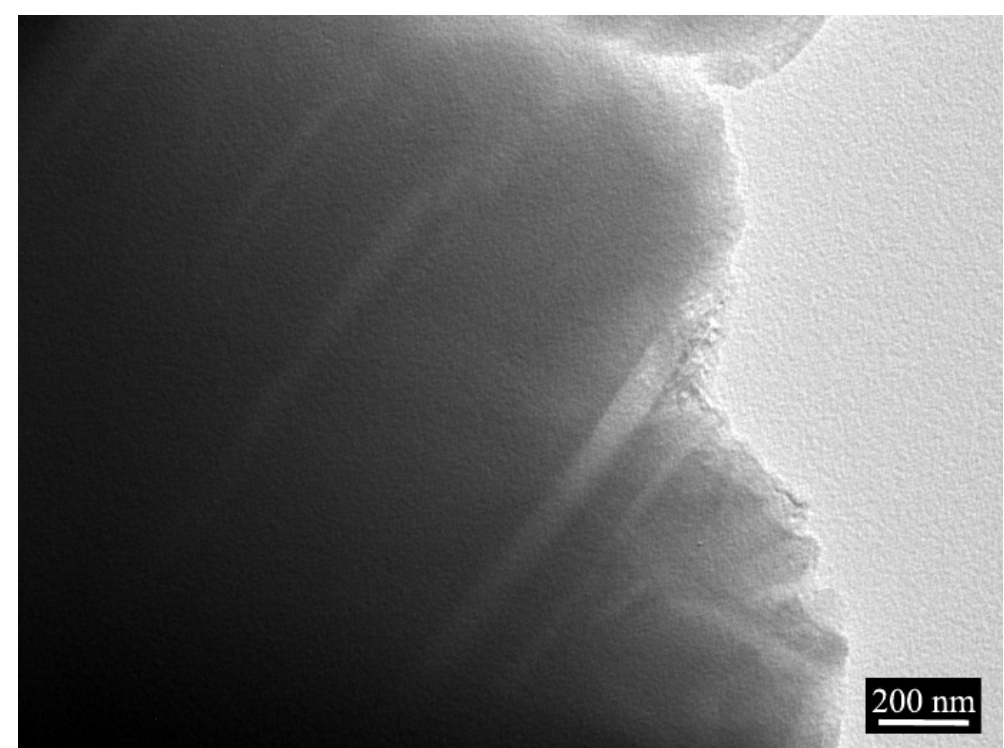

Figura 5.36. Microestructura lamelar de la aleación Ti 30Nb 2Sn.

De la aleación Ti 30Nb 4Sn si que se han realizado análisis SAD pero no de forma tan extensa. Se ha identificado el plano (2 11 5) correspondiente a la fase $\alpha$ dentro de una lamela en la zona con microestructura lamelar lo que confirma, que a pesar de que la formación de lamelas es menor, siguen habiendo y éstas tienen la misma microestructura $\alpha$. 


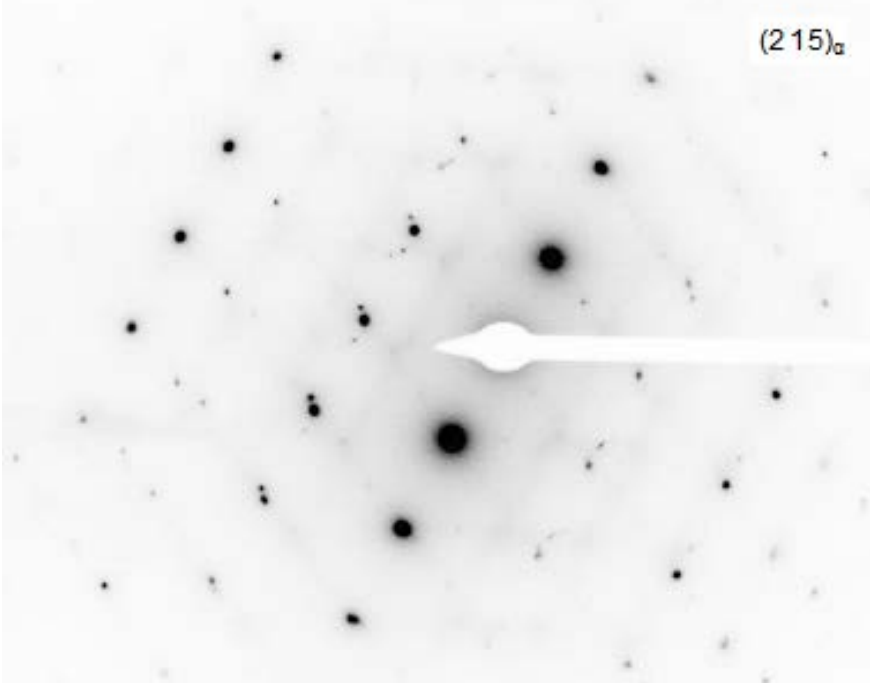

Figura 5.37. Análisis SAD de la aleación Ti 30Nb 4Sn correspondiente a la zona con microestructura tipo $\alpha$.

Las imágenes de campo claro muestran la misma estructura lamelar ya estudiada. La figura 5.38 es un ejemplo claro de este tipo de microestructura y de la alineación de las lamelas. 


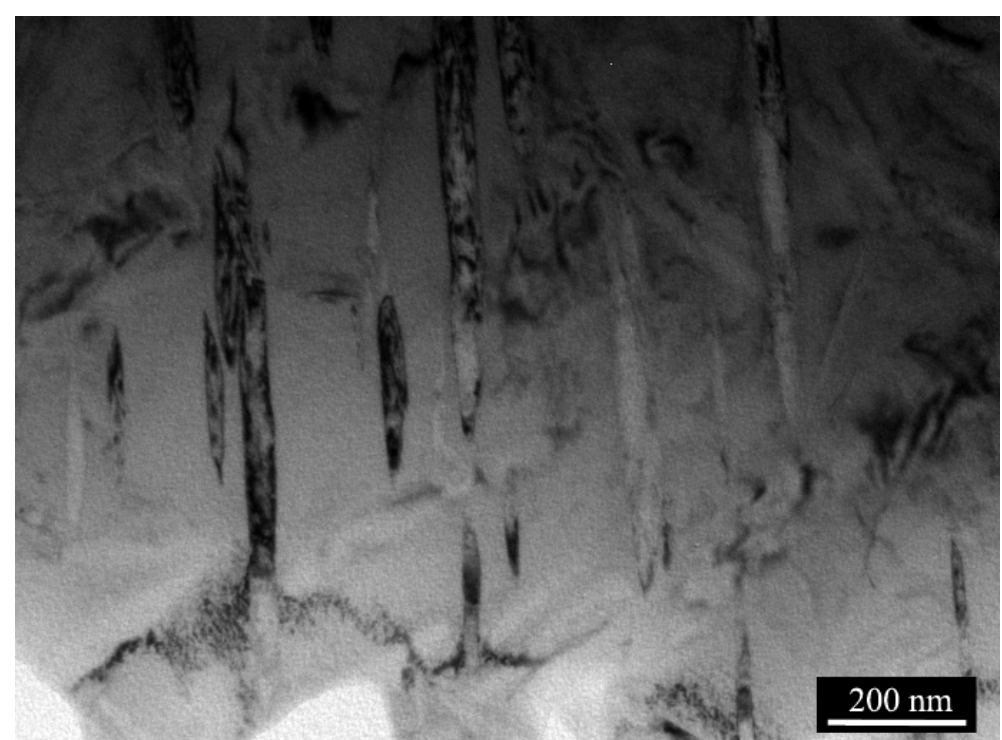

Figura 5.38. Microestructura lamelar de la aleación Ti 30Nb 4Sn. imagen de TEM tomada en campo claro.

Por otro lado se ha realizado un mapa de elementos mediante rayos $\mathrm{X}$ (EDS) para observar la distribución de los elementos dentro de las aleaciones. Como anteriormente el análisis se ha centrado en las zonas con microestructura lamelar $\alpha+\beta$. En las siguientes figuras se muestran los resultados obtenidos para cada aleación. 


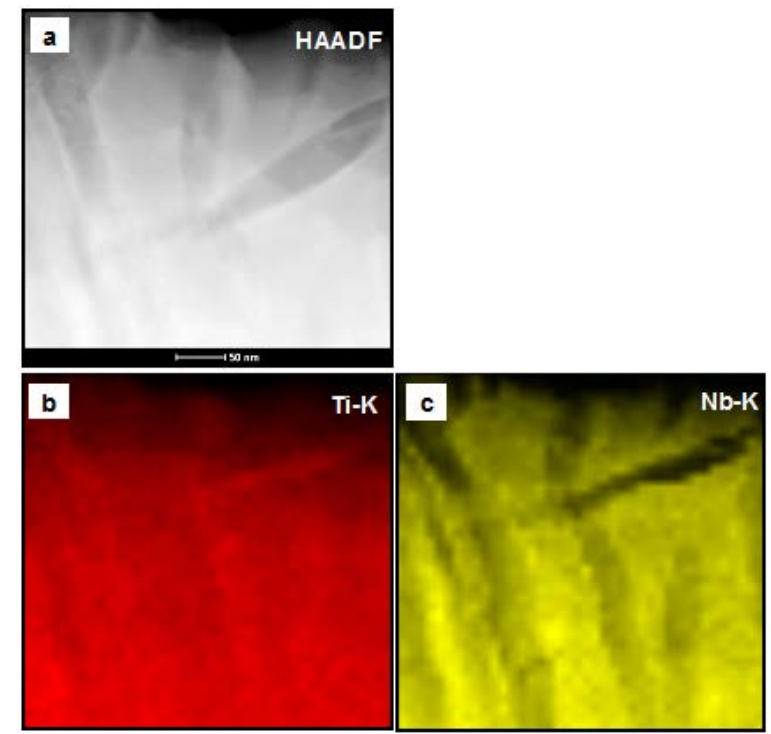

Figura 5.39. Mapa composicional de la aleación Ti 30Nb. Imagen HADDF de la zona de análisis (a), distribución del titanio (b) y distribución del niobio (c) en la aleación.

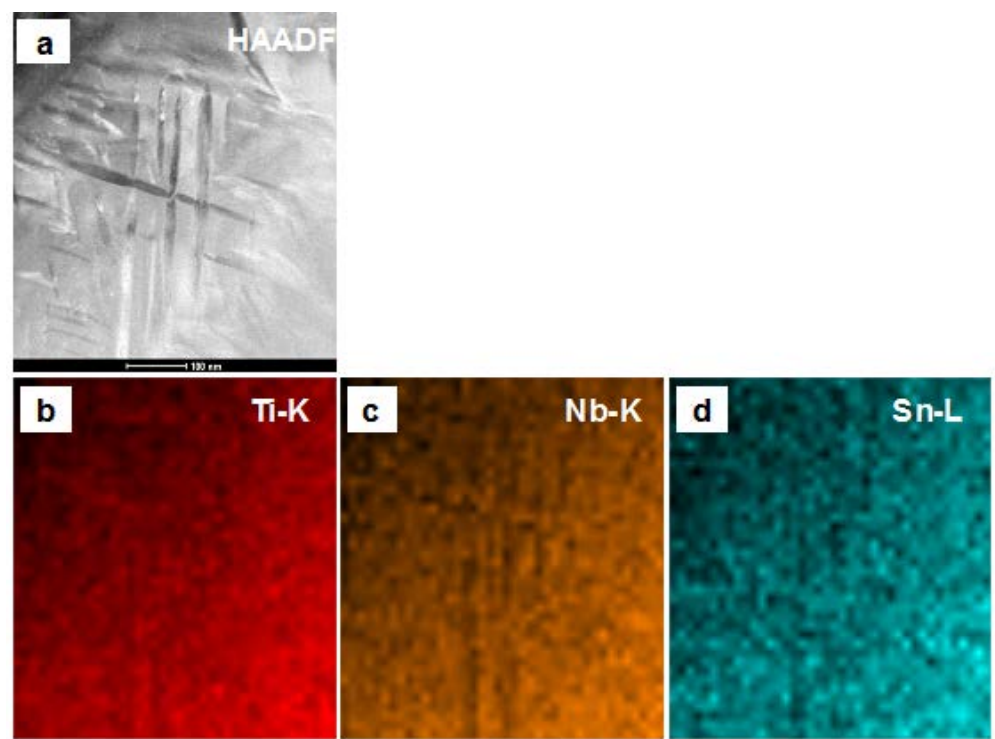

Figura 5.40. Análisis de composición mediante EDS de la aleación Ti $30 \mathrm{Nb} 2 \mathrm{Sn}$. imagen HAADF de la zona (a), en color rojo la distribución del Ti (b), en color naranja la distribución del Nb (c) y en azul la del Sn (d) 


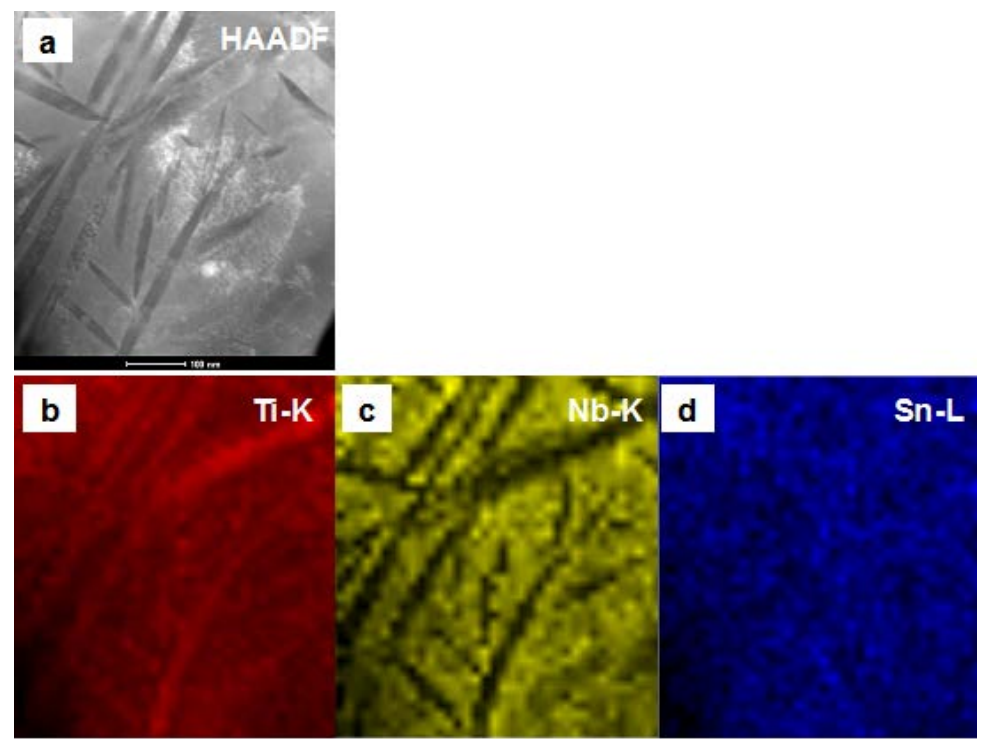

Figura 5.41. Mapa composicional zona mostrada (a) con la distribución del Ti (b), la del Nb (c) y la del estaño (d) de la aleación Ti 30Nb 4Sn.

La primera imagen (a) de todas las figuras corresponde a la zona de análisis. Es una imagen de STEM tomada con el modo HAADS. La imagen (b) corresponde al mapa del pico K del titanio, en color rojo, la imagen (c) pertenece al niobio, también del pico $\mathrm{K}$ en color amarillo o naranja, y en las aleaciones con estaño la imagen (d) corresponde a la distribución pico L del estaño en el mapa, en azul.

Por último, y para cerciorarse claramente de que las lamelas presentan estructura $\alpha+\beta$ se ha realizado un análisis composicional dentro de cada tipo de lamela. Se trata de un análisis por EDS de una zona muy pequeña y concreta que aporta la composición exacta de cada lamela. El estudio se ha realizado sólo de la aleación Ti $30 \mathrm{Nb}$ por las 
facilidades anteriormente comentadas. La tabla 5.9 muestra los resultados para la lamela de $\alpha$ y la lamela de $\beta$.

Tabla 5.9. Composición de las lamelas de $\alpha$ y la lamela $\beta$ de obtenida por análisis de EDS de la aleación Ti 30Nb.

\begin{tabular}{|l|c|r|c|r|}
\cline { 2 - 5 } \multicolumn{1}{c|}{} & \multicolumn{2}{c|}{ Lam ela tipo o. } & \multicolumn{2}{c|}{ Lamela tipo $\beta$} \\
\hline Elem ento & Peso (\%) & Atómico (\%) & Peso (\%) & Atómico (\%) \\
\hline Ti & $73.91 \pm 1.20$ & 84.60 & $38.29 \pm 0.77$ & 54.62 \\
\hline Nb & $26.08 \pm 1.09$ & 15.39 & $61.70 \pm 1.70$ & 45.37 \\
\hline
\end{tabular}

Se observa como el contenido en niobio en la zona de $\alpha$ es mucho menor. Esto es totalmente coherente con la teoría ya que el niobio es un elemento muy betágeno en las aleaciones de titanio lo que genera que su contenido sea mayor en las zonas con microestructura tipo $\beta$.

La figura 5.42 muestra la zona de análisis por EDS con la información relativa a cada análisis. Es una imagen de STEM en el modo HAADS de la aleación Ti 30Nb. 


\section{Lamela $\beta$}

\section{Lamela $\alpha$}

$100 \mathrm{~nm}$

Figura 5.42. Zona de análisis EDS de cada lamela en la aleación Ti $30 \mathrm{Nb}$.

\subsubsection{Difracción de rayos $X$.}

Mediante difracción de rayos $\mathrm{X}$ se obtiene como fases presentes las fases $\alpha$ y $\beta$. En la figura 5.43 se muestra el difractograma obtenido de las tres aleaciones. 


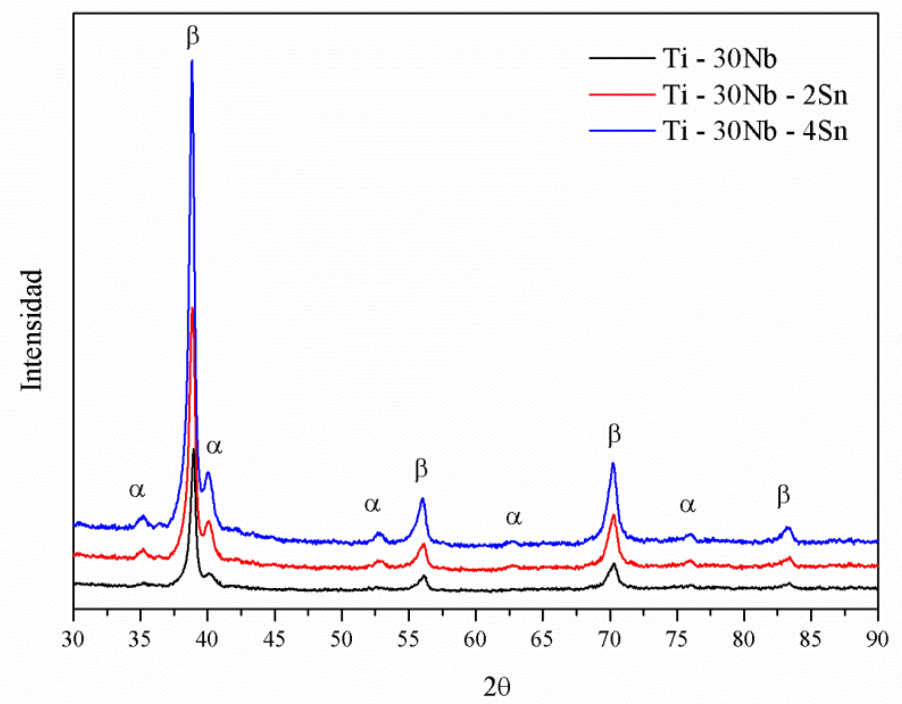

Figura 5.43. Difractograma de las aleaciones Ti 30Nb XSn.

Se puede diferenciar la progresión de los picos característicos de cada fase $(\alpha y \beta)$.

\subsubsection{Discusión de resultados de características microestructurales.}

En primer lugar cabe destacar que el enfriamiento llevado a cabo después del ciclo térmico de sinterizado es un enfriamiento muy lento. La velocidad de enfriamiento es de $10{ }^{\circ} \mathrm{C} / \mathrm{min}$ pero existe la limitación de que el horno de alto vacío utilizado no tiene refrigeración por lo que en las etapas de más baja temperatura, a partir de los $600{ }^{\circ} \mathrm{C}$ hasta temperatura ambiente, esta velocidad de enfriamiento es mucho más lenta. De este modo, se favorece la obtención de las fases más estables 
del diagrama de equilibrio, fase $\alpha$ y fase $\beta$. Por este motivo se va a comparar principalmente con materiales de otros autores en condiciones de enfriamiento muy lento, para que las analogías en el procesado sean lo mayor posible.

También cabe destacar que el tiempo de sinterizado es suficientemente extenso para que la difusión sea relativamente alta y no se necesiten ciclos posteriores de tratamientos térmicos 0 tratamientos termomecánicos como solubilización o laminación en caliente. En cambio en la mayoría de trabajos de fusión que se encuentran en la bibliografía, los autores exponen procesos en los que la refusión para homogeneizar es necesaria llegando incluso a cinco refusiones y posteriores ciclos térmicos [3]. Por último destacar que la atmósfera utilizada en estudios de otros autores es, en su mayoría, atmósferas inertes y no alto vacío como en este proyecto.

El contenido en oxígeno es muy alto en todos los casos. La incorporación de oxigeno promueve la formación de microestructura $\alpha$. Dicha estructura no es beneficiosa para las propiedades buscadas en este proyecto de bajos módulos elásticos. Esta influencia se va a discutir con mayor precisión en el apartado de caracterización mecánica ya que es donde se observa de forma clara las consecuencias de estos altos valores. El alto contenido en oxígeno mostrado en la tabla 5.7 minimiza el efecto betágeno de la adición de niobio. Este alto contenido promueve la aparición de fase $\alpha$ en forma de lamelas en las zonas próximas al borde de grano y en el propio borde de grano. 
Dicha influencia es mayor en la aleación Ti $30 \mathrm{Nb} 4 \mathrm{Sn}$ ya que el contenido en oxígeno es mayor $(0.550 \%)$. En consecuencia la heterogeneidad microestructural se ve comprometida ya que, por un lado el niobio estabiliza la fase $\beta$ pero por otro el oxígeno fomenta la formación de fase $\alpha$.

Como ya se ha comentado, el mayor contenido de oxígeno en la aleación con un $4 \%$ de estaño entorpece la formación de microestructura $\beta$ a temperatura ambiente e impide que se observe de forma clara la evolución esperada hacia mayores contenidos de microestructura $\beta$. Recordar que el mayor contenido de estaño no interviene de forma directa en la mayor presencia de microestructura $\beta$, ya que es un elemento neutro en las aleaciones de titanio, pero sí que mejora la homogeneidad de la distribución del niobio ya que fomenta su difusión, también reduce la aparición de la fase $\omega$.

Entrando ya en el estudio propio de cada aleación y la influencia de los elementos aleantes en la microestructura obtenida cabe destacar que el valor de molibdeno equivalente ( $\mathrm{Mo}_{\text {equi }}$ ) obtenido en los tres casos es de 8.4. Se ha obtenido según la ecuación que se expone en el trabajo de Y. Yuan et al. [4].

$$
M o_{\text {equi }}=1.0 \mathrm{Mo}+0.6 \mathrm{~N}+0.44 \mathrm{~W}+2.9 \mathrm{Fe}+1.6 \mathrm{Cr}+0.3 \mathrm{Nb}+0.22 \mathrm{Ta}-1.0 \mathrm{Al}
$$

Dicho valor relaciona la microestructura con la cantidad de elementos aleantes y representa un baremo para predecir la microestructura que 
se va a obtener en condiciones de enfriamiento lento. En las tres aleaciones estudiadas el valor de $\mathrm{Mo}_{\text {equi }}$ es el mismo ya que el Sn es un elemento neutro dentro de las aleaciones de titanio y no influye en el cálculo de $\mathrm{Mo}_{\text {equi }}$.

Pero esto no impide que influya de forma indirecta en la microestructura final de las aleaciones. Se observa una evolución clara en función del contenido en Sn. Las aleaciones con estaño, Ti 30Nb 2Sn y, sobre todo, $\mathrm{Ti} 30 \mathrm{Nb} 4 \mathrm{Sn}$ muestran menores zonas con microestructura laminar de fase $\alpha+\beta$. En la figura 5.44 se observa dicha diferencia comparando las tres aleaciones. Las siguientes imágenes se han tomado utilizando la técnica de alto rango dinámico o High dynamic range (HDR) que proporciona un mayor contraste entre la fase $\beta$ y las fases $\alpha$ del borde de grano y las lamelas.

En la aleación $\mathrm{Ti}$ 30Nb aparecen muchas más zonas con microestructura lamelar perpendicular al borde de grano que en la aleación Ti 30Nb 2Sn. La aleación con 4 \% de estaño presentan menor presencia aún de estas lamelas pero se observa un ataque químico más heterogéneo. 

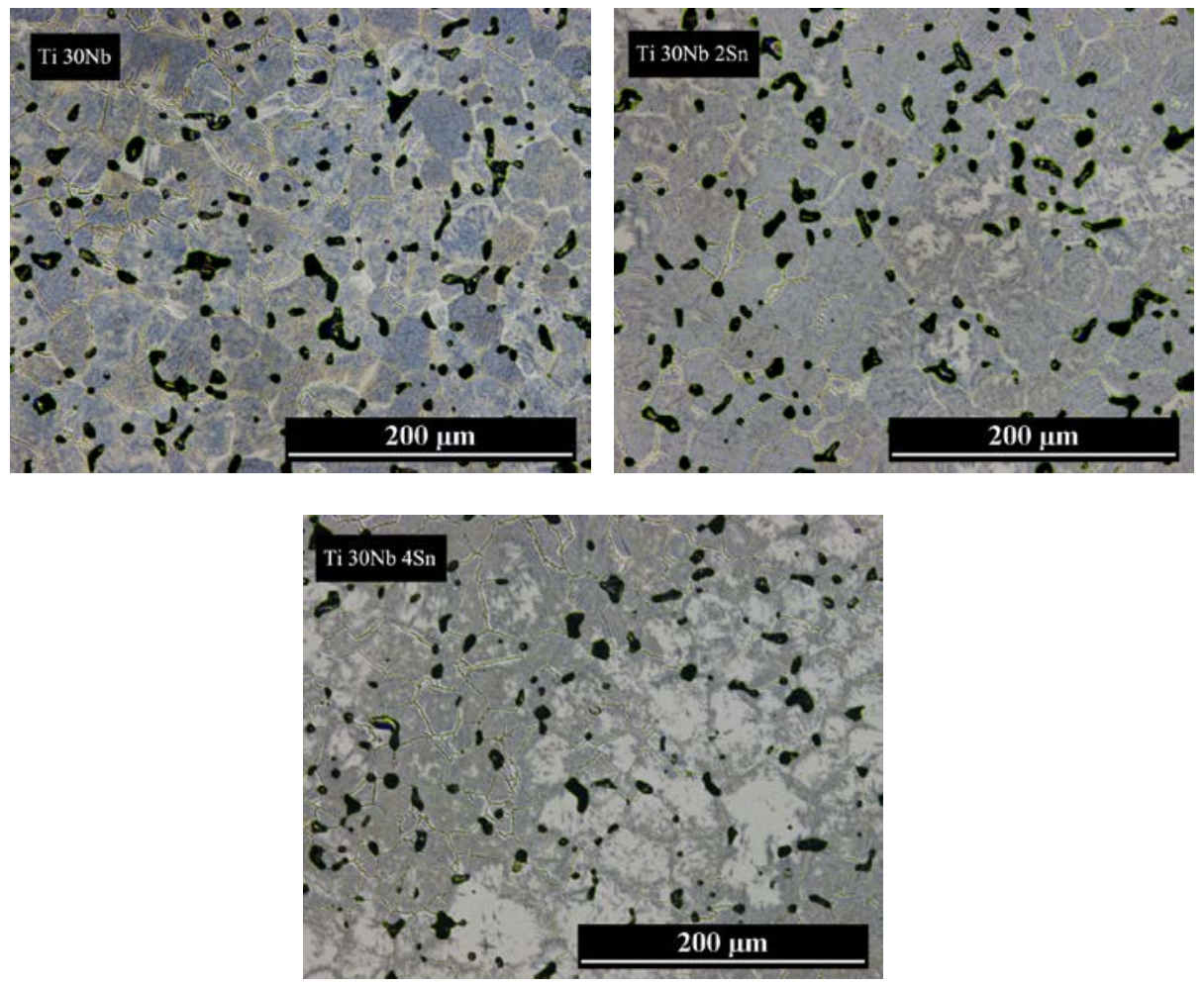

Figura 5.44. Imágenes de microscopía óptica de las tres aleaciones estudiadas tomadas con la técnica HDR.

La confirmación de la mayor difusión con la presencia del estaño viene dada por los análisis de EDS por TEM (figura 5.39 y figura 5.40.). El pequeño porcentaje de niobio presente dentro de las lamelas de $\alpha$ frente al obtenido en las lamelas de $\beta$, tabla 5.8, muestra como estas zonas de lamelas $\alpha+\beta$ poseen valores muy distintos de contenido en niobio por lo que se confirma la mejor difusión del niobio con la utilización de estaño ya que las zonas con microestructura lamelar se han reducido. 
Los análisis de SEM confirman la mayor presencia de niobio en las zonas totalmente $\beta$ frente a las zonas con microestructura $\alpha+\beta$ en las tres aleaciones: 33.76 frente a 35.20 para la aleación Ti $30 \mathrm{Nb}, 31.93$ frente a 32.25 para la aleación Ti 30Nb 2Sn y 30.02 frente a 32.02 para la aleación Ti 30Nb 4Sn.

Pero en los mapas de composición de TEM se observa la mayor heterogeneidad de la aleación $\mathrm{Ti} 30 \mathrm{Nb} 4 \mathrm{Sn}$ frente a la aleación Ti 30Nb 2Sn. Se observa cómo, en los mapas llevados a cabo en la zona lamelar de $\alpha+\beta$, la distribución del niobio es mucho mejor en la aleación con $2 \%$ de estaño, figura 5.40, frente a la aleación del 4 \%, figura 5.41, ya que la imagen del pico $\mathrm{K}$ del niobio muestra mayor homogeneidad en la aleación con 2 \%. En la aleación con 4 \% de Sn las láminas de $\alpha$ aparecen con menor contenido de $\mathrm{Nb}$.

La aleación Ti 30Nb 2Sn presenta mayor homogeneidad que la aleación sin Sn, Ti 30Nb porque presenta menor presencia de zonas de microestructura lamelar $\alpha+\beta$ como se observa en la figura 5.44 y que la aleación con 4 \% de Sn ya que la distribución del niobio dentro de la aleación es mucho mejor como se observa en los mapas de composición.

Para comparar la microestructura obtenida con la proporcionada por otros investigadores se puede observar la siguiente figura. Se muestra la homogeneidad microestructural conseguida por Rodriguez V.A.H. (como segundo autor) [5] utilizando la misma técnica 
pulvimetalúrgica y mezcla elemental de polvos. La energía aportada en la etapa de sinterizado es muy similar ya que aportan mucha más temperatura pero durante menor tiempo.
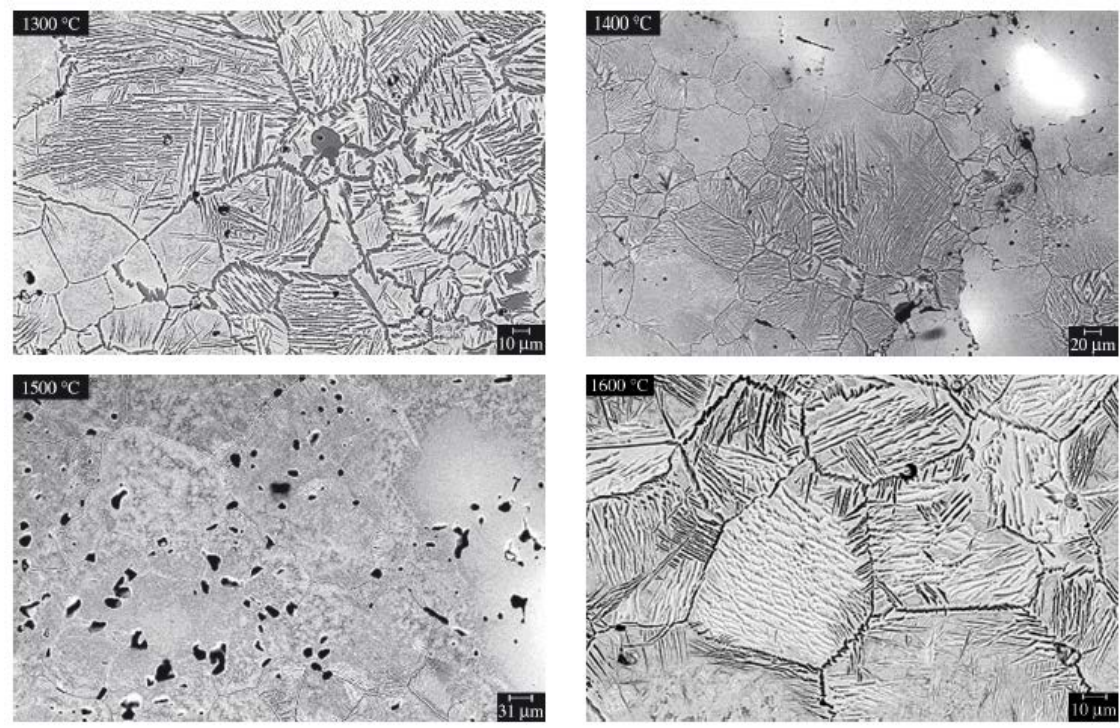

Figura 5.45. Microestructuras obtenidas de la aleación Ti 35Nb por Rodriguez V.A.H. [5] con un procesado similar al llevado a cabo en este estudio.

El estudio llevado a cabo por Rodriguez V.A.H. está elaborado sobre la aleación Ti 35Nb que en teoría debería mostrar una microestructura $\beta$ más marcada como muestran nuestros ensayos previos. Pero la falta de difusión y la presencia de partículas de $\mathrm{Nb}$, que no han difundido, desembocan en una estructura $\alpha+\beta$ y en una falta de homogeneidad clara. Se observa como aparecen granos en los que la microestructura es totalmente lamelar y en los granos de microestructura $\beta$ aparece un notable crecimiento de láminas de fase $\alpha$ perpendiculares al borde de grano. 
La mejora obtenida en nuestro proyecto en la homogeneidad microestructural es clara comparándola con la obtenida por Rodriguez V.A.H. La presencia de partículas de niobio sin difundir, la obtención de granos con microestructura totalmente lamelar y la mayor presencia de laminas de fase $\alpha$ junto a las fronteras de grano indican una falta notable de difusión del niobio. Gracias a la incorporación de pequeños contenidos de estaño y el procesado seguido en nuestro trabajo se ha conseguido una microestructura más homogénea en la que la microestructura mayoritaria es la $\beta$, no aparece partículas sin difundir de niobio y sólo aparece pequeñas zonas con laminas de fase $\alpha$ junto al borde de grano. Gracias a esta mejora en la homogeneidad de la microestructura y a la mayor presencia de fase $\beta$ se consigue que las propiedades sean mucho más adecuadas para la vida en servicio de las aleaciones obtenidas.

La presencia de sólo las fases más estables del titanio, $\alpha$ y $\beta$, viene justificada por el enfriamiento lento y la presencia de estaño en las aleaciones, que limita la posibilidad de la aparición de la fase $\omega$ como ya han demostrado otros autores en procesado por técnicas de fusión [6] y otros trabajos con el procesado por pulvimetalurgia [5].

En los difractogramas se observa cómo se obtienen las fases $\alpha$ y $\beta$, que se corresponde con la microestructura aportada por otros autores. Remarcar que la difracción de rayos X se ha utilizado para identificar fases y que no se ha pretendido conseguir otro tipo de caracterización 
referente a las fases o a las características de la red cristalina. A pesar de esto, en figura 5.46 se observa con más detalle el pico de mayor intensidad de la fase $\alpha$ (a) situado en el ángulo de difracción $2 \theta 40.22$ o, correspondiente al plano $(1,0,1)$, y el pico con la segunda mayor intensidad de la fase $\beta$, situado en $69.67^{\circ}$ correspondiente al plano (1, $1,2)(b)$.
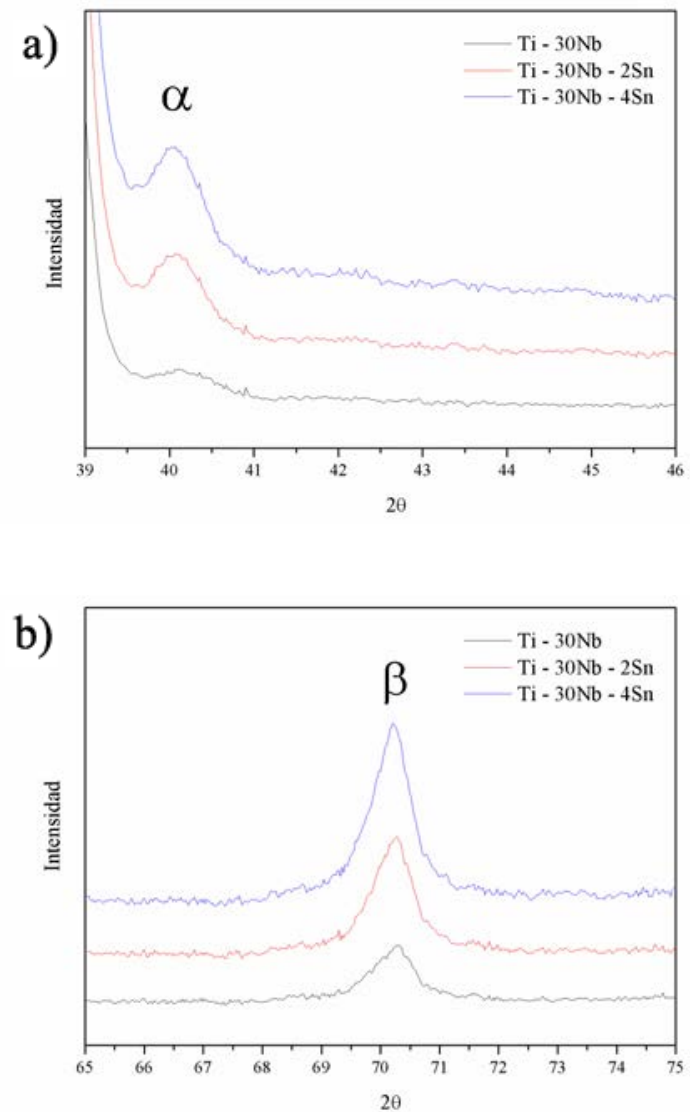

Figura 5.46. a) Detalle del pico situado a $40.22^{\circ}$ correspondiente al plano $(1,0,1)$ de la fase $\alpha$ y b) del pico situado en $69.67^{\circ}$ correspondiente al plano $(1,1,2)$ de la fase $\beta$ de las aleaciones estudiadas. 
Se observa como en ambos casos los picos están desplazados de su posición teórica para las tres aleaciones porque existe una distorsión en la red cristalina debido al tamaño de átomo de niobio y estaño (radio medio $145 \mathrm{pm}$ ) mayor que el del titanio (140 pm), los difractogramas patrón están tomados con Ti puro. También es debido a que puede aparecer algún elemento en solución sólida aunque no se ha observado en las imágenes obtenidas [7]. Las tensiones residuales debidas al procesado provocan el ensanchamiento de los picos [7].

La figura 5.47 y la figura 5.48 muestran la microestructura y los difractogramas obtenidos por Aleixo G.T. [8]. Este autor efectúa el ensayo Jominy sobre aleaciones de $\mathrm{Ti} 30 \mathrm{Nb} 2 \mathrm{Sn}$ y $\mathrm{Ti} 30 \mathrm{Nb} 4 \mathrm{Sn}$. Coloca varios termopares para comprobar la velocidad de enfriamiento según la posición, cuanto más alejado está el termopar de la superficie en contacto con el agua menor es la velocidad de enfriamiento registrada. Los datos son referentes a la zona más alejada $\mathrm{y}$, en consecuencia, con la que menor velocidad de enfriamiento.

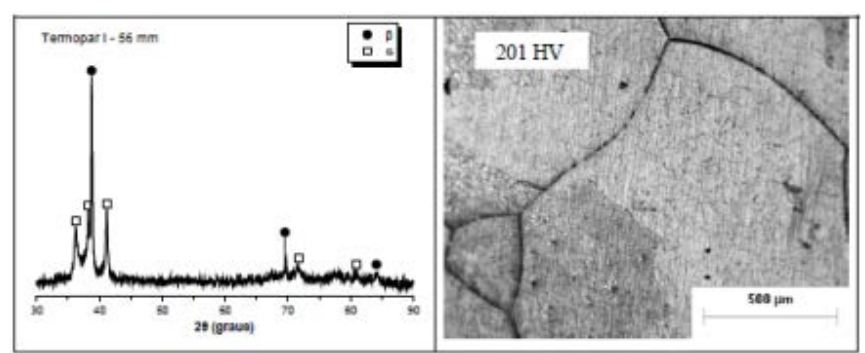

Figura 5.47. Difractograma y metalografía de la aleación Ti 30Nb 2Sn del estudio realizado por Aleixo G.T. [8]. 


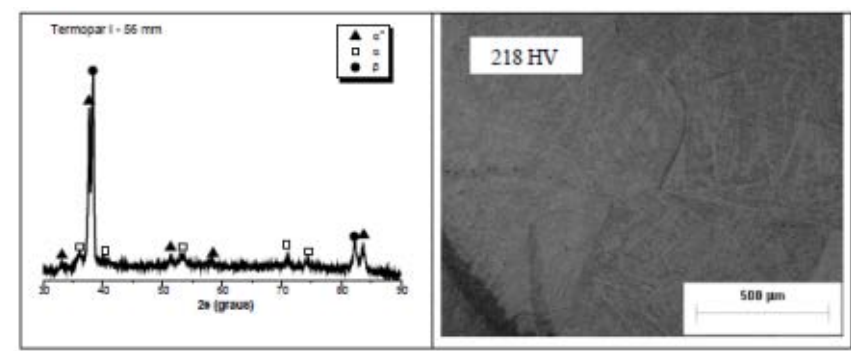

Figura 5.48. Difractograma y metalografía de la aleación Ti 30Nb 4Sn del estudio realizado por Aleixo G.T. [8].

Se observa como en la aleación Ti 30Nb 4Sn si que aparece algo de fase $\alpha$ '” ya que, a pesar de ser la velocidad más lenta de enfriamiento del estudio, es una velocidad mucho más rápida que la que se utiliza en este proyecto.

Por otro lado, en un trabajo anterior del mismo autor, se efectuó el mismo tipo de ensayo pero con la aleación Ti 30Nb [9]. Obteniendo resultados algo sorprendentes ya que en ninguna condición aparece fase $\alpha$, solo obtiene fase $\beta$ en las velocidades de enfriamiento más lentas. La velocidad de enfriamiento más lenta corresponde al difractograma I de la figura 5.49. La zona I es la del enfriamiento lento y la zona VI es la zona con el enfriamiento más rápido en la que sólo aparece microestructura $\alpha$ ’’ 


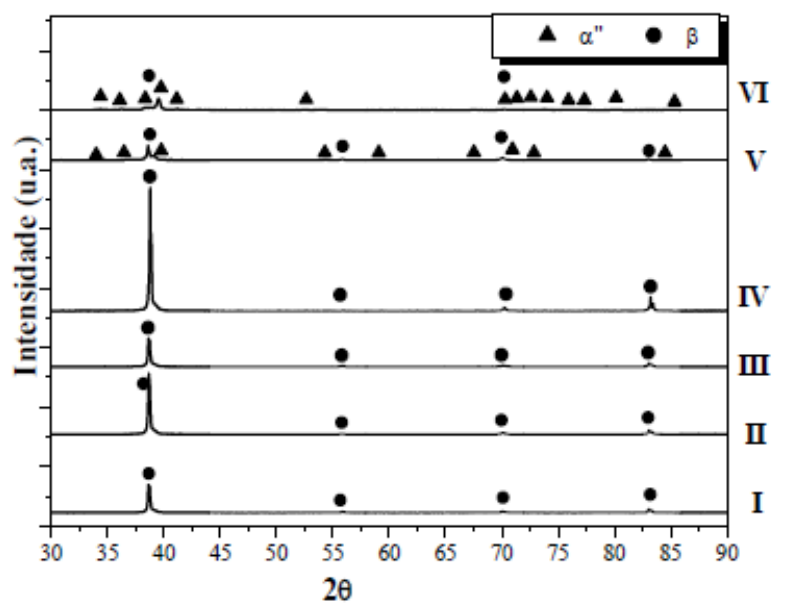

Figura 5.49. Difractogramas de la aleación Ti 30Nb en el estudio previo de velocidad de enfriamiento de Aleixo G.T. [9].

En un trabajo de Lopes E.S.N. [3] en el que se investiga mediante tratamientos térmicos la microestructura obtenida se observa que con un tratamiento térmico mínimo de $400{ }^{\circ} \mathrm{C}$ y 0.9 ks se obtiene microestructura $\alpha$ y $\beta$ en las aleaciones Ti 30Nb y Ti 30Nb 2Sn.

Pero existe otro trabajo del mismo autor, Lopes E.S.N. [10], trabajando con las tres aleaciones que, en ningún caso, los resultados expuestos son comparables porque no obtiene el mismo tipo de microestructura con fase $\alpha$ y fase $\beta$. Sólo en el caso de la aleación Ti $30 \mathrm{Nb} 4 \mathrm{Sn}$ se obtiene esta combinación de microestructura con un tratamiento térmico de $400{ }^{\circ} \mathrm{C}$ durante 8 horas. En la figura 5.50 se observan las fases obtenidas en cada caso y los valores de dureza y módulo elástico en función del tratamiento térmico. 
a)

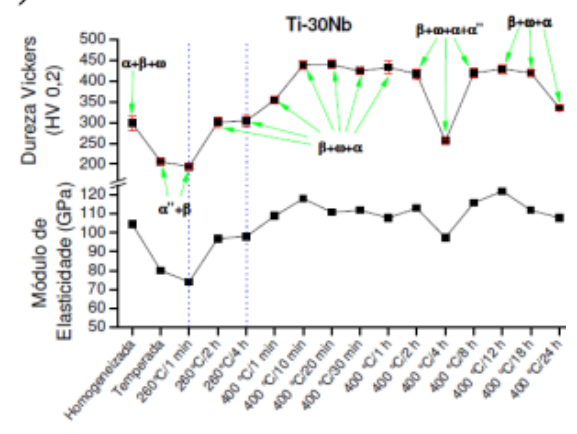

b)

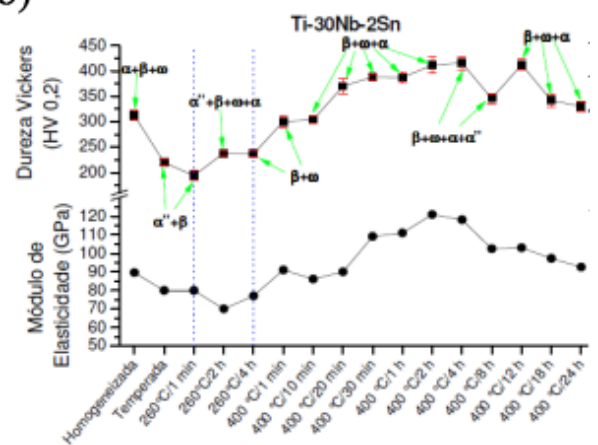

c)

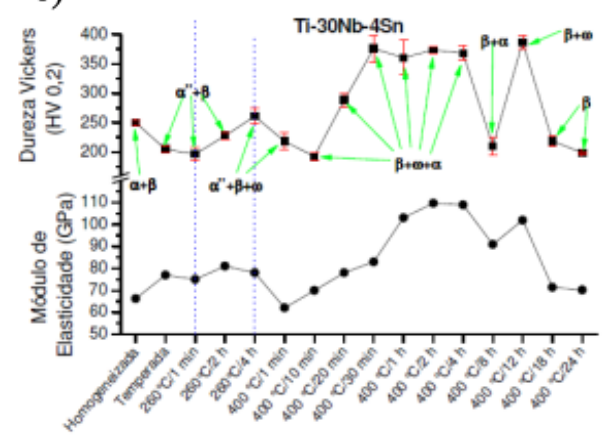

Figura 5.50. Microestructura, H y E obtenidas según el tratamiento térmico llevado a cabo en el trabajo de Lopes E.S.N. [10]; Ti 30Nb (a), Ti 30Nb 2Sn (b) y Ti 30Nb 4Sn (c).

Las propiedades mecánicas de este estudio no se van a tener en cuenta en la comparación con los resultados obtenidos en este proyecto por el mismo motivo, la microestructura no es comparable.

Los difractogramas aportados por otros autores muestran, en su mayoría, presencia de otras fases diferentes a la que se consigue en nuestro caso. La aparición de estas fases indeseadas no se ve mitigada por la adición de estaño en la composición como muestran los estudios de Aleixo G.T. ya que evoluciona de microestructura totalmente $\beta$ a microestructura $\beta+\alpha+\alpha$ ', de la aleación Ti 30Nb 4Sn. 
La presencia de otras fases es debida a que el enfriamiento se realiza de forma mucho más rápida que en el tipo de procesado que nosotros hemos realizado. En nuestro caso no se obtiene un cambio en la microestructura en función del contenido de estaño, en las tres aleaciones estudiadas se obtiene fase $\alpha$ y fase $\beta$ pero la incorporación de estaño minimiza la presencia de laminas de fase $\alpha$.

Cabe remarcar que microestructuralmente la aleación que presenta mejores resultados es la aleación Ti 30Nb 2Sn ya que aparecen pocas zonas de microestructura lamelar de $\alpha$ y $\beta$. En su mayoría la microestructura presente es de granos equiaxiales de fase $\beta$. Por otro lado, aparece una mejor distribución del niobio como se ha comprobado en los mapas por EDS realizado mediante TEM en los que la homogeneidad composicional de la aleación Ti 30Nb 4Sn es peor.

\subsection{Caracterización mecánica.}

Se ha determinado la influencia del estaño en las propiedades mecánicas. Se ha caracterizado la dureza de los materiales, la resistencia a flexión y se ha caracterizado las propiedades elásticas de las aleaciones, el coeficiente de Poisson y módulo elástico (E). Los valores de módulo elástico han sido obtenidos mediante distintas técnicas. 


\subsubsection{Microdureza.}

Los valores de microdureza se han obtenido a partir de las muestras preparadas metalográficamente en estado de pulido. Los valores obtenidos se muestran en la tabla 5.10 para cada aleación Ti 30Nb, Ti 30Nb 2Sn y Ti 30Nb 4Sn.

Tabla 5.10. Microdureza de las aleaciones estudiadas.

\begin{tabular}{|c|c|}
\hline Aleación & Dureza (HV) \\
\hline Ti $30 \mathrm{Nb}$ & $282.47 \pm 14.95$ \\
\hline Ti $30 \mathrm{Nb} 2 \mathrm{Sn}$ & $232.46 \pm 15.92$ \\
\hline Ti $30 \mathrm{Nb} 4 \mathrm{Sn}$ & $225.98 \pm 24.72$ \\
\hline
\end{tabular}

Se observa como existe una tendencia descendente en función del contenido en estaño y que la aleación que no tiene $\mathrm{Sn}$ en su composición alcanza una dureza superior en comparación al resto de materiales.

\subsubsection{Flexión a tres puntos.}

En este ensayo se ha obtenido la resistencia máxima de los materiales de estudio siguiendo la expresión 4.2 que aparece en el punto 4.4.2. No se ha calculado la pendiente de la zona elástica en el ensayo de flexión como una aproximación al módulo elástico para no inducir a ningún tipo de error. Dicha pendiente está relacionada con el módulo elástico de las aleaciones pero no es el módulo elástico. 
En la siguiente figura se observa los resultados obtenidos de resistencia máxima a flexión, relacionándolos con el contenido de estaño de cada aleación.

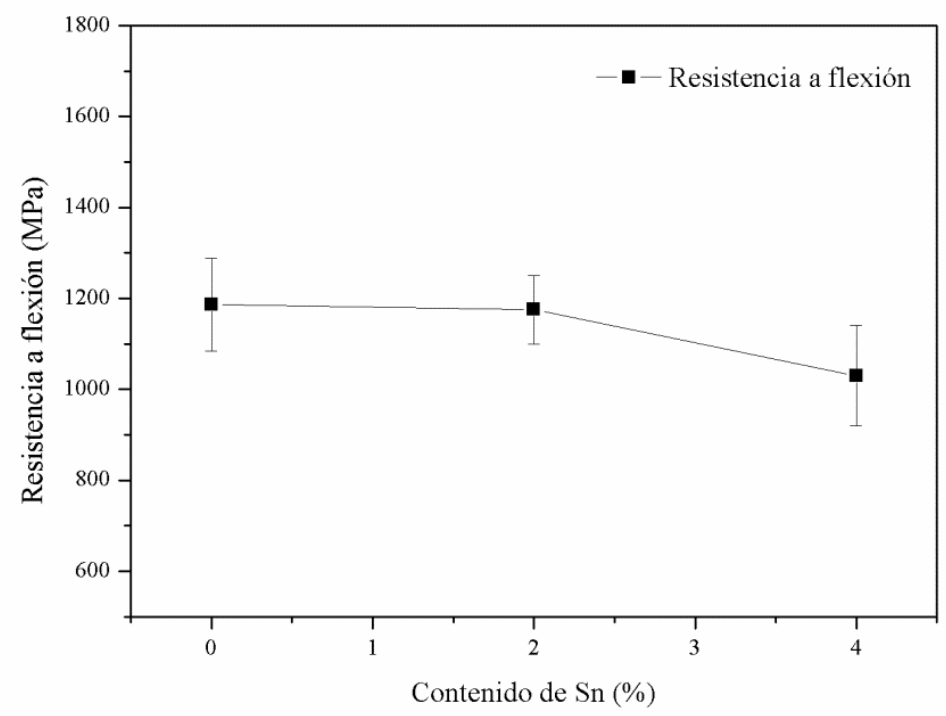

Figura 5.51. Resistencia máxima de las aleaciones estudiadas en el ensayo de flexión a tres puntos.

Se observa un descenso marcado en la resistencia a flexión cuando el contenido en estaño es del $4 \%$ frente a las aleaciones con menor contenido de estaño que poseen valores muy parecidos de resistencia.

\subsubsection{Obtención del módulo elástico por medio de ultrasonidos.}

En primer lugar se ha calculado el coeficiente de Poisson, ecuación 4.4, que expresa la deformación en la dirección transversal de 
aplicación de la carga. A continuación y siguiendo la ecuación 4.3 del apartado de procedimiento experimental referente al ensayo de ultrasonidos se ha calculado el módulo elástico de las aleaciones.

Tabla 5.11. Coeficiente de Poisson y módulo elástico de las aleaciones estudiadas obtenidos mediante el ensayo de ultrasonidos.

\begin{tabular}{|c|c|c|}
\hline Aleación & $\mathbf{E}_{\text {ultrasonidos }}$ (GPa) & Poisson \\
\hline Ti 30Nb & $78.68 \pm 4.89$ & $0.352 \pm 0.015$ \\
\hline Ti 30Nb 2Sn & $73.47 \pm 2.09$ & $0.358 \pm 0.005$ \\
\hline Ti 30Nb 4Sn & $72.92 \pm 2.32$ & $0.356 \pm 0.004$ \\
\hline
\end{tabular}

En este caso los valores de módulo elástico disminuyen de forma notable con la inclusión de estaño en las aleaciones estudiadas, en cuanto al coeficiente de Poisson los valores son muy próximos, y algo superiores a 0.35 .

\subsubsection{Ensayo de nanoindentación.}

En este ensayo se ha realizado el cálculo de la dureza (H) y del módulo elástico siguiendo dos metodologías totalmente diferentes: el propuesto por Oliver y Pharr y mediante la técnica de medida de rigidez continua o Continuous Stifness Measurement (CSM). Para el cálculo en ambos casos se ha utilizado los valores del coeficiente de Poisson de cada aleación obtenidos por el ensayo de ultrasonidos. 
En las siguientes figuras se puede observar la matriz resultante de cada ensayo en la que se observan las 25 indentaciones y el detalle de las indentaciones de cada aleación.
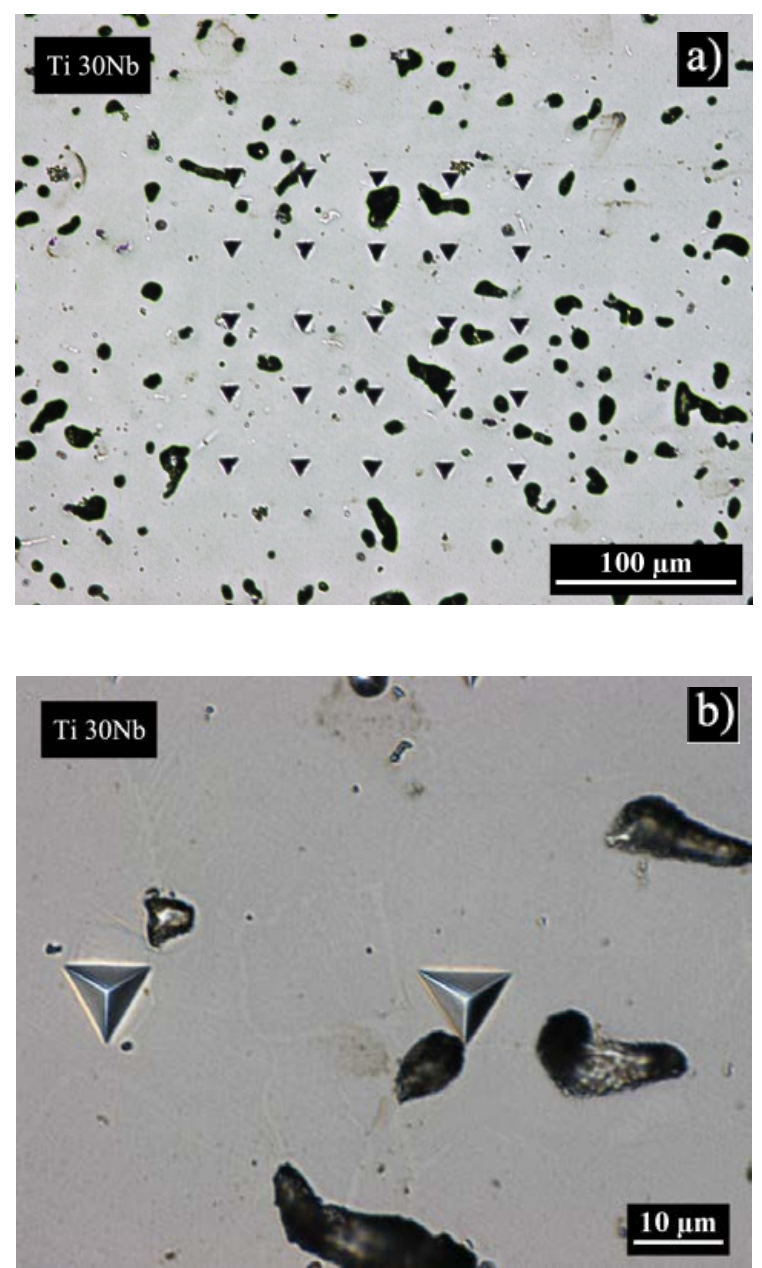

Figura 5.52. Matriz de nanoindentación (a) y detalle de las indentaciones (b) para la aleación Ti 30Nb. 

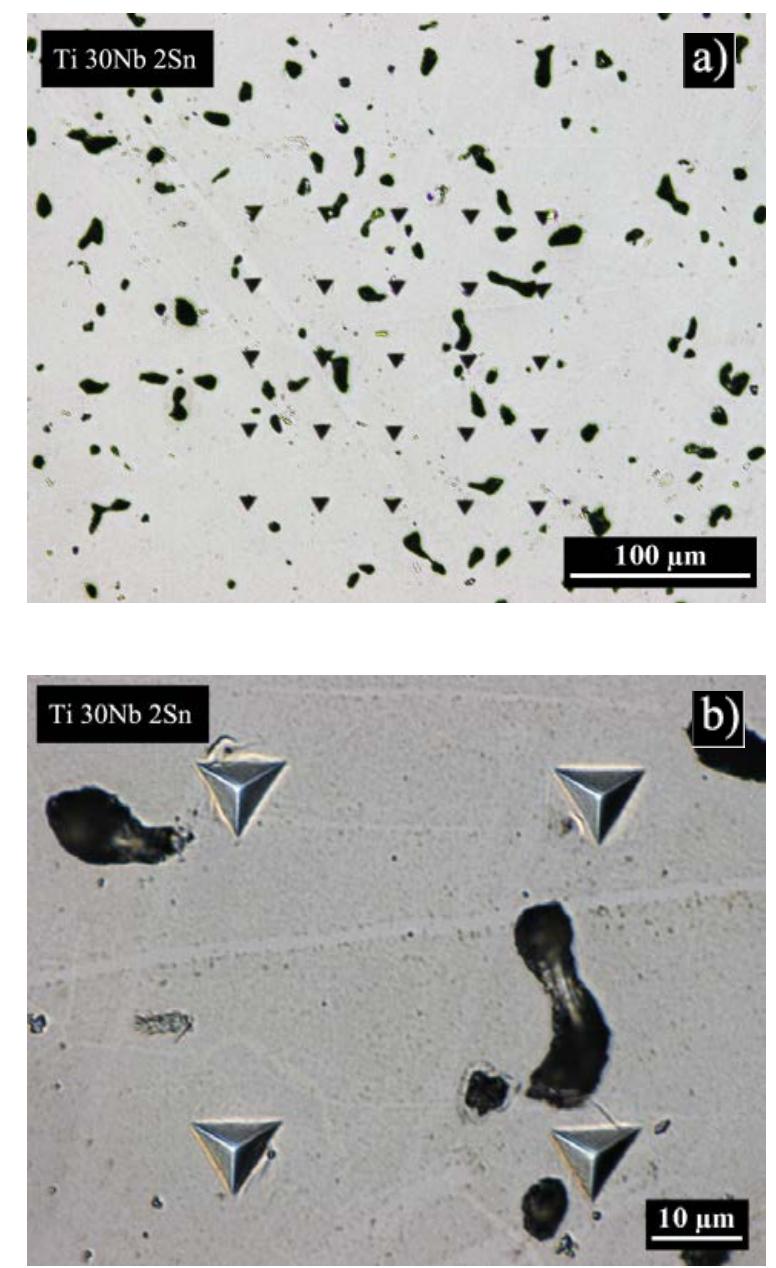

Figura 5.53. Matriz 5x5 de las indentaciones (a) y detalle de 4 indentaciones (b) en la aleación Ti 30Nb 2Sn. 

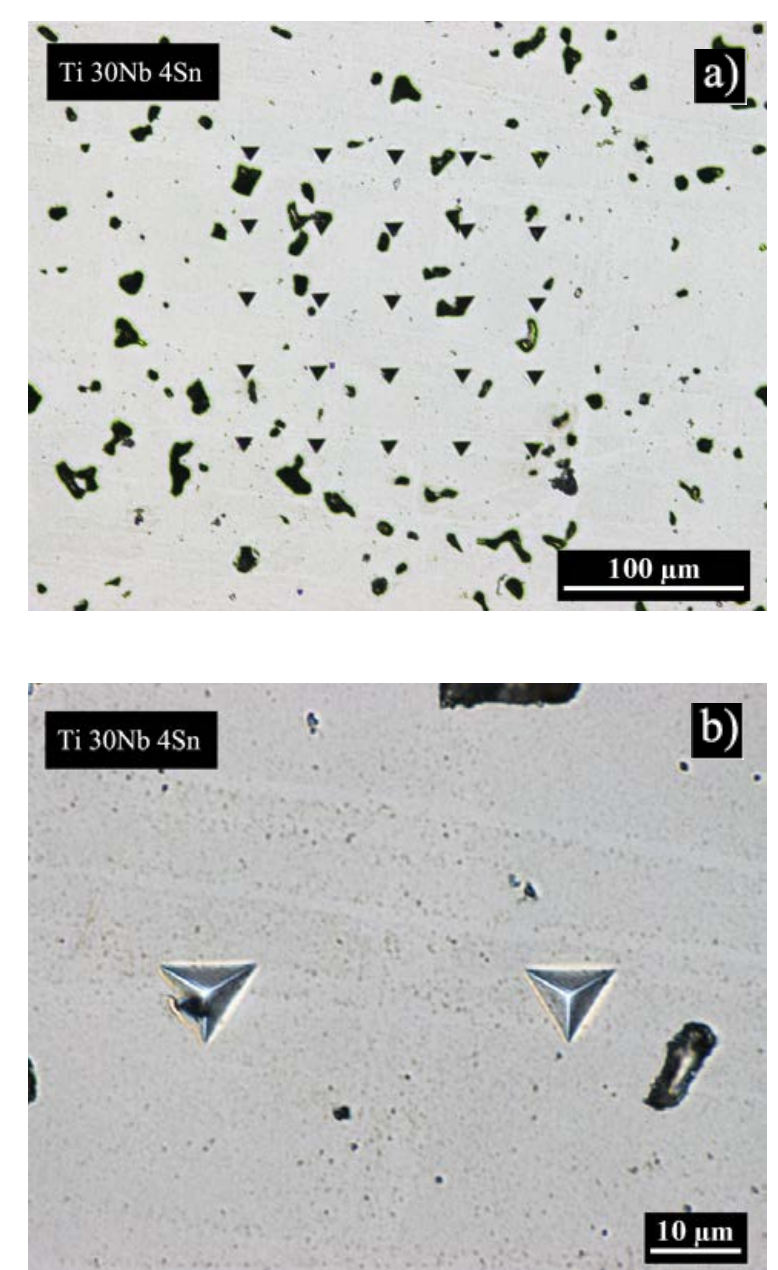

Figura 5.54. Huellas del ensayo de nanoindentación en general (a) y en detalle (b) de la aleación Ti 30Nb 4Sn.

Evidentemente, se ha eliminado las indentaciones que mostraban algún tipo de irregularidad tanto en la inspección con el microscopio óptico como en la curva de P-h o en los perfiles de E o H. 


\subsubsection{Cálculo por Oliver y Pharr.}

Como ya se ha dicho con anterioridad el método de Oliver y Pharr utiliza la primera zona de descarga de la curva P-h del ensayo. En la tabla 5.12 se muestra los valores de dureza obtenidos y los valores de módulo elástico.

Tabla 5.12. Dureza y módulo elástico de las muestras obtenidas por el método de Oliver y Pharr.

\begin{tabular}{|c|c|c|}
\hline Aleación & $\mathbf{H}_{\text {O\&P }}$ (GPa) & $\mathbf{E}_{\text {O\&P }}$ (GPa) \\
\hline Ti $30 \mathrm{Nb}$ & $3.643 \pm 0.260$ & $81.658 \pm 3.965$ \\
\hline Ti $30 \mathrm{Nb} 2 \mathrm{Sn}$ & $3.658 \pm 0.212$ & $79.009 \pm 4.297$ \\
\hline Ti $30 \mathrm{Nb} 4 \mathrm{Sn}$ & $3.409 \pm 0.173$ & $74.025 \pm 4.418$ \\
\hline
\end{tabular}

\subsubsection{Cálculo mediante medida de rigidez continua (CSM).}

En este caso se calculan los valores de $\mathrm{H}$ y E en toda la profundidad del ensayo con lo que se obtiene un perfil de dureza y otro de módulo elástico. En la siguiente figura se observa una gráfica típica de $\mathrm{H}$ y E en función de la profundidad de penetración de una aleación de titanio con microestructura tipo $\beta$. 

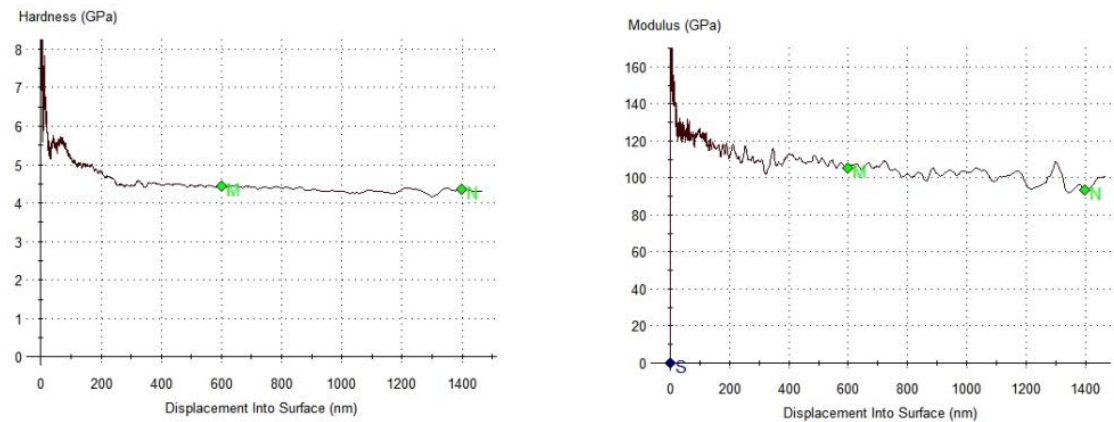

Figura 5.55. Ejemplo de los perfiles de E y H obtenidos directamente del equipo en el ensayo de nanoindentación mediante el cálculo por CSM de una aleación $\beta$-Ti.

Se observa como en los primeros nanómetros de penetración los valores no son fiables dado que hay problemas de contacto entre la pieza y la punta del indentador debido al redondeo de ésta, fuerzas de corto alcance, mala detección de la superficie, etc. por lo que estos valores se descartan para observar la influencia del contenido de estaño en la dureza y el módulo elástico.

En el tramo siguiente se estabiliza la curva y ofrece un valor constante de $\mathrm{H}$ y E respectivamente. Se puede observar como el perfil en el caso de $\mathrm{H}$ es mucho más estable que en el caso de $\mathrm{E}$ debido a que la distribución de presión de contacto plástico es mucho menor que la distribución de presión de contacto elástico. Debido a la naturaleza del material (poros, cambios de fase, etc.) el perfil de E se ve afectado antes por este tipo de irregularidades.

En las siguientes figuras se muestra la media de los perfiles de $\mathrm{H}$ y E de cada aleación, Ti 30Nb, Ti 30Nb 2Sn y Ti 30Nb 4Sn. 

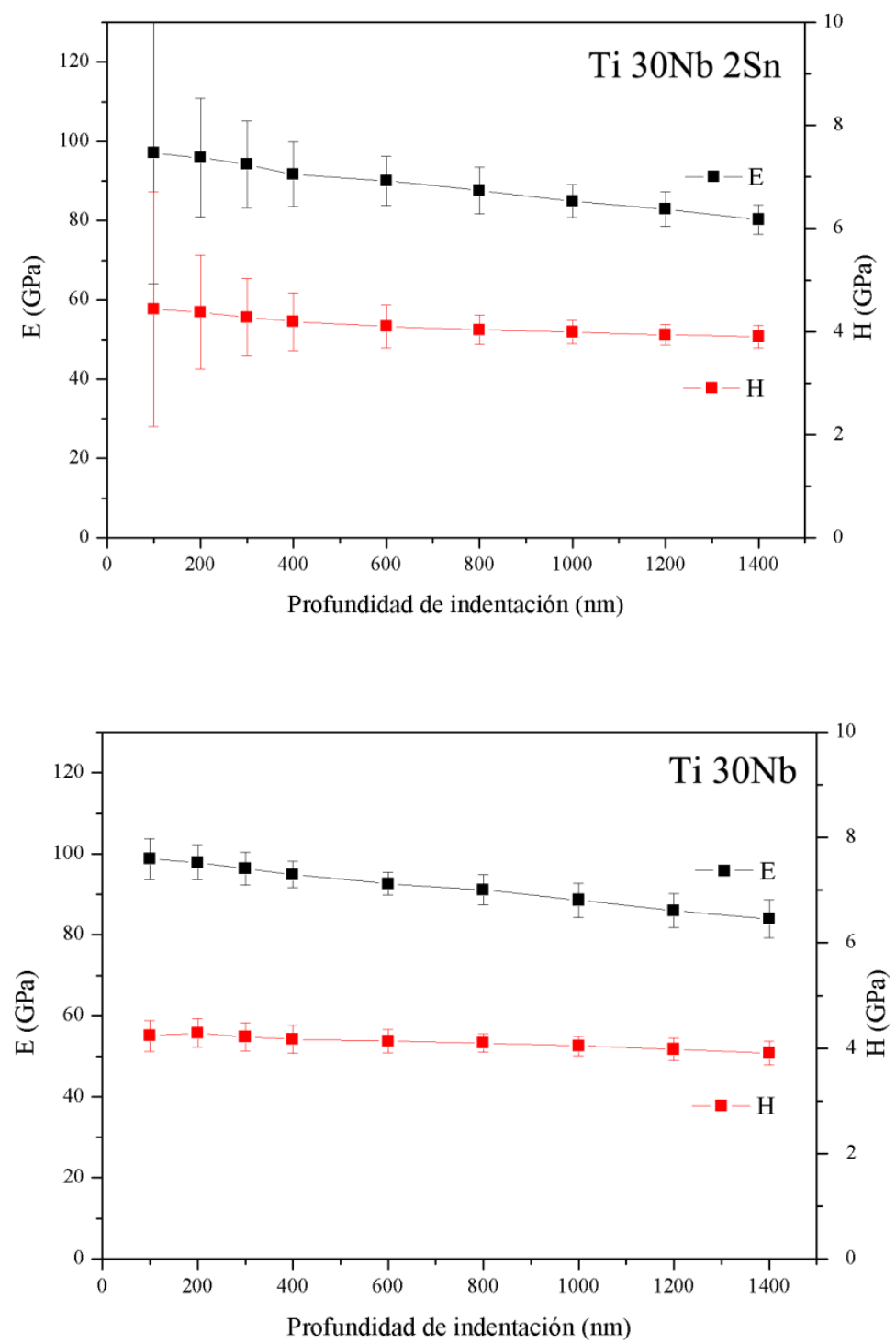


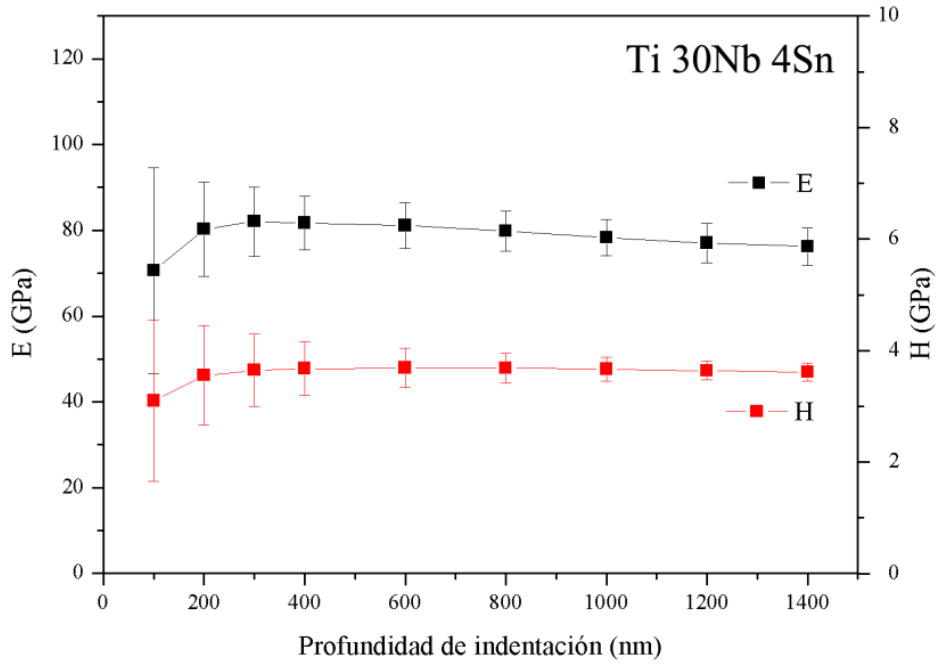

Figura 5.56. Perfiles de E y H de las aleaciones estudiadas.

Para obtener un valor medio de E y $\mathrm{H}$ se ha realizado el promedio del tramo lineal del perfil, concretamente se ha trabajado con los resultados entre 600 y $1400 \mathrm{~nm}$. De este modo se evitan los problemas de contacto que se ha comentado y también la capa de pasivación que forman estas aleaciones. La tabla 5.13 ofrece los valores medios de E y H obtenidos por CSM.

Tabla 5.13. E y H obtenidos por nanoindentación mediante el cálculo por CSM.

\begin{tabular}{|c|c|c|}
\hline Aleación & $\mathbf{H}_{\text {CSM }}$ (GPa) & $\mathbf{E}_{\text {CSM }}$ (GPa) \\
\hline Ti 30Nb & $4.054 \pm 0.173$ & $89.042 \pm 3.652$ \\
\hline Ti 30Nb 2Sn & $4.001 \pm 0.251$ & $85.797 \pm 4.807$ \\
\hline Ti 30Nb 4Sn & $3.666 \pm 0.230$ & $78.766 \pm 4.417$ \\
\hline
\end{tabular}


En la siguiente figura se observa los valores de dureza y módulo elástico obtenidos por CSM y los anteriormente expuestos obtenidos por Oliver y Pharr.

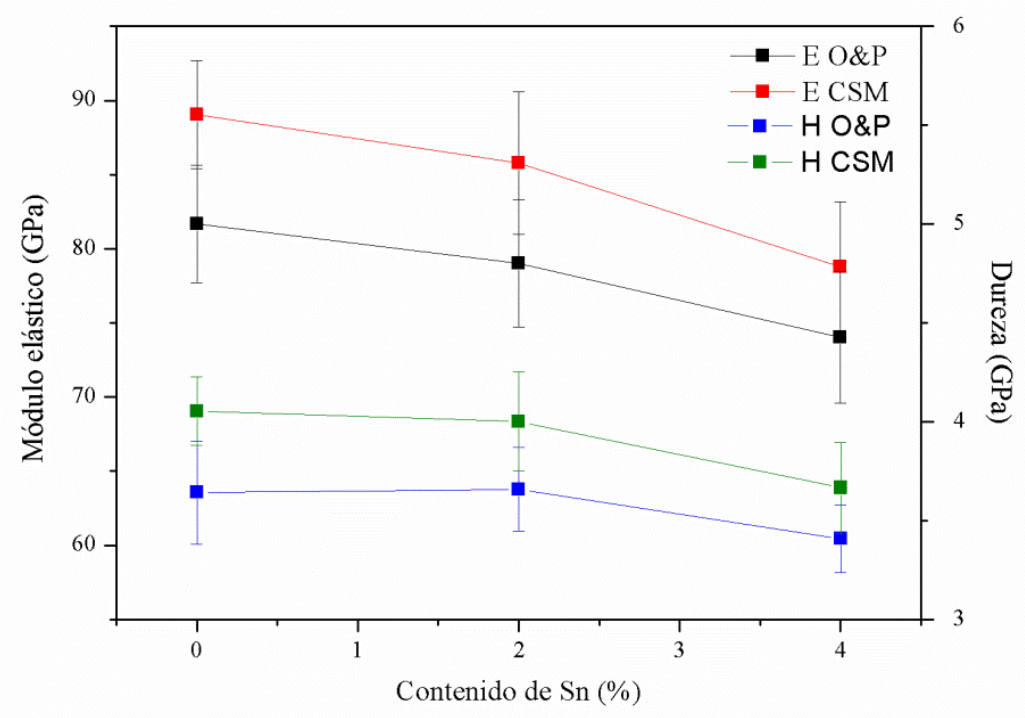

Figura 5.57. Media de H y E en el ensayo de nanoindentación calculados por CSM y por Oliver y Pharr de las aleaciones estudiadas.

Los valores obtenidos por O\&P son ligeramente menores que los calculados por CSM. En todos los casos de dureza y módulo elástico se muestra el mismo descenso de propiedades con la adición de estaño.

\subsubsection{Ensayo de compresión.}

Por último, en este ensayo se ha obtenido el valor del módulo elástico y del límite elástico de las aleaciones. Debido al comportamiento 
plástico de las aleaciones estudiadas en ningún caso se ha llegado a la rotura del material, los ensayos se han detenido a los 3/4 de la carga máxima de la célula de carga, es decir 75 kN.

De este modo, los valores de módulo elástico y límite elástico se muestran en la tabla 5.14 .

Tabla 5.14. Resultados del ensayo de compresión de las aleaciones estudiadas, valores de módulo elástico y límite elástico.

\begin{tabular}{|c|c|c|}
\hline Aleación & $\mathbf{E}_{\text {Compresion }}$ (GPa) & $\mathbf{R}_{\mathbf{p}}$ (MPa) \\
\hline $\mathrm{Ti}$ 30Nb & $52.29 \pm 5.78$ & $927 \pm 16$ \\
\hline $\mathrm{Ti}$ 30Nb 2Sn & $47.57 \pm 1.19$ & $904 \pm 11$ \\
\hline $\mathrm{Ti}$ 30Nb 4Sn & $48.60 \pm 1.74$ & $895 \pm 13$ \\
\hline
\end{tabular}

Se observa como el comportamiento de módulo elástico es muy similar al obtenido mediante el ensayo de ultrasonido, aunque valores bastante inferiores. La tendencia de los valores de límite elástico es casi la misma que la obtenida de otras características resistentes como la resistencia máxima en el ensayo de flexión $\left(\mathrm{R}_{\mathrm{tr}}\right)$.

\subsubsection{Discusión propiedades mecánicas.}

Las propiedades mecánicas obtenidas se han comparado en una primera aproximación entre sí para obtener la evolución en función del contenido en estaño. Posteriormente se ha discutido los resultados con los propuestos por otros autores. 
El contenido en oxígeno obtenido después del procesado de las piezas es alto como se ha podido observar en la tabla 5.7 de los resultados. El valor aproximado de 0.5 \% para las tres aleaciones, en la aleación Ti $30 \mathrm{Nb} 4 \mathrm{Sn}$ se obtiene mayor contenido en oxígeno, repercute en el comportamiento y se puede manifestar en dos consecuencias claras: en primer lugar y dado el carácter alfágeno del oxígeno se promueve la formación de fase $\alpha$ que tiene mayores valores resistentes y mayores valores de módulo elástico que la fase $\beta$ [11]. Dado que el contenido de oxígeno en la aleación con $4 \%$ de estaño es mayor la influencia es también mayor, el comportamiento final de esta aleación no es tan favorable como debería ser debido a este mayor porcentaje en oxígeno. Se acentúa la presencia de lamelas de $\alpha$, si el contenido de oxígeno fuese menor la presencia de microestructura $\alpha$ también lo sería. En segundo lugar, la aparición de la temida alpha case [12] pero en este estudio no ha habido ningún indicio en las imágenes tomadas con el microscopio óptico ni con el microscopio electrónico de barrido.

En una primera aproximación se ha observado la influencia de parámetros intrínsecos del procesado por pulvimetalurgia (porosidad, contenido de oxígeno, etc.) en las propiedades mecánicas finales de las aleaciones.

La figura 5.58 muestra la evolución de la porosidad, el tamaño del poro y el tamaño de grano respecto al contenido en estaño de las aleaciones: 


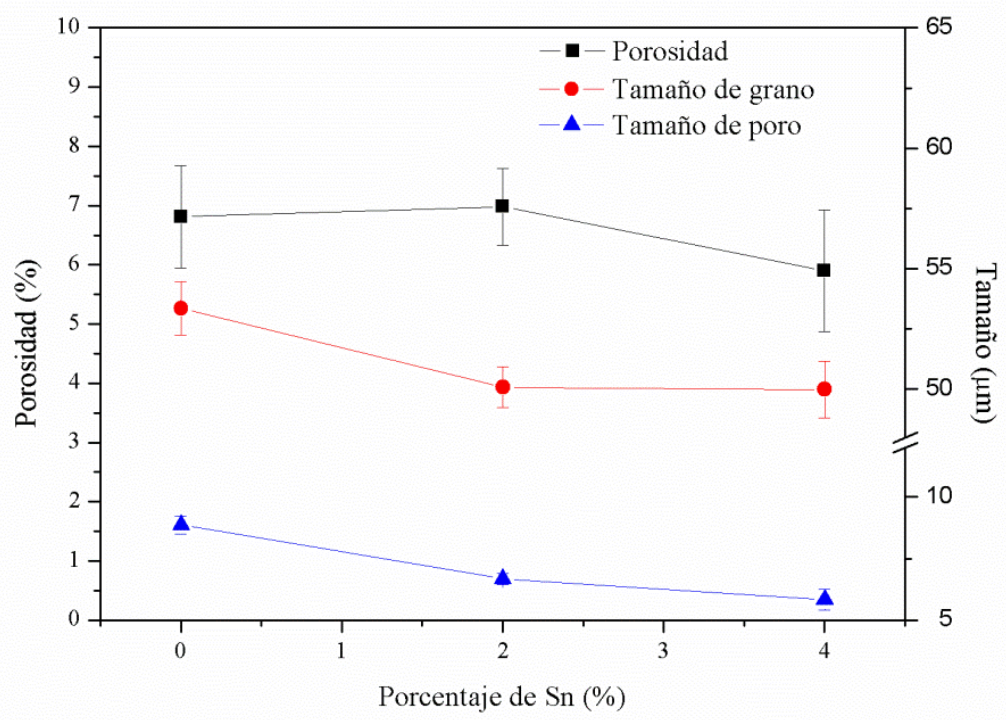

Figura 5.58. Evolución de la porosidad, el tamaño de poro y el tamaño de grano con relación al contenido de estaño.

Se observa cómo se obtiene una menor porosidad, un menor tamaño de poro y un menor tamaño de grano. Según estos resultados, debería haber un incremento en las propiedades resistentes del material. La disminución de la porosidad, del tamaño de poro y del tamaño de grano favorece las propiedades resistentes de los materiales. Pero esto no se refleja en los resultados obtenidos en los ensayos mecánicos macroscópicos realizados de flexión y compresión, donde disminuye con el porcentaje de Sn.

En la siguiente figura se observa la evolución de la resistencia máxima a flexión y el límite elástico en el ensayo de compresión en función del contenido en estaño. 


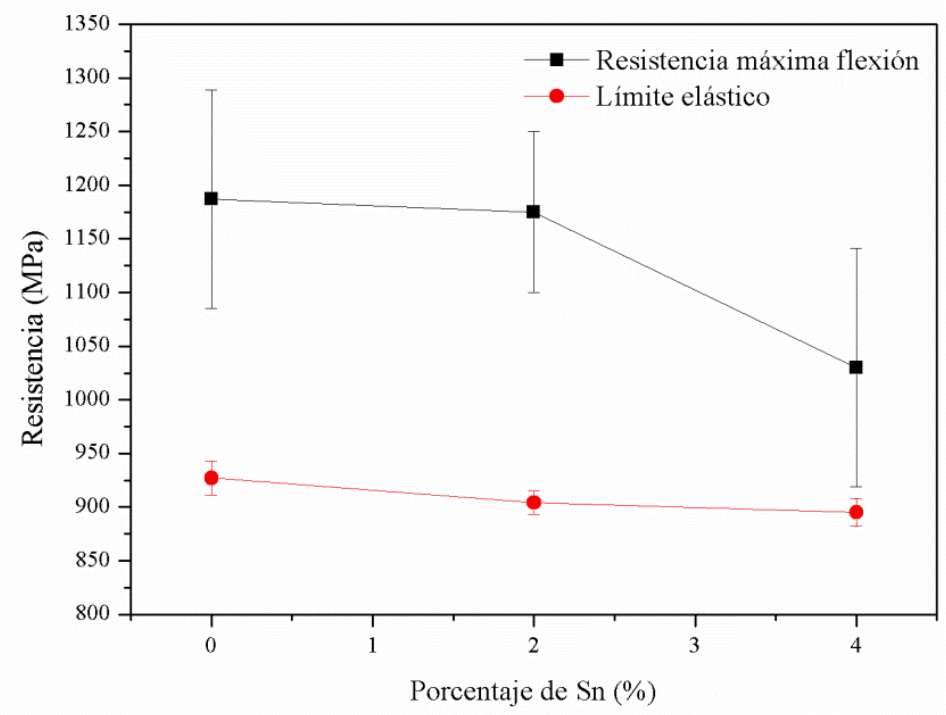

Figura 5.59. Evolución de la resistencia máxima a flexión y el límite elástico en función del contenido en Sn.

Se observa que a pesar de la evolución de la porosidad, el tamaño de los poros y el tamaño de grano de la figura 5.58 con el aumento del contenido de estaño la resistencia a flexión y el límite elástico es cada vez menor.

Como se ha comprobado anteriormente, al aumentar el contenido de estaño la presencia de microestructura tipo $\beta$ es mayor en relación a la microestructura lamelar $\alpha+\beta$. Los datos obtenidos demuestran que la influencia de la microestructura es mucho mayor que la influencia de la porosidad, tamaño de poro y tamaño de grano ya que la aleación con mayores características resistentes es la Ti 30Nb. También se 
observa como los valores de la aleación Ti 30Nb 2Sn son ligeramente más fiables ya que el intervalo de confianza es menor.

Los valores de dureza obtenidos en el ensayo de nanoindentación por el método de CSM muestran como los perfiles de dureza tienen un plato estable muy similar en los tres casos siendo la dureza de la aleación $\mathrm{Ti} 30 \mathrm{Nb} 4 \mathrm{Sn}$ algo menor. En la figura 5.60 se observa la evolución de los perfiles, desde la primera zona de estabilización, donde los valores no son representativos por los errores que se cometen y que se ha comentado en apartados anteriores, hasta la zona de estabilidad donde las medidas se estabilizan y son totalmente válidas.

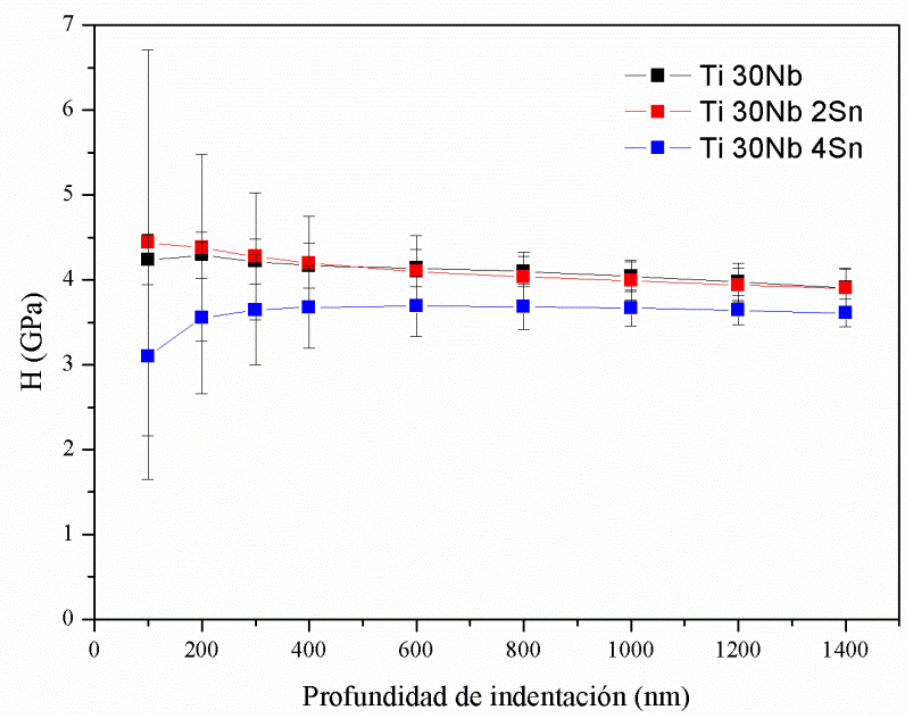

Figura 5.60. Perfiles de dureza de las tres aleaciones estudiadas obtenidos por el ensayo de nanoindentación por el método de CSM. 
Los valores de dureza obtenidos por los tres métodos utilizados (nanoindentación por Oliver y Pharr, nanoindentación por CSM y microdurezas) se observan en la gráfica 5.61 y su evolución en función del contenido en estaño. Los valores de dureza obtenidos en el ensayo de microdureza se han convertido a GPa [13] para poder ser comparables con los obtenidos por nanoindentación.

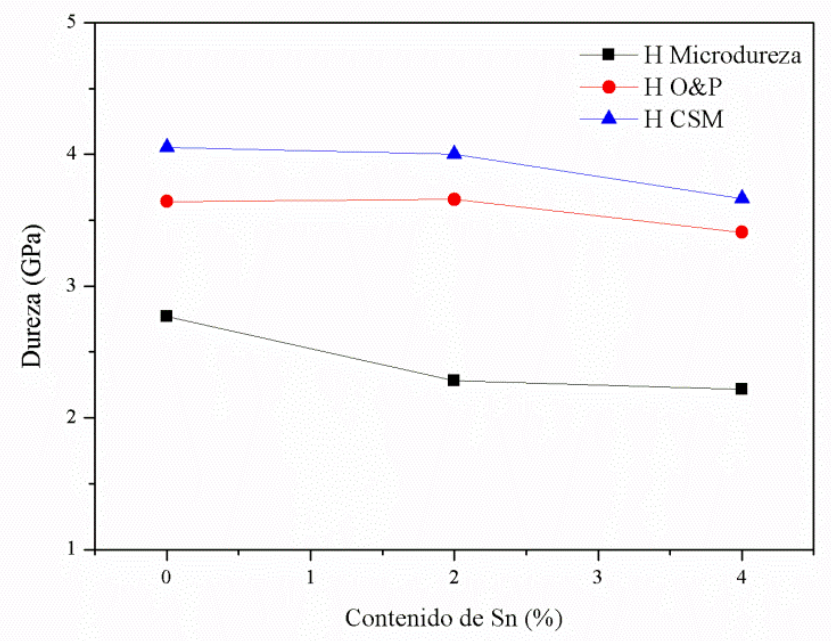

Figura 5.61. Evolución de la dureza en función del contenido en estaño de las distintas técnicas utilizadas.

Se obtiene el mismo comportamiento en los valores de dureza que en el ensayo de resistencia a flexión. La pérdida de propiedades resistentes entre la aleación Ti 30Nb 2Sn y la aleación Ti 30Nb 4Sn es mayor que la pérdida entre las aleaciones con estaño y la aleación Ti $30 \mathrm{Nb}$ excepto en el caso de la dureza obtenida por microdureza. 
Sí se comparan los valores obtenidos con los de otros autores que trabajan con las mismas aleaciones pero procesadas mediante técnicas de fusión y tratamientos térmicos con velocidades de enfriamiento muy lentas, se observan diferencias notables. Se ha comparado los valores de dureza que se presentan en los trabajos de Aleixo G.T. [8, 9] comentados en la discusión de la microestructura y los datos obtenidos por Lopes E.S.N. [3]. Todos estos datos de dureza de otros autores han sido obtenidos mediante microdureza Vickers.

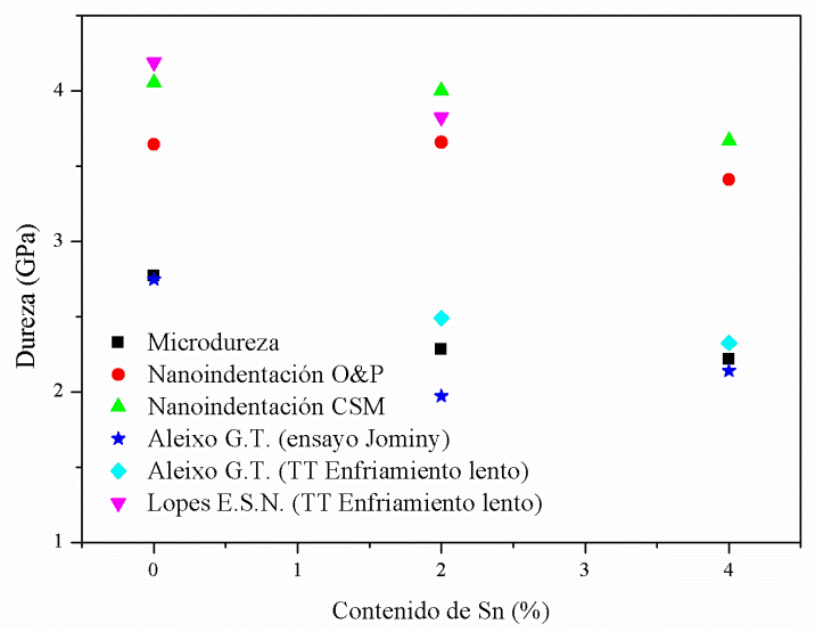

Figura 5.62. Evolución de la dureza con el contenido en estaño comparando los datos obtenidos por otros autores.

Se observa como la dureza sigue la misma evolución, hay un descenso con el aumento del contenido en estaño. Excepto en el caso de los datos aportados por Aleixo G.T. (ensayo Jominy). Recordar que estos resultados de Aleixo G.T. son sobre materiales de forja a los que se le ha realizado un ensayo Jominy para observar la influencia del 
enfriamiento y los datos mostrados corresponden al enfriamiento más lento.

Destacar que los valores de durezas mostrados por otros autores son totalmente equiparables a los obtenidos en este proyecto por el ensayo de microdureza, a pesar de estar procesadas por pulvimetalurgia convencional y del alto contenido en oxígeno. La evolución del contenido en fase $\alpha$, más resistente, justifica la evolución de la dureza de las aleaciones.

Los perfiles de módulo elástico obtenidos en el ensayo de nanoindentación calculados por CSM se muestran en la figura $5.63 \mathrm{y}$ siguen el mismo comportamiento que los valores de dureza del mismo ensayo. 


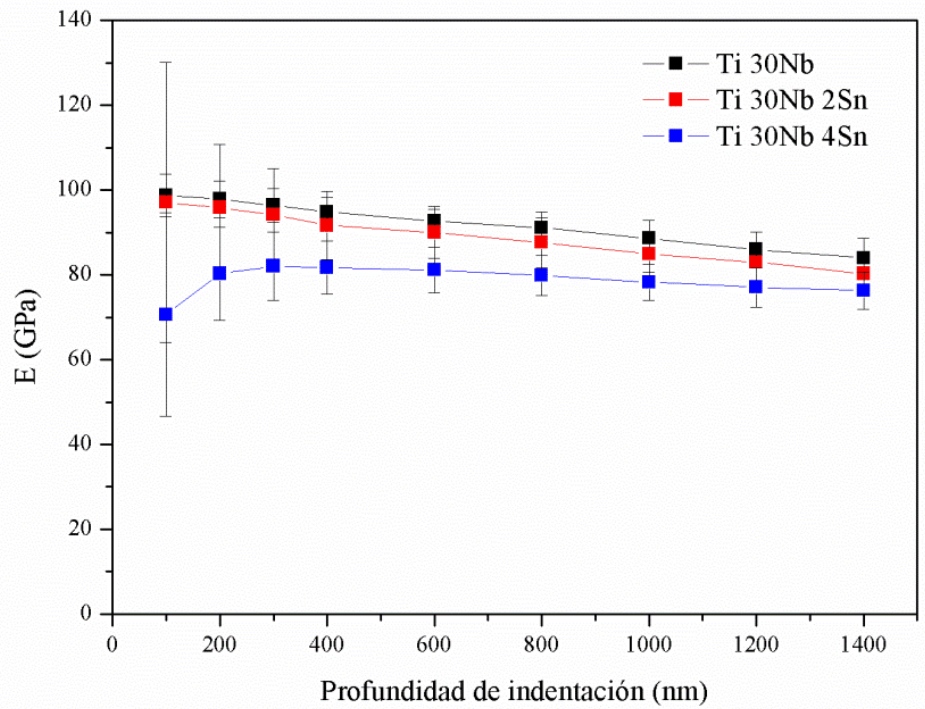

Figura 5.63. Perfiles de módulo elástico de las aleaciones estudiadas obtenidos en el ensayo de nanoindentación y calculadas por CSM.

En la figura 5.64 se puede observar los valores de módulo elástico obtenidos con las distintas técnicas y relacionados con el contenido de estaño.

Se observa como al aumentar el contenido de estaño los valores experimentan un descenso, más destacado en los datos obtenidos por nanoindentación. Los valores obtenidos por ensayos de ultrasonidos y compresión experimentan un descenso menor del valor de módulo elástico en función del contenido de estaño, incluso en ambos casos aparece un pequeño incremento, debido a que la porosidad afecta a estos valores y la porosidad de la aleación Ti 30Nb 4Sn es la menor como se observa en la figura 5.58. 


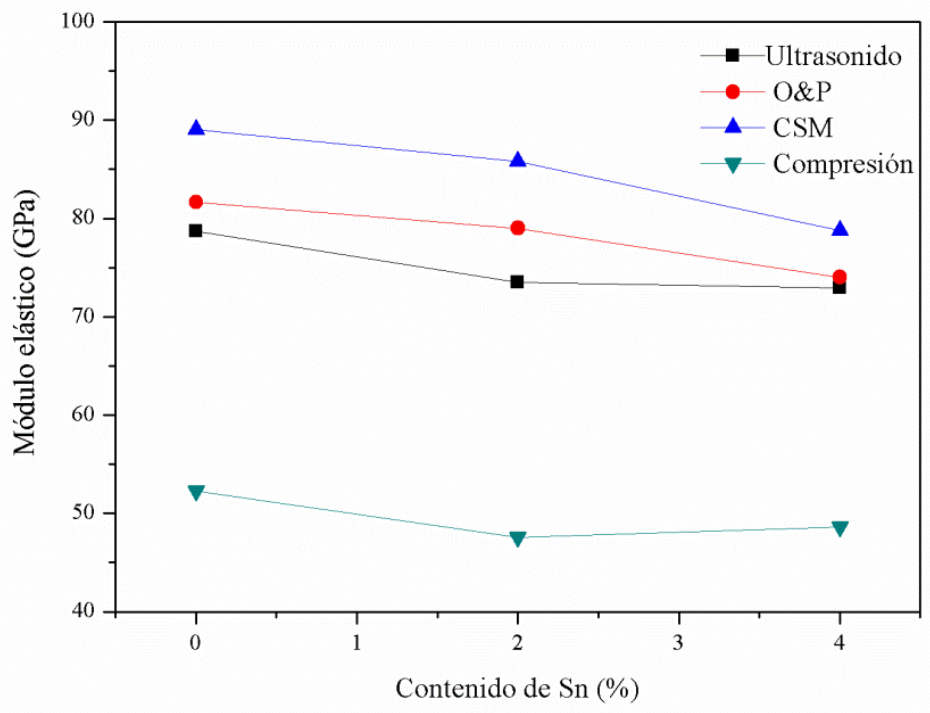

Figura 5.64. Módulo elástico obtenido mediante los distintos ensayos de las aleaciones estudiadas en función del contenido de estaño

La gran diferencia entre los resultados obtenidos en las distintas técnicas, entre los ensayos, se fundamenta en los propios ensayos y en las características de éstos. Es decir, en los ensayos de nanoindentación no se tiene en cuenta la porosidad de las muestras ya que es un ensayo a nivel nanométrico. En los ensayos de ultrasonidos y compresión sí que se tiene en cuenta esta porosidad ya que son ensayos macroscópicos. Esta porosidad disminuye el módulo elástico de los materiales.

Las variaciones observadas entre los valores obtenidos mediante compresión y ultrasonidos se justifican también por la naturaleza del ensayo. En el ensayo de compresión al ejercer una solicitación sobre 
la muestra, ésta soporta la tensión y se deforma elásticamente hasta el límite elástico, posteriormente se deforma plásticamente. Esta tensión soportada está relacionada de forma directa con la sección útil de la pieza de trabajo, pero en esta sección no se tiene en cuenta la distribución de la porosidad dentro de la pieza.

Dada la naturaleza de los materiales y del procesado aparece una porosidad que se distribuye de forma homogénea en la pieza como se observa en la figura 5.8 en la que se muestra una imagen de la aleación Ti 30Nb para obtener la porosidad. Aunque la distribución sea homogénea siempre aparece una zona con menor sección útil que el resto de la muestra. Por dicha sección será por donde falle el material cuando se realiza el ensayo, simplemente porque la sección de trabajo es menor. En consecuencia, los valores de módulo elástico que se obtienen son menores ya que la sección útil es menor.

En cambio en el ensayo de ultrasonidos no se realiza ningún tipo de solicitación y el valor de módulo elástico se obtiene a partir de la velocidad de propagación del sonido en el material. Esta velocidad de propagación se ve afectada también por la porosidad pero no por los pequeños cambios de sección ya que la medición de la velocidad de propagación del sonido se realiza a través de toda la muestra, y dos veces ya que se trabaja en modo emisor receptor, y el valor de velocidad de propagación es la media de todas las velocidades en cada tramo de la muestra. 
Por este motivo aparecen grandes diferencias entre el módulo elástico medido mediante compresión y por ultrasonidos, a pesar que ambos ensayos tienen en cuenta la porosidad.

Se observa la misma evolución si se compara los valores de módulo elástico obtenidos en esta tesis con los expuestos en los trabajos mencionados anteriormente de Aleixo G.T. [8, 9] y Lopes E.S.N. [3].

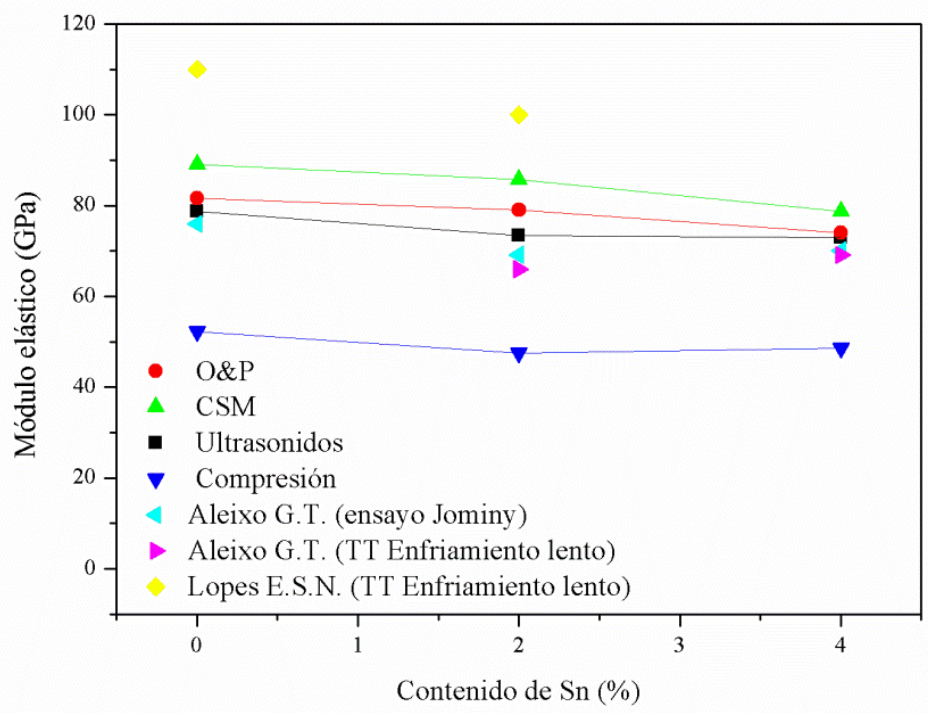

Figura 5.65. Módulo elástico de las aleaciones estudiadas y los valores mostrados en bibliografía.

Como ocurre con los datos obtenidos en este estudio, en bibliografía aparece un ligero aumento en el módulo elástico de la aleación Ti 30Nb 4Sn. Los datos expuestos de bibliografía han sido obtenidos por el ensayo de ultrasonidos. Destacar que en todos los casos los resultados son muy parecidos excepto en el ensayo de compresión que 
muestran valores de módulo elástico muy bajos. Pero esta diferencia también se observa en otros estudios donde comparan la evolución del módulo elástico por distintas técnicas [14].

La adición de estaño a las aleaciones hace disminuir tanto la resistencia máxima o dureza, como el módulo elástico obtenido por diversas técnicas, debido a la mayor presencia de microestructura $\beta$ y a la disminución de las zonas de microestructura lamelar $\alpha+\beta$. A pesar de que estos cambios no son muy reseñables. Dado el gran interés que despiertan estas aleaciones procesadas por pulvimetalurgia convencional y mezcla elemental de polvos, cabe destacar que con la adición de un porcentaje muy pequeño de estaño, solo un $2 \%$, se consigue reducir el módulo elástico en un $9 \%$, obtenido en el ensayo de compresión.

También se ha observado en los análisis que los resultados obtenidos son muy sensibles al tipo de esfuerzo sometido o al ensayo realizado para su determinación. Por esto, se dificulta la relación entre el contenido de estaño y los resultados obtenidos debido a los bajos niveles de adición de estaño investigados.

\subsection{Caracterización tecnológica.}

Los ensayos de corrosión y tribocorrosión ofrecen una idea clara del comportamiento de las aleaciones estudiadas puestas en servicio como 
biomaterial. En un primer acercamiento se ha obtenido parámetros químicos del comportamiento a corrosión pura, posteriormente se ha realizado ensayos de tribocorrosión para observar el comportamiento de las aleaciones. Los ensayos se han realizado en un electrolito que simula los fluidos del cuerpo humano, Phosfate Buffered Solution (PBS), y a una temperatura de $37^{\circ} \mathrm{C}$.

\subsubsection{Corrosión.}

En primer lugar, se ha realizado el ensayo potenciodinámico para obtener los parámetros más importantes de potencial y densidad de corriente: potencia de equilibrio $\left(\mathrm{E}_{\text {corr }}\right)$ y la densidad de corriente $\left(\mathrm{I}_{\text {corr }}\right)$. En la siguiente figura se muestra el comportamiento de las tres aleaciones estudiadas. 


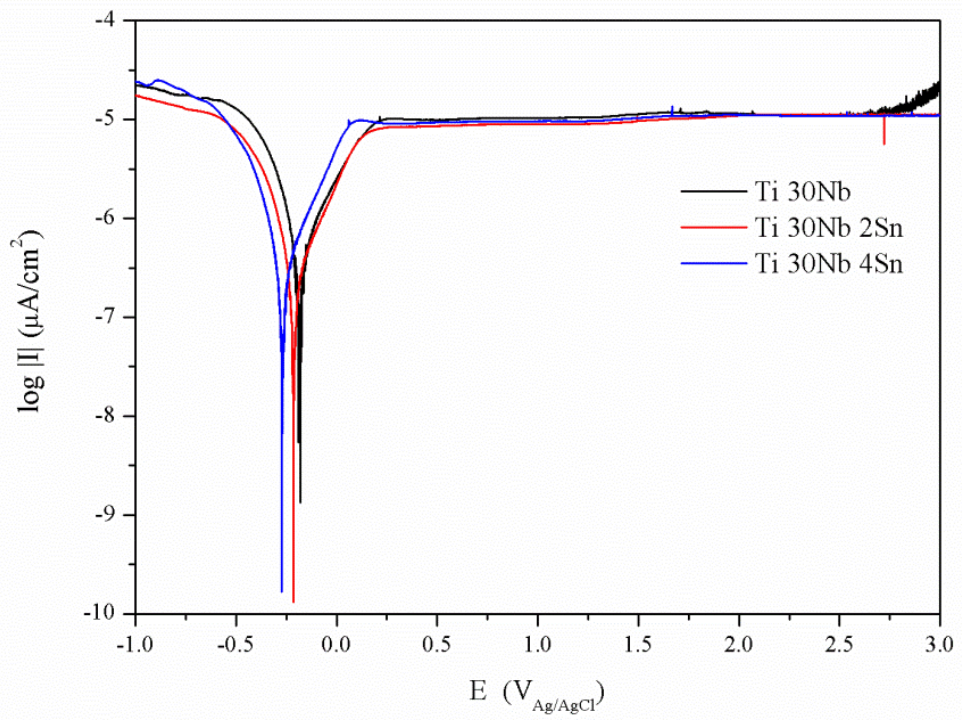

Figura 5.66. Comportamiento potenciodinámico de las aleaciones Ti 30Nb, Ti 30Nb 2Sn y Ti 30Nb 4Sn.

La zona de dominio de la región pasiva en los tres casos es totalmente horizontal, no evoluciona con el tiempo, por este motivo solo se ha realizado el cálculo de la densidad de pasivación $\left(\mathrm{I}_{\mathrm{p}}\right)$ al potencial de 1 $\mathrm{V}_{\mathrm{Ag} / \mathrm{AgCl}}$.

A continuación se ha realizado los ensayos de potencial a circuito abierto (OCP). Se ha rechazado los primeros instantes del ensayo que corresponden a la zona de transición en el que el potencial evoluciona desde valores cercanos a cero hasta estabilizarse. Los valores obtenidos corresponden a la media de los últimos cinco minutos registrados en el ensayo. La figura 5.67 muestra la evolución del potencial de las aleaciones. 


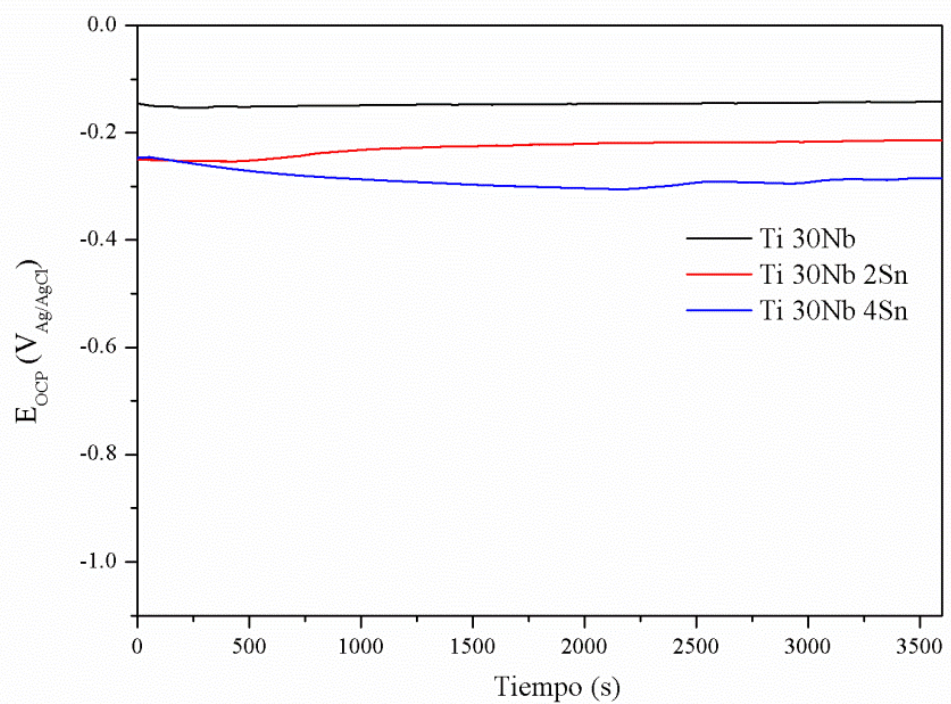

Figura 5.67. Ensayos de OCP de las aleaciones estudiadas.

Como resumen de las propiedades más importantes en los ensayos de corrosión se pueden observar la tabla 5.15. Los valores de las pendientes de Tafel corresponden a las rectas tangentes para calcular el valor de $\mathrm{I}_{\text {corr }}$, ba corresponde a la zona de dominio catódico y bc al dominio anódico.

Tabla 5.15. Resumen de las propiedades a corrosión de los materiales estudiados.

\begin{tabular}{|c|c|c|c|c|c|c|}
\hline \multirow{2}{*}{ Aleación } & \multirow{2}{*}{$\begin{array}{c}\mathbf{E}_{\mathrm{OCP}} \\
\left(\mathrm{V}_{\mathrm{Ag} / \mathrm{AgCl}}\right)\end{array}$} & \multirow{2}{*}{$\begin{array}{c}\mathbf{E}_{\mathrm{Corr}} \\
\left(\mathrm{V}_{\mathrm{Ag} / \mathrm{AgCl}}\right)\end{array}$} & \multirow{2}{*}{$\begin{array}{c}I_{\mathrm{Corr}} \\
\left(\mu \mathrm{A} / \mathrm{cm}^{2}\right)\end{array}$} & \multirow{2}{*}{$\begin{array}{c}\mathrm{I}_{\mathrm{p}} 1 \mathrm{~V} \\
\left(\mu \mathrm{A} / \mathrm{cm}^{2}\right)\end{array}$} & \multicolumn{2}{|c|}{\begin{tabular}{|c} 
Pendientes de Tafel \\
(m V)
\end{tabular}} \\
\hline & & & & & ba & bc \\
\hline Ti $30 \mathrm{Nb}$ & -0.148 & -0.182 & 0.18 & 9.7 & 98 & -81 \\
\hline Ti 30Nb 2Sn & -0.217 & -0.222 & 0.14 & 8.4 & 118 & -92 \\
\hline $\mathrm{Ti} 30 \mathrm{Nb} 4 \mathrm{Sn}$ & -0.281 & -0.261 & 0.14 & 9.0 & 109 & -79 \\
\hline
\end{tabular}




\subsubsection{Tribocorrosión.}

El comportamiento a tribocorrosión ofrece una perspectiva muy interesante ya que se simula el desgaste en un ambiente agresivo. Este ensayo ofrece la posibilidad de ver el comportamiento de los materiales y la reacción cuando se forma la capa pasiva e inmediatamente es desprendida por efecto del desgaste. Es decir, el material está continuamente repasivando.

En primer lugar se ha realizado los ensayos de OCP con el montaje de la celda específica para tribocorrosión. Se ha medido el valor de OCP sin rotación. Es el mismo ensayo que el realizado en corrosión pero en este caso se ha monitorizado la zona de transición de los primeros instantes del ensayo. En la figura 5.68 se observa el resultado para cada aleación. 


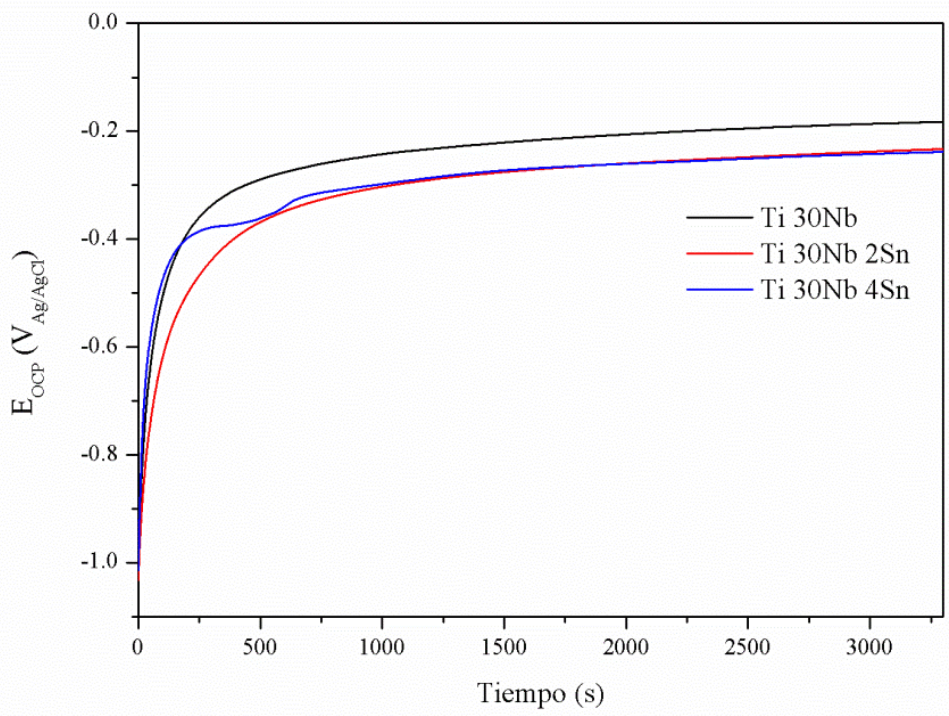

Figura 5.68. Ensayo de OCP con el montaje de tribocorrosión en el que se muestra la zona inicial de transición de las aleaciones estudiadas.

A continuación, y en el mismo ensayo, ha empezado la tribocorrosión propiamente dicha, es decir ha empezado el deslizamiento del pin sobre el material. La figura 5.69 muestra el comportamiento a tribocorrosión y el valor de potencial a circuito abierto de las aleaciones estudiadas. 


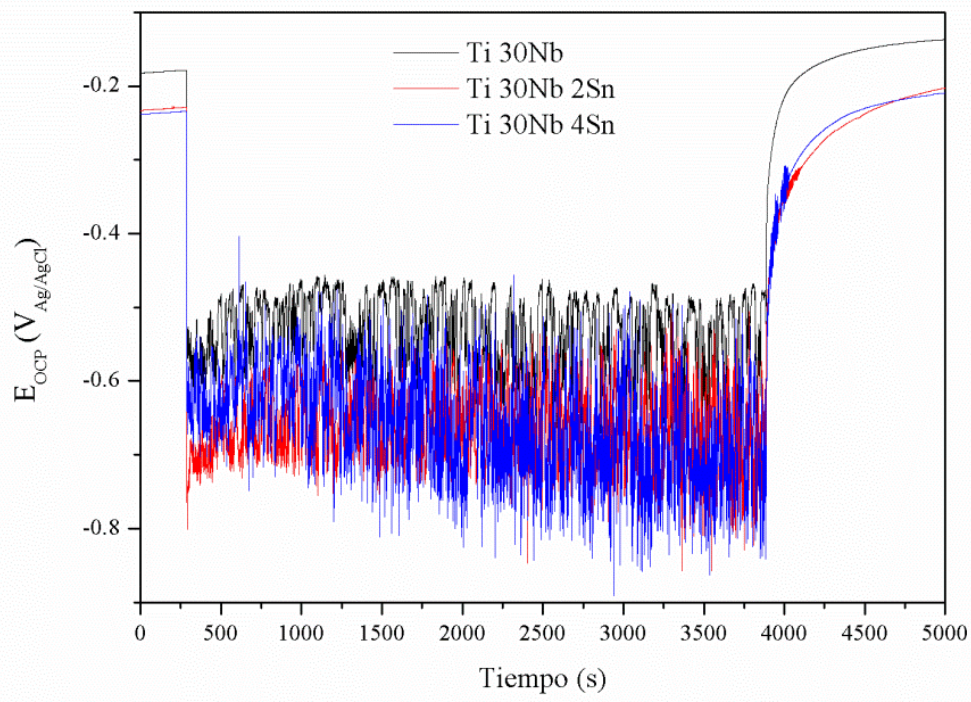

Figura 5.69. Valores de tribocorrosión antes, durante y después del ensayo de las aleaciones Ti 30Nb XSn.

El inicio de las gráficas anteriores se corresponde con el final de las gráficas de la figura 5.68. Se podría haber mostrado en una sola gráfica pero de este modo el nivel de detalle es mucho mayor. La tabla 5.16 muestra la media de los valores obtenidos en cada etapa en el ensayo de OCP de tribocorrosión.

Tabla 5.16. Ensayo de tribocorrosión, valores medios de OCP antes, durante y después del ensayo de las aleaciones estudiadas.

\begin{tabular}{|c|c|c|c|}
\hline Aleación & $\begin{array}{c}\mathbf{E}_{\mathrm{OCP}} \text { inicial } \\
\left(\mathrm{V}_{\mathrm{Ag} / \mathrm{AgCl}}\right)\end{array}$ & $\begin{array}{c}\mathbf{E}_{\text {OCP }} \text { durante el ensayo } \\
\left(\mathrm{V}_{\mathrm{Ag} / \mathrm{AgCl}}\right)\end{array}$ & $\begin{array}{c}\mathbf{E}_{\text {OCP }} \text { final } \\
\left(\mathrm{V}_{\mathrm{Ag} / \mathrm{AgCl}}\right)\end{array}$ \\
\hline $\mathrm{Ti} 30 \mathrm{Nb}$ & -0.180 & -0.534 & -0.137 \\
\hline $\mathrm{Ti} 30 \mathrm{Nb} 2 \mathrm{Sn}$ & -0.232 & -0.661 & -0.205 \\
\hline $\mathrm{Ti} 30 \mathrm{Nb} 4 \mathrm{Sn}$ & -0.235 & -0.661 & -0.210 \\
\hline
\end{tabular}


Posteriormente se ha realizado los ensayos de potencial constante (1 $\mathrm{V}_{\mathrm{Ag} / \mathrm{AgCl}}$ ), se ha medido los valores de $\mathrm{I}_{0}$ (densidad de pasivación antes de tribología) e $I_{\text {sliding (densidad de pasivación durante la tribología) }}$ La evolución de la intensidad de las tres aleaciones se muestra en la figura 5.70 para antes del ensayo.

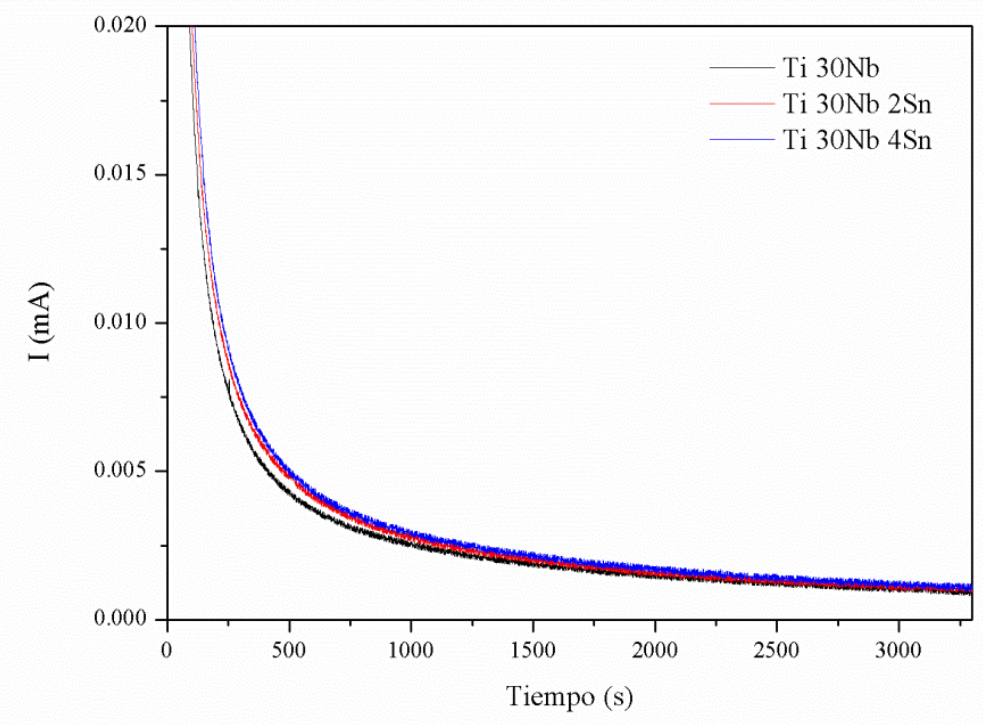

Figura 5.70 Gráfica de intensidad a potencial constante para las aleaciones estudiadas antes del ensayo de tribocorrosión.

De la gráfica anterior se obtiene el valor de $\mathrm{I}_{0}$. En la figura 5.71 se observa el valor de intensidad cuando se ha iniciado el ensayo. 


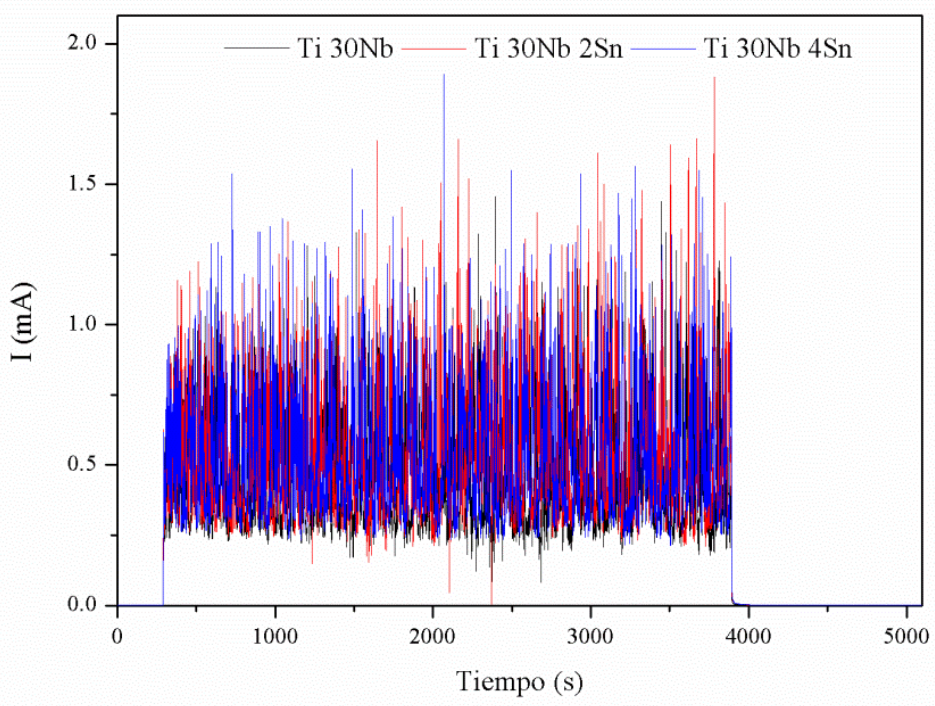

Figura 5.71. Intensidad de las aleaciones estudiadas durante el ensayo de tribocorrosión a potencial constante.

De la misma forma, de la gráfica anterior se obtiene el valor medio de $\mathrm{I}_{\text {sliding }}$ para cada aleación. Los valores de $\mathrm{I}_{0}$ e $\mathrm{I}_{\text {sliding }}$ de las aleaciones se muestran en la tabla 5.17.

Tabla 5.17. Valores obtenidos de $\mathrm{I}_{0}$ e $\mathrm{I}_{\text {sliding }}$ de las aleaciones Ti 30Nb XSn.

\begin{tabular}{|c|c|c|}
\hline Aleación & $\mathbf{I}_{\mathbf{0}}(\mathbf{m A}) \mathbf{x} \mathbf{1 0}^{-\mathbf{3}}$ & $\mathbf{I}_{\text {sliding }}(\mathbf{m A}) \mathbf{x} \mathbf{1 0}^{-\mathbf{3}}$ \\
\hline Ti $30 \mathrm{Nb}$ & 1.00 & 449.19 \\
\hline Ti $30 \mathrm{Nb} 2 \mathrm{Sn}$ & 1.05 & 535.64 \\
\hline Ti $30 \mathrm{Nb} 4 \mathrm{Sn}$ & 1.07 & 527.46 \\
\hline
\end{tabular}

Con los valores de $I_{\text {sliding }}$ obtenidos y según la ecuación 4.13 expuesta en el apartado 4.5 de caracterización tecnológica del desarrollo experimental se obtiene la fracción de volumen químico de pérdida 
$\left(\mathrm{V}_{\text {quim }}\right)$. Siguiendo las directrices de este mismo punto del experimental se ha calculado el volumen de pérdida total $\left(\mathrm{V}_{\text {total }}\right)$ para posteriormente calcular el volumen de pérdida mecánico $\mathrm{V}_{\text {mec }}$ según la ecuación 4.14.

Tabla 5.18. Volúmenes perdidos durante el ensayo de tribocorrosión a potencial constante de las tres aleaciones.

\begin{tabular}{|c|c|c|c|}
\hline Aleación & $\mathrm{V}_{\text {quim }}\left(\mathbf{m m}^{\mathbf{3}}\right) \times \mathbf{1 0}^{-\mathbf{5}}$ & $\mathrm{V}_{\text {mec }}\left(\mathbf{m m}^{\mathbf{3}}\right)$ & $\mathrm{V}_{\text {total }}\left(\mathbf{m m}^{\mathbf{3}}\right)$ \\
\hline Ti 30Nb & 6.04455 & 0.739126618 & 0.739187064 \\
\hline Ti 30Nb 2Sn & 7.36023 & 1.119762284 & 1.119835886 \\
\hline Ti 30Nb 4Sn & 7.39376 & 1.488196230 & 1.488270168 \\
\hline
\end{tabular}

\subsubsection{Discusión caracterización tecnológica.}

El comportamiento tecnológico de las aleaciones estudiadas muestra una evolución clara en función del porcentaje de estaño presente. En condiciones de corrosión pura se observa una evolución a mayores tasas de resistencia a la corrosión. Se observa como los parámetros químicos $\mathrm{I}_{\text {Corr }}$ e $\mathrm{I}_{\mathrm{p}}$ son menores con la adición de estaño lo que demuestra la mejor resistencia frente a la corrosión. A pesar de ésto, los valores más bajos se obtienen para la aleación Ti 30Nb 2Sn, como se muestra en la tabla 5.14, ya que la homogeneidad en la distribución del niobio es mayor en esta aleación.

También se puede observar como la inclusión de estaño hace descender de forma clara dichos valores, existe una gran diferencia entre la aleación sin estaño y las aleaciones con estaño. 
La obtención de valores constantes de potencial de circuito abierto durante todo el ensayo demuestra la formación de una capa de pasivación que limita la corrosión del material. Estudios recientes [15, 16] demuestran que no sólo se forman óxidos de titanio $\left(\mathrm{Ti}_{2} \mathrm{O}_{3}, \mathrm{TiO}_{2}\right)$ en dicha capa sino que también presentan óxidos de $\mathrm{Nb}\left(\mathrm{Nb}_{2} \mathrm{O}_{5}\right)$. El niobio provoca una mayor estabilidad de la capa pasiva lo que hace que las aleaciones sean más resistentes a la corrosión [17]. También aparecen óxidos de estaño $\left(\mathrm{SnO}_{2}\right)$ en la capa pasiva formada [16].

Esta ligera mejoría con la adición de estaño viene marcada por una mayor homogeneidad de la microestructura $\beta$ obtenida. La microestructura $\beta$ posee mejor comportamiento a corrosión que la microestructura $\alpha$ por este motivo el comportamiento de las aleaciones con estaño es mejor que el de la aleación Ti 30Nb.

Comparado con otros materiales [18] utilizados en implantología se muestra como las aleaciones estudiadas ofrecen mejor comportamiento, el valor de $\mathrm{I}_{\text {Corr }}$ es menor. 
Tabla 5.19. Valores de $\mathrm{E}_{\mathrm{OCP}}, \mathrm{E}_{\mathrm{Corr}} \mathrm{e} \mathrm{I}_{\text {Corr }}$ de las aleaciones estudiadas y de otras aleaciones de Ti utilizadas como biomaterial [18].

\begin{tabular}{|c|c|c|c|}
\hline Aleación & $\begin{array}{c}\mathbf{E}_{\text {OCP }} \\
\left(\mathbf{V}_{\text {Ag/AgCl }}\right)\end{array}$ & $\begin{array}{c}\mathbf{E}_{\text {Corr }} \\
\left(\mathbf{V}_{\text {Ag/AgCl }}\right)\end{array}$ & $\begin{array}{c}\mathbf{I}_{\text {Corr }} \\
\left(\boldsymbol{\mu A} / \mathbf{c m}^{2}\right)\end{array}$ \\
\hline Ti 30Nb & -0.148 & -0.182 & 0.18 \\
\hline Ti 30Nb 2Sn & -0.217 & -0.222 & 0.14 \\
\hline Ti 30Nb 4Sn & -0.281 & -0.261 & 0.14 \\
\hline Ti grado 2 & -0.305 & -0.447 & 1.81 \\
\hline Ti 6Al 4V & -0.297 & -0.497 & 0.18 \\
\hline Ti grado 5 & -0.281 & -0.329 & 1.30 \\
\hline Ti 6Al 4V ELI & -0.308 & -0.411 & - \\
\hline
\end{tabular}

Estos materiales han sido ensayados con los mismos parámetros que en nuestro estudio, utilizando el mismo electrolito (PBS) y a la misma temperatura por lo que los resultados son totalmente comparables.

Por otro lado los ensayos de tribocorrosión a circuito abierto muestran que hay una repasivación de la capa formada durante todo el ensayo muy buena ya que los valores de $\mathrm{E}_{\text {оср }}$ iniciales y $\mathrm{E}_{\text {оср }}$ final son muy parecidos. Durante el ensayo los valores de potencial muestran el mismo comportamiento por lo que las propiedades a corrosión no se ven afectadas por la realización del ensayo de potencial abierto. En cambio sí que hay grandes diferencias en los valores de volumen de pérdida en el ensayo de potencial constante. Como se puede observar en la tabla 5.17 el volumen de pérdida debido a fenómenos químicos sufrido es prácticamente despreciable en relación a la pérdida de volumen mecánico. Esta gran diferencia y la evolución a mayores volúmenes de pérdida mecánica con la adición de estaño se justifican por el buen comportamiento de la microestructura $\beta$ frente a la 
corrosión pero el malísimo comportamiento de ésta frente al desgaste. La mayor presencia de microestructura $\alpha+\beta$ obtenida en la aleación Ti 30Nb mejora de forma notable el comportamiento a tribología y en consecuencia disminuye la pérdida de volumen mecánico. Este efecto se reafirma con los resultados obtenidos por M.K. Dimah [18] en el que se observa que, en las mismas condiciones de ensayo, aleaciones comerciales de Ti tienen mejor comportamiento en desgaste debido a su microestructura $\alpha+\beta$.

Comparando los valores de $I_{0}$ e $I_{\text {sliding }}$ obtenidos se observa como cuando aún no ha empezado el desgaste los valores $\left(\mathrm{I}_{0}\right)$ son bastante parejos pero durante la realización de la tribocorrosión los valores de $\mathrm{I}_{\text {sliding }}$ se disparan.

Tabla 5.20 Parámetros de $\mathrm{I}_{0}$ e $\mathrm{I}_{\text {sliding }}$ de las aleaciones estudiadas y de otras aleaciones de Ti utilizadas en biomateriales [18].

\begin{tabular}{|c|c|c|}
\hline Aleación & $\mathbf{I}_{\mathbf{0}}(\mathbf{m A} \mathbf{A}) \mathbf{~} \mathbf{1 0}^{\mathbf{3}}$ & $\mathbf{I}_{\text {sliding }}(\mathbf{m} \mathbf{A}) \mathbf{x} \mathbf{1 0}^{-\mathbf{3}}$ \\
\hline Ti 30Nb & 1.00 & 449.19 \\
\hline Ti 30Nb 2Sn & 1.05 & 535.64 \\
\hline Ti 30Nb 4Sn & 1.07 & 527.46 \\
\hline Ti grado 2 & 1.88 & 483.07 \\
\hline Ti 6Al 4V & 1.42 & 189.15 \\
\hline Ti grado 5 & 0.87 & 152.28 \\
\hline Ti 6Al 4V ELI & 0.68 & 166.57 \\
\hline
\end{tabular}

Se demuestra que las aleaciones con microestructura $\beta$ presentan mejor comportamiento en corrosión. En cambio, en tribocorrosión, la combinación de fenómenos de corrosión y desgaste debilitan de forma notable el comportamiento frente a aleaciones $\alpha+\beta$. Se observa que la 
pérdida de volumen debido a efectos mecánicos es excesiva para las aleaciones Ti 30Nb XSn.

\subsection{Referencias.}

[1] Devesa F., Candel J.J., Franconetti P., Amigo V., "Estudio de la difusión, en la etapa de sinterizado, de elementos estabilizadores de la fase $\beta$ del titanio". IV Congreso Nacional de Pulvimetalurgia Sevilla 2012.

[2] Pérez-Soriano E. M., Gallardo J.M., "Método de caracterización de porosidad en piezas metálicas obtenidas por sinterizado con laser”. IV Congreso Nacional de Pulvimetalurgia Sevilla 2012.

[3] Lopes E.S.N., Cremasco A., Contieri R., Caram R., "Effects of Aging Heat Treatment on the Microstructure of Ti-Nb and TiNb-Sn Alloys Employed as Biomaterials”. Advanced Materials Research Vol. 324 (2011) pp 61-64.

[4] Yang Yulan, Wang Weiqi, Li Fengli, Li Weiqing, Zhang Yongqiang: "The Effect of Aluminium Equivalent and Molybdenum Equivalent on the Mechanical Properties of high Streng and Hingh Toughness Titanium Alloys" Materials Science Forum Vols. 618-619 (2009) pp 169-172.

[5] Santos D.R., Rodriguez V.A., Alves C.A., Santos C.A., "Production of a Low Young Modulus Titanium Alloys by Powder Metallurgy”. Materials Research, Vol. 8, No. 4, 439442, 2005.

[6] Hanada S., Matsumoto H., Watanabe S., "Mechanical compatibility of titanium implants in hard tissues". International Congress Series 1284 (2005) 239- 247. 
[7] C. Hammond "The Basics of Crystallography and Diffraction" International Union of Crystallography, Oxford University Press, 2000.

[8] Aleixo G.T. "Obtenção, Caracterização Microestrutural e Mecânica de Ligas Ti-Nb-Sn Aplicadas em Implantes Ortopédicos”. UNICAMP. Departamento de Engenharia de Materiais.

[9] Aleixo G.T. "Estabilidade e Metaestabilidade de Fases em Ligas Ti-Nb” UNICAMP. Departamento de Engenharia de Materiais.

[10] Lopes E.S.N. "Correlação entre transformações de fases e comportamento mecânico de ligas Ti-Nb-Sn e sua aplicação na concepção de implantes ortopédicos com propriedades otimizadas”. UNICAMP. Departamento de Engenharia de Materiais.

[11] Wei Q., Wang L., Fu Y., Qin J., Lu W., Zhang D., “Influence of oxygen content on microstructure and mechanical properties of Ti-Nb-Ta-Zr alloy”. Volume 32, Issue 5, May 2011, Pages 2934-2939.

[12] Guilin Y., Nan L., Yousheng L., Yining W., "The effects of different types of investments on the alpha-case layer of titanium castings”. Volume 97, Issue 3, March 2007, Pages 157164.

[13] http://www.gordonengland.co.uk/hardness/hvconv.htm

[14] Torres Y., Rodríguez J.A., Arias S., Echevary M., Robledo S., Amigó V., Pavón J.J., "Processing, characterization and biological testing of porous titanium obtained by space-holder technique”. J Mater Sci (2012) 47:6565-6576.

[15] Metikoŝ-Huković, M., Kwokal, A., Piljac, J., "The influence of niobium and vanadium on passivity of titanium-based implants in physiological solution”. Biomaterials, 2003 24, 3765-3775. 
[16] Kuroda, D., Niinomi, M., Morinaga, M., Kato, Y., Yashiro, T., "Design and mechanical properties of new $\beta$ type titanium alloys for implant materials”. Materials Science and Engineering, 1998 A243, 244-249.

[17] Wang, W., Mohammadi, F., Alfantazi, A., “Corrosion behavior of niobium in phosphate buffered saline solutions with different concentrations of bovine serum albumin”. Corrosion Science, 2012, 57, 11-21.

[18] Dimah M.K., Devesa Albeza F., Amigó Borrás V., Igual Muñoz A., "Study of the biotribocorrosion behavior of titanium biomedical alloys in simulated body fluids by electrochemical techniques”. Wear 294-295(2012)409-418. 


\section{CONCLUSIONES.}

Los resultados de esta tesis han permitido obtener y evaluar el comportamiento de aleaciones base $\mathrm{Ti} 30 \mathrm{Nb}$ con distintos contenidos de estaño.

En primer lugar se ha obtenido un protocolo de actuación para procesar aleaciones de titanio $\beta$ con altos porcentajes de elementos aleantes mediante pulvimetalurgia convencional y mezcla elemental de polvos. Utilizando el tamizado del polvo de los elementos de partida se ha maximizado la superficie útil para favorecer y fomentar los procesos de difusión en estado sólido que se originan en la etapa de sinterizado. Con el tamizado por debajo de $25 \mu \mathrm{m}$ del tamaño de partículas del polvo de los elementos aleantes se maximiza la homogeneidad final de las aleaciones y no se dificulta en exceso el procesado ya que el tamizado con tamiz de $25 \mu \mathrm{m}$ es el mínimo para tamizado en seco.

Con todo esto los puntos clave de este protocolo son los siguientes:

- Tamizar el polvo por debajo de $25 \mu \mathrm{m}$ del elemento aleante.

- Mezclar el polvo inmediatamente después de tamizarlo para evitar que se apelmace.

- Utilizar tiempos muy largos en la túrbula para homogeneizar la distribución, justo antes de la compactación para evitar la 
estratificación del polvo de cada elemento por diferencia de densidades.

En segundo lugar se ha obtenido que, para el procesado anteriormente optimizado, el contenido mínimo de niobio para que la microestructura final sea $\beta$ es del $30 \%$. La aleación Ti $30 \mathrm{Nb}$ presenta microestructura tipo $\beta$ en su gran mayoría, solo aparecen pequeñas lamelas de microestructura tipo $\alpha$ que crecen desde el borde de grano de forma perpendicular hacia el centro del grano. La adición de altos porcentajes de niobio estabiliza la microestructura $\beta$ a temperatura ambiente con enfriamientos desde la temperatura de sinterizado lentos. Contenidos menores del $30 \%$ de niobio muestran estructura lamelar $\alpha+\beta$ y contenidos superiores muestran la misma microestructura que la aleación Ti 30Nb aunque empiezan a aparecer defectos de falta de difusión por sobresaturación en el contenido de niobio alrededor de las particular primitivas del polvo de niobio.

Aumentando el tiempo de sinterización de las aleaciones Ti 30Nb XSn hasta cuatro horas se ha conseguido aumentar la homogeneidad microestructural de las aleaciones. Dicho aumento del tiempo de sinterizado no repercute negativamente en otras características como el tamaño de grano. El crecimiento del tamaño de grano se ve limitado por la porosidad intrínseca del procesado por pulvimetalurgia convencional. El borde de grano se ancla a los poros y se limita el crecimiento del grano, por este motivo se ha observado la mayoría de los poros en el borde de grano. Por otro lado con el aumento del 
tiempo de sinterización se consigue valores más bajos de porosidad y un tamaño de poro menor. En consecuencia, y unido a una contracción mayor durante el sinterizado, los valores de densidad final son muy altos, mayores del $91 \%$, muy cercanos a los valores de la densidad teórica.

Se ha conseguido que el contenido de oxígeno no aumente en exceso, el gran problema ha sido el oxígeno contenido de partida. $0.362 \%$ es un porcentaje muy alto de contenido de oxígeno antes del procesado. A pesar de solo incorporar un $0.5 \%$ aproximadamente las propiedades finales se han visto afectadas por la presencia de oxígeno sobre todo en la aleación Ti $30 \mathrm{Nb} 4 \mathrm{Sn}$ con un contenido de oxígeno mayor. Posiblemente si se hubiera partido de un polvo de titanio con un contenido de oxígeno menor los resultados hubieran sido mucho más apropiados para la vida en servicio como biomaterial: se hubieran alcanzado valores de módulo elástico más bajos ya que se hubiese reducido aún más la presencia de microestructura $\alpha$ dado el carácter alfágeno del oxígeno. También se hubiera podido estudiar con más precisión la influencia del estaño en las propiedades finales y se hubiera observado mejor la evolución de las propiedades en función del contenido de estaño.

Pero a pesar de esto, se observa que la aleación Ti 30Nb 2Sn presenta un homogeneidad microestructural muy buena. Como características microestructurales más relevantes se obtiene granos equiaxiales de aproximadamente $50 \mu \mathrm{m}$ con microestructura $\beta$ y solo pequeñas 
lamelas de microestructura $\alpha$ en el borde de grano que crecen de forma perpendicular hacia el centro de este. La inclusión de estaño evita la aparición de fases no deseadas, sobre todo la fase $\omega$, y mejora la homogeneidad microestructural debido a su bajo punto de fusión. Las aleaciones con estaño en su composición presentan menos zonas con microestructura $\alpha$ por la mejoría en la distribución del niobio ya que las zonas de microestructura $\alpha$ contienen menos $\mathrm{Nb}$. La adición de un $4 \%$ de Sn se ha mostrado como excesiva, a pesar de lo observado en los difractogramas de rayos $\mathrm{X}$, ya que aparece una pérdida en la homogeneidad de la distribución del niobio en las zonas con microestructura lamelar.

Esta evolución hacia la estabilización a temperatura ambiente de la microestructura $\beta$ con la adición de estaño propicia un descenso de las propiedades resistentes del material. A pesar de la reducción en el tamaño de grano, el descenso de la porosidad y la reducción en el tamaño de poro experimentado por las aleaciones estudiadas con la adición de estaño, la mayor estabilidad de la microestructura $\beta$ favorece la reducción de las propiedades mecánicas. Por este motivo se puede afirmar que la evolución de la microestructura es más influyente que la evolución de las propiedades intrínsecas de las aleaciones procesadas por pulvimetalurgia convencional mediante mezcla elemental de polvos.

Como era de esperar, debido a su microestructura más propicia, la mayor reducción en el valor de módulo elástico se observa en la 
aleación Ti 30Nb 2Sn. La microestructura $\beta$ favorecida por la incorporación de un $2 \%$ de estaño y una porosidad ligeramente mayor que la aleación con un 4 \% desemboca en una reducción de hasta un 9 \% del módulo elástico medido en el ensayo de compresión con respecto al valor de la aleación sin estaño. Esta reducción en los valores de módulo elástico hace que estén más próximos al del hueso cortical, por lo que se favorece la utilización de esta aleación como biomaterial. Se minimiza el efecto de apantallamiento de tensiones, y en consecuencia, se disminuye la posibilidad de pérdida de masa ósea por reabsorción. Como se ha visto, la relación de valores obtenidos mediante los distintos ensayos para obtener el módulo elástico para un mismo material es bastante amplia debido a la propia naturaleza de las técnicas, del nivel en el que se realiza el ensayo y de las características que se tienen en cuenta. Por todo esto se puede afirmar que el valor más confiable es el obtenido mediante ultrasonidos ya que es un ensayo macroscópico y tiene en cuenta la porosidad del material ensayado.

Pero el estudio de la evolución en las propiedades se ve entorpecido por el tipo de esfuerzo sometido y por la naturaleza del ensayo realizado para su determinación ya que los materiales estudiados se muestran muy sensibles a estas variables. Esto dificulta una determinación más precisa de la relación entre la incorporación de estaño y las propiedades finales obtenidas debido al pequeño porcentaje adicionado. 
Por último, se ha conseguido una mejor tasa de resistencia a la corrosión con la incorporación de estaño ya que los valores de $\mathrm{I}_{\text {Corr }} \mathrm{e}$ $\mathrm{I}_{\mathrm{p}}$ son menores. La capa de pasivación formada es estable y limita la corrosión ya que los valores de potencial a circuito abierto son constantes. El comportamiento a tribocorrosión demuestra la mejoría de las propiedades de resistencia a corrosión debido a la microestructura $\beta$ ya que la pérdida de volumen químico desciende con la adición de estaño, pero el pobre comportamiento a desgaste de este tipo de microestructura empeora de forma notable el comportamiento global. La aleación Ti $30 \mathrm{Nb}$, con mayor contenido de microestructura $\alpha$, ofrece un mejor comportamiento general a tribocorrosión promocionado por una pérdida de volumen por efectos mecánicos mucho menor, pero esta pérdida se considera excesiva en todas las aleaciones. 


\section{FUTURAS LÍNEAS DE INVESTIGACIÓN.}

Dados los resultados analizados y las conclusiones obtenidas a partir de este proyecto es posible continuar con las investigaciones trabajando principalmente en tres campos.

En primer lugar, y debido a las pequeñas diferencias encontradas en la adición de estaño, se podría afinar aun más obteniendo aleaciones con un 1 y $3 \%$ de Sn. De este modo, y viendo los buenos resultados obtenidos en la aleación $\mathrm{Ti}$ 30Nb 2Sn, se ajustaría mucho en el análisis de la microestructura y, en consecuencia, en las propiedades final de las aleaciones. Además no es una investigación excesivamente costosa ya que toda la metodología del proceso ya ha sido estudiada y es totalmente aplicable.

Por otro lado, se podría mejorar de forma notable las propiedades finales de los materiales utilizando procesos pulvimetalurgicos más complejos: Mediante el procesado por prensado isostático, tanto en frio (CIP) como en caliente (HIP), se podrían obtener características resistentes mayores. Debido a las características de estos nuevos procesos se alcanzan porcentajes de porosidad menores y se pueden llegar a alcanzar mayor homogeneidad microestructural que minimice la aparición de microestructura $\alpha$. 
Por último, sería de gran interés continuar con la labor de caracterización de estas aleaciones como biomaterial. Mediante ensayos in vitro de cultivo celular se obtendrían valores de biocompatibilidad mucho más aplicados, posteriormente, sería posible afrontar la ejecución de ensayos in vivo que corroborasen los buenos resultados obtenidos en esta investigación. 